Commercialisation of Non-Timber Forest Products:

Review and Analysis of Research

Roderick P. Neumann

and Eric Hirsch

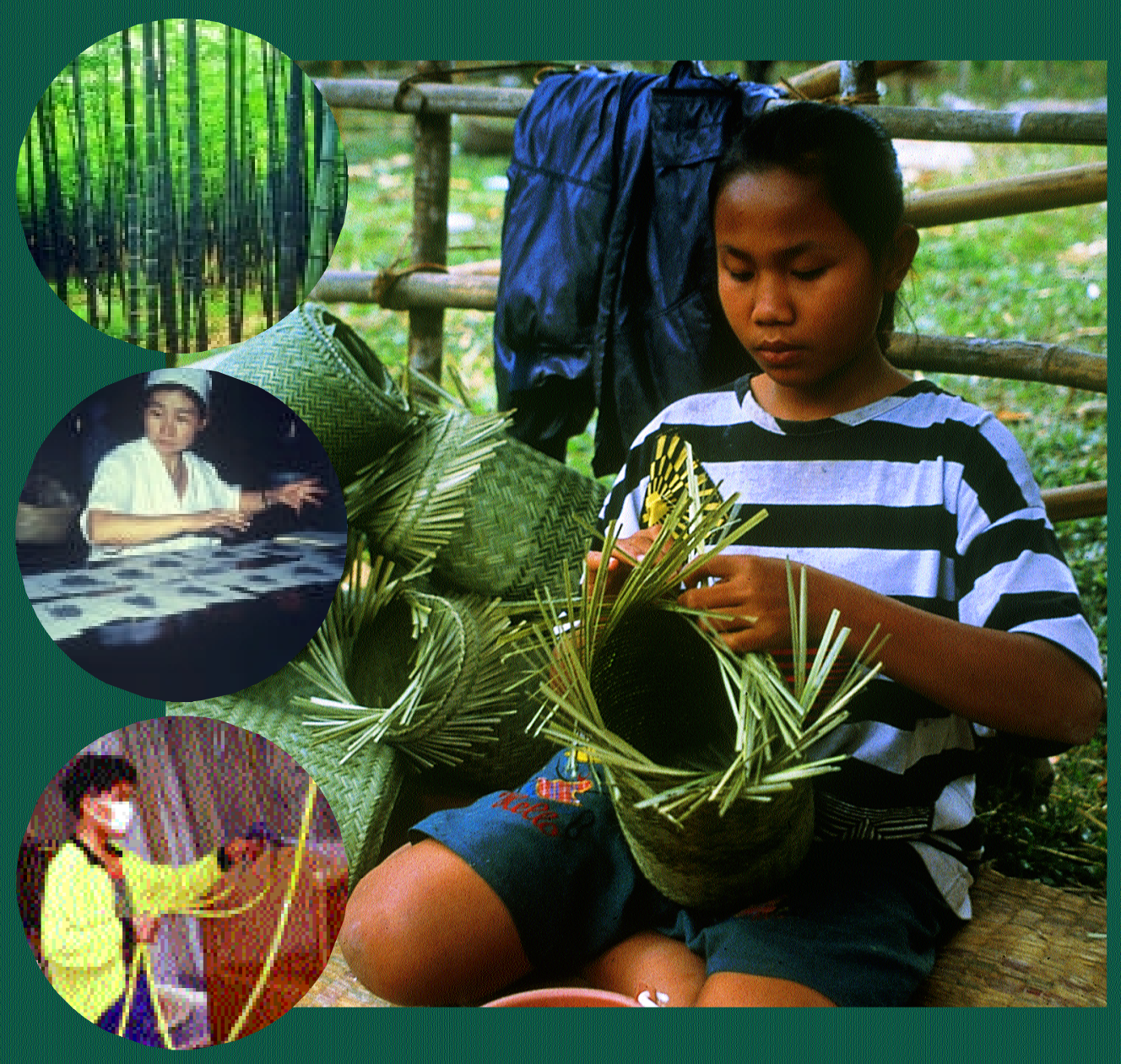




\section{Commercialisation of Non-Timber Forest Products: Review and Analysis of Research}

Roderick P. Neumann and Eric Hirsch
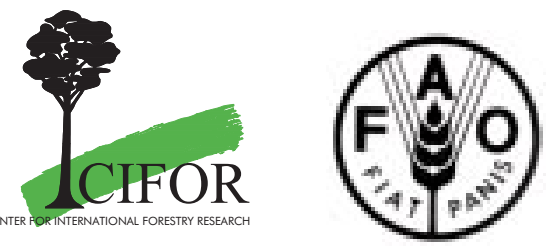
(c) 2000 by C enter for International Forestry Research

All rights reserved. Published in N ovember 2000

Printed by SM T Grafika D esa Putera, Indonesia

\section{ISBN 979-8764-51-X}

Cover photos:

Brian Belcher

Christian Cossalter

\section{Published by}

Center for International Forestry Research

Bogor, Indonesia

M ailing address: P.O . Box 6596 JK PW B, Jakarta 10065, Indonesia

Tel.: +62 (251) 622622; Fax: +62 (251) 622100

E-mail: cifor@cgiar.org

Web site: http://www.cifor.cgiar.org

\section{with support from}

Food and Agriculture $\mathrm{O}$ rganization of the $U$ nited $\mathrm{N}$ ations

Viale delleTerme di C aracalla, 00100 Rome, Italy

Tel.: +39.0657051; Fax: +39.0657053152

Web site: http://www.fao.org 


\section{Table of C ontents}

Foreword vi

Acknowledgements ix

Chapter O ne: Introduction 1

O rigins of this Study $\quad 5$

Purpose and Scope 6

$\begin{array}{ll}\text { M ethods } & 7\end{array}$

About the Literature $\quad 8$

O rganisation of the Work $\quad 12$

Chapter Two: Socio-Political Aspects of

NT FP Commercialisation $\quad 17$

Land and Resource Tenure $\quad 17$

Gender and NTFP Commercialisation 28

Poverty, Wealth D istribution and N TFP Commercialisation 33

Summary $\quad 42$

Chapter Three: Economic C onsiderations in N T FP

Extraction and Trade $\quad 45$

Estimates of the Potential Value of NTFP Resources 46

Economics of D epletion and Sustainability 56

M arketing N etworks: Structure and Function 63

Summary $\quad 74$

Chapter Four: M anagement Issues for Commercial N T FPs 77

State-led M anagement of Commercial N TFPs 78

Customary M anagement of Commercial NTFPs 85

Participatory and C o-M anagement $\quad 90$

$\begin{array}{ll}\text { Summary } & 98\end{array}$

Chapter Five: Ecological Aspects of N T FP C ommercialisation 101

Ecological Effects of Commercial H arvesting 102

Ecological Influences on Commercialisation Potential 113

M ethods and Purpose of Ecological Studies 118

Summary 
Chapter Six: Directions for Research

Socio-Political Issues

Economic Issues

133

$M$ anagement Issues

136

Ecological Issues

Summary

Bibliography

149

Appendix A

173 


\section{Acronyms}

BATH Belize Association of Traditional H ealers (Belize)

CIFOR Center for International Forestry Research

CPR common property resources

FAO Food and Agriculture $O$ rganization of the U nited $\mathrm{N}$ ations

FPCs forest protection committees (India)

GSCS Girijan Service Cooperative Societies (India)

IFTA Insect Farming and Trading Agency (PN G)

JFM Joint Forest M anagement (India)

LAM PS Large Scale Agricultural M ultipurpose Societies (India)

MAPs medicinal and aromatic plants

MPCS Multipurpose Cooperative Societies (India)

MSY maximum sustained yield

NGO non-governmental organisation

NTFP non-timber forest product

PAE Projeto de Assentamento Estrativista - Extractive Settlement Project (Brazil)

PFM participatory forest management (India)

PFM U Participatory Forest M anagement Unit (Ghana)

RTADCF Rajasthan Tribal Area D evelopment Cooperative Federation (India)

SFD P Social Forestry D evelopment Project (Indonesia)

TDCCOL Tribal D evelopment C ooperativeC orporation of $\mathrm{O}$ rissa Limited (India)

TSI tree stand improvement 


\section{Foreword}

Commercial opportunities for non-timber forest products (NTFPs) are emerging throughout the world as economic liberalisation is opening new markets and governmental decentralisation and democratisation is enabling communities to have a greater role in the management of forest resources. But what will be the impact of increasing commercialisation on forest resources? Or to reframe the question: can there be both commercialisation and conservation of resources?

In a strategy that supports the linking of conservation of the forest with income generation activities, development agencies and donors are developing initiatives that attempt to link income-generation (especially for the rural poor) and conservation objectives: integrated conservation and development projects. An underlying assumption is that a community and its members (potential entrepreneurs) will conserve and protect forest resources, if it receives the economic benefits from sustainable forest use.

But is this an oversimplification? If welook at the history of forest products we often find overexploitation of the product combined in many instances with economic exploitation of the forest dweller that actually harvested or collected the product. The result was the degradation of the resource and poverty or even indebtedness of the collector. Current initiatives are attempting to achieve devel opment of enterprises based on products from the forests (and the trees outside the forest) without the environmental and social exploitation that occurred in the past.

This study is one in a series of activities undertaken by CIFO R to reach a better understanding of the role and potential forest products in development and conservation. For example, two international workshops were organized by CIFOR in 1995 and another the following year to analyse key research issues in the field of N TFP development. The first, entitled 'Research on N ontimber Forest Products', was organised in conjunction with the U niversity of Zimbabwe, and held in $\mathrm{H}$ ot Springs, Zimbabwe, Aug. 28 - Sept. 2, 1995. The proceedings were published in the book Current I ssuesin N on-timber F orest Products Research (Ruiz Pérez and Arnold, eds., 1996). A follow-up meeting, hosted by the $C$ entro de Investigación de Espacios Protegidos Fernando González Bernáldez in Soto del Real (M adrid), Spain, Feb. 11-16, 1996. A joint CIFOR-IUCN meeting held in Cianjur, Indonesia, M ay 21-23,1996, 
resulted in the book Incomes from the Forest: M ethods for the D evelopment and Conservation of Forest Products for L ocal Communities (Wollenberg and Ingles, eds.,1998). These workshops recognized that the process of NTFP commercialisation interacts with people's welfare, forest management, tenure and control of resources, and forest structure and function (through ecological processes).

Earlier review and analysis had generated a number of hypotheses, theories and conclusions related to the effects of commercialisation. For example, there is wide acknowledgement that many NTFPs are important to poor people because they are accessible and because they act as important buffers during times of hardship. H owever, the poor often lack the necessary knowledge, capital, or legal rights to beable to exploit market opportunities wherethey do exist. O utsiders who have knowledge, commercial networks, and product concessions commonly capture the greater portion of the benefits of NTFP commercialisation. In the past (and continuing into the present) this resulted in the forest dependent often losing access to forest resources when there was increasing market demand.

$C$ an this be avoided by current initiatives? Forest and resource tenure are likely to both affect the way a resourceis managed and utilized, and be affected by changes in value due to commercialisation. From the conservation perspective, what is the impact of the harvesting of N TFPs on forest resources? O $n$ biodiversity? M any authors have suggested that N TFP harvesting will be less damaging to biodiversity and other environmental valuesthan management for timber. 0 thers suggest that market pressures are likely to lead to the decline and eventual disappearance of valuable products and to severe impacts on the ecosystem. Or will market pressures deflect pressure from particular products?

W hat is clear from these questions is that while there is a growing understanding (and acceptance) of the economic importance of forest products, especially for the poor, the potential impact of N TFP commercial isation needs to be better understood. O ne of the recommendations arising out of the workshops was to undertake a thorough overview of the available literature to synthesizethe key lessons about these areas of interaction. It was intended that such a review would critically examine the available information and analyses and identify key research areas needing further attention.

FAO and CIFOR worked together to address this recommendation. We sought potential authors and were rewarded with a high level of interest and enthusiasm among prospective collaborators. In the end Dr. Rod N eumann and $\mathrm{M} \mathrm{r}$. Eric $\mathrm{H}$ irsch accepted the daunting task of reviewing and synthesizing a large and diverse literature. The N TFP literature is notoriously unstructured _ studies relevant to understanding the key questions have been done by authors 
from a wide range of disciplines, using diverse methods and investigating a host of different questions on an equally wide range of systems. It is fertile ground for contradictory hypotheses, but al so, with the right questions, a rich source of new insights.

The product of their work is valuable at different levels. First, it is an excellent overview of the English language literature on various aspects of N TFP development. The authors have taken pains to sample from the full breadth of this literature. The manuscript will no doubt prove to be a valuable resource for other researchers. The analyses and syntheses make a novel contribution. The authors have created a structure for their review and in doing so have added value to the literature. And their conclusions help set the stage for new research that is needed in this area. They have identified problems inherent to thefield of study, including difficulties of inter-disciplinary research, highlighted difficulties arising out of inconsistent nomenclature and definition, and identified the relatively poor baseline of systematically collected data about NTFPs and commercial harvesting and marketing systems.

And, very importantly, they have noted that there has been inadequate attention paid to theoretical issues with the result that research in NTFPs has not fully benefited from advances in other related fields. Their analysis, informed by a thorough assessment of this literature, will be a valuable contribution in reaching a better understanding of the impact of commercialisation and assist in identifying specific areas needing further research.

Brian Belcher

Programme Leader of

Forest Products and People

CIFOR
Katherine Warner

Senior Community Forestry 0 fficer $\mathrm{H}$ ead, Community Forestry U nit Forestry D epartment, FAO 


\section{Acknowledgements}

$M$ any individuals and organisations lent invaluable support to this study by sharing their knowledge, advice and resources. Individuals include Joanne Abbot, D avid Bray, Jeff Burley, W ill Cavendish, Ina C haudhury, O livier D ubois, K atherineH omewood, Sarah Laird, James M ayers, C hristine Padoch, C harles Peters, M ichael Richards, Kate Schreckenberg, Gill Shepherd, D avid W ilkie and $C$ harles Zerner. A number of organisations and institutions offered assistance and provided access to their collections. These include the International Institute for Environment and Development, $O$ verseas D evelopment Institute, 0 xford Forestry Institute, Rainforest Allianceand $\mathrm{N}$ ew York Zoological Society.

Gail H ollander helped formulate the original plan of study and guided the early stages of the literature collection. Judith Rasoletti helped with a number of tasks including database entry, manuscript editing and statistical analysis. D anny M CG lynn assisted in the retrieval of published materials. Florida International U niversity and the D epartment of International Relations provided institutional support. Thanks especially to $M$ anuel Ruiz Pérez at CIFO R and KatherineWarner at FAO for their interest and financial support of the project and for their critical reading of the manuscript. Yvonne Byron did a crack job of editing the manuscript, saving us from the embarrassment of seeing our oversights and typos in final publication. Last, but far from least, special thanks to $\mathrm{M}$ ike Arnold for generously sharing his vast knowledge of the people, the literature and the institutions in tropical forestry, and for his insightful comments on an earlier draft. 


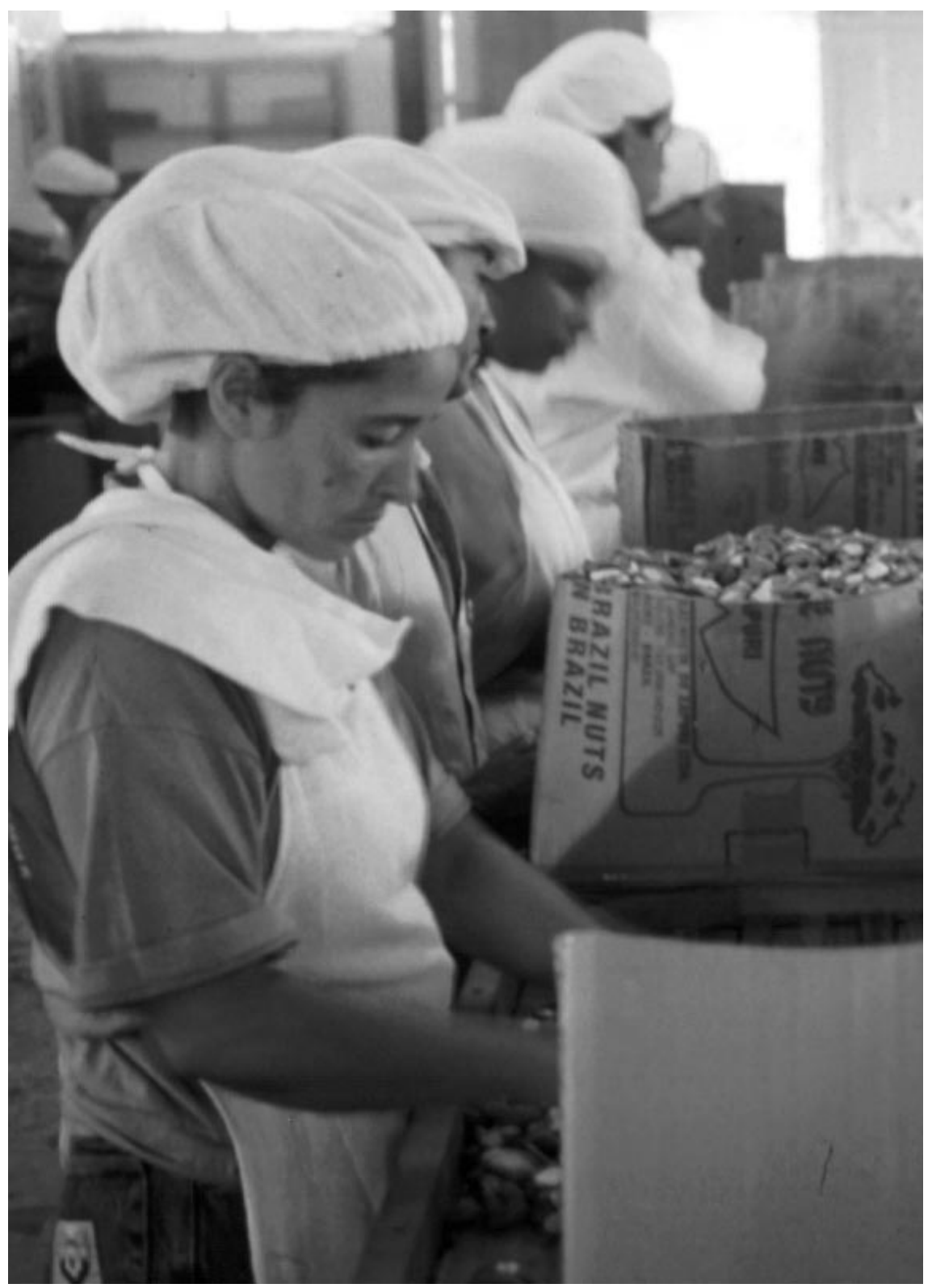

Brazil nut factory, Acré, Brazil (Photo: Manuel Ruiz Pérez) 


\section{Chapter 0 ne}

\section{Introduction}

O ver the past ten years or so several new slogans related to the sustainable management of tropical forests have entered the popular lexicon. 'Rainforest harvest', 'green marketing' and 'use or lose it' all refer to the essential principle that the best way to ensure the maintenance of the tropical forests (and their biodiversity) is to make them economically relevant to nearby residents. $D$ ove (1993) has labelled this the 'rainforest crunch thesis', after one of the better known internationally marketed rainforest products that emerged at the end of the 1980s. The underlying reasoning of thethesis is multifaceted. 0 neaspect is the premise that many tropical forests have a greater long-term economic valueif they are left standing. Second, local forest communitieswill tend towards careful, sustainable management of the forest if they receive direct economic ben efits from harvesting its resources. Third, poverty in local forest communities is both a cause and result of deforestation and environmental degradation. If poverty can be alleviated through the harvesting of forest resources, then deforestation pressures will be reduced.

The notion that tropical forest conservation and rural development are not only compatible but al so mutually beneficial has sent international donors, researchers, N GO s and government agencies into forest communities around the tropics to test its applicability and validity. The rubber-tappers' successful defence of standing tropical forest under threat from cattle ranching interests in the Brazilian Amazon in the late 1980s provided an encouraging example of the social and ecological possibilities (Schwartzman 1992). A series of meetings, research conferences and edited collections, focusing on commercial forest product extraction as a conservation and development strategy, emerged in the late 1980s and early 90s(e.g. C ousell and Rice 1992; N epstad and Schwartzman 1992; Plotkin and Famolare 1992; Redford and Padoch 1992). These were not necessarily attempts to replicate the experience of Amazonian extractive reserves, but to assess the potential social, economic and conservation benefits of commercially developing tropical forest resources.

The focus of the investigations has been on non-timber forest products (NTFPs). At times referred to as minor forest products or non-wood forest products, the concept of NTFPs encompasses a wide range of disparate and varied natural resources. As with the term, 'non-governmental organisation' (N GO ), the N TFP concept is inexact and cumbersome since it is defined not 
by what it is, but by what it is not. A N TFP is literally any and every natural resourcefrom the forest except timber. This isillustrated in the definition of Wickens (1991: 3) that NTFPs are 'all the biological material (other than industrial roundwood and derived sawn timber, wood chips, wood-based panels and pulp) that may be extracted from natural ecosystems, managed plantations, etc., and be utilised within the household, be marketed, or have social, cultural or religious significance'. As an analytical category, the NTFP concept is not particularly helpful since the property rights, harvesting practices, management strategies and ecological effects associated with, for example, extracting mammal furs or tree bark are quite different. It is difficult to conceive of developing

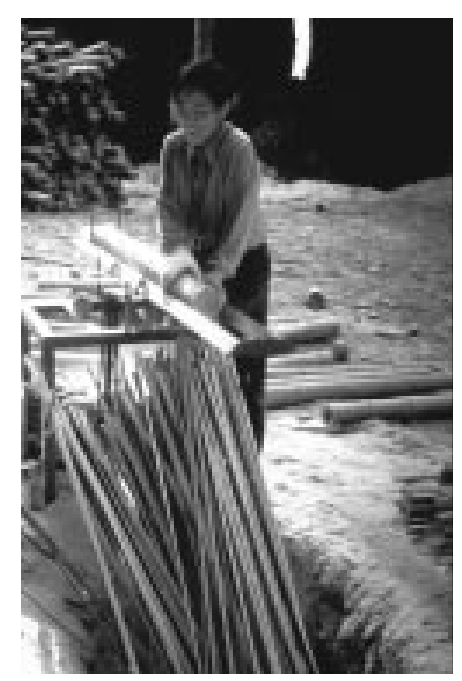

Semi processed bamboo flooring in Xiangchong, Hunan, China

(Photo: Manuel Ruiz Pérez) principles for NTFP harvesting equivalent to those associated with logging timber. N evertheless, what makes N T FPs different from timber and important as a conservation strategy isthe assumption that theforest will remain standing and more or less biologically intact under sustained N TFP harvesting. This accounts for much of the attention given to commercial NTFPs as the foundation upon which to build policies of conservation and development.

We can place the current commercial and scientific interest in NTFPs within a long history of European and N orth American attraction to tropical resources. Somehistorianshave considered theinterest in theeconomic potential of tropical natural resources to be the main force behind British imperialism (Worboys 1990). The British Imperial Institute, founded in 1887, acted as a clearinghouse for knowledge on the commercial potential of the natural resources of the tropical colonies. It sponsored scientific studies on what we today refer to as N TFPs - medicinal plants, vegetable tanning agents, fibres, oil-nuts, gums and resins, waxes and rubbers - and was publishing the results at a rate of 450 reports per year by 1910 (W orboys 1990). Thecentral scientific and technological activities of theinstitute sound strikingly contemporary with regard to the interest in NTFPs. These activities fell under three headings:

'(1) the scientific investigation of potential or little-known products;

(2) comparative investigations of these products with established ones, including commercial appraisal; and

(3) advising on all sciences relating to the utilization of natural products in the Empire' (Worboys 1990: 171). 
Except for the reference to empire, there is little to differentiate the Institute's activities from many multilateral agencies and N GO s today.

The establishment of the British I mperial Institute towards the end of the 19th century did not mark the beginning of the $\mathrm{N}$ orth's interest in commercial NTFPs. Large-scale trade with Europe in the 1840s witnessed the first boom in the extraction of Southeast Asian natural rubbers (D ove 1993) and the international trade in Brazil nuts dates back to 1866 (C lay 1997a). Even these early N T FP boom periods were preceded by several decades by theestablishment of a global network of tropical botanical gardens anchored by K ew G ardens in England. In the 1780s, an employee of the British East India Company convinced botanists in England to establish a network of naturalists in India reporting to Kew (Grove 1995). Through Kew Gardens, this network would be linked to other botanical gardens in other parts of the British empire, such as that of St Vincent in theWest Indies and, as it happened, to gardensin other empires such as that of France (Grove 1995). Thus, by the end of the 18th century, a global network of naturalists and institutions was in place that was able to acquire and disseminate knowledge of economically useful tropical plants. Indeed, not only knowledge, but also the plant materials themselves were disseminated around the European colonial empire.

Given the long history of commercial NTFP extraction and trade, we might ask what accounts for the current rise in interest. The answer is complex and partly shaped by major shifts in global political-economic forces and concomitant changes in ecological knowledge and management policies. We can, nevertheless, identify five key factors behind the growing interest in commercial NTFPs in the 1980s.

1. The international political-economic context for tropical forest management strategies has changed. W ith the disintegration of the Soviet U nion and its network of associated communist states, global strategies and philosophies of T hird W orld development have shifted dramatically. A broad neoliberal philosophy now provides the basis for government policies on social welfare and environmental management. Thenew Third W orld development slogan, trade, not aid', captures this shift. 0 ver the past decade or so, greater faith has been placed in the potential of freetrade, privatisation and the market to address problems of underdevelopment and environmental repair and stabilisation in the Third World (Watts 1991; Peet and Watts 1993; Schroeder 1995). T hisincorporatesan emphasis on the efficient allocation of property rights, including rights of access to forest resources, and on the development of new international markets for these resources. A spin-off of this general shift has been a decline of confidence in the institutions of the state to effectively lead 
development and environmental management efforts and a parallel rise in the importance of the actions of multinational corporations and NGOS.

2. The recent popular 'discovery' of the tropical rainforest as an endangered biomerich in biological and genetic diversity. Books such as N orman M yers' The Sinking Ark (1979) and Catherine Caufield's In the Rainforest (1984) detailed for educated western readers the species richness of tropical forest ecosystems and warned of the perils of deforestation. These and other writings conveyed a general presumption that the 'diversity of tropical forests is so complex and poorly understood' (Place 1993: 96) that we cannot predict the effects of human activities on the functioning of the ecosystem, and should therefore proceed cautiously. As researchers accumulated and disseminated knowledge of the complexity of the tropical rainforest, the linked threats of deforestation and species extinction became primary concerns.

3. Closely to the second issue, is the recognition of the limitations of traditional forest and protected area management. $M$ ajor failures in forest and reserve management led to the birth of a new approach labelled 'social forestry' or 'community forestry' in the mid to late 1970s (see Chapter Four). The central idea behind these initiatives was that forest management and conservation in the tropics could not succeed without the cooperation and participation of the communities whose livelihoods were tied to the forest.

4. The concept of 'sustainable development' emerged, articulated as the new framework for international donor and NGO actions in 0 ur Common Future (World Commission on Environment and D evelopment 1987). According to the Commission, the crisis of Third World underdevelopment and the environmental crisis are one and the same (p. 4). T heframework for sustainable development therefore integrates environmental management and economic development. Continued economic growth is essential, particularly in the Third World, but must be accomplished without environmental destruction (p. 40). T he underlying reasoning for the current interest in N TFPs, that sees increased commercial use of NTFPs as promoting better tropical forest management, reflects this framework. Although the concept of sustainable development has been widely criticised as contradictory and politically naïve(e.g. Adams 1990; 0 'C onnor 1994; Escobar 1995), it remains an important goal in the policy agendas of major lenders, such as the World Bank, and a wide range of international NGOS. 
5. In the 1980s UN agencies, N GO s and donors began to give greater attention to the plight of tribal or indigenous peoples in the tropics and the importance of historical land and resource rights and claims to their survival. It has become increasingly clear that the livelihoods of millions of tribal peoples worldwide are dependent in varying degrees upon access to forest resources (e.g. Stiles 1994). M uch of their use is to meet subsistence needs, but the cultural survival of tribal peoples is also often linked to their involvement in NTFP production and tradeand, ultimately, their role in forest management. In many cases, the numerous indigenous movements organised to gain political autonomy and the legal recognition of land claims have forcefully articulated these linkages.

If one considers the ambiguity of the term NTFP, the long history of global tradein N TFPs, and thecomplex political, economic and environmental factors, the scope of an inquiry into the commercialisation of NTFPs is potentially boundless. In this study, we have opted to deal with this problem, not by setting absolute boundaries, but by emphasising some categories of research into N T FP commercial isation over others. Specifically, we concentrate on the literature about non-wood plant products, although wildlife, insects and charcoal are not entirely excluded. Further, we focus on research related to the current interest in NTFP commercialisation as a conservation and development strategy that emerged in the mid-1980s.

\section{0 rigins of this Study}

This study had its origins in two workshops on NTFP research organised by CIFOR in 1995 and 1996. These were designed to contribute to a process of identifying what research might be needed in order to provide information necessary to make sound policy and management decisions relating to NTFP management and use. Thefirst, held in $\mathrm{H}$ ot Springs, Zimbabwe, was attended by 18 researchers brought together to review the status of current research on NTFPsand propose appropriatehypotheses, questions and methods for future research. An edited volume entitled Current Issuesin N on-T imber F orest Products (RuizPérez and Arnold 1997) resulted from thisworkshop. A follow-up meeting was held a few months later in M adrid, Spain, to further refine and prioritise a set of research questions and methods that could be implemented in different locales and provide research results that could be compared across different situations.

At both workshops it was noted that questions about the effects of commercialisation, or commodification, of NTFPs arose repeatedly when considering other aspects of thelinkages between N T FPsand forest conservation goals and social welfare (livelihoods, governance, management, ecological). At 
the $M$ adrid workshop it was agreed that this could be the most important area on which to focus the first stage of the effort to identify research needs. It was al so recognised that thiscould most logically beinitiated by a review and analysis of existing information. Subsequently, CIFOR and FAO commissioned the authors to carry out such a study, which was begun in July 1997.

\section{Purpose and Scope}

The overall goal of the study was specified to beto improve our understanding of issues relevant to policies and practices bearing on the management of N TFP resources. In order to achieve this, the study had the following objectives:

- D etermine what research has been carried out, what has been studied, and how this research has been conducted.

- Evaluate and analyse this research in terms of its quality and usefulness in addressing the four research questions outlined below.

- Present a set of conclusions and hypotheses derived from this review, and identify critical research needs.

The purpose of this inquiry, then, could be stated as: W hat are the management, socio-economic and ecological effects resulting from the commercialisation of N TFPs for sustainable development? O $r$, conversely: $\mathrm{H}$ ow do existing management practices and socio-economic conditions affect the initiation, process and outcome of N TFP commercialisation?

We decided that, given the present stage of knowledge, it would be most useful to think in terms of broad questions for which we seek evidence in existing studies. In an effort to categorise the literature for the purposes of the study, we used the four major areas of investigation that the two earlier workshops had identified (forest management, land and resource tenure, community and household welfare and forest ecosystems) as the foundation for formulating these questions. We thus initially organised the study of the literature on the basis of the following four research questions:

1. What aretheinteractions between NTFP commercialisation and forest management practices?

2. What aretheinteractions between N TFP commercialisation and land and resource tenure systems?

3. What are the interactions between NTFP commercialisation and community and household welfare?

4. W hat arethe interactions between N TFP commercialisation and forest ecosystems? 
Asthestudy progressed, two difficulties were raised by thislist of questions. First, all four areas are interrelated in very complex ways so that it was often difficult to separate or categorise studies and their findings based on this organisation. Nevertheless, we were forced to decide the most critical contribution of a particular study or essay, and the questions did ultimately help us categorise in a way that made the collection of literature more manageable. Second, this organisation wastheimagined ideal which, in practice, was not always a perfect fit with the reality of the literature on NTFP commercialisation. We had use each of these questions as the basisfor a chapter. $\mathrm{H}$ owever, the interrelationships between the areas led to a reassessment. The question on community and household welfare tended to bea catchall category for everything 'social', 'cultural' or 'economic'. Thequestion about tenure had the opposite problem; it was too specific for the literature collected. Consequently, valuation and supply and demand issues were taken out of the welfare question and addressed separately in a chapter on economic issues, and tenure was collapsed into a socio-political chapter.

\section{Methods}

There were three processes involved in conducting this study of the literature: 1) collecting; 2) organising and recording; and 3) analysis and synthesis. To collect the literature we:

- used standard university library electronic resources, such as on-line catalogues, indices and abstracts, as the principal sources for published books, journal articles, dissertations and theses;

- visited the (often-idiosyncratic) collections of a variety of organisations and institutions involved in research or project implementation in tropical forest use and management; and

- contacted a number of individuals conducting research related to NTFP commercialisation.

The latter two sources were the principal means by which we obtained the 'grey literature' produced for and by N GO s and donor agencies. The specific individuals and organisations are listed under acknowledgements.

In order to record and organise this large collection of literature, we designed and devel oped a specialised database using $\mathrm{M}$ icrosoft V isual FoxPro ${ }^{\mathrm{TM}}$ programming software and $M$ icrosoft Access ${ }^{\mathrm{TM}}$ database software. Two broad types of fields were created comprising: 1) the standard bibliographic information to define each 'record'; and 2) the information related to specific 'case' results. The case fields record the findings of each study. It is possible for one record entry to have more than one case. For example, an article comparing 
the market potential of three different NTFPs by analysing post-harvesting processing requirements for each product is treated as three separate cases or sets of findings.

These case data are the most crucial element for this study, and a great deal of time was spent conceptualising the fields and the range of possible categories contained in each (see Appendix A for codes, field descriptions and valid entries). Thegoal wasto record the literaturein such a way that it could be organised and reconfigured using multiple parameters, thereby facilitating comparisons and analysis. If we wish to ask what type of methods have been used to document income derived from the extraction of latex from rubber trees, it is a simple matter of restricting the parameters of the field for 'resource name' to rubber and then sorting using the field for 'method'. To compare

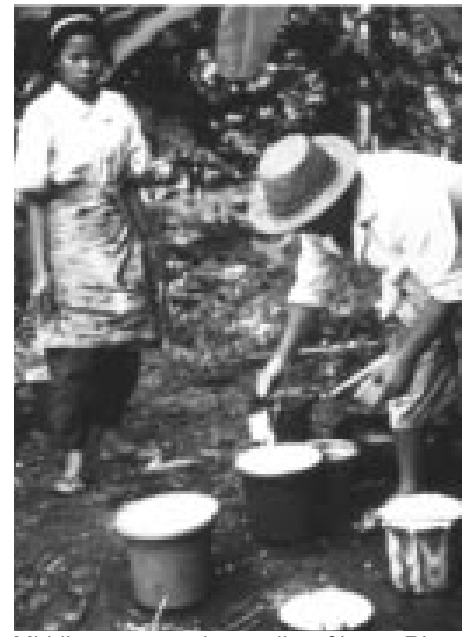

Middleman tests the quality of latex, Riau, Indonesia (Photo: Lesley Potter/Justin Lee) methods used in South American versus Southeast Asian studies, we simply add an extra command to sort by geographic region. The database is quite powerful and the fields are fairly detailed so that the literature can be compared, synthesised and analysed in almost limitless ways.

The final process of analysis and synthesis was guided by the initial four research questions and facilitated by using the database to compare methods and findings among studies. N eumann took thelead rolein most of this process, with the exception of the investigation of economic issues where $\mathrm{H}$ irsch was the principal. The organisational structure of each chapter is essentially the result of our attempt at synthesis. After each major subheading and in the final chapter, we offer our analyses and critiques of the research literature. From the literature reviewed, we selected those works that most directly addressed the particular issue under discussion and that provided the best empirical support. The broader body of work that is included in the bibliography is reflected in the summaries of each chapter and in C hapter Six, 'D irections for Research', although not every individual work is cited in the text.

\section{About the Literature}

The body of literature related to N TFP usein the tropics is massive, written in several languages by people representing professional and scholarly specialisations ranging from marketing to ethnography to genetics. We often 
found published studies that were derivative of other research, relied on anecdotal evidence, or had no clear methods. Some of thesenevertheless contain the best available information or important insights and so were included. Above all, we sought to locate the best empirically based studies of NTFP use, management and ecology. H owever, we make no claims to comprehensive coverage of this literature or to having assembled a representativesample. Rather, we have been quite selective in choosing the literature to be included.

- The literature selected reflected the study's particular focus on the four research questions, and the topics within each that were identified as being of importance.

- We sought out studies that dealt specifically with the process of NTFP commercialisation. Literature that might deal with this indirectly, through study of topics such as subsistence use or non-farm incomes, was given lower priority.

- We periodically evaluated the literature we had collected in an effort to achieve a modicum of balance among geographic regions, study foci and species studied.

- Constraints of time and funding did not allow us to delve into the non-English literature. The literature reviewed is exclusively written in English.

- We concentrated our search on the literature from the mid-1980s to the present, reflecting the recent period of interest in N TFPs described above. The review therefore does not cover the considerable literature on NTFP resources and product characteristics that was produced during the earlier periods of interest in tropical resources.

- We emphasised research on non-wood plant products, though not to the complete exclusion of all other types of products.

Even given these boundaries, the literature is still quite large since in this study we are concerned with all stages of harvesting, processing and trade. In some cases, the studies addressed or emphasised only one of these stages. In other studies all of the stages for a particular resource might be investigated. Both of thesetypes of studies were reviewed. H owever, given the policy interest in NTFP commercialisation as a form of sustainable development for local forest communities, we give particular attention to the primary stage of harvesting and collecting practices. Less emphasis is paid to processing and trade, or to broader factors affecting theevolution of market demand for N TFPs.

In the end, a few studies stand out as providing key empirical evidence, useful research methods or theoretical insights. We tended to use these as extended case studies for exploring particular topics throughout the chapters. 
$\mathrm{N}$ ot all of the materials we collected were included in the database and bibliography, partly because accounts of the same research and findings are available in different publications under different titles. We tried to avoid redundancies. We also found that some collected titles were not appropriate for our needs. In addition, we reviewed only the relevant chapters from some of the monographs and dissertations cited. The description of the literature that follows is thus a reflection of our selection and screening process.

In constructing the database, we included fields for country and world region. The tropical regions designated were Africa, South Asia, Southeast Asia, East Asia, Central America and South America. A large majority of the studies reviewed (88 percent) had a specific regional focus. Of the 186 studies and reports (called 'articles' for convenience), published from 1987 to 1998, ${ }^{1}$ the predominant regional focus was South America, followed by South Asia (Figure 1). South America was the subject for more than onequarter of the articles. The overall distribution of studies is disproportionate to both population and geographic size of the regions. If the amount of tropical rainforest by region is considered, the distribution becomes more proportionate, though South Asia would then stand out as overrepresented.

Figure 1. Articles per Region, 1987-1998

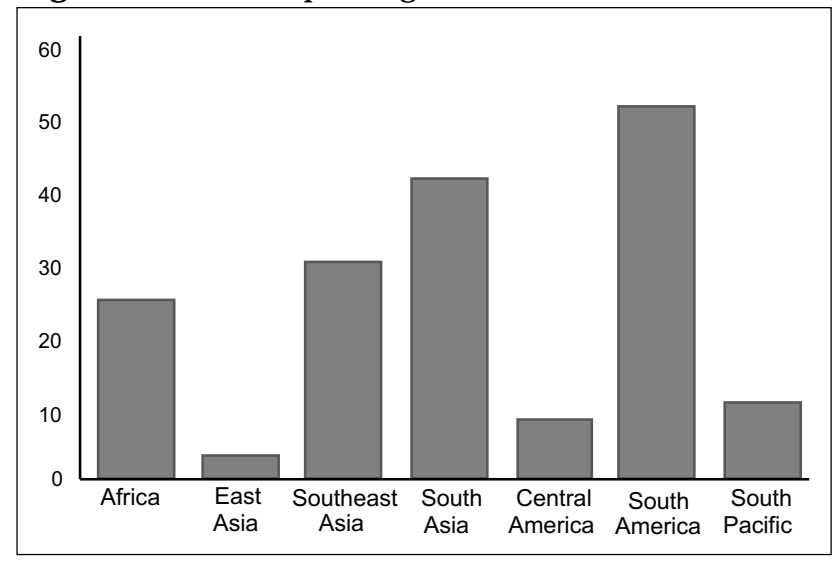

Although this is not a random sample, we feel confident that it is a fairly accurate representation of the actual regional focus of research. Extractive reserves and 'rainforest crunch' originated in South America in the late 1980s and helped to spark a new wave of interest in NTFPs. It is not surprising that the lion's share of studies were focused in that region. Dividing the regional

${ }^{1}$ The earliest publication date in our review was 1985, and only four pieces were published prior to 1987. 
totals into two time periods, 1987-92 and 1993-98, clearly reveals the South American origins of the current interest in NTFPs (Figures 2 and 3). In the first period, South America accounted for $53 \%$ of all articles and South Asia for very few. In the second period, the distribution shifts dramatically and three interesting patterns emerge. First, there is an overall boom in the number of articles published on commercial NTFPs. Of those with a regional focus, $69 \%$ were published after 1992. Second, South America's share of the total drops significantly, from $53 \%$ to $16 \%$ t. Finally, South Asia emerges as the focus for the largest proportion of studies (30\%). The general growth in the number of articles reflects the widespread interest in NTFPsin the mid-1990s following events in South America. Theemergence of South Asia as a region of interest may be closely related to shifts in national forest policies in the region, which we discuss in later chapters.

Figure 2. Articles per Region, 1987-1992

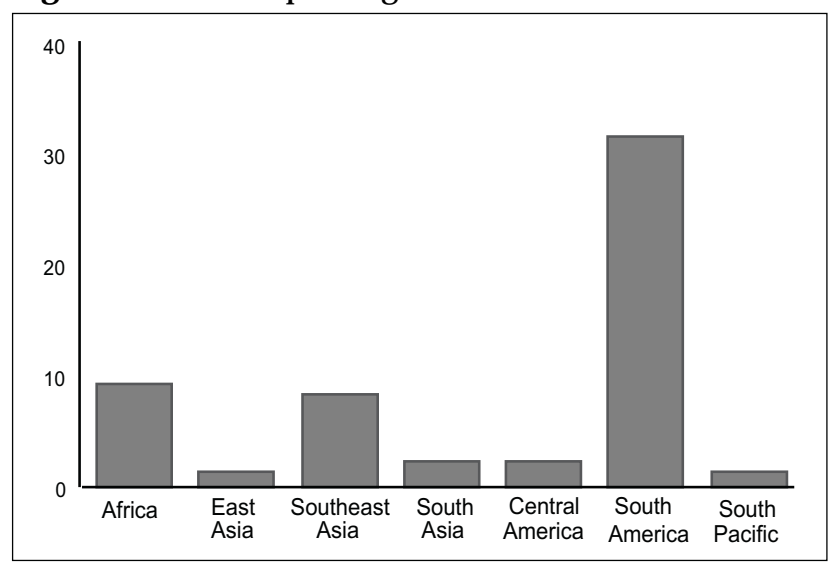

Figure 3. Articles per Region, 1993-1998

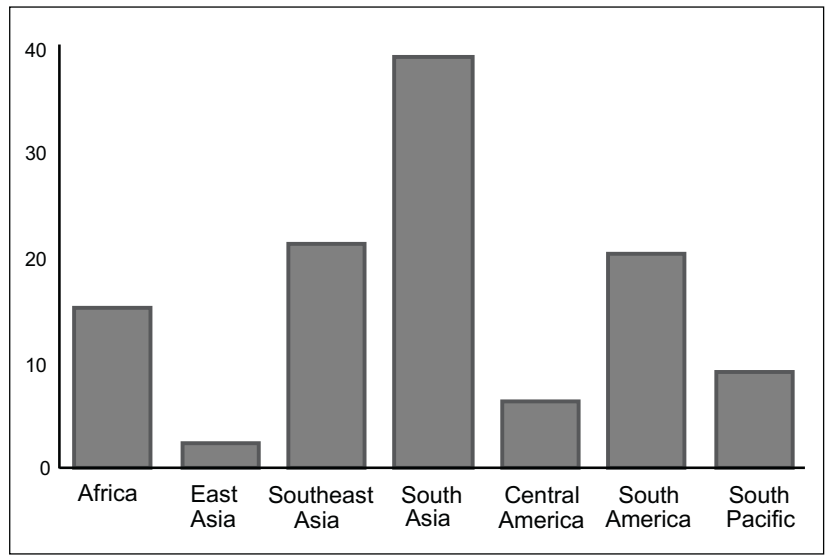


If we examine the distribution of articles by NTFP resource type, only two significant patterns emerge. $M$ any of them did not focus on a specific resource, but either addressed NTFPs in the abstract or examined a number of resource types. About $53 \%$ of thearticles had no resourcefocus, although somedid contain fairly detailed examples of specific N TFP resources. Of thearticlesthat did focus on a specific resource, four N TFPs - açai palm, rattan, Brazil nuts and rubber were the subjects for $27 \%$. The rest of thestudies focused on a wide range, often geographically limited, of N TFP resources. The basic issue that emerges is the lack of knowledgeabout theuses, biology, and management of most commercial NTFPs, even those that have a high market value.

These patterns reflect another factor that has contributed to the balance of material covered in the review; namely the concentration of research literature on particular topics, and the relative paucity of material on other topics. Thus, the balance between numbers of articles from South America and Africa in part reflects the fact that much more attention was paid during the period to products that entered international trade than to products that were traded domestically within countries to meet local market demand. Consequently the review has been able to examine the former in more depth than the latter. $O$ ther consequences of the patterns of literature availability are brought out in later chapters.

A final descriptive characteristic of the literature is the general methodological approach of individual articles. By this we do not mean the specific methods employed, such as vegetation transects or participant observation, but the general sources of knowledge and information contained in the article - historical documents, field study, literature review or project report. $\mathrm{H}$ istorical documents, both primary and secondary, wereused to develop case studies of N TFP commercialisation. Field studies collected primary data from a specific site. These studies employed a range of methods from both the social and natural sciences and in many cases were conducted using rigorous experimental design. In many articles, the primary source of information was previously published field results that were then synthesised and discussed. Finally, we reviewed numerous reports from authorsworking on specific projects that may have included primary baseline data obtained through a variety of methods, but did not detail experimental design. For most articles, we were able to document a primary and secondary approach, e.g. many field studies contained extensive literature reviews.

\section{O rganisation of the Work}

The chapters are organised around four themes: socio-political factors, economics, management issues and ecology. Chapter Two examines the results and findings of research and project reports on broadly conceived socio-political 
interactions between the process of N TFP commercialisation and people. By broadly conceived, we mean that this literature tends to link N TFP commercialisation with larger questions of social justice, social welfare, land reform, rural poverty and political empowerment. Adding to the immensity of the research and policy scope is the fact that individual projects and studies reviewed do not always share a common understanding of these terms and, more often than not, use these and related terms without explicit definition.

In order to deal with the problems of both the breadth and ambiguity of the socio-political issues involved, wehave chosen to organise the chapter around some of the key concerns that emerged from the literature we reviewed. First, questions of ownership and control of access to NTFPs and the forests that contain them have been central to socio-political studies of commercialisation. Second, the important and often dominant roles of women in NTFP harvesting,

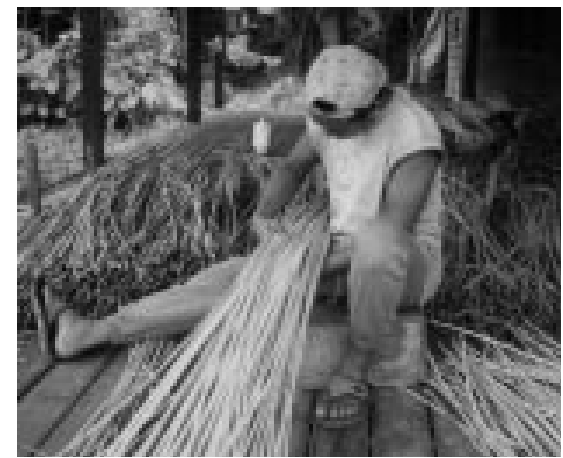

Selecting split rattan to be used in making a lampit mat, Amuntai, South Kalimantan, Indonesia (Photo: Rita Mustikasari) processing and marketing, in combination with their disadvantaged economic and political status in theT hird World, have made gender a key focus in many studies. Third, the existence of relatively high levels of poverty among tropical forest users has linked poverty alleviation and NTFP commercialisation in research and policy. Webegin, therefore, by examining land and resource tenure as it relates to NTFP commercialisation, followed by a discussion of gender interactions, and we then address the relationship between NTFP use and poverty and weal th distribution.

Chapter Three, on economic considerations, reviews the findings of the research literature regarding the potential value of NTFP resources, the contribution of N TFP-related incomes, and the profitability of N TFP-related enterprises. M ost of the analysis presented in this chapter is generalised over many studies, the majority of which do not address economic questions primarily. Where appropriate, studies with a central economic focus with significant findings are described in detail.

We begin by examining studies that attempt to calculate the potential value of NTFPs from tropical forests at various scales of analysis. The focus includes theoretical issues related to valuation as well specific study findings. The second section examines the economics of depletion and sustainability, focusing on the way the terms 'supply' and 'demand' have been used in much of the literature on NTFP economies, and on prices, imperfect markets and 
demand curve elasticity. The third section reviews material on marketing networks, patterns of exploitation in trade and marketing, and marketing institutions.

In Chapter Four, on management issues, we have opted to concentrate on the technical and formal institutional aspects of management. That is, we focus on the practices and techniques employed for the purpose of producing commercial NTFPs from forest lands and on the institutions established to implement them. M any of the political, social, ecological and economic aspects of management weaddress in other chapters. We also concentrate on NTFP management in forests and avoid delving very far into questions of cultivation. There remains, however, a grey area in

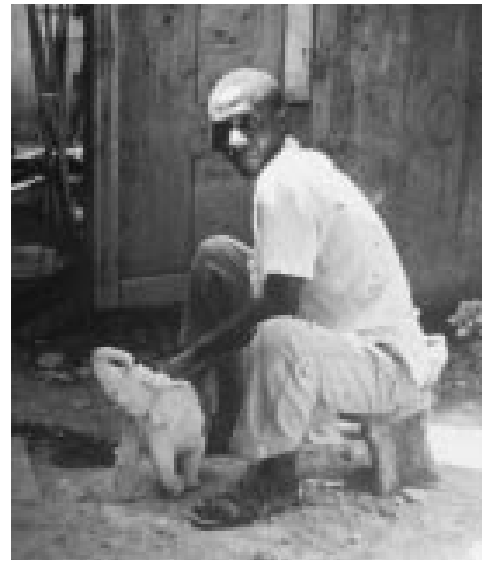

Woodcarver in Zimbabwe (Photo: Susan Kabiling) which the line between intensive management and cultivation, between natural forest and managed forest, or between extraction and agroforestry, is blurred. We enter that grey area through the management literature on a range of forest types including forest fallows in swidden systems, secondary forests and abandoned forest settlements. It is important to do so partly because intensively managed systems are often mistaken for natural forests and can be counted as such in national and regional tallies, and also becausethese are often themost important sources of commercial N TFPs (see C hapter Five) and the sites where most customary management takes place.

Wehave organised the chapter by first making a rough distinction between state-led, 'scientific' forest management and 'customary' forest management (which refers to the everyday practices of people living in countless tropical forest communities). The following section looks at the research on 'participatory management' or 'co-management', which integrates community-based customary and state-led scientific management for NTFP production. This topic necessarily leads further into social and political questions, but we try to restrict the review here to the more technical aspects of institutional arrangements and avoid overlaps with C hapter Two.

In Chapter Five, on ecological aspects, we explore the interactions of commercialisation and forest ecology, with special attention to biodiversity conservation issues. In assembling theliterature, we concentrated on gathering writings that reported the findings of field studies that in some way addressed the ecological aspects of commercial N TFP exploitation. For most researchers, 
the central ecological question in any system of commercial exploitation is how much of the resource can beharvested without diminishing its capacity to regenerate or degrading the environment. In other words, the current interest in the connection between forest ecology and N T FP commercial isation can be viewed as the most recent application of the principle of maximum sustained yield in forest management.

Webegin thechapter by examining the empirical evidenceon theecological effects resulting from commercial NTFP extraction. We divided the studies into those that found negative ecological effects and those that found neutral or positive outcomes, giving special attention to theroles of market, institutional and ecological conditions. We then look at the relationship between commercialisation and ecology in the other direction, focusing on findings that indicate how ecological conditions influence the potential for successful N TFP commercialisation. The final section focuses on methodological issues, examining how causal linkages between ecological conditions and commercialisation are demonstrated (or not) in this research.

In Chapter Six, the last, we lay out some of the key directions for future research. For each of the four issuesaddressed in the corechapters, we critically examine the theoretical and empirical implications of the NTFP studies reviewed. The proposals for future research therefore derive in large part from what was reviewed, and reflect the balance and patterns of material and topics identified in the Introduction. Wealso present suggestions on the possibilities for cross-fertilisation from other areas of research, the need for rigorous research design, and the importance of clear and explicit theorisation and conceptualisation. These suggestions are derived both from the published insights of experts studying N TFP commercialisation as well as our own critique of the research we reviewed here. 


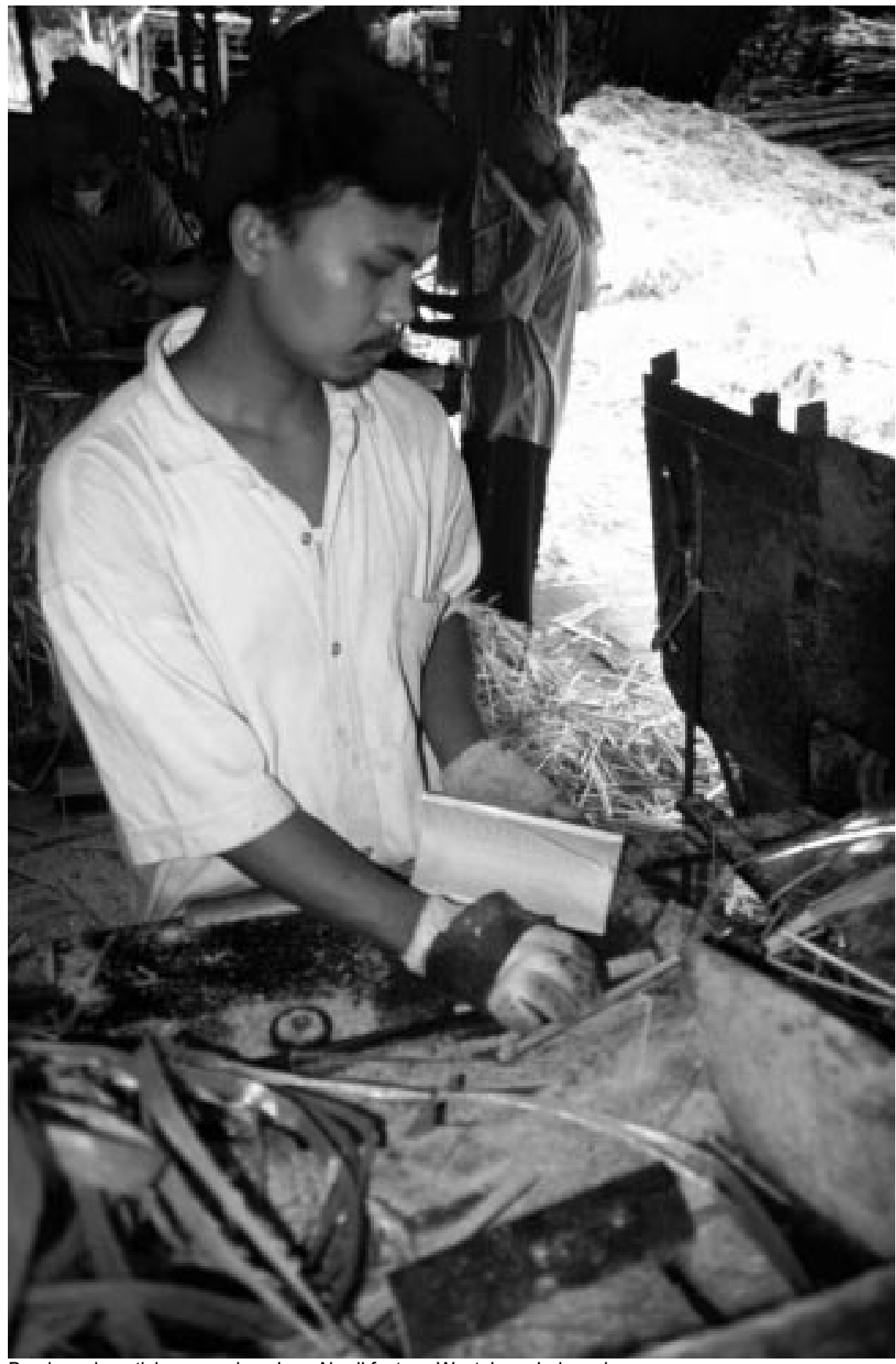

Bamboo chopstick processing, Jaya Abadi factory, West Java, Indonesia (Photo: Manuel Ruiz Pérez) 


\section{Chapter Two}

\section{Socio-Political Aspects of N T FP Commercialisation}

This chapter examines the results and findings of research and project reports on broadly conceived socio-political interactions between the process of N T FP commercialisation and people. Commercialisation has been associated with efforts to politically empower and economically advance some of the most disadvantaged sections of society - poor peasants, the landless, rural women and indigenous (or tribal) peoples. The literature tends to link NTFP commercialisation with larger questions of social justice, social welfare, land reform, rural poverty and political empowerment. Adding to the magnitude of the research and policy scope, individual projects and studies reviewed do not al ways share a common understanding of terminology and, more often than not, fail to provide explicit definitions.

In order to deal with the problems of both the breadth and ambiguity of the socio-political issues involved, the chapter is structured around some of the key concerns emerging from the literature reviewed. First, questions of ownership and control of access to N T FPs and the associated forests have been central to socio-political studies of commercialisation. ${ }^{2} \mathrm{~N}$ ext, the important and often dominant roles of women in NTFP harvesting, processing and marketing, in combination with their disadvantaged economic and political status in the Third World, have made gender a key focus in many studies. Finally, the observed relatively high levels of poverty among tropical forest users have led research and policy to link poverty alleviation and NTFP commercialisation. We begin, therefore, with a section examining land and resource tenure as it relates to NTFP commercialisation. It is followed by a discussion of gender interactions, and then a section on therelationship between NTFP use and poverty and wealth distribution.

\section{Land and Resource Tenure}

An analysis of land and resource tenure is an appropriate place to begin an examination of the socio-political aspects of NT FP commercialisation. Tenure

\footnotetext{
${ }^{2} O$ wnership and control of access are al so critical to questions dealing with institutions of forest management. Institutional issues in management aretreated in Chapter Four, although there is significant overlap with the following section on tenure.
} 
arrangements govern the most direct interactions between a society and living N TFP resources: harvesting and management. Tenuresystems provide therules for governing who gets to harvest a resource, where they can harvest, how much they harvest, and for whose benefit. Thus the concept of tenureincludes both the notion of ownership and a corresponding parcel of rights. The widely accepted classification of tenure systems defines four types of ownership - state, private, communal and open access - and four basic kinds of rights - use, transfer, exclusion, and enforcement. The many combinations of rights and forms of ownership means there is limitless complexity in tropical forest tenure systems. M ost of the studies on N TFP commercialisation concern either stateowned or communal forests. Few of the studies in our bibliography provide significant amounts of empirical evidence on the relationship between systems of tenure and the process of N TFP commercialisation.

Q uestions concerning the relationship between N T FP commercialisation and land and resource tenure systems arise most frequently in the literature on extractive reserves. The defining characteristic of extractive reserves is a specialised tenure arrangement between the state and a portion of its citizenry. Thisfact, and because much of the current interest in N TFP commercialisation was sparked by the extractive reserve concept in Amazonia, makes extractive reserves a logical place to begin a discussion of the relevance of tenure systems. We begin with a short review of the history of extractive reserves as the basis for N TFP commercialisation efforts. Thisis followed by a review of the findings on the success of extractive reserves and a discussion of some of the critiques of the concept and of its usefulness as a widely applicable model. The effects of commercialisation on tenure more generally are then examined.

$M$ any of the questions raised in the tenure section around who controls access to forest lands and resources overlap with the questions raised in Chapter Four about institutional arrangements for forest management. Tenure questions are indisputably bound to management practices and institutions, but they are also bound to state political and legal systems, to ethnic and class relations, and to issues of social and economic justice. For this reason, we have chosen to treat tenure in this chapter, but also to call attention to points of overlap with institutional aspects of management as they arise.

\section{Extractive Reserves as Special Tenure Arrangement}

The most commonly cited definition of extractive reserves is Schwartzman's reference to that used by the Brazilian M inistry of Agrarian Reform and D evelopment. Extractive reserves 'are forest areas inhabited by extractive populations granted long-term usufruct rights to forest resources which they collectively manage' (1989: 151). Thus extractive reserves in essence are stateowned land with access and use rights legislatively allocated to local groups or communities. In the Brazilian Amazon, extractive reserves were created by the 
1987 Projeto deAssentamento Estrativista(PAE) - ExtractiveSettlement Project - which was an important innovation in land law (Schwartzman 1992: 208). In these PAEs, the land is state owned and local communitiesor associations are granted usufruct. The sale or transfer of rights is prohibited. This type of tenure arrangement is viewed as attractive because it appears to represent a socially just form of land-use that can reconcile economic development and environmental conservation' (Anderson 1992: 213). As Lescure et al. (1994: 1) observe, the extractive reserve debate 'brings to the fore the central question of land tenure in Brazilian society'. Thebasic appeal for forest conservation

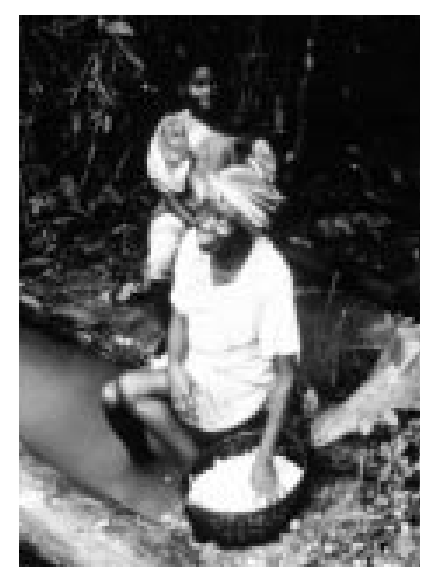

Washing forest beans in Cameroon (Photo: Timothy Boyle) is that areas are reserved for the sustained extraction of renewable commercial forest products by traditional resident populations (Browder 1992a: 174).

The extractive reserves in Brazilian Amazonia exist due to an organised social movement that devised them as a strategy to deal with immediatepressing social problems (Schwartzman 1992). The movement began among rubbertappers in Acré in the mid-1970s as a spontaneous resistance to growing deforestation and concentration of land holdings in fewer hands. By 1987, the first legal form of extractive reserve, the PAE, was established. The creation of reserves was made possible by a combination of legal mechanisms devised by the N ational Rubber-tappers' Council, the Institute for Amazon Studies and their supporters within government agencies (Schwartzman 1992). It was a model based on the experience of independent rubber-tappers who had escaped the condition of debt peonage typical of Amazonia. AsFearnside(1989) stresses, the fact that the extractive reserve idea emerged from a grassroots movement makes it almost unique among Amazon development projects. By the early 1990s, three million hectares of extractive reserves had been created in the Brazilian Amazon.

\section{Research into and Analysis of Extractive Reserves}

Following the implementation of extractive reserves in Amazonia in the late 1980s, there have been a number of efforts to analyse the socio-economic and conservation implications of this tenure arrangement. Some of these studies are based on empirical research whileothers are reviews and critiques. Browder (1992a) found that published research findings indicated that the usefulness of extractive reserves for socio-economic improvement and forest conservation waslimited. Thisconclusion is based partly on thefindings of threeethnographic case studies of Amazonian rubber-tappers that emphasisefour common themes: 
- rubber-tapping populations are heterogeneous in their social relations of production, economic activities and degree of organisation;

- the vast majority of rubber-tappers are financially indebted to landowners, bosses and patrons, and are among the poorest of the Amazon's non-indigenous rural population;

- themajority of rubber-tapper households are residentially unstable; and

- natural resource degradation occurs and may be accelerating.

A review of extractivism by Lescure et al. (1994) confirms many of these observations.

In Seringal Porongaba, part of the C hico M endesExtractive Reserve, N epstad et al. (1992) compared the biotic impoverishment associated with non-timber forest product extraction with that of ranching and logging in northeastern Pará. The results show that Brazil nut is the only tree species that may be undergoing population decline through extractor activities. Exactly why is not clear but it may be due to overharvesting, reduced populations of dispersal agents (agoutis) through hunting, low germination rates, seed vulnerability to fungus, seedling dependence on large openings and/or burning ben eath adult trees. N evertheless, a much larger percentage of the forest $(90 \%)$ remains intact during NTFP extraction than is the case through logging $(50 \%)$ or ranching $(50 \%)$. Forest conversion to pasture, practised by both ranchers and to a lesser extent N TFP extractors, clearly provokes thegreatest biotic impoverishment compared to other activities. When provided with clear usufruct rights to an area of land, NTFP extractors will have an incentive to maintain resources, if continued access is dependent on the maintenance of an intact forest. H owever, in the Seringal Porongaba study, N TFP extractors were found to be expanding pasture at the expense of standing forests. The authors concluded that biotic impoverishment can continue within extractive reserves as long as cattle are viewed as the most logical investment of surplus income' (N epstad et al. 1992: 10).

0 ther researchers have critiqued the extractive reserve model with respect to economic viability, environmental conservation and social equity. Extractive economies are notoriously unstable, and therefore cannot guarantee that residents will not destroy the forest to meet short-term needs (Anderson 1992). This type of tenure arrangement requires that a great deal of land be allocated to individual households, far more than for other development projects, and therefore raises questions as to which populations will benefit. Browder (1992b) sharesthis concern and argues that social complexities work against an extraction model based on the tenurial rights of the 'extractor household,' which defies definition. H ealso questions the ecological sustainability of extractive reserves, noting that as many as two-thirds of the rural inhabitants of Amazonia who extract NTFPs do not have a relationship to the natural environment similar to that of 'reservist' movements, such as the autonomous rubber-tappers. 
D espite these criticisms, there is evidence that the granting of secure usufruct rights to extractive reserves can move exploitative social relations towards greater equity. In his analysis of the U pper Juruá extractive reserve, Schwartzman (1992) noted that the reserve had its origins in a rent strike. Rubber baron patrons claimed land ownership and charged rent to tappers. The power of the patrons was broken by creating an extractive reserve, combined with a new presidential decree. ' 0 nce the extractive reserve was declared, those claiming property rights within it were obliged to present legal documentation of valid title to theFederal Prosecutor's O ffice' (p. 209). This reversed the burden of proof of legal occupation of land, where the presumption had been on the side of the titleholders. In this case, the creation of an extractive reserve and the accompanying shift in tenure relations translated into greater social justice for a traditionally exploited group.

Much of the extractive reserve literature views security of tenure as a necessary prerequisite to 'successful' NTFP commercialisation. G ray (1992) argues that security of tenure must come before any efforts to market N TFPs. 0 therwise, the situation will be unstable and indigenous people, in particular, will lose control over decision-making, leading to highly exploitative relationships. He points to the 1894-1914 rubber boom in the U pper Amazon when indigenous peopleswere brought into slavery and debt bondage. Although security of tenure may be crucial, M ay (1991) points out that rubber-tapper leaders in the Amazon soon realised that land rights, while an essential first step towards local development, are not enough. In order to improve their living conditions, forest dwellers need to ease the difficulties of getting their goods to market and to receive fair prices for their products. An important lesson from Brazilian extractive reserves is that security of tenure is important, but not always enough to ensure improved forest conservation and local economic development.

\section{The Effects of C ommercialisation on Tenure}

W hilethe extractive reserveliterature stresses the effects of tenure on successful commercialisation, we are also concerned with how commercialisation affects existing tenure arrangements. It is very difficult to separate the direct effects of NTFP commercialisation from larger social, political and economic forces influencing the transformation of tropical forests and societies. Population migrations, the activities of multinational corporations, military conflict and conservation policies, for example, can radically alter ownership claims and the regulation of forest access. Thus it is important that we consider the results of particular studies as highly contextual and geographically and historically specific. It is safe to say that rural communities' customary claims of forest ownership and access have generally been under attack from outside interests 
everywhere in the tropics for at least a century and commercialisation can either exacerbate this trend or aid in the defence of local tenure.

M cElwee (1994) is one of the few studies reviewed that explicitly attempts to draw conclusions about the effects of commercialisation on tenure. Specifically, the thesis looks at a series of published cases to determine the effect of the process on community property regimes (CPRs). Commercialisation may benefit CPRs because it provides an incentive for organising and strengthening communal action, as there is much to lose or gain. H owever, disadvantages are many and commercialisation may lead to increased disputes, privatisation, encroachment by outsiders, dependence on outside institutions, state interference, the usurpation of women's marketing and money control roles by men, and overharvesting. M cElwee concludes that factors which appear to help CPRs endure include an absence of colonial interference in the past, a history of commercial production, strong group cohesion, a small homogeneous population of users and well-defined distribution of benefits.

In two cases from the South Pacific, most of the above conditions are in place, yet increased market integration appears to be leading to the collapse of CPRs and a corresponding increase in private ownership. In Western Samoa, Arvidsson (1996) noted that local communal tenure systems have been eroding, particularly on land managed for agricultural production. The general trend is towards individual private property rights. $\mathrm{He}$ speculates that increased commercialisation of NTFPs would similarly weaken customary tenure and increase private property. O Isson's (1991) discussion of N TFP development in Vanuatu also indicates a shift away from customary land tenure. The Constitution of Vanuatu states that all land not acquired by the government belongs to the indigenous customary owners and their descendants. In reality, disputes over control of customary land are increasing as cash crop production and logging expands integration into larger markets. Interestingly, 0 Isson found that greater market orientation in agriculture, combined with tenure disputes, has diminished the rate of extraction of N T FPs that, at this point, do not have important market values.

Jodha's (1986, n.d.) long-term study in 82 I ndian villages found that land reform begun in 1950-52 had reduced the area of CPR s by between $30 \%$ and $50 \%$. D uring the same period, population increased threefold in most villages. The decline in the area under CPR was the direct result of a programme of land privatisation that did little to help the economic status of the rural poor. Consequently, there was greater demand for reducing CPRs, leading to overexploitation and subsequent declines in the quality and diversity of N TFPS available. Jodha's research shows that the privatisation of CPRs had a negative effect on both the rural poor and the qual ity and quantity of collected N TFPs. 
In Latin America, the issue of whether common property institutions can stand up to increasing economic, commercial and demographic pressures remainsan open question. Theevidence shows that there have been both positive and negative experiences (Richards 1997). On one hand, market integration (and other factors) has eroded informal indigenous institutions. $O \mathrm{n}$ the other hand, communities in lowland Amazonia have organised to create new CPR institutions that havebeen succesfful. Recently established arrangements include those developed by frontier colonists (this is rare), extractive reserves, community-based natural forest management models, and evolving cooperation in open access forests among N TFP harvesters. CPR systems are clearly vulnerable to economic or commercial pressures, and state or market-oriented donor intervention may hasten their decline. 0 ne analysis of market-oriented forest management projects among Amerindian groups (Richards 1997) shows that not one of these projects has proved sustainable, due mainly to the incompatibility and confusion of incentives between market and traditional institutions. $M$ arket forces have al so brought greater risks and, in the case of many N TFPs, led communitiesinto a 'boom-bust' downward cycle. In another study in Amazonia, the same author found that the movement of tenurefrom various forms of usufruct towards privatisation meant that peasant harvesters of babáçu lost access to a valuable N TFP (Richards 1993a). In general, the evidence indicates that market-oriented approaches to conservation and management as a general strategy must be seriously questioned.

A final example from Latin America on chicle latex extraction in Petén, Guatemala, reveals how commercialisation can result in new forms of tenure that may go legally unrecognised. D ugelby (1998) demonstrates that extraction in Petén operates in a situation of overlapping property rights, including state, open access and common property regimes. In this case, the state claims ownership, and no privateindividuals are granted holdings or legal concessions. Technically, chicle is extracted on state-owned land under open access conditions. Contractors, however, have partitioned the forest among themselves, resulting in a 'common-property-like' arrangement (p. 164).

In Southern Africa the interactions between N TFP commercialisation and tenure systems can vary greatly within even very small geographical areas. A study of the economics of basket production from palm leaves in two sites in $\mathrm{N}$ gamiland, Botswana, reveals a complex interaction of tenure, management, the health of the resource and socio-cultural variation (Bishop and Scoones 1994). Women are the main participants in the basketry economy and their harvesting techniques differ between villages. In one study site ( 0 gxe), women enforce a ban on hoe/axe cutting because it is too destructive of the palms. At a second village (Wabe), women prefer hoes and axes for cutting and, consequently, the palms are short and stunted. $M$ anagement strategies differ 
in the two villages with 0 gxe employing a selective harvesting regime, while the women of Wabe are non-sel ective. The differences are attributed to a strong system of access control in 0 gxe compared to an open access situation in Wabe. In addition, the women of $\mathrm{O}$ gxe make better qual ity baskets and are therefore more concerned with maintaining a source of high-quality palm leaves. In this case, cause and effect is not clear, but a complex interrelationship between tenure, management and ecology is evident.

In a second study, twenty-seven workshop participants were involved in a 14-day research project in the $\mathrm{H}$ ot Springs area of Zimbabwe $(\mathrm{H}$ ot Springs Working Group 1995). Researchers studied two villages, Jinga and $M$ atendeudze. Resource maps drawn by villagers were used to identify major resourceunits (e.g. fields or forested hills) in each village. These village resource maps became thebasisfor developing a tenuremap showing the range of resource controls that apply to the various

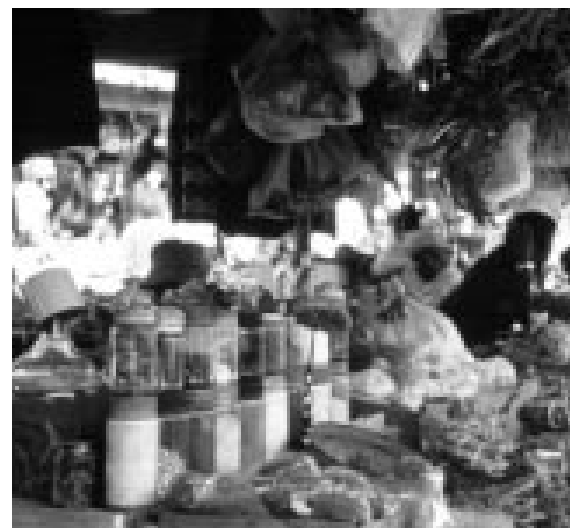

NTFP medicines in the market in Harare, Zimbabwe (Photo: Manuel Ruiz Pérez) resource units in and around the villages. Both communities identified sacred sites where access and resource use were greatly restricted in the past. T he types of controls on resource use are similar in both villages, al though lineage leaders in Jinga appear to have greater authority to control resource use. In $M$ atendeudze, enforcement appears to have largely weakened. T he researchers speculate that this may account for a variation between the two villages in quality and availability of standing woodland, with Jinga having a clear advantage over $M$ atendeudze. The rules of access and use in $M$ atendeudze have broken down, moving the tenure system in the direction of open access.

Four studies from Indonesia further illustrate the politico-economic complexities that influencetheinteractions between N T FP commercialisation and tenure systems. The first two indicate how commercialisation, for very different reasons, can work to strengthen customary land claims against those of outsiders. D ove (1995) describes how tribesmen of Kalimantan sometimes planted Pará rubber as a way of strengthening claims to the land on which it was planted. In other words, Pará was planted primarily for tenurial benefits. In contrast, wild trees, while recognised as the property of the first user, did not provide any such support for claims on the land. The fact that rubber does not occur naturally in Southeast Asia is one of the reasons for patterns of rubber exploitation being different to that occurring in South America. It is planted 
crops, not wild trees, that are symbols of possession in both regions. M aryani (1995) relates how commercialisation is helping to secure access rights in a forest development project on state-owned forest in West Kalimantan. State forestry law and policy have often restricted local forest access. Even though customary land rights are officially recognised by Indonesian law they are often superseded by forestry law to provide forest production and protection in the national interest. In this project, to be partly funded by N TFP marketing, the Indonesian $\mathrm{M}$ inistry of Forestry will grant long-term usufruct rights (70 years) to a newly formed participatory forest management bodies.

The importance of larger-scale politico-economic forces is well-illustrated in the study by Peluso (1992b) of the potential for creating extractive reserves for N TFPs (especially rattan) in East Kalimantan, Indonesia, where forests are being rapidly destroyed. She uncovered a number of constraints including the difficulties of defining access rights, the political climate in Indonesia and the realities of trying to enforce exclusion. First, newcomers and migrants from other parts of Indonesia are changing the nature of N TFP management from a common property arrangement with rules of access and sanctions for transgressors to an open access situation beyond effective control. Second, relationships between collectors and traders, and among traders themselves, are highly complex, involving various elements of collusion and resistance. Finally, a number of factors have made the collection of and trade in rattan more lucrative since the 1970 s, bringing increasing government intervention in the trade. In this case, it appears that increased marketing of rattan has taken place at the expense of both the rights of customary forest communities and the forest itself, which suffers from overexploitation as a result of its conversion to an open access system.

In West Kalimantan, Peluso and Padoch (1996) examined the regulation of access rights in various types of managed forests and the effects of commercialisation on those rights. They compared two D ayak villages where resources are managed by a range of access institutions under various forms of common and private property which change among land uses and through time. Individuals or households hold private rights to specific resources, and these can be rotated among individuals, such as siblings, for agreed periods. Common property rights are held collectively by villages or descent groups. $M$ any resources on community forest lands arecommon property, whileplanted or protected species in the community forests may be private property. In both villages, durian fruit (D urio zibethinus) has important cultural and economic values. Recent developments, such as road building, have increased the commercial importance of durian. The effects of commercialisation in the two villages are neither parallel nor predictable. In one village, there appears to be a general move toward increasing privatisation of resources, while in the other village there appears to be a conscious decision not to privatise. The effects of 
commercialisation were found to differ from village to village and even from household to household within the same village.

We close this discussion of tenure with a brief examination of some of the tenure peculiarities of N TFP extraction from state-owned forests. Studies from virtually every region of the tropics indicate two common phenomena, often closely related, in state-owned forests: 1) that a significant though unquantified amount of N TFP extraction, including commercial extraction, is doneillegally in state-owned forests; and 2) that the state in many cases does not have the institutional capacity to enforce its claims of ownership. The former is often true in the case of national parks and other strict reserves, where all or most extractive uses are outlawed. Though N TFP extraction may be illegal in these cases, it is often extremely important to local economies. The sale of bushmeat illegally obtained from Korup $\mathrm{N}$ ational Park in Cameroon is estimated to account for al most half of household incomes locally (Amadi 1993). Likewise, at the Sinharaja M an and the Biosphere Reserve, Sri Lanka, nearby residents have had to adapt to the rules governing the protected area (Caron 1995). $D$ ata collected through participant observation and interviews indicated that men and children illegally gather many edibleN TFPs. Theonly N TFP activity legally allowed in Sinharaja is the tapping of kitul palm trees, but even these are illegally tapped (i.e. without permits), as locals claim that forest officers are rarely encountered to check for valid permits. A final example comes from a study in the Philippines that explored the utilisation and economic importance of commercial NTFPs in one lowland village adjacent to state-owned forests on Leytelsland (Siebert and Belsky 1985). The researchers' fieldwork reveal ed that villagers gather eight species of rattan for a vigorous, though illegal, trade. All of the rattan marketed in the regional market town is gathered illegally from public forest lands.

Illegal NTFP extraction often coincides with a breakdown in control of forest access by either customary or state authorities. State legislation or policy that outlaws NTFP extraction in protected areas can often usurp local customary controls over resource use without replacing them with effective institutions (Peluso 1992a; N eumann 1998). The result is a situation of open access. Siebert (1995) reports that in two national

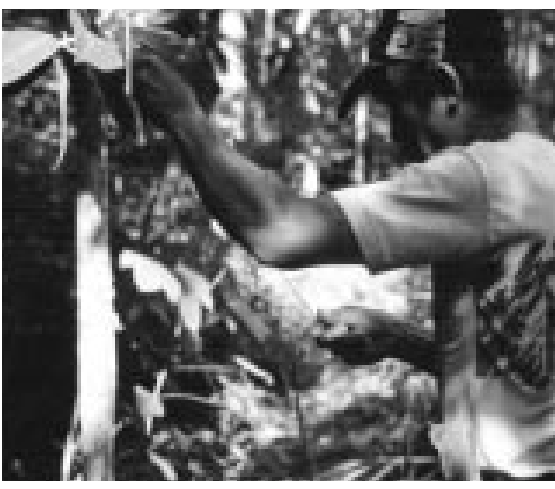

Rattan harvesting, East Kalimantan, Indonesia (Photo: Brian Belcher) parks in Sulawesi, Indonesia, wild rattan harvesting is an important activity in the local economies, although illegal. 'Villagers interviewed in and around 
both parks reported that no recognized or traditional tenure rights exist to individual rattan plants or to rattan-producing areas' (p. 214). T hey say that customary law does not specify extraction rates for rattan, nor does it recognise areas of exclusive harvesting rights to villages. The state, though claiming ownership, has not stepped in with workable rules of access and use rights. Thus, the Si ebert assert, ill-defined resource access and tenure arrangements are major constraints on sound local management.

A similar illustration is provided by Pachauri (1990), who points out that as a result of the state claiming ownership over the forests of West Bengal, India, well-to-do outsiders gained access to resources at the expense of the local forest communities. Under state ownership, the condition of the forests deteriorated and tribal communities and other forest dwellers had no interest in conservation without management rights or ownership. Finally, Richards (1997) notes that the state in several South American countries has made extensive claims of territorial ownership (some $80 \%$ of the forests in Bolivia, Brazil, Venezuela and Peru are state owned). These claims essentially supplant existing tenure systems and outlaw customary rights, yet management by the state is frequently non-existent.

In the above cases, lack of clearly defined access rights and institutional control under state ownership leads to a de facto open access situation. In the state-owned forests and reserves, N T FP extraction activities areal so punishable offences. These two linked situations raise somechallenging questions of social justice, social equity and benefit distribution in commercial N TFP extraction. For instance, growing market demand for an N TFP can lead to an increase in natural resource crime (as defined by the state) in state-owned forests and associated phenomena of violenceand corruption. The ecological sustainability of state ownership in the absence of management capability is al so questioned. Several of the studies document deteriorating ecological conditions in stateowned forests. Finally, the issue is raised about what types of tenure systems, institutional arrangements and legal mechanisms exist or need to be developed in order to effectively managestate-owned forests under open access conditions. These are concerns that need to be addressed in future research (discussed further in Chapter Six).

The review of literature on land and resource tenure in several regions of the world has highlighted a number of key points:

- Amazonian-style extractive reserves have limited applicability as general isable tenure models because of the specificity of the historical, social and economic contexts in which they were established.

- The effects of NTFP commercialisation on existing customary tenure systems vary greatly depending on such cultural and historical factors 
as internal group cohesion, intra-community distributive mechanisms and the role of the state.

- State-owned forests in the tropics often have inadequate management and institutional control with regard to NTFPs, resulting in an openaccess situation with negative ecological and economic outcomes.

\section{Gender and N T FP C ommercialisation}

Studies from virtually every region of the tropics confirm that both men and women are involved in commercial NT FP activities. In some cases women are the primary harvesters, processors and marketers of N TFPs (e.g. H echt et al. 1988; Falconer 1990; M alhotra et al. 1993; Terry and Cunningham 1993; Bishop and Scoones 1994; G hatak 1995; Boffa et al. n.d.; M asters and Puga n.d.). An examination of gender differences is thus critical for a complete understanding of the effects of NTFP commercialisation on social justice, equity and welfare. A focus on gender as a social category reveals significant and complex differences, inequalities and divisionsin the interactions between NTFP commercialisation and society. Some projects have focused specifically on women as a way of improving their political and economic power vis-à-vis men. In other cases, commercialisation has had the effect of shunting women out of traditional sources of income, thereby reducing their economic status. A number of complexly interrelated factors influence whether

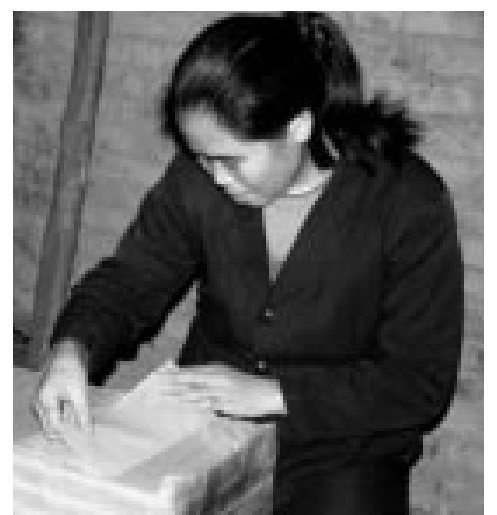

Traditional bamboo paper mill, Sichuan, China (Photo: Manuel Ruiz Pérez) commercialisation will benefit or harm women's socio-economic status. Specifically, study findings indicate that the gender division of labour and the gender control of income can vary spatially, by species, by level of technology, and by the type of task in the chain of activities from harvesting to marketing. Within this variety and complexity, there are some general patterns in the literature ranging across cases from diverse geographic locations.

The first common feature is that where women are the main NTFP processors, the processing technology is rudimentary, returns on labour are relatively low, and the work is often conducted in or near the family residence. In M aranhão State, Brazil, the babaçu palm is an important forest resource for over 300,000 families. Pinheiro and Frazao (1995) report that the extraction of kernels for processing is slow, labour-intensive, and conducted by women. 'Kernel extraction has traditionally been carried out by women and children 
who take a whole fruit and split it lengthways by pounding it with a mallet against an upturned blade' (p. 32). As H echt et al. (1988) explain, women can processkernels at home, thereby avoiding conflict with other domestic activities. Thus for poor women in M aranhão, it is the single most important source of income. Another Brazilian N TFP, palm heart, is commercially harvested exclusively by men, but women make up most of thework forcein theprocessing factories located near their residences (Clay 1997b). Though these factories are legally obligated to pay women the minimum wage, they rarely do so.

In Sarawak, East M alaysia, the Penan have become known for producing fine woven rattan mats and baskets. Women are the exclusive processors and weavers of these products in a labour-intensive production process. Based on the amount of labour time required, returns are extremely low (Brosius 1995). Similarly, a study from Botswana reveals that women are the primary source of labour in an expanding hand-woven basket industry (Bishop and Scoones 1994). Again, the return on labour is low compared to other activities. The latter study indicates, however, that basket-weaving is advantageous for women because it can be conducted at home and simultaneously with other economic activities. In parts of India (e.g. southwest Bengal) making plates from sal is one of the most important income-generating activities for women (G hatak 1995). Sal leaves are stitched together by hand, again generally in the home, to produce plates for sale. Most work in the biri-processing industry of the Ibrahimpur region in India is contracted out to home piece-workers, usually women and children (Agarwal and Amroha 1995).

The predominance of women'slabour in small-scale, low-technology N TFP processing has important implications for commercialisation. This is because one feature common to many NTFP commercialisation programmes is an effort to improve processing technologies for a variety of reasons: to improve quality, to increase locally added value, or to increase or accelerate product supply (e.g. Pinheiro and Frazao 1995; M asters and Puga n.d.). Some studies of new technology introductions reveal a pattern whereby men displace women from N TFP processing. Campbell (1991 cited by Tewari 1994) found in Kamataka, India, that with increased N TFP commercialisation aided by new mechanised technologies, men took over the processing as well as the income previously accruing to women. In the case of sal platesin India, theintroduction of machines for stitching attracted men to the process (Ghatak 1995). M achinestitched plates command prices ten times that for the hand-stitched product. The number of men involved in machine stitching is increasing while women are consequently losing out on income. The author speculates that women may be excluded from the new value-addition techniques because they do not have the technical know-how or access to the machines for stitching sal plates. In another case from India, the introduction of a new forest management plan to promote NTFP extraction led to men taking over what had been primarily an activity of women (Tewari and Campbell 1996). In a galip nut 
commercialisation project in Papua N ew Guinea, women have not been able to participate in new wage employment opportunities because the project centralised the processing in a town distant from women's households (W issink 1996). Various economic and cultural constraints prevent women from travelling to the town and taking employment in the processing plant.

$\mathrm{N}$ one of the studies reviewed provided evidence of the opposite outcome of women retaining or gaining income with the introduction of new NTFP processing technologies. In the case of babaçu palm processing, however, Pinheiro and Frazao (1995) suggest that the gradual replacement of the traditional system of manual breaking by mechanised integral processing at thelocal level will reduce burden of women'slabour. N onetheless, they reported great anxiety in the communities that mechanisation would cost women in terms of employment opportunities. The authors argue that this will not be a problem, but no empirical evidence based on a study of the effects was given in support. In fact M ay (1990 cited by Richards 1993b) relates a case where a shift in babaçu-processing technology eliminated women's involvement. In that study, whole fruits were gathered and processed at a central processing unit that employed exclusively men.

A second common pattern is the differences in harvesting and collecting practices between men and women. In general, studies indicatea distinct spatial division of labour, whereby men harvest from distant forest areas and women harvest from fallows, gardens and forest margins near residences. In U ganda both men and women collect shea nuts, but men gather further afield in 'bush' areas, while women gather from gardens and cultivation plots (M asters and Puga n.d.). $M$ en and women hold usufruct rights to their respective areas and these are clearly defined and uncontested. Similarly, in dissertation research investigating the use of indigenous tree products in the savanna region of Benin, Schreckenberg (1996) found that both men and women collect NTFPs, although men undertake special long-distance 'collecting trips' while women collect opportunistically. In six villages near a national forest reserve of rural $M$ ali important differences exist in the way men and women use the forest as a source of N TFPs (G akou et al. 1994). Interviews with 92 household members revealed that women collect firewood, leaves for sauces, shea nuts and seeds, while men collected house and construction materials and animal feed. Perceptions of forest use are al so highly gender-based. M en who wereinterviewed usually identified al most the entire range of products collected by women, but did not know the actual frequency, as reported by the women. Women did not talk about all the products collected by men.

O ver a period of two years, Edwards (1996a) identified two groups of collectors involved in the N TFP trade in N epal, specialists and generalists. Specialists, mostly men, work in groups and go on high-altitude collecting trips 
of several days duration. Generalists, including women, tend to collect near villages, often in conjunction with other activities. Research targeting extractive activities by women in the forest communities in the newly formed extractive reserves in Acré, Brazil, identified the most common species used by women, and documented specific information on the management, collection and processing of these plants (Kainer and D uryea 1992). T hewomen demonstrated refined botanical knowledge and plant management skills, exploiting over 150 wild and domesticated species in their communities. D espite this, in terms of collection activities, the foreststended to bethemen's domain and women rarely ventured there alone. The Penan make mats and baskets from the best qualities of rattan, which arelocated deep in the primary forestsand areharvested exclusively by men (Brosius 1995). Although this spatial division is common worldwide, it is not universal. In southwest Bengal Ghatak (1995) found that NTFPs are gathered by three times more females than males. Women in this study spent much more time in the forest than men and 71 species are collected exclusively by females, as compared to 23 by males and 10 by both.

Another common trend is that women often do not have control over the income generated, even though they may be primarily involved in harvesting, processing and marketing. This may vary by species. In a brief overview of general facts concerning the use and occurrence of wild fruits in south-central Africa, Packham (1993) observed that while women market both exotic and wild fruits, they control only the income from the latter. It can also vary depending on who is the collector. U gandan women do most of the processing and marketing of shea butter ( $M$ asters and Puga n.d.). H owever, men havefull control over the proceeds from nuts they have collected after they have been processed and sold by the women of thehousehold. In southwest Bengal, despite women's role in N TFP collecting and harvesting, men do the marketing almost exclusively and they control the income earned (Ghatak 1995).

Finally, despite the mixed findings, there appears to be a general interest among women in a variety of settings to become more involved in commercial N TFP production and marketing. Brosius (1995) identifies a trend among the Penan away from extraction aloneand towards more manufacture, and a greater involvement of Penan women in the trade of NTFP-based products. In an extractive reserve in Acré, Brazil, women displayed a great desire to enter the market economy, and had begun to test potential market products on a small scale (Kainer and Duryea 1992). H ence, researchers speculate, women can play a key rolein production, diversification and development of economically valuable plant products, and ultimately in the success of extractive reserves. A new Botswanan basket industry, that had its roots in an effort to find income for a refugee group from Angola, has become extremely popular among women from other populations (Terry 1984; Terry and Cunningham 1993; Bishop and Scoones 1994). M arkets have expanded, designs have been developed and 
quality improved such that the industry is now a significant exporter raising large revenues. Basket weaving has thus become a very important source of income to rural women, despite thelow returnson labour. The primary partners in the U gandan shea butter project are over 1300 women farmers. They are members of more than 40 women's groups throughout the country that have been identified as the most dynamic agents of organised local development ( $M$ asters and Puga n.d.). In Ghana, an experimental effort to promote community-based forest management received an enthusiastic response from women leaf gatherers (Agyemang 1994). T he new leaf gatherers association, established as part of the experiment, appears to have strengthened women's positions vis-à-vis the forest department as well as increased their political influence within the village.

The research literature indicates that women's social, political and economic status can be helped or harmed through NTFP commercialisation efforts. The most negative impacts appear to occur under two conditions. First, when men have control over the income derived from NTFP collection and sale, women are not likely to directly benefit from commercialisation. Second, when mechanisation and centralisation

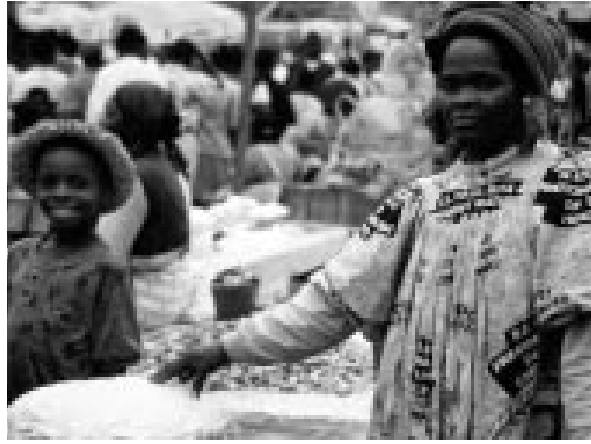

NTFP traders in the humid forest zone of Cameroon (Photo: Manuel Ruiz Pérez) of processing is part of the commercialisation process, women processors tend to be displaced. The most positive situations for women are those that include an institutional or organisational component specifically designed to increase women's political power. Among other outcomes, political empowerment provides women with tools to defend their economic interests in NTFPs. In the absence of specific mechanismsto redress existing gender inequities, NT FP commercialisation efforts can and do result in negative economic and social consequences for women.

Thus, important issues and concerns relating to gender that need to be addressed whenever planning and implementing projects for the commercialisation of N TFPs include:

- Women are often the primary harvesters, processors and marketers of NTFPs from tropical forests.

- The labour for various activities involved in getting N T FPs from the forest to the market is commonly divided between genders, though not in an easily generalisable pattern. 
- D espite women's active roles in harvesting and use, they often do not have direct control of the income derived from commercial NTFPS and therefore may not directly benefit from increased commercialisation.

- $\quad$ There is a general pattern of women being displaced by men when new labour-saving technologies for N T FP processing are introduced.

- NTFP commercialisation projects that explicitly focus on women's participation can have the effect of increasing women's political and economic power vis-à-vis men.

\section{Poverty, Wealth Distribution and N TFP Commercialisation}

There is no doubt that NTFPs play a significant and often critical role in providing subsistence and cash incometo a large part of the world's population (Pimentel et al. 1997). Studies from all tropical regions indicate that it is often the poorest households in rural communities that are most directly dependent on N TFPs (e.g. Jodha 1986; H echt et al. 1988; Fal coner 1992). In this section we examine the nature of the connection between poverty and NTFP commercialisation. We focus particularly on explaining the dependence of the poor on NTFPs and searching for insights into the effects of NTFP commercialisation on poverty in forest communities.

\section{NT FP Extractors are Poor}

The people involved in NTFP extraction and processing are more often than not among the poorest in thetropical regions and, hence, in theworld. Browder (1992a) noted that extractor households arethe poorest non-Amerindian group in the Amazon region. In M aranhão, Brazil, H echt et al. (1988) found that $86.4 \%$ of the babaçu collectors and processors were women, $93.2 \%$ of whom were landless. Romanoff (1992) investigated rubber-tappers on estates in the Bolivian Amazon and revealed that this group faces relatively more frequent food shortages than other populations, with $22 \%$ of the children in the study found to be malnourished. M argoluis (1994) discovered interesting links between poverty, commercial NTFP use and peasant household economics in Central America. Thestudy was designed to investigatethe association between natural resource use and human health in the Sierra de las M inas Biosphere Reserve of Guatemala. The primary hypothesis was that the small-scale utilisation of non-timber forest resources (mainly materials for making baskets) by rural families has a positive impact on their quality of life, as defined by indicators of health. N o statistically significant differences were shown between 
N TFP user and non-user groups for health indicators such as children's weightfor-height, weight-for-age, height-for-age, mid upper-arm circumference, diarrhoea, fever, or acute respiratory infection. $M$ argoluis reasons that this can be explained by the fact that commercial N TFP use is driven by demand from cash-poor households. Per capita incomes of N TFP user and non-user groups are nearly the same. Thus, income generated from N TFPs is used to fill a cash shortfall, not to make improvements in family health and nutrition.

Shifting to South Asia, Thomas (1996) notes that tribes (Girijans) are considered to be the most economically impoverished community of India. Girijan N TFP collectors in Kerala display a heavy dependence on the forest the average contribution of NTFPs to total tribal income was $58 \%$. In impoverished tribal areas of India, households often live only on edible products collected from theforest during drought and adverseconditions (Burman 1992). A study of the economics of N TFP extraction in three districts of N epal found that the poorer households and those living nearer the forests were relatively more dependent on economic support from N TFP collection (Karki 1995). Some of the clearest evidencefor the relative dependence of the poor on N TFPS comes from work that estimated the composition of income in communities peripheral to the newly created Knuckles $\mathrm{N}$ ational W ilderness A rea of Sri Lanka (Gunatilake et al. 1993). D ata were collected using structured questionnaires from 60 households in threvillages in the vicinity of the forest. The net income contributed by each activity was estimated using market prices, opportunity costs and other indicators. The results showed a nearly perfect inverse relationship between the percentage of income derived from N T FPs and total household income. As incomes declined there was a steady rise in the reliance on N TFPs. O nce again, N TFP extraction activities seem primarily to makeup shortfalls in incomerather than providea path to socio-economic advancement. N TFP extraction is often less about 'poverty alleviation' (Tewari 1993) than about basic survival for the rural poor.

In Sub-Saharan Africa, studiesfrom $G$ hana indicate that it is poor women, generally the poorest members of rural society, who are the most reliant on N TFP extraction, sometimes as their only means of livelihood (Fal coner 1992; Agyemang 1994). Veld Products Research (a NGO promoting Botswana's natural resources) examined commercialisation of NTFPs in the formal and informal sectors of that country (Taylor et al. 1996). By and large it is mainly the poor are involved in the harvesting of NTFPs. A recent dissertation (C avendish 1997) based on data collected from 213 Zimbabwean households addressed the research questions: 1 ) what is the contribution of environmental resources to rural household welfare; and 2) what are the economic determinants of environmental resource use, and thus environmental change? In this study environmental resources were defined as those that are 'wild', that are 'freely provided by natural processes'. Again, the results indicatethat poorer households 
are more dependent on environmental resources than richer ones. As in Guatemala (M argoluis 1994), commercial N TFP exploitation fillsa significant income gap for the poor. Cavendish points out that there are dramatic and significant reductions in measured poverty when environmental income is included in household accounts. Environmental income is also a strongly and significantly equalising agent, bringing about roughly a 30\% reduction in measured inequality. However, the causes of rural differentiation remain unchanged - the structural origins of poverty are not addressed through commercial N TFP exploitation.

While these studies demonstrate the strong link between poverty and dependence on N TFP use, other researchers havefound different relationships and factors influencing N TFP use. Godoy et al. (1995) examined the relationship between income and the use of NTFPs, drawing on worldwide ethnographic literatureand on preliminary results of fieldwork among theSumu Indians of $\mathrm{N}$ icaragua. They proposed that as incomerises specialisation increases, the share of household non-foraging incomeincreases, and the value of N TFPS extracted per hectare may rise or fall. Contrary to expectations, specialisation in foraging does not increase as income rises. Indeed, in plant foraging, the variety of wild fruits collected increases with income. W hile the contribution of foraging to household income is less among richer households, it appears highest not among poorest households (who cannot afford guns, dogs, etc.) but among slightly richer households.

0 ther factors, like proximity to the resource base and household demographics, have also been found to influence use. In a study of the relative importance of N TFPs in providing cash income for 13 villages in the I quitos region of the Peruvian Amazon, Padoch (1992a) found considerable variation in the type of production among and within villages. C hief determinants of this variation includeaccess to resources and markets, local history of settlement, and specialisation. Within villages, there are considerable differences among households, partly determined by demographics. Some heavy NT FPs require the labour of young men within the household for collection and transport. H owever, proximity and access to forest resources and household demographics are often strongly correlated with poverty, as we will discuss below.

Although it is clear that there is a complexity of factors influencing N TFP use, there is overwhelming evidencethat thepoorest segments of societiesaround the world are the populations principally engaged in N TFP extraction. Yet if research results indicate a high correlation between levels of poverty and N TFP use, the nature of this relationship remainsunclear. D o people engage in N TFP extraction because they are poor or are they poor because they are dependent upon extraction for their livelihoods? There is evidence to support both relationships, most strongly the former. 
From the literature, we can identify three basic reasons why poor people engage in N TFP extraction. First, N TFP extraction generally requires very littlecapital investment. AsFalconer (1990) observed in G hana, women have little or no access to capital and thus rely on N TFPs. Schreckenberg (1996: 228) found in Benin, '[f]or both men and women a major attraction of N TFP gathering activities is that they require no cash investment'. Anderson's (1992) analysis of the economics of rubber tapping points to low capital requirementsasthe main advantage of extraction. It should be noted, however, that some extractive activities require specialised equipment and therefore access to capital is important. For example, in Bangladesh a boat is required for one to three-month excursions to collect N TFPs from mangrove forests Bhuiyan's (1995). Extractors are therefore forced to secure loans at high interest to maintain the family and finance the expedition. In this case, motivations other than low capital requirements are encouraging the involvement of the poor in NTFP extraction.

A second reason that people engage in N TFP extraction arises because, in most of the world's regions, forests are geographically remote from the centres of economic and political power. The significance of thisfact is that geographical and economic marginalisation are often mutually reinforcing (Blaikie and Brookfield 1987). In short, tropical forests tend to be occupied or surrounded by the poorest, most economically marginalised segments of society. A map produced by the N ational Geographic Society in 1988 shows a near-exact correspondence between the main concentrations of Amerindian populations and the remaining forests of Central America. Throughout the Americas, indigenous peoples have extensive knowledge of forests and of NTFPs, but have been politically and economically marginalised for several centuries(Alcorn 1995). Similarly, in South Asia, there is a strong geographic overlap between extensive areas of forest and concentrations of impoverished tribal people. $M$ adhya Pradesh accounts for one-fifth of the total forest area in India and possesses vast species diversity. The largest population of tribal people in India is also found in the region and their livelihoods are intimately linked to the forest (Prasad and Bhatnagar 1993).

Finally, the poor engage in N TFP extraction in the absence of alternative income sources. In M adhya Pradesh, the problem of seasonal unemployment in rural areas is met by the collection of N TFPs (Prasad and Bhatnagar 1993). Padoch's (1992a) findings from the Peruvian Amazon indicate that lack of access to prime rice cultivation land was one of the factors influencing dependence on NTFP extraction. To use the terminology of economics, the opportunity costs of poor households are low. AsJodha (1986: 1173) concluded from his extensive study of common property resource use in India, 'poor households, with surplus labor and low opportunity cost, readily accept the 
low pay-off activities possible through CPRs'. Richer households were less engaged in the collection of NTFPs at low producer prices because they had alternative sources of income that were more remunerative.

\section{D oes Reliance on Extraction Perpetuate Poverty?}

Viewing the relationship in theother direction - that is, that engaging in N TFP extraction perpetuates poverty - there are two sources of evidence providing support. First is the fact that returns from N TFP extraction are low relative to alternative types of land use (e.g. Browder 1992a). Exploring alternative land uses, Anderson (1992) compared three cases from Brazil: the Cachoeira extractive reserve in Acré; 'extensive' agroforestry practised by river dwellers on Combu island near Belém; and intensive agroforestry undertaken near thetown of TomeAcu. He found that net household returns per land holding were roughly 10 times greater for intensive agroforestry than for NTFP extraction. O $n$ a per hectare basis, net income from intensive agroforestry was about 144 times

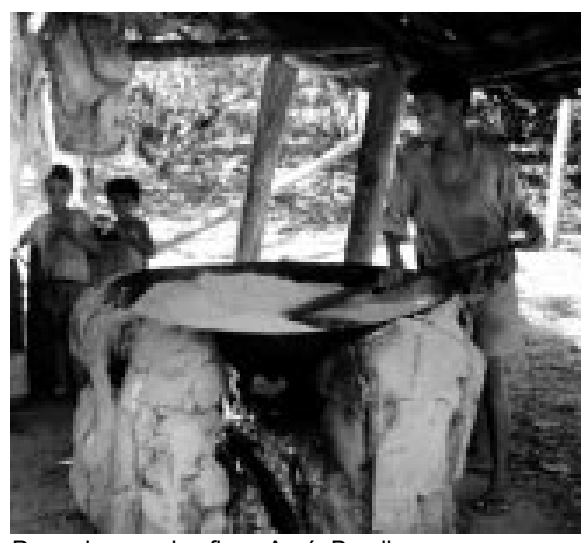

Preparing manioc flour, Acré, Brazil (Photo: Manuel Ruiz Pérez) greater than NTFP extraction. Using different methods, Schwartzman and Allegretti (1987) al so found colonist agriculture to be more remunerative than extraction.

In South Asia, Jodha (1986) studied the use of CPRs (including N TFPs) in 21 districts in seven states in the dry tropical region of India. H e surveyed CPR use for a stratified random sample based on three categories of wealth: landless labourers and small farmers; larger farmers; and medium farmers. D ependence on CPRs was indicated by the proportion of the households in each group making use of CPRs and the average number of CPRs used per household. From $84 \%$ to $100 \%$ of the poorest group gathered NTFPs and other CPRs, compared to only $10 \%$ to $28 \%$ of the wealthiest group. Jodha also argues that the poorer households engage because of low opportunity costs. This situation perpetuates the reliance of the poor on CPRs, not in order to accumulate, but merely to survive. 'T hus a self-selection process of CPR users, governed by low pay off from CPR use and still lower opportunity cost of labour of the users, initiates and perpetuates the poor's dependence on these resources' (Jodha 1986: 1173). 
0 ther research showsthat, given theopportunity, peopleinvolved in N TFP extraction will indeed opt for alternative income-generating activities. Women in Benin would prefer to earn their living in activities less physically demanding than N TFP extraction, even if N TFPsare more readily available(Schreckenberg 1996: 274). O 'D onnell Sills (1990 cited by Richards 1993a) observed that Brazil nut extractors in the M arabá area of Pará, Brazil, were not interested in setting up communally managed forests. Instead, the local unions were lobbying for access to cultivatable land. Likewise, in a survey of 51 extractor families near Rio Jaú, Amazonia, Sizer (1993: 796) found that the 'overwhelming desire of most of the peopleinterviewed was to switch to... a more fixed life based on agriculture'. As al ready noted, extractors in the C hico M endesExtractive Reserve invest their profits in cattle and clearing forest to expand pasture ( $N$ epstad et al. 1992). M ay (1990 cited by Richards 1993a) highlighted resultsthat showed extractivism declines when rainfall allows for increased agricultural activities. Padoch (1992a) discovered a similar drop-off in extractive activities when agricultural opportunities become available. Lescure et al. (1994) point out that in areas of the Amazon where agriculture is developed, farmers only engage in extractivism in cases of urgent financial necessity. A final example comes from a detailed analysis of the cash income derived from N TFPs collected by the Soliga group, an aboriginal tribe of the Biligiri Rangan $\mathrm{H}$ ills, Karnataka, India (H egde et al. 1996). In this study, a logit model was used to estimate the probability that a given household would derive at least Rs 2500 from N TFP collection, given the following independent variables: percentage of educated adult members in thefamily, family size, percentage of dependants (very young or very old) and income from other vocations. The results indicate that N TFP extraction decreases with the percentage of educated family members and income from other vocations, and increases with family size. Furthermore, the analysis highlighted a preference for vocations other than extraction.

A second source of support for the position that reliance on extraction can perpetuate poverty comes from the documentation of boom periods for N TFPs. The general observation is that even in a situation of expanding markets and rising prices, extractors' economic situations do not change (e.g. Fearnside 1998). M ay's (1990 cited by Richards 1993a) study of the babaçu industry in $M$ aranhão, Brazil, showed that extractors' real terms of trade fell even as prices rose. Burman (1990) observed that, while N TFPs have become increasingly important for the Indian economy, the situation of the tribal peoples who harvest them has not improved significantly. Alcorn (1995) reasoned that in a situation of rising commercial values, indigenous peoples can be subject to exploitation because they often lack secure property rights that allow them to exclude outsiders.

U sing interviews and surveys from O rissa, India, Fernandes et al. (n.d.) analysed data by class and ethnic groups to provide insightsinto the relationship between commercial NTFP extraction and poverty. Categorising forest 
populations into five socio-economic classes, a pattern was found in which the threelower classes have the greatest dependence on N TFPs for their livelihoods, with the two upper classes being less dependent but having greater access. When class membership was cross-tabulated with type of product - fruit, leaf or seed - other trends emerged. The lower classes had to travel further for access to fruits, and these fruits were of lower market and nutritional values than those available to the upper classes. This was partly because the upper classes either owned land and were able to produce their own fruits or were able to monopolise control of forest commons for their own use.

Exacerbating the problem of access is deforestation for commercial timber that has reduced overall access to NTFPs. Another pattern develops with the collection of kendu leaves, which are supposedly accessible to all. In real ity, poorer individual sharvest leaves as employees of wealthier individuals who get full wages from the forest department but pay their employee collectors only a fraction. This arrangement is a result of the fact that the employers are also the moneylenders and poorer people are forced to enter into the relationship to

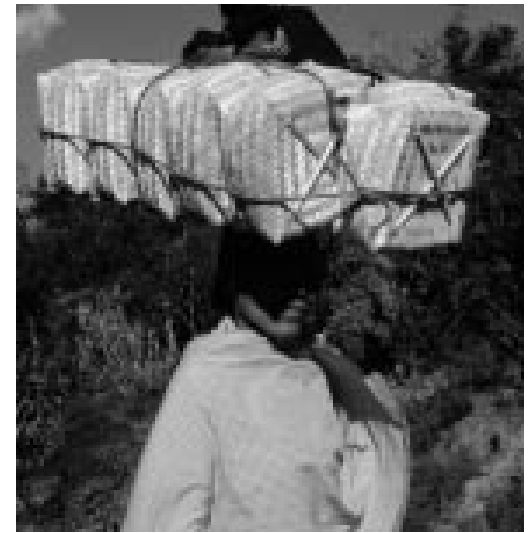

Headload of bamboo crafts, Manifur, India (Photo: Brian Belcher)

pay off debt. This has implications for commercialisation, as it appears that NTFPs formerly consumed by the collectors' households are instead sold in order to pay off debts.

N ot all studies report findings in agreement with an assessment of relatively low remuneration from extraction. O Isen (1997) recently researched the trade in medicinal and aromatic plants (M APs) from N epal to India in the Gorkha D istrict, $\mathrm{N}$ epal. Interviews were conducted with traders, collectors and farmers, and harvesting was studied through active participation. 0 Isen found that in the northern and middle parts of the district, $25 \%$ to $100 \%$ of households in a given village participatein the collection and that the average daily income is competitive with other income-generating activities in the area. Coles-Ritchie (1996) assessed whether tagua harvesting in Ecuador is an economically rational activity. Interviews and other data indicate that daily earnings from tagua approximate the reported off-farm wages. Likewise, in rural Benin, though NTFP-extraction activities produce low profits, they arein the range of incomes from other sources (Schreckenberg 1996). The emergence of basket making for tourist and export markets has meant a significant boost in some rural women's incomes in southern Africa, (Terry 1984, Terry and Cunningham 1993). Between 1970 and 1992, income in N gamiland, Botswana, rose from 
$£ 300$ per year earned by a handful of women to $£ 60,000$ earned by approximately 2,000 (Terry and Cunningham 1993). ${ }^{3}$

Two studies from the Amazon region provide further evidence that sustained N TFP extraction can bea source of household accumulation. M unizM iret et al. (1996) examined the productivity, costs and revenues associated with managing açai for fruit and palm heart in secondary forests and home gardens of the Amazon estuary floodplains. Interviews and field measurements in three different communities along the estuary and in the city of Belém provided data on the prices received by producers and costs associated with producing and marketing açai. Thenet present value of hypothetical one-hectare plots of home gardens and managed secondary forests at different distances from Belém was calculated. The results indicate that the economic value of açai is quite high, yielding present values for managed secondary forest ranging from $\$ 896$ to $\$ 1814$ at a $30 \%$ interest rate. The research also showed that açai is managed at various levels of intensity, ranging from NTFP collection to intensive management in home gardens.

Another study in the Amazon estuary by Anderson and Ioris (1992) also reports high average annual income per household ( $\$ 4000$ ) derived primarily from the harvest and sale of NTFPs, especially açai fruit and cacao. The high economic returns are partly explained by three conditions: 1) poor soils have contributed to the maintenance of forest cover on the island; 2) forest cover is characterised by a dominance of economically important species, resulting in increased concentration of valuable forest resources; and 3) the nearby port city of Belém is thelargest market centrein the Amazon, thus reducing transport costs. Finally, Godoy and Feaw (1989) reported that smallholders in Central Kalimantan, Indonesia, preferred N TFP crops (specifically rattan) to other crops, but this was under cultivation, not extraction.

$M$ ost of the analyses of the persistent poverty of extractors stress that the typical structure of extractive markets tends to keep wages and prices to producers low, whilethe relative share of profitsincreases as the product moves closer to the consumer. For example, Brazil nut collectors were receiving $\$ 0.03$ to $\$ 0.04$ per pound of nuts which were being exported at $\$ 1.00$ to $\$ 1.20$ per

\footnotetext{
${ }^{3}$ Research literature on the evolution of the rural non-farm economy (e.g. H aggblade and Liedholm 1991) indicates that, where population is growing faster than per capita incomes, lack of alternative sources of income results in a high proportion of those engaged in processing and trading entering labour-intensive, low-return activities that can contribute very little to livelihood enhancement. $\mathrm{H}$ owever, where incomes are rising, more productive and remunerative activities serving growing and diversifying rural and urban markets can emerge. There are some indications that this may be one reason explaining differences between stagnant and income-enhancing N TFP activities (FAO 1987; Arnold et al. 1994).
} 
pound (Baker 1989). The aviamento system in Brazilian rubber extraction has become a classic example of labour exploitation in extractive markets. The system is based on the delivery of consumer goods on credit at inflated prices to be paid for with extractive products (Lescure et al. 1994). In short, it is a form of debt peonage. Some analyses have found that the vast majority of extractors are trapped in a cycle of debt that keeps them impoverished (e.g. Romanoff 1992). These findings support those who argue that a strategy of N TFP commercialisation can perpetuate poverty (e.g. Browder 1992a,c). Even when income from extractivism is comparable to alternative rural income sources, as in the cases mentioned in the previous section, it does not mean that poverty is alleviated or even reduced. The alternatives that are being compared, such as agricultural wage labour, are al so poorly remunerated. Thus, even when NTFP income is relatively high, structural poverty remains.

0 ther analyses of extractor poverty highlight the role of 'middlemen' in extractive markets (which we will also address in our discussion of state marketing interventions in C hapter T hree). 'M iddleman' is used in theliterature as a blanket term to refer variously to people involved in the purchase, wholesaling, transport, processing or export of NTFPs. Particular emphasis is placed on the unequal distribution of profits that results when NTFP traders havemonopoly control over purchasing and transport (e.g. Baker 1989; Burman 1990; Bhuiyan 1995). In tagua extraction and marketing it is just a small group of processor-exporters who make 'supernormal' profits while income for collectors is no better than that for unskilled rural labour (Southgate 1998: 51-57). In contrast, Padoch and de Jong (1989) and Padoch (1992a, b) noted that the profit margins of middlemen can be overemphasised. For intermediate agents, transportation costs are high and the financial risks in often unpredictable markets great. Furthermore, N TFP merchants are themselves often in debt to downstream traders and so indebtedness is passed on (e.g. Peluso 1992b).

These last observations notwithstanding, monopoly control of marketing leaves producers relatively powerless to capture a greater share of the surplus. For this reason, recent commercialisation strategies have attempted to intervene in the market to break the grip of merchants. The most widely cited instances of such an attempt areinterventions into theBrazil nut tradeby Cultural Survival and the Body Shop (see Baker 1989; M ay 1991; Clay 1992; Richards 1993a). In these cases, marketing is more direct and a portion of revenue is reinvested in local processing cooperatives and further product and market research. In these projects, reducing the role of merchants has increased prices to extractors. H owever, in a critique of these attempts, Corry (1993) observed that Brazil nut prices are unstableand in fact dropped after an initial sharp rise. H esuggests that in taking the place of 'middlemen' these companies 'tie the people into exactly the same relationship of dependence and patronage' (p. 6). 
In South Asia, the attempts to reduce the control of middlemen have not been successful in returning a greater share of profits to N TFP extractors. Efforts have focused on direct state control over product marketing through various institutional mechanisms. The Indian government set up the Forest D evelopment Corporations in 1976 to help tribal N TFP collectors by eliminating the large profit margins of local entrep reneurs and providing tribals with better wages (Tewari and Campbell 1996). Cooperatives wereal so created as part of this plan, but they have often been detrimental to tribal people who sometimes receive as little as $10 \%$ to $40 \%$ of the sale price in the local market. Some states in I ndia nationalised a number of NTFPs, forcing tribal people to sell to the Forest $D$ epartment or their appointed agent contractors. This led to tensions between community members and the $D$ epartment, as prices remained unfavourable (Tewari 1994). In Bangladesh's mangrove forests, state policy is meant to protect N TFP collectors' rights by eliminating monopolistic control by middlemen, but now illicit payments are demanded by regulatory bureaucrats. Under these conditions, extractors will remain poor regardless of NTFP commercial promotion (Bhuiyan 1995).

The relationship between commercialisation of NTFPs and poverty is complex and linked to many factors. The following important issues can be identified from the review of literature in this field:

- In the majority of cases, thepopulationsmost engaged in and dependent upon the harvesting of NTFPs are also among the poorest classes of their respective societies.

- Poor households commonly opt out of commercial N TFP harvesting when given alternative means of livelihood, such as agriculture.

- The socio-economic status of poor collector households has not been significantly altered by the exceptional profits generated during historic boom periods of rapidly rising prices for NTFPS.

- Profits from NTFP extraction and marketing tend to be unequally distributed along the chain from forest to market, with the smallest proportion generally accruing to collectors.

- Some households do accumulate significant capital from commercial N TFP extraction, but questions remain whether this represents a process of class differentiation or a stage in household life cycles.

\section{Summary}

Thefindings on the relationship between tenure and N T FP commercialisation demonstrate the difficulty of extrapolating or general ising from specific cases. The case of Brazilian extractive reserves, for example, is an excellent illustration 
of how questions of forest tenure and access rights are tied to political struggles for economic and social justice. Its usefulness as a model for tropical forest conservation and development elsewhere is, however, limited. The key tenure studies that we have cited all point to the complexity of political, economic, historical and social factors that influence the relationship between commercialisation and common property systems. Furthermore these factors can vary greatly from community to community, leading to very different impacts on customary tenure systems over short distances. Thismakes it extremely difficult to predict outcomes or identify general patterns. Virtually all authors agree that it is important to clarify tenure and property claims prior to commercial isation efforts. If any further generalisation is possible, it is that the increased commercialisation of N T FPsis likely to eventually lead to a breakdown of common property systems and a trend towards individual private property.

Studies of gender questions related to the commercialisation of NTFPS indicate both negative and positive outcomes for women. Thenegative outcomes tend to be associated with two situations. When women arethe main processors of NTFPs and innovations in processing are introduced to increase product quality and production efficiency, associated central isation of production often shuts out women as men replace them as processors. When women are active in the collection, processing or marketing of N TFPs, but do not directly control the income derived, men are more likely to benefit from commercialisation. Positive outcomes for women are most closely associated with situations in which commercialisation is taking place within alarger social context of growing political and economic empowerment of women.

Several general patterns emerged from the review of research on the relationship between poverty and commercial N TFP collection and marketing indicate, but with important exceptions. First, findings from around thetropics suggest that the rural poor are dependent on the commercial extraction of NTFPsfor their livelihoods, and at certain times almost completely dependent on them. O nereason that the poor rely so heavily on N TFPsfor their livelihoods is because of the low capital requirements. $0 \mathrm{n}$ the other hand, some studies identified situations in which only those with sufficient capital, either for equipment or for labour mobilisation, can reap benefits from commercial NTFPs. Second, whether or not increased involvement in commercial N TFP extraction and sales perpetuates poverty or provides the basis for household accumulation is an open question, but trends are detectable. There is ample evidence, particularly in situations of chronic debt, that involvement in N TFP extraction perpetuates rural poverty. It is possible, however, that relatively high rural incomes can be derived from NTFP extraction and sales, especially in situations where markets for high-val ue products are close to the resource base. Finally, although N T FPsareextremely critical for the rural poor as a livelihood strategy, and often provide the means to close the income gap with wealthier classes, they rarely provide the means of socio-economic advancement. 


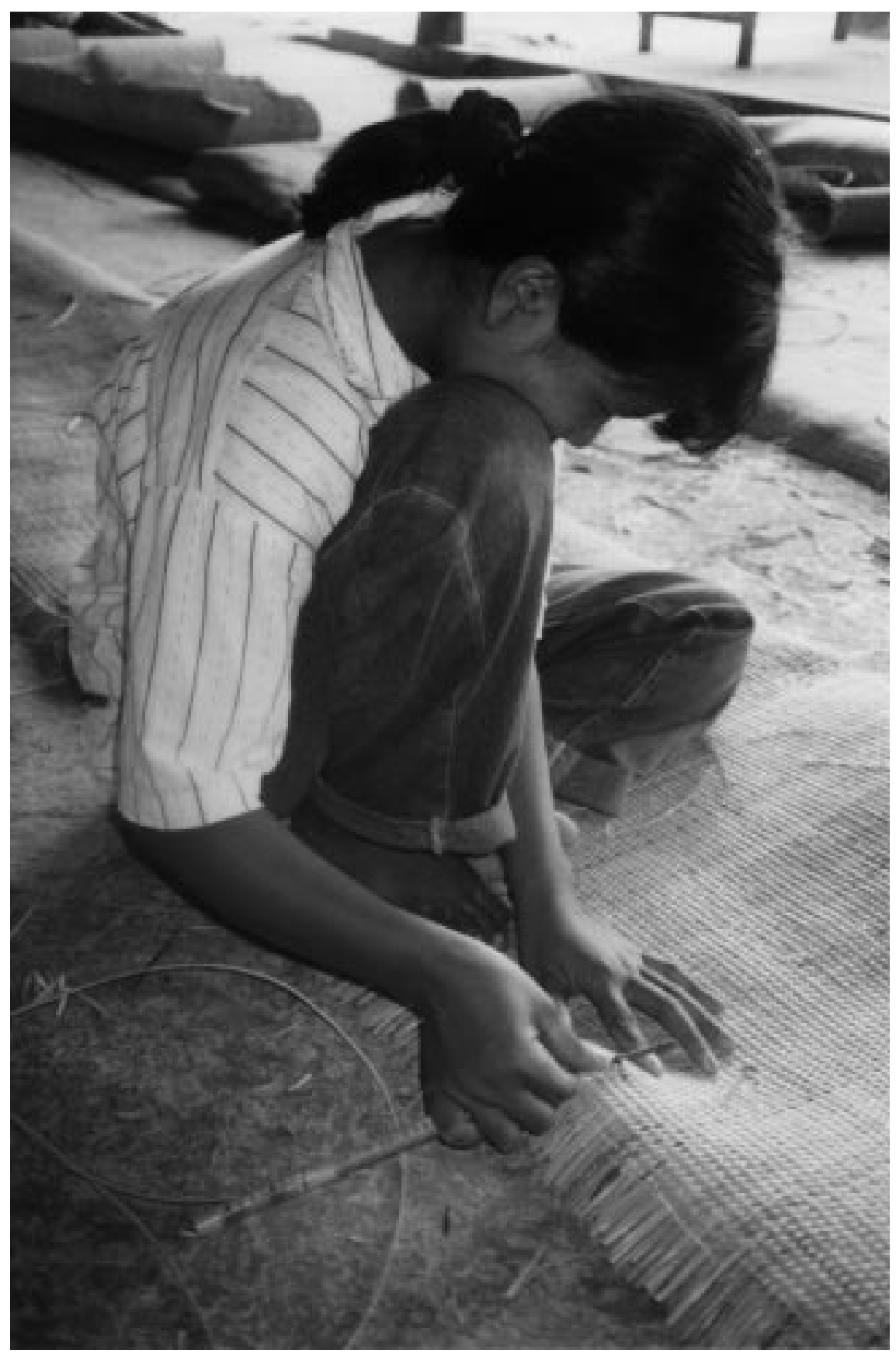

Finishing the irregular patches in rattan webbing, Rengasdengklok, West Java, Indonesia (Photo: Rita Mustikasari) 


\section{Chapter Three}

\section{Economic Considerations in N TFP Extraction and Trade}

Enquiries into the commercialisation of N TFP resources touch, not surprisingly, on many issues of economy including production, trade, consumption, efficiency and pricing. H owever, the theory and methodology of economics, particularly neoclassical economics, are most commonly employed in this literatureto arguethreedistinct though related points: 1) NTFPshaveeconomic value; 2 ) thereare predictable paths of price and quantity over timeas resources are depleted; and 3) the ben efits of N TFP resource exploitation are distributed, often inequitably, throughout trade networks. Specifically, the principal economic questions in this context are: the potential value of N TFP resources; the actual contribution of NTFP production to national and household incomes; and the profitability of NTFP enterprises.

The literature does not fall neatly into those research papers that are concerned with these economic questions and those that are not. Rather, questions of economy are scattered throughout the literature, sometimes representing a significant research focus and sometimes appearing as supplemental or incidental. Approximately $75 \%$ of the articles present at least rudimentary economic arguments or data, about $50 \%$ take on someeconomic question in a more comprehensive manner, and about $20 \%$ percent address the economic question as a central focus. Often incidental data (e.g. the demonstration of heavy reliance within a village on NTFP income) may not be central to the researchers' thesis but may be used to argue a more general point when it is combined with similar data from other studies.

These economic research questions are not the exclusive domain of trained economists. Given thevarying importance of theissuethroughout the literature, this is not surprising, especially where economics was only marginally considered. Of the $50 \%$ of articles with substantial economic foci, many were researched by teams that included biologists and foresters, as well as economists, agricultural economists and economic devel opment specialists. O verall, research into the economic significance of N TFPs has not been particularly quantitative, complete or definitive. M ost describe, explicitly or implicitly, a favourable picture for the marketing of NTFP products.

Researchers employ many methodologies, including qualitative assessments, estimates based on prices, measures of household and national 
income, and cost-benefit analysis. Field studies include market surveys, interviews and questionnaires. Economic methods are used alongside many other tools such as footpath surveys, plots, rapid appraisal methods, ethnobotanical methods and participant observation. U nits of analysis likewise vary enormously and include plots, households, projects and forests. Regional and resource diversity reflects the variation within the literature as a whole: a strong economic focus is found in research on Africa, Latin America, South Asia, East Asia, Southeast Asia and the South Pacific.

In this chapter we review the findings of the NTFP literature on the potential value of N TFP resources, the contribution of N TFP-related incomes, and the profitability of N TFP-related enterprises. We begin by examining the studies that attempt to calculate the potential value of N TFPs from tropical forests at various scales of analysis. The focus includes both theoretical issues related to valuation as well as specific study findings. The remaining two subsections review the findings on costs of and income derived from NTFP extraction and trade.

\section{Estimates of the Potential Value of N T FP Resources}

In N TFP commercialisation research, studies focusing on valuations of standing forest are important for assessing alternative forest uses and for identifying the possibilities for conservation and development initiatives based on extraction. In fact, a fundamental assumption of the conservation rationale for commercialisation is that the sustainable extraction of NTFPs will produce more value than will logging. The picture that emerges of 'potential value', however, is somewhat inconsistent and inconclusive, as a lack of extensive data and theoretically sound methodology renders findings speculative and idiosyncratic. These data caution us to use care when drawing conclusions from estimates of potential value. $0 \mathrm{n}$ the other hand, the significance of N TFPrelated income, particularly to rural households, is well demonstrated. At the same time, there is a great deal of social variation in income distribution within regions, villages, households and complex trade networks. While the data on N TFP enterprise profitability is al so rather sketchy, there do appear to beclear and consistent patterns of enterprise costs. M ost of the analysis presented here is generalised over many studies, the majority of which do not address economic questions primarily. Where appropriate, studies with a central economic focus presenting significant findings are described in detail.

\section{Valuation: Theory and Empirical Results}

Researchersfrom many fields and in many contexts haveargued for thepotential value of NTFPs, relative to other resources, other forms of labour, the costs of 
production and other forms of production. A consideration of value in NTFP production is not at all straightforward, however. This is well demonstrated by Chopra (1993), who identifies two primary issues in his assessment of the value of the non-timber products of India's tropical deciduous forests:

1. To what does value refer? 'Value' may account for value in exchange, value in use, option value (new options for use may emerge in the future if resources are maintained now), and perhaps existence value (the 'deep ecology' view that the natural habitat and its sustainability have 'value' independent of the human agent). Forests also provide positive externalities, such as preventing soil erosion and helping conservebiodiversity. Should theseexternalities beconsidered in value assessment?

2. How is value to be measured? $M$ arket price, the cost of an alternative, the cost of labour time in collection, and the loss of productivity in alternative use may all be used to approximatevalue. Thequestion of value for N T FPsisparticularly complicated becausenot all non-timber forest resources that have use potential are actually used, and many products that are used are not marketed. Therefore the relationship between value and price is problematic.

N ot surprisingly, there is little consistency in the literature as to how value is understood, eval uated or theorised. G odoy and Lubowski (1992) undertook a comprehensive review of studies that estimate the economic value of nontimber tropical-forest products and make a number of important observations that are relevant to this review:

- Chronic problems of incompatibility in design and methods among studies has resulted in widely varying results, even for research conducted at the same time and place.

- Efforts to estimate value rarely make a comprehensive assessment of all NTFP resources, e.g. they found no study that measured the combined economic value of both plants and animals.

- The degree to which studies are based on representative samples of ecosystems or human populations is either low or indeterminate. Thus the ability to generalise from study findings with confidence is limited.

- Assigning prices to N TFPs in the absence of an existing market can be highly speculative. A commonly used tool, contingent valuation, is of littleusein thenonmonetised economies where many studies take place.

$\mathrm{N}$ othing in our review would contradict Godoy and Lubowski's conclusions. Keeping in mind all the complexities of valuing N T FPs implied, we examine some of the research dealing specifically with commercial N TFPs. 
Themost general investigations into the potential value of NTFP resources are those that broadly calculate ranges of value for entire forest areas. Chopra (1993) estimated the total present value of non-timber goods and services available from tropical deciduous forests in India to vary from a minimum of $\$ 219$ to a maximum of $\$ 357$ per hectare annually. M ost commonly, however, researchers begin their inquiry by estimating the value of a much more limited area, often one or more clearly defined forest plots. The most widely cited study in this genre is the valuation of a one-hectare plot of rainforest in Peruvian Amazonia by Peters et al. (1989). They designed the study to inventory the plant species in the plot, measure N TFP production and determinetheir current market value. The annualised net value of NTFPs produced from the onehectare plot, after deducting collection and transportation costs, was estimated at $\$ 422$. Given that NTFPs can be harvested every year, the researchers concluded that the rainforest plot produces a much higher monetary value if used for N TFP collection rather than timber extraction.

W hile early plot studies were highly optimistic, more recent work has highlighted the problemswith drawing conclusionsfrom plot studies. LaFrankie (1994) examines the variability, accessibility and seasonality of forest fruit production in M adredeD ios, Peru, by monitoring three plots with contrasting soils. Results indicate three important points. First, productivity varies greatly from one forest type to another. Second, even in the forest type with highest productivity (alluvial-soil forest), production values arequitelow. Finally, when figures are adjusted to reflect local people's preferences and weighted for accessibility, the percentage of production readily availableto human collectors falls to $13 \%$ to $29 \%$ of total production. These figures are clearly lower than earlier studies suggested.

Plot studies often aim only for rough estimates; even so, not enough attention is paid to the problematic nature of value estimation. M any estimate potential value through the use of local price information. This approach raises a number of theoretical and practical issues, as is demonstrated by Fui and Ismail (1994) in their study of economic values for NTFPsin the Pasoh 50-ha permanent research plot managed by the Forest Research Institute of M alaysia. 0 nly trees and rattans were considered. Roughly $34 \%$ of the tree species identified had nontimber value. The authorsidentify many of the issues that make the assignment of potential value problematic: 1) not all resources

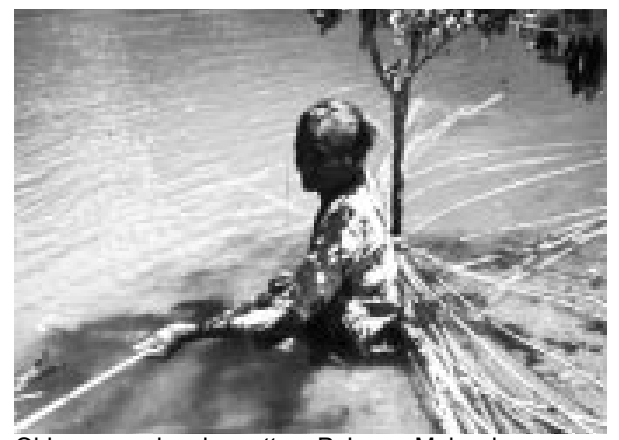

Old woman cleaning rattan, Pahang, Malaysia (Photo: Francis Ng) 
in the plot are marketed and so assumptions must be maderegarding production and marketed substitutes; 2) not all resources in the plot with potential uses are actual ly used; 3) choices must bemade between farm prices and end-product prices; and 4) prices would certainly fall if all N TFPs were actually marketed.

The use of priceinformation to estimate potential valueis less problematic if the study's purpose is to make comparisons among several plots of particular species. Peters (1992) uses this simple approach in order to compare the value of fruits in oligarchic forest and commercial fruit orchards. Fruits of six species collected from plots in Peru and Brazil were weighed and local markets were surveyed to determine average selling prices. In terms of both density and yield, the study determined that oligarchic forests compare favourably with commercial fruit orchards in the tropics (see also Prance 1989). Because Peter's findings depend on comparison of particular species in separate plots, the problems with the price data tend to diminish.

Where the production, marketing and use of species is well established, price information is also more reliable. Siebert (1995) uses market price information to compare two species of rattan. D emographic characteristics and the potential for sustained-yield harvesting of wild populations of two species of rattan (Calamus exilis and Calamus zollingeri) were assessed in two national parks, in Sulawesi, Indonesia (see C hapter Five for further description). In one park it was estimated that each hectare contained about 1910 metres of harvestable C. exilis cane, worth approximately US $\$ 15.80$. In the other park, each hectare contained between $\$ 200$ and $\$ 333$ worth of unprocessed $C$. zollingeri canes. Because thestudy is limited to a comparison within one genus with a well-established market, estimates of value are relatively more reliable.

Plot studies are the most common way to estimate potential value, but few researchers address the more complex theoretical questions concerning the issue of value. ${ }^{4}$ Certain environmental goods, for example, are 'used' but will never appear in accounting or markets. Some idiosyncratic and creative approaches to N TFP value estimation are found in the literature that address one or more of these issues directly. The H ot Springs Working Group (1995) project (see Chapter Two) employs value estimation in a non-neoclassical framework. The study describes a workshop whose aims were to undertake a resource valuation exercise in the $\mathrm{H}$ ot Springs area of Zimbabwe featuring participatory rural appraisal techniques. Eighty-five maps drawn by villagers

\footnotetext{
${ }^{4}$ The importance of labour as a cost reflects the fact that this can often be the limiting factor in N TFP production. In these situations analysis of the profitability of NTFPS to smallholder producers are likely to be better reflected in returns to labour rather than returns to land (which is what plot studies illuminate).
} 
were used to identify major resource units (for example, fields or forested hills) in each village. Villagersthen listed the products derived from each unit. Villagers were also asked to role play various individuals with specific interests in woodland resources, which allowed for the identification of many aspects of resource values. These were then ranked and scored by villagers. The methodology contrasts sharply with neoclassical approaches. Workshop participants noted that merging the paradigms of neoclassical economics and participatory rural appraisal presents a number of challenges. Participatory rural appraisal makes more use of qualitative data, uses other measures of 'trustworthiness' than statistical analysis, regards the researcher as part of an interdisciplinary field-based team which includes villages rather than a distant analyst, and emphasises empowerment over 'objective' research.

As the example of the workshop demonstrates, there is little consistency of method or purpose in valuation studies. Research projects that assign economic value to large forest areas or to large numbers of species within a plot are important when they remind us of the potential weal th of NTFP resources compared to other forest uses. H owever, they are only broadly indicative; theoretical problemsin value estimation and the difficulty of generalising render the meaning of actual numbers generated somewhat ambiguous. Further, potential value does not account for costs and other factors that would impinge on the actual profitability of N TFP enterprises (these factors will be addressed in the next section). Valuation studies may be used to effectively compare particular species under varying conditions, or to make assessments regarding limited projects with species that have established markets. The choice of a broad theoretical framework within which to place a valuation study depends largely on the researcher's purpose: to argue broadly for the significance of N TFPs within the national economy; to assess a more limited set of questions regarding forest use; or to work with potential NTFP producers for their empowerment.

\section{Cost Factors in N TFP Value Estimations}

Estimations of potential value have helped to turn policy-makers interests in the direction of NTFP commercialisation. The demonstration that many households worldwide are already reliant on NTFP incomes may likewise support the argument for creating successful new N TFP projects. H owever, neither is sufficient to predict the profitability of new programmes because they leave out critical information, particularly the costs associated with NTFP production. As Godoy and Lubowski (1992: 428) note, '[r]searchers have not often calculated the cost of the materials used in extraction, and this cost can be high'. Few studies directly evaluate the profitability of NTFP enterprises. $M$ any, however, lend insight into some of the cost and market issues that would inhibit NTFP enterprise profitability. 
An analysis that accounts for relative costs in addition to relative benefits can substantially alter the economic picture for specific NT FPs. Such studies serve as important reminders of the danger of relying on simple 'valuation' studies to assess economic potential. Unfortunately, most researchers who identify costs do so indirectly, without quantifying them. Thus difficulties with harvesting, processing, trading, transporting and marketing products are often described but their effects on costs are not estimated. Thismakes the evaluation of profitability, viability and economic sustainability difficult or impossible. $\mathrm{H}$ owever, certain patterns do emerge that suggest that profitability depends on the identification and minimisation of certain types of cost.

The costs of collection and harvesting appear to vary widely, from negligible to prohibitive. NTFP collection may be physically arduous (see Siebert and Belsky 1985, on rattan collection in Leyte, Philippines), require special collection tools (seeT homas and Bai 1993, on collectors in Kerala, India), requirea great deal of skill or experience (see Nilkamhaeng 1995, on lac production in Thailand), or require the collector to search further afield as resources are depleted. W hilethese costs are rarely estimated in money terms, for someN TFP households collection costs are clearly a significant percentage of return (see Godoy et al. 1995 described below). For example, the total investment for an extraction expedition (which is often highly dangerous) by the Bawalis of Bangladesh into the Sundarbans mangrove forests hardly equals return (see Bhuiyan 1995).

In addition to the costs of N TFP collection, a number of studies recognise transportation costs as among the most critical for determining the profitability of an NTFP enterprise. In the Iquitos region of Peru, transportation costs (which can be extremely high) are often the determining factor in what is marketed and in what quantity (Padoch 1992b). Similarly, MuñizMiret et al. (1996) show that profitability and management intensity of the açai palm in secondary forests and home gardens in Pará, Brazil, are clearly tied to proximity to the main market. $\mathrm{H}$ igh

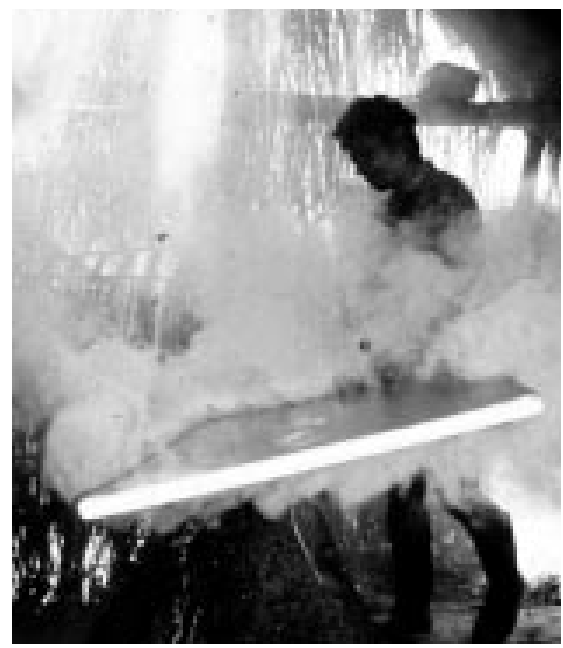

Vegetal leather processing of the natural rubber in Alto Jurua Extractive Reserve, Acré, Brazil (Photo: Manuel Ruiz Pérez) transportation costs inhibit the commercialisation of canarium nut in the Solomon Islands (Pelomo et al. 1996), while low transportation costs partly explain high economic returns among N TFP collectors on Combu Island, Brazil (Anderson and Ioris 1992). T hus, 
research that estimates high economic value for given N T FP resources in regions far from major markets is suggestive but incomplete. For example, agroforesters in Santa Rosa in the Peruvian Amazon are capable of producing substantial quantities of commercial crops but thelack of markets within easy reach remains highly problematic (Padoch and de Jong 1989). O ne detailed study from the Jaci-Parana State Extractive Reserve in Brazil well illustrates the impact of transportation costs on economic profitability. Akella and Ankarfjard (1997) assessed the economic viability of extracting fruits from two palm species, açai (Euterpe precatoria) and buriti ( $M$ auritia flexuoso). Cost estimates were made on the basis of group interviews with harvesters to identify theprocesses involved in the harvest or processing of each fruit. Results indicate that the net present value of açai extraction is only positive when the total travel time to market is less than 3.6 days or 114 kilometres.

$M$ any other costs besides collection and transportation are described in the literature, some of which are significant among a wide variety of NTFPS. The need for increased marketing and advertising of N TFPs is often identified (see Padoch and de Jong 1989; Amadi 1993; Leocadio 1995; Ling 1995; Ting 1995). These activities would necessarily entail costs, which are described, sometimes in detail, but are rarely quantified. ${ }^{5}$ Costs associated with product storage are another example, and researchers have identified problems with improper storagein, for example, honey production during boom in Rajasthan, India (C hakravarti and Verma 1991) and jatamanshi in N epal (Rawal 1995). The economics of N TFP processing has not received adequate attention, but costs (and returns) may be significant depending on whether local low-tech methods or large processing plants are used. Another common cost is training, whether for collection, storage, processing and/or marketing (see G autam 1995). Some costs are difficult to quantify, such as those associated with the risks of operating in a climate of sudden and dramatic price shifts (Padoch 1992b). In addition to costs commonly associated with NTFP production, somearehighly specific to particular markets. Siscawati (1995) describes the costs of rattan certification ('green labelling') in Indonesia, including capital expenditures to update resource management activities and the costs of testing and verification. The costs of certification could be passed on to producers, thereby adversely affecting their incomes. At the national level, the costs of monitoring compliance from the point of extraction to the point of export may be prohibitive for poorer countries.

N TFP enterprise profitability clearly depends on a complete analysis and understanding of the costs of production, which include not only collection,

\footnotetext{
${ }^{5}$ See M uniz-M iret et al. (1996) for an exception: the net present value of açai is calculated using costs of production and marketing.
} 
and transportation but al so many other costs depending on the resource. They need to becarefully enumerated, quantified, described over timeand accounted for in assessments of the success of N T FP exploitation. H ow costs change over time, and other considerations regarding markets and the shape of supply and demand curves, are considered in the next section.

\section{The C ontribution of NTFP-Related Production to Income}

Whatever the potential value of NTFPs, researchers have documented significant actual subsistence and cash income generated for a large number of households in many areas. 0 ften these studies investigate particular villages or regions, using a combination of interviews, questionnaires and observation. While not every village or even region has been covered comprehensively, the literature generally suggests similar income-related phenomena over widespread and varied areas. The estimation of the value of subsistence income is complicated in ways that are similar to the estimation of the potential value of resources: not all N TFPs used for subsistence are also marketed, and some have no obvious market substitutes. The estimation of cash income is more straightforward, although problems with the quality and accuracy of interview and questionnaire data remain. 0 ften, researchers do not attempt to estimate income directly, but use other data to demonstrate the importance of NTFP income to household life.

In assessing the value of NTFP subsistence benefits to households, researchers employ methods ranging from off-the-cuff estimations to sophisticated econometric techniques. At one extreme, many authors identify the importance of NTFPs to subsistence income without attempting a quantitative estimation. For example, the sheer number of different kinds of N TFPs used by a household may indicatethe significance of N TFP production to subsistence. In M ali, West Africa, 55 different NTFPs are used in the household, of which two-thirds areal so sold in themarket (G akou et al. 1994). In N epal, 800 N TFPs are not traded, but have many subsistence uses as foods, spices, herbal medicines, tannins, dyestuffs, gums, resins, incenses, oils, fibres and construction materials (Edwards 1996b). Villagers were found to use a wide variety of NTFPs for many purposes in a study of 12 forest protection committees in M idnapore D istrict, India - over 75 species were used regularly for subsistence needs (M alhotra 1993). Since many N T FPs are seasonal, they are important to household subsistence because of when they appear in the diet. In Benin, NTFPs are available during the dry and early rainy season or 'hungry period' when cultivated cropsarein short supply (Schreckenberg 1996). Some researchers simply notetheimportance of N TFPs to subsistence without further elaboration (such as Rao and Singh 1996 in Bihar and southwest Bengal, India, and Prance et al. 1992 in Amazonia). 
The most common form of subsistence valuation is to compare market prices or prices for comparable substitutes. These studies can reveal high levels of subsistence income from N TFPs. Cavendish (1997) showsthat, on average, 'environmental resources' or non-marketed NTFPs comprise 35\% of total household incomes in Zimbabwe. Sincethese resource usages are not measured elsewhere, this represents an increase in incomes of nearly $50 \%$ over standard household surveys. The author also finds that poor households are more dependent on environmental resources than rich ones, so that environmental income brings about a 30\% reduction in measured inequality as well. G unatilake et al. (1993), in a study more detailed and comprehensive than most in its estimation of NTFP income, similarly find that subsistence use of NTFP is very important to the household. The study estimates the composition of income in communities peripheral to the newly created Knuckles $\mathrm{N}$ ational Wilderness Area of Sri Lanka. Particular attention is paid to the extraction of NTFPs, which will or will not be restricted in the area (depending on sustainability of present use.) $D$ ata were collected using structured questionnaires from 60 households in three villages in the vicinity of the forest. $\mathrm{N}$ on-timber forest products provide a value equivalent to $\$ 253$ in cash per year per family, or $16.2 \%$ of total income. On average, however, they contribute only $5.3 \%$ to money income, indicating that extraction is mainly done for subsistence.

In a moretechnically sophisticated study, $\mathrm{H}$ ydeand Amacher (1996) offer the application of the 'new household economics', a technical econometric remedy to the problem that household supply and demand functions may have elasticities that differ from those of the market, even at the same price. In other words, the use of market prices distortstheactual behaviour of households that may bemoreor less willing to sell or purchase N T FP products than supply and demand curves suggest. The article also describes the small number of other studies that have used this approach.

Cash incomecan beestimated more directly than subsistence and measured at the individual, household, local or national levels. N ationally, the impact of NTFPs on cash income varies significantly. In India as a whole, NTFP production contributes about $40 \%$ of total official forest revenues and $55 \%$ of forest-based employment (Tewari and C ampbell 1996). In M adhya Pradesh, India, the collection and sale of N TFPs accounts for between $40 \%$ to $63 \%$ of total annual income of the rural population, and provides an important incomegenerating activity to offset seasonal unemployment rate. Several authors note the growing importance of rattan to export earnings in Indonesia (de Fretes 1992; van Valkenburg 1997). In Botswana, only recently has the government recognised that the value of N TFPs exceeds that of timber exports (Taylor et al. 1996). Baskets in particular have become significant export items (Bishop and Scoones 1994). In Petén multiple-use reserve in Guatemala, the harvest of three items (chicle gum, allspice and xate palm) produces between four and seven million dollars in export income per year ( $N$ ations 1992). The 
contribution of Amazonian products to the world economy is also welldocumented (seePrance 1989). O n the other hand, many N TFPsare produced in small quantities and consumed locally, and countries such asT hailand have gone from being net exporters to net importers of non-timber forest products (D e Beer and M CD ermott 1989).

At the household level, the contributions of NTFPs to rural incomes are more consistently high compared to national-scaleestimates, as the following brief cases illustrate. The N TFP trade is the main source of livelihood for a substantial proportion of Ghanian households (Agyemang 1994; Falconer n.d.). Surveys indicate that rattan income forms a significant part of total household income in parts of Indonesia (Prempeh 1993) and the

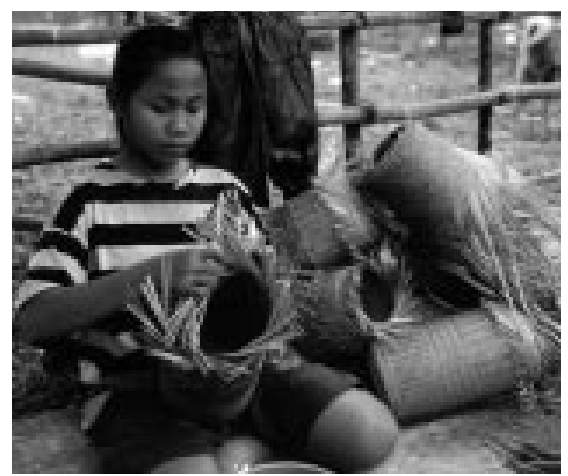

Weaving bamboo rice baskets, Laos

(Photo: Brian Belcher)

Philippines (Siebert and Belsky 1985). In Iquitos, Peru, the forests and fallow fields supply rural people with a critical amount of income in most villages surveyed. There, virtually all village residents depend on them, at least seasonally, for part of their annual monetary income (Padoch 1992a). O n C ombu Island, Brazil, annual average income per household, derived primarily from theharvest and sale of açai fruit and cacao, was found to be over $\$ 4000$ (Anderson and Ioris 1992), greater than from other income sources. In and around Korup $\mathrm{N}$ ational Park in Cameroon, the sale of bushmeat constitutes up to half of the household income and is one of the main occupations of young men (Amadi 1993). Earnings from selling fruit were found to exceed local agricultural wages in Puerto Ayacucho, Venezuela (M elnyk 1996).

W hile NTFPs contribute to household income in many places, this contribution is uneven geographically and socially. Income earned from the collection of medicinal and aromatic plants is higher in the north than the central regions of $\mathrm{N}$ epal (Olsen 1997). A comparison of south Bihar and southwest Bengal, India, indicates the geographical difference in incomes from NTFPs (Rao and Singh 1996). In Bihar about 17\% of total revenues from forest production is received from N TFPs, while in southwest Bengal it is only $1.7 \%$. At a biosphere reserve in southern India, villages within the interior are more dependent on NTFPs than less isolated villages (Ganesan 1995). In I quitos, Peru, there was considerable variation among 13 villages studied by Padoch (1992a) in terms of types of products marketed and income generated from NTFPs. Even among households within any particular village or population there may be wide variation (see Padoch 1992a on Peru; Browder 1992a on rubber-tappersin Brazil). In other words, careshould betaken when 
generalising from the data on any given locality. The contribution of NTFP income is also uneven across social groups and can be highly differentiated by gender, class and ethnicity. These variationswere explored at length in Chapter Two as they are closely related to issues of power and access.

In summary, the importance of N TFP income to total household income is apparent across many regions, particularly in rural households. NTFP products may be critical to overall subsistence, and can supply a high percentage of household cash income. H ouseholdersmay rely on N TFPsduring particular seasons when other income is low. H owever, income is not evenly distributed. Control over labour, product and incomemay vary across regions, within villages and within households. For example, N TFP income is especial ly important to the rural poor, and in some regions it is of particular importance to women's livelihoods. That NTFP production and marketing can be succesfful is widely demonstrated, but attention must be given to who gains and how sales revenue is controlled and distributed. These questions require more precise quantification of incomes and moreelaboration of dynamics within households, villages and trade networks in order to understand better the control and management of NTFP enterprises.

Thereview of the literature has identified a number of important issues to be considered when examining the value of NTFPs and their contribution to household livelihoods, as well as their potential for commercialisation:

- The results of valuation studies have been inconsistent and inconclusive because of varying measures of value, different estimation methods and non-representative sampling.

- Theprofitability of N TFP extraction and marketing ishighly dependent on multiple costs, including labour, specialised technology, advertising and transport, which are rarely fully quantified in project studies.

- Proximity to markets is one of the most important factors determining the profitability of NTFP extraction and marketing enterprises and therefore one of the most limiting factors for commercialisation initiatives.

- Valuation studies based on actual earned income indicate that the extraction and sale of NT FPsis extremely significant in tropical regions at the household, community and national levels.

\section{Economics of D epletion and Sustainability}

Amongst economists, the terms 'suppy' and 'demand' have quite technical meaning. H owever, in the studies reviewed, these terms are often employed less rigorously. O ften, demand equates to use, either for subsistence or the 
market. This is explicit in Falconer's (1992) description of a study conducted by the Forest Resources $M$ anagement project on the uses and markets for nontimber forest products in the southern forest regions of $G$ hana. 'Assessment of demand' is a project objective to 'examine people's use of NTFPs' and 'the trade of N TFPs' (p. 136). 'Assessing the supply of N TFPs' is the second project objective of inventorying the existing stock of selected N TFPs' in forest reserves (p. 140). Thussupply is analogous to theamount of stock in theforest. Similarly, Appasamy (1993: 258) observed that 'according to some estimates, the total demand N TFPs outstrips the sustainable yield of the forests in India.'.

Economists would take issue with these conceptualisations. When economists speak of supply and demand, they are describing a function that relates the price of a product to quantity. In economic terms, supply is not the amount of an N TFP resource naturally available in the forest, but the amount that producers would be willing to supply at a given price. Therefore, the idea that 'demand' will outstrip 'supply' has no basis in economic theory.

U sing supply and demand in this way is not particularly helpful in assessing how the resource base will change over time as prices change. Time is the key component to any question in the economics of sustainability. If the marginal costs of offering a particular NTFP rise steeply over time, then a range of possible reactions could be expected before resource depletion or extinction takes place. As Homma (1992) points out, high prices can stimulate domestication of the product, substitution by similar products, or substitution by synthetics. O Isen (1997) makes a similar argument. Based on his study of NTFPs in N epal he argues that economic extinction - that is, when costs of collection outweighs benefits- precludes botanical extinction. Furthermore, if returns from collection of a species remain competitive over a period of time and availability decreases significantly the species is subjected to domestication and/or cultivation, as H omma's model suggests.

To further illustrate the importance of the proper application of the concepts of supply and demand in NTFP economics, it is useful to examineat length $\mathrm{H}$ omma's model of the economic dynamics of extractivism(see Figure 4). He identifies four developmental phases for NTFPs. In the expansion phase, there is clear growth of extraction. Prices begin to risein thestabilisation phase, after supply and demand have reached equilibrium. Policies to stimulate or protect the sector may be adopted. The decline phase, caused by shrinkage of the resource base and the increased cost of harvest, leads to the gradual failure of extraction. The domestication phase begins to take form during the stabilisation phase, as long as technology for cultivation is available, substitutes do not yet exist and prices remain high. In this model, four main factors contribute to the decline of forest product extraction: (1) the inelastic supply of forest products; (2) harvest rates that exceed regeneration rates; (3) the domestication of the forest product; and (4) the development of industrial 
substitutes for the product. Rising prices do lead to increase harvesting and resource depletion in this model, but that is only a temporary phase as the supply and demand curves shift over time.

Figure 4. The historical cycyle of forest production in Amazone (H omma, 1996)

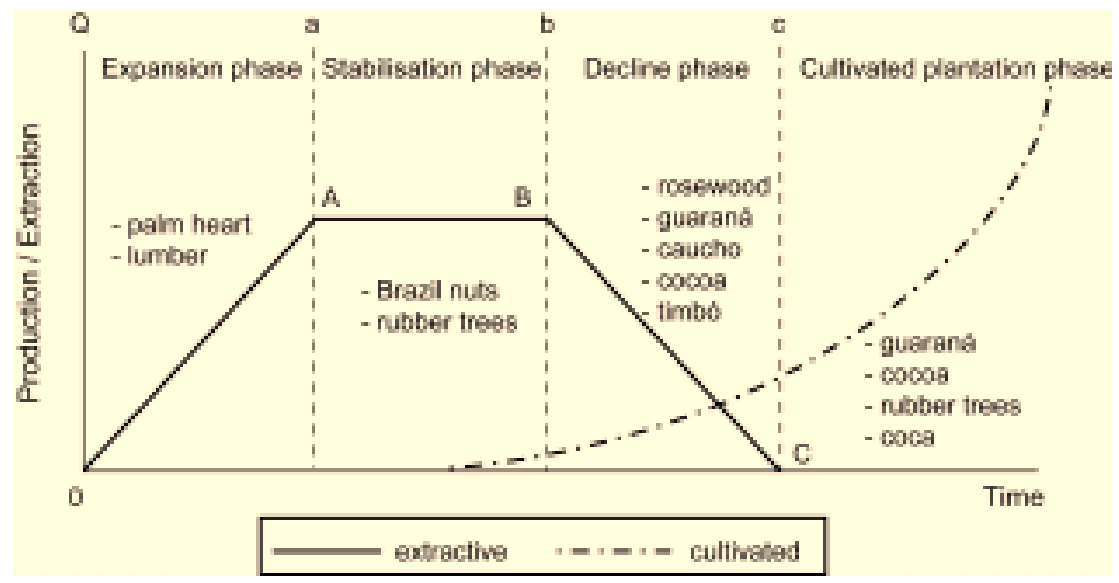

Underlying H omma's model are two related assumptions: that supply curves are steep and that their shapes are more important in determining dynamics than the shapes of demand curves. In this section we review the empirical evidence related to these assumptions. We make two observations: that the assumptions do not hold true in all cases and, second, that when they do hold true there remains considerable variability that will make the phases look very different. We first look at cases that match $\mathrm{H}$ omma's description of supply and demand, but that reveal a great degree of variability in terms of the actual processes of depletion, substitution and domestication. Second, we consider how market imperfections can greatly alter the dynamics of prices and production and therefore alter the phases of the model. Finally, though there has been little research, several studies point to the importance of demand and some suggest highly inelastic demand curves for certain products. This again could significantly alter the model.

As we discuss the empirical evidence, it will also become clear that the possibilities for domestication and substitution vary widely among NTFP species, adding further complications to the model. Q uestions about the relationship between supply and demand and resource depletion can not be answered theoretically through an ideal model of the economic dynamics of NTFPs. Empirical studies are necessary that in fact demonstrate a range of possible paths that NTFP resources can follow. As Afsah (1992) observed, there are numerous N TFPs that go through $\mathrm{H}$ omma's four phases but with 
different consequences. For example, the decline phase is not al ways associated with the collapse of the production system. Browder (1992a) contends that resource depletion occurs during the 'expansion' (boom) phase as well as during the 'decline' (bust) phase. D uring the expansion phase, harvesters deplete the resource in a rush to cash in on quick profits and during the declinephase they are forced to overharvest to maintain living standards. Thus H omma's model, as all models, is a generalisation that is most useful for providing a framework for interpreting empirical findings rather than for actually predicting outcomes for every possible case.

\section{Prices and the Complexities of Resource D epletion}

An empirical study that well illustrates H omma's model is Karki's (1995) study of the economics of N TFP extraction in three districts of N epal, which partly focuses on the factors associated with deforestation and domestication. In this case, as prices rose, buyers and traders induced harvesters to collect more. $\mathrm{H}$ arvesters responded by increasing extraction rates, resulting in overexploitation of NTFP resources. Underlying the rise in prices was the construction of transportation infrastructure that more closely linked the region to outside markets. In terms of H omma's model, as infrastructure improved, the N TFPs in the region quickly moved through the stabilisation and decline phases. As yet, thereis only scattered evidence of new cultivation and domestication efforts in the three villages. Karki correlated a number of constraints with the absence of significant domestication efforts, including labour requirements, land ownership, farm size, production costs and lack of knowledge.

$O$ ther studies highlight the problems of fitting a generalised model to empirical reality. To begin, the notion of resource depletion encompasses a great deal of complexity. Resource exhaustion may vary greatly from place to place. Exhaustion in one place may lead to a geographic shift in extraction activities rather than to domestication or cultivation. Siebert and Belsky (1985) found in their study of rattan harvesting in the Philippinesthat when resources were depleted locally, extraction moved to another part of the region. This geographic shift in extraction occurred in spite of the fact that rattan cultivation was common in the Philippines and supported by government institutions. The geographic shift also increased the costs of extraction, doubling theamount of labour time and exposing extractors to greater personal risks. In this case, land shortages and the local land tenure system inhibited the transition from extraction to cultivation. In the case of the commercialisation of bark paper paintings in M exico (Peters et al. 1987) producers al so shifted to other regions for materials after the depletion of more geographically local resources.

When researchersfocus on the depletion or maintenance of a singleN T FP resource, they also tend to lose sight of the complexity of ecological changes. 
Rising prices can lead to increased extraction rates for a particular species, resulting in either an increase or decrease in species diversity. The study of commercial butterfly harvesting in Papua N ew Guinea by Slone et al. (1997) found that the evidence for commercial harvesting of insects leading to exhaustion or extinction is highly speculative. M ost studies point to habitat destruction as theusual cause of extinction. They distinguish between perceived rarity of a species in a market and actual ecological rarity in terms of low population numbers. Rarity, whether perceived or actual, tends to drive prices up. In the case of perceived rarity of an ecologically common species, rising prices and increased harvesting can actually promote an increase in biodiversity. Conversely if rarity is related to low population numbers of a species, rising prices could lead to depletion or extinction and therefore lower biodiversity.

Another factor in the response to rising prices that is often overlooked when focusing simply on species depletion is that of resource quality. Rising prices may not lead to a decrease in theamount of a resource, but can result in poor or declining quality of the resource. Results from Edwards' (1996b) study of the NTFP trade from the Koshi $\mathrm{H}$ ills of eastern $\mathrm{N}$ epal to Calcuttain India contradict the

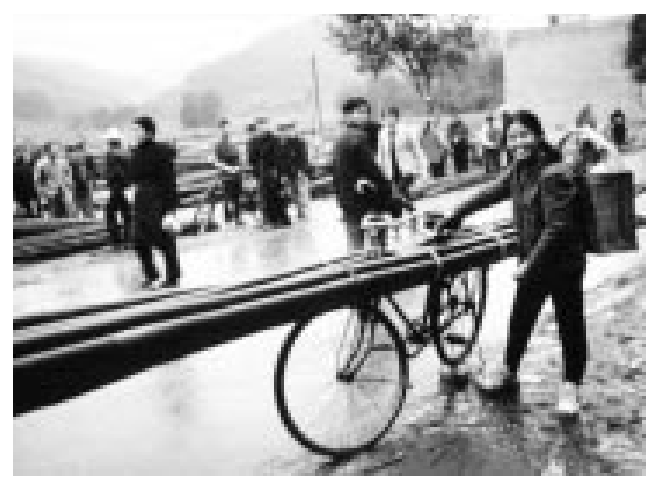

Bamboo market in Daoming Township, Sichuan, China (Photo: Manuel Ruiz Pérez) model that rising prices will lead to increased harvesting and possibly exhaustion. In some regions of $\mathrm{N}$ epal, the resource base may be increasing even as prices remain high. This is due to a number of factors including outmigration from the region and the disruption of traditional marketing channels. Furthermore, though prices are high, there is no incentive to selectively harvest, sincehigherquality produce does not receivea higher price. Buyers pay according to weight regardless of quality. A second study from $\mathrm{N}$ epal also illustrates the problem of quality versus quantity. Rawal (1995) described the quality problems associated with production, processing and marketing of two NTFPs in N epal: timur (zanthoxylum armatum) and jatamanshi (N ardostachysjatamansi). Q uality issues with timur production include adulteration to increase weight, immature harvesting to capture seeds before others do, and improper drying. O Id seeds, often mixed with fresher ones, yield inferior oil. In the case of immature harvesting, high prices lead to increased competition for the resource. In government forests, where first come, first serve rules operate, there is a strong incentive to harvest low quality immature seeds before a competitor. Private and community-managed forests regulate competition and the quality is much better. As a final point of interest, Edwards (1996b) found that increased 
competition among collectors was leading to local experimentation with cultivation of some N TFP species.

\section{Prices in Imperfect $M$ arkets}

In H omma's discussion of the economic cycle of extraction, he anticipates that markets for N TFPs may be imperfect. The empirical evidence indeed suggests that the range and depth of market imperfection can be great, thus diminishing the power of the model to predict what may happen to the resource base over time as prices rise. As Warner (1995) suggests, perfect markets depend on many independent producers, many independent buyers, products of similar quality and kind, and full knowledge of market prices among market actors. Perfect markets are 'more a concept than a reality (p. 103). ' In particular, whiletheremay be many independent producers, thereis often little competition among wholesalers or processors. Furthermore, collectors may have littlemarket information about products, prices or consumer needs.

An excellent example is found in Richards' (1993a) overview of the main N TFPs of the Amazon. In the 1970s in M aranhão, babaçu prices increased steadily in response to rising market demand. This price rise did not result in increased extraction activities, however, since merchants and landowners did not pass on the price increases to producers. In butterfly harvesting in Papua N ew Guinea (Slone et al. 1997), the market is not purely competitive because wholesalers and retailers have exclusive control over the trade. Thus, their optimum prices may be higher than those of a purely competitive market, possibly encouraging producers to overharvest. In this case there would be greater and faster depletion and higher initial prices than in the H omma model. In addition, the very nature of the collector market for butterfly species means that substitution is not an option as prices rise.

In somecases prices can be depressed, that isheld below competitive market prices. An illustration is the production, marketing and sale of sal plates (leaf plates) and thals (plates with a polythene seal to prevent leaking) in M idnapore District of West Bengal, India (Pachauri 1990). In this situation, prices to producers are unrelated to production costs, partly because supply is in excess of demand for localised markets and partly because traders control the market and dictate prices. Since traders are marketing the entire available product, the market sale price will also be depressed. In H omma's model, it is assumed that supply curves are based on the costs of production, but in this case there is little impact on pricing. Thus, according to the model, as demand increases, prices rise (in a proportionately greater amount) and this leads to set of consequences, such as substitution. If the link between production cost and price is broken, the results are not immediately evident. If prices remain low, as in this case, there would belittle incentive to substitute or domesticate. Karki's 
(1995) study of N TFP extraction in N epal documents a similar de-linking of production costs and price.

\section{D emand C urve Elasticity}

The demand curve for N TFPs can also bean important factor in theeconomic dynamics of tropical resources. As Belsky and Siebert (1998) noted, many studies overestimate the potential value of NTFPs because they assume an unlimited market demand. Similarly, Bhuiyan (1995) concluded that lack of demand for NTFPs is one of the major impediments to the development and maintenance of an extractive system. Hulse (1996) explicitly predicts a progressive growth in demand in the wealthy N orthern countries for NTFPS and suggests rising prices and the possibility of synthetic substitutes, similar to H omma's model. The model does appear to accurately describe demand curve behaviour in many cases, accounting for low demand in the early phase of commercialisation, and describing progressivegrowth in demand which brings on higher prices (as in the study by H ulse). H owever, although there has not been extensive research, there is evidence in the literature that reviewed that the demand curves for many commercial NT FP resources differ in two respects from $\mathrm{H}$ omma's conditions. First, demand curves may be highly inelastic. Clay (1997a) observed that the demand for edible nuts is characterised by low price and income elasticities. Thus, there is little incentive for producers to make great efforts to increase overall supply. $0 \mathrm{n}$ the other hand, consumers may be very willing to accept substitutions of one kind of nut over another. Together, these two factors make the shape of individual and overall nut market demand curves important determining factors in the nut trade.

Second, even in the cases wherean NTFP has moved through the substitution/domestication phase, the future demand curve for the extracted product is not completely predictable. In a report of a Social Forestry Development Project (SFDP) in Sanggau, West Kalimantan, Indonesia, Graefen (1995) noted that world prices for damar (resin tapped from Hopea spp. and Shorea spp.) had been depressed due to the widespread substitution with synthetics. Extraction of damar thus declined and the trade disappeared from the

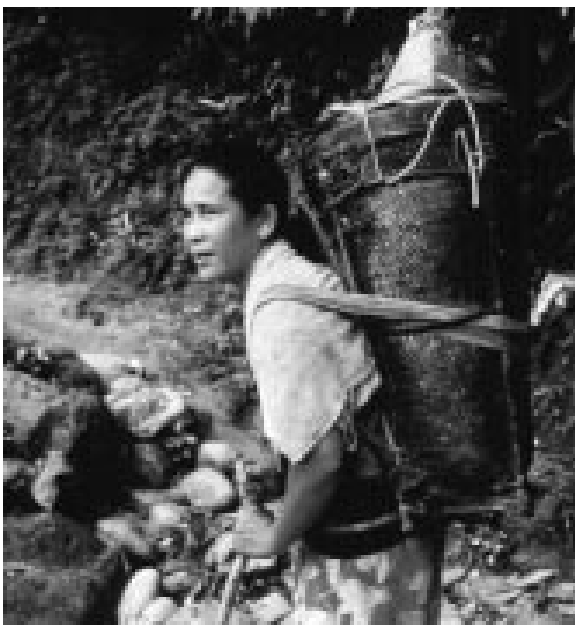

Woman carrying damar back to the village, Lampung, Indonesia (Photo: Lini Wollenberg) 
region as H omma's model predicts. Recently, however, thereisnew and growing demand for paints and varnishes based on natural raw materials. There is potential for market prices two to four times higher for natural resin than for the synthetic substitute. Based on this promising shift in the demand curve, the project is planning to resuscitate damar extractivism in Sanggau and export it under the trade name 'Pontianak damar'. A nother example is for tagua nuts (Coles-Ritchie 1996; Southgate 1998). Tagua exports had declined significantly when vegetable ivory was replaced by synthetic substitutes. Currently, international demand for tagua is rising as clothing designers seek to incorporate natural sources for buttons into their product lines. Therefore, it is critical that models of economic dynamics of N T FPs address the importance of the elasticity of demand.

While Homma's model of the economic cycle of extraction provides a basis for predicting the change to the NTFP resource base over time, reality does not always conform to theory. Case studies illustrate that there can be a range of outcomes and the literature highlights a number of critical issues:

- Rising NTFP prices can have a variety of ecological consequences, including resource depletion, changes (positive or negative) in biodiversity and changes in resource quality, but rarely extinction.

- NTFP resource depletion as a result of rising prices produces a range of responses in different situations including cultivation, domestication and geographic relocation.

- M odelling the interaction of prices and the NTFP resource base is made difficult and complex because of market imperfections.

- Since demand curves for NTFPs are often extremely elastic, models assuming an inelastic demand curve can result in misleading predictions.

\section{M arketing N etworks: Structure and Function}

This section focuses on marketing networks; how they function, how they do or do not result in the economic exploitation of extractors, and the results of market reform efforts intended to reduce exploitation. Commercial NTFP producers may sell their products themselves, sell to merchants, or exchange them for manufactured consumer goods. N ormally, goods are sold at small markets or to middlemen. Some researchers have described intricate chains of intermediaries, village traders, wholesalers and exporters. $M$ any studies have also stressed that extractors tend to be an excessively exploited group within the often-complex set of social relations that structure marketing chains in tropical forest settings. The apparent high levels of exploitation of poor and politically powerless extractors have resulted in state efforts to intervene in the 
marketing networks to create more equitable distributions of income. ${ }^{6}$ These are the issues we examine below. We begin by exploring the dynamics of marketing networks and follow with sections analysing evidence for the exploitative character of extractor relations with traders and intermediaries. Weclose with a section that reviewstheliterature on interventions in the market, mostly stateled, intended to reduce exploitation and evaluate the reasons for successes and failures.

\section{The Structure and $D$ ynamism of $M$ arketing $N$ etworks}

The structure of relationships between collectors, middlemen, traders and wholesalers can be highly complex, involving various elements of exploitation, risk, cooperation, collusion and resistance (e.g. Padoch 1992a,b; Peluso 1992b; Coles-R itchie 1996; Edwards 1996b). The character of these relationships can shift through time, from locale to locale, and at different points along the marketing chain. Coles-Ritchie's (1996) detailed description of the role of intermediaries in the Ecuadorian tagua trade provides a good starting point to illustrate of some of these points. Thestudy compares thetradein two provinces, Esmeral da and $\mathrm{M}$ anabi. Intermediaries, both itinerant and resident, buy from collectors and sell to transporters. Seasonal shifts in tagua purchasing by intermediaries are greater in $\mathrm{M}$ anabi than in Esmeralda. The percentage difference between purchase price and sale price is three times greater in Esmeralda, yet the total earnings of $\mathrm{M}$ anabi intermediaries are greater because they buy four times the volume. Padoch (1992a) describes in detail the marketing networks in the N TFP trade in Amazonia, illustrating the multiple forms that middlemen may take. The 'mayoristas' are urban wholesalers who hire 'corredores' of travelling agents who buy from extractors. The 'rematistas' are second-tier buyers who compete fiercely among themselves and the volume they handle varies widely. 'Transportistas' are boat-owners who may also purchase directly from extractors, often in an exchange of goods rather than cash payments. $M$ iddlemen, in any of their various guises, may also function as contractors or subcontractors who advance payment to a group of extractors in exchange for exclusive rights to the products.

$M$ uch of the research that focuses on marketing networks reveals dynamism in the relationships between producers and intermediaries further downline.

\footnotetext{
${ }^{6}$ States have often intervened in the trade in NTFPs for a variety of other reasons as well, such as to control forest use, protect the role of the state as a producer, and to control prices of particular consumer products, such as wood fuels (see D ewees and Scherr 1996 for a recent review of these issues).
} 
These relationships are not fixed, but can change over time. O ne of the most common forms of traditional relationships is that of patron and client, sometimes associated with debt peonage. Several of the studies reviewed noted that these traditional relationships can break down under a variety of circumstances. In a description of the aviamento system of extractivism in the M iddle Rio N egro region of Brazil, Emperaire and Pinton (1993) observe that some collectors are able to reduce or manage their debt, thereby reducing the power of the patron over them. This effort is usually associated with a certain level of education among the collectors. 0 thers are ableto break the relationship completely and enter into new activities based on monetised exchange. Lescure et al. (1994) note that the loss of patrons' monopolies, the development of urban centresand roads, and the emergence of local political power all contribute to the development of a monetised economy. 'This evolution towards a monetized system of exchanges permits a decrease in the social constraints linked with the aviamento' (p. 10).

Another example of the decline of patron-client relationshipsin the N TFP trade comes from East M alaysia. Brosius (1995) examined the dynamics of the collection and trade of forest products by Penan hunter-gatherers in Sarawak. Penan have long been suppliers of forest products to regional trade networks and have traditionally played a client role to longhouse patrons. Brosius found that the type of product gathered changed greatly through time, and that many products had disappeared from the trading networks for a variety of reasons. The traditional relationshipsin the tradehave also changed in recent years. A number of factors underlie the breakdown in patron-client relations, including the expansion of a cash economy, the extension of government institutions and, most significantly, the appearance of logging companies. Road development associated with logging improves access to markets and allows the Penan to by-pass the longhouse patrons. In nearby East Kalimantan, Indonesia, alogging boom has also helped to bring remote regions further into a monetised environment

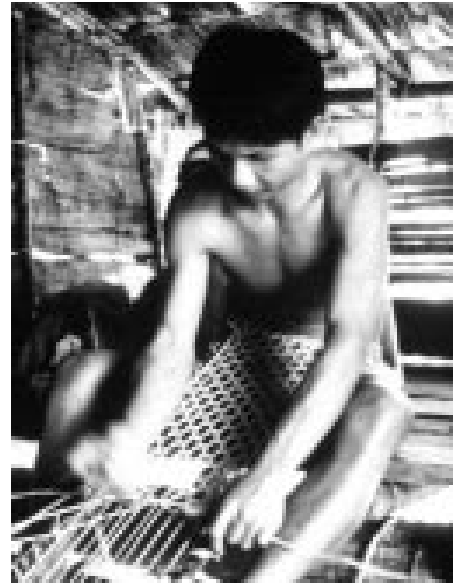

Punan man weaving a rattan basket, East Kalimantan, Indonesia

(Photo: Ester Katz)

(Peluso 1992b). The result has been an increase in the number of rattan traders and a subsequent decline in patron-client relations as collectors have more opportunities to sell for cash. Thus in both the Amazonian and the Southeast Asian cases, monetisation of the economy and urbanisation/infrastructure development are central to the decline of patron-client relationships. 
The roles and returns on profit to actors in the marketing chains also may change over time. D escribing the trading network for damar (from various species) from farmers in Pesisir, Indonesia, K isdwiutomo (1995) compares data from 1984 and 1994. A complex chain of intermediaries, village traders, wholesalers, exporters and users characterises damar trading. 0 ne of the most significant changes in roles was that of the wholesalers. In 1984, they were primarily transporters between village traders and exporters. In 1994, they were al so grading the product and their return on investment grew from $2 \%$ to $15 \%$. A field study undertaken to assess N TFP availability and utilisation in Garhwal, India(ED A 1993), describes the shifting roles of network participants. The traditional structure of collecting and trading was widely viewed as corrupt and leading to both environmental degradation and the perpetuation of poverty among hired extractors. A new organisation, Bhashaj Sangh (M edicinal D rug Unions), was formed by the government to issue collector's licences only to local members of village cooperative societies who were trained in the correct, sustainable methods of N TFP extraction and collection. The major role of the Bhashaj Sangh was intended to be to encourage greater local involvement in medicinal NTFP collection. The outcome, however, was that the licensed collectors werenow able to capture $20 \%$ of the final value without performing any useful function other than arranging transport.

Another aspect of market network dynamism could be labelled 'simultaneity'. In some cases, multiple trading networks can be operating simultaneously in one region, with great variation in the identity and roles of marketers for different N TFP resources. Townson's (1995) report on N TFP incomes in southern $G$ hana offers one of the best examples of this phenomenon. $\mathrm{He}$ found that buyers range from individuals in the same village to traders from large urban areas. W hether the producers sell to local traders or outside traders partly depends on the resource. For example, honey is sold almost exclusively to outside traders whilemats go equal ly to local and outsidetraders. In addition, the primary customer varies depending on which stage of the NTFP extraction and processing activities the seller is engaged in. Finally, the structure of trading networks for the same products can vary geographically. Townson noted that in areas with relatively well-developed infrastructure, producers are more likely than average to name outside traders as their most important customers.

\section{Patterns of Exploitation in Trade and $M$ arketing}

There is a common assumption in much of the NTFP literature that the relationships between producers and traders are economically exploitative. Part of the evidence supporting this assumption comes from market studies that show levels of profit at different points in the marketing chain. Profit margins 
for contractors, wholesalers, transporters and exporters are often quite high. Exploitative relationships appear to be most evident in cases where intermediaries or middlemen are the primary point of salefor producers. Peluso (1992b) describes how exploitative relationships function in the rattan trade in East Kalimantan, Indonesia. Beginning with the collector, actors al ong the marketing network are linked through debt. Traders are tied vertically to the collectors through one or a series of intermediaries. Traders protect themselves from competition with other traders through debt or patron-client type relationships with collectors. Traders are then able to cooperate to both fix prices and control delinquent collectors.

Several studies of N TFP production in India indicate that private traders dominate the market, often take the lion's share of profits, and manipulate prices to their advantage (Pachauri 1990; Prasad and Bhatnagar 1993). Forest dwellers in 0 rissa, India, identified three main factors in their relationships with intermediaries that they considered exploitative: 1 ) the low prices given; 2) lending money in the lean months in order to get NTFPs at low prices in the harvest season; and 3) cheating in measurement. Actual prices given were well bel ow official prices in villages where onemerchant had monopoly control (Fernandes et al. n.d.).

Similar patterns of monopolisation and exploitativerelationships are found in Amazonia (detailed also in Chapter Two). Sizer (1993) presents the results of a socio-economic and ecological survey in a community of the Jau $\mathrm{N}$ ational Park, Brazil. A large part of the working time of adult male members of most families is spent in theforest, collecting plant productsthat aresold to merchants or exchanged for manufactured goods. Extractors are subject to high levels of exploitation, and most arein perpetual debt to patrons, typical of the aviamento system in A mazonia. A number of factors keep extractors in a relatively powerless position. For example, collectors lack sufficient capital to buy a motor boat to transport their produce to market. This forces a reliance on traders who have monopoly control of transport and can therefore fix prices well below market rates. In remote forest communities, intermediaries may also havea monopoly on information. In the Iquitos region of the Peruvian Amazon, Padoch (1992a) observed that prices for some N T FPs vary widely by season. M any collectors are at a disadvantage in relation to traders because they do not have access to current price information from distant markets. In Guyana, on the other side of Amazonia, an anecdotal account of the experience of Amerindian collectors reveals the difficulties faced by producers attempting to market their products directly (Verheij and Reinders 1997). Lack of access to credit, transportation, information on price fluctuations and storage facilities combine to keep producers at a great disadvantage in the marketplace. And these conditions provide plenty of opportunities for intermediaries to position themselves as almost unavoidable links in the marketing chain. 
W hile the opportunities for intermediaries to cheat producers can be numerous, as in the cases cited above, some researchers urge caution towards both the veracity of claims of exploitation by middlemen as well as the calls to eliminatethem from tradenetworks. Based on the results of research in western Amazonia, Padoch (1992b: 45) believes that the 'elimination of all intermediaries does not appear to be a feasible or even desirable early step'. Rather than being wealthy patrons, she observes that the common lot of 'rematistas', the petty, independent merchants who function as small-scale mobile wholesalers of N TFPs in I quitos, was one of poverty and long working days. Risks for rematistas are numerous and high, competition is fierce, and they 'are constantly losing their shirts' (p. 49). Peluso's (1992b) rattan trade study reveal ed that middlemen and traders are themsel ves caught up in debt to benefactors who advance goods or cash. In other words, debt, vulnerability and poverty may be endemic to significant parts of the long trading chain and not just restricted to victimised collectors. ${ }^{7}$

Based on the differences in purchasing and selling prices or the difference between what producers receive and the world market price, it is reasonable to infer that shortening the marketing chain would leave more of the N TFP value in the hands of the extractors. In South Sumatra, Indonesia, a study of the highly complex chain of trade for damar indicates that profits for producers would begreater if the trading chain was shorter (Kisdwiutomo 1995). H owever, if the costs borne by intermediaries and the functions they perform are considered, the differences in purchasing and selling priceslook less exploitative. Coles-Ritchie's (1996) tagua study in Ecuador found that intermediaries provide important functions between the points of purchase and sale, including transport, storage and shelling. Costs borneby theintermediary include salaries, packing sacks, transportation and the financial cost of forgoing interest on the money invested in stored tagua. Edwards (1996a) points out that, while harvesters in $\mathrm{N}$ epal would increase their incomes if they sold directly at the roadhead, the essential services of the traders would have to be replaced by a cooperative where harvesters could share the costs. By eliminating two levels of intermediaries, an extra $11.6 \%$ percent mark-up would become available to a hypothetical collector's cooperative, but the costs of transportation, administration and other transactions would have to be subtracted.

$M$ any of the studies on marketing networks reveal that intermediaries are often exposed to high levels of risk. If these links are bypassed, producers will then be exposed more directly to the same risks and subject to the economic

\footnotetext{
${ }^{7}$ Asan important counterpoint to this general pattern of indebtedness, Edwards (1996a) shows that credit is extended in the opposite direction in N epal. There, traders 'at all levels attempt to increase their proportion of the trade through the advancement of capital to intermediaries above them in the marketing chain' (p. 6).
} 
consequences. Prices can fluctuate wildly and swiftly, easily destroying the investment of timeand money of petty traders (Padoch 1992b). Linking producers more directly to export markets may al so heighten the level of risk. Taylor (1997) suggests that as the type of market shifts from local rural to national urban to international, the relative risk increases. Specifically, international markets in NTFPshavea history of boom and bust and aresubject to higher quality standards, sophisticated market preferences and international trade rules.

To summarise, relationships between producers and middlemen are often exploitative, but they are not necessarily so. $\mathrm{N}$ or does the elimination of middlemen appear to beeconomically beneficial to producers in all cases, or at least the benefits may not be as large as they appear before taking costs into account. $M$ any intermediaries perform critical tasks, bear significant costs and expose themselves to great financial risks. $\mathrm{N}$ evertheless, enough cases of exploitation and extraordinary profit-taking by middlemen exist in the literature to identify certain patterns. Four key conditions appear to be conducive to exploitation:

1. When intermediaries areal so creditorsto collectors, variations of debtpeonage emerge that keep collectors impoverished and subject to the control of traders.

2. When intermediaries have a monopoly on transport, an effective monopsony exists whereby the buyer can set prices far bel ow market rates, thereby reaping extraordinary profits.

3. When intermediaries have a monopoly on information, producers are extremely vulnerable to exploitation because they lack the knowledge of market prices that would allow them to negotiate with traders.

4. In some cases the intermediary adds little or no value to the product, but merely funnels the fruits of many collectors and then sells to the next link in the chain.

D espite the dynamism of many N TFP trade networks, these conditions persist in a number of regions and states, and non-state actors have intervened in marketing in an attempt to break these exploitative ties.

\section{State and N on-State M arketing Institutions}

O ne of the most common strategies for reducing the level of exploitation by middlemen and protecting producers from marketplace volatility is the establishment of state marketing cooperatives. India has the longest and most extensive experience with state interventions in the N TFP marketplace. It will be instructive to use India as a case study and review the results of state 
interventions at length. We will first develop a general history of state N TFP marketing institutions and then examine the effectiveness of specific institutions in relieving exploitation and redistributing profits toward the producers. We then review state marketing institutions in other regions and assess non-state interventions in the market.

Thehistory of stateinvolvement in N TFP marketing in India can be traced to government efforts in 1956-57 to reduce NTFP merchant exploitation of 'tribals' and other forest dwellers. This initial effort, which failed for a variety of reasons, centred on the creation of tribal cooperative societies (Fernandes et al. n.d.). In the 1970 s a variety of other public sector organisations, such as Large Scale Agricultural Multipurpose Societies (LAM PS) and Multipurpose Cooperative Societies (M PCS), were formed in combination with local tribal societies. These societies and cooperatives procure NTFPs from collectors and sell them to wholesalers with the intention of eliminating exploitation by intermediaries. In some cases, tribal LAM PS operate also as retailers of N TFPS, or aswholesalersfor some products and retailersfor others (e.g. Sekar et al. 1993).

Individual states enacted their own legislation to deal with the problems of exploitation of producers. In Kerala, the government recognised that tribals (or Girijans) as a social group was the most exploited by NTFP merchants. In 1978, they were granted a monopoly over the procurement and marketing of all NTFPsthrough institutionssuch as the Girijan Service Co-operative Societies, which was initially established in 1956 (Thomas and

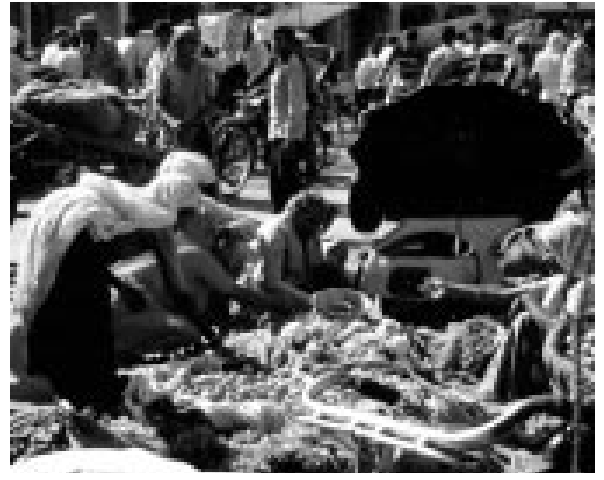

Vegetable market in Andra Pradesh, India (Photo: John Poulsen)

Bai 1993). The Bheshaj Sanghs cooperatives were created in G arhwal to ensure that collectors obtained a fair price for NTFPs, particularly medicinal plants and herbs, by intervening in the marketing of NTFPs in one of three ways: direct purchase; commission sale; and pledged purchase (ED A 1993). D irect sales to the Bheshaj Sanghs are conducted at government fixed prices, commission sales involvean 8\% commission for assistancein obtaining a fair pricefrom wholesalers, and pledged purchase involves an initial payment of $40 \%$ to $60 \%$ and the remainder after it is sold in the market. The majority of transactions are commission sales. The Rajasthan Tribal Area D evelopment Cooperative Federation (RTAD CF) was created in 1976 with the responsibility to ensure that the N TFPs collected by tribals are sold only to the cooperative societies (e.g. LAM PS) it nominates (Chakravarti and Verma 1991). It is also involved in processing activities as a way of commanding an even greater share of the final 
sale price to consumers. In O rissa, the Tribal Development Cooperative Corporation of O rissa Limited (T D CCO L) wasformed in 1975 with theobjective of purchasing tribal NTFPs at fair prices (Fernandes et al. n.d.).

Some of the regulation efforts are resource-specific. Tendu leaf, sal seed and bamboos were nationalised by the government in 1972, 1982 and 1988 respectively (M ahapatra and M itchell 1997). Individual state governments then enacted their own legislation to control the trade of these products. O rissa was, in 1972, the first state to take full control of tendu marketing from stateowned and degraded forests, though most tendu-growing states have similar legislation (Dawar 1994; M ahapatra and M itchell 1997). Essentially, these states have a monopoly over the tendu leaf trade. A uniform price is set for the resource by the government. Theforests of each state are divided geographically into units, and the purchaser assigned to each unit is required to buy all of the tendu leaves produced there. Some states remit a portion of the revenue back to local bodies, such as village panchayats, in recognition of the fact that part of the produce comes from community forests ( $D$ awar 1994).

Several studies have evaluated the results of state efforts to monopolise power over procurement and marketing of NTFPs and thereby reduce the exploitation of collectors. Results of these analyses have been mixed, but the findings are to a large degree negative for the producer. Tewari and C ampbell (1996) assert that state cooperatives intended to help tribal peoples market their N T FP have not been cost-effective and significantly underpay collectors. Production levels have declined in states where NTFPs are nationalised (i.e. wherecollectors must sell exclusively to the Forest D epartment). In Tamil N adu, price information indicates that collectors appear to be underpaid by LAM PS and tribal members do not get sustained employment for reasonable remuneration (Sekar et al. 1993). O rissa cooperative societies have not really succeeded in eliminating middlemen, as they have become de facto agents of LAM PS and M PCS. Fernandeset al. (n.d.) found that, in 50 out of 68 villages, former middlemen had positioned themselves as purchasing agents for these societies. In the villages where collectors sold directly to the agencies, they received higher prices. Similarly, in Bihar, marketing of N TFPs remains in the hands of private traders who may be colluding with government officials (Burman 1990). '[T ] he nationalization of M FP or formation of co-operatives to channelisethe marketing of M FP has not helped the tribals to any significant extent' (p. 652).

Thomas and Bai (1993) evaluated the success of the Girijan Service CooperativeSocieties (GSCS), which haveexclusiverights to NTFP procurement in Kerala, in liberating tribalsfrom theexploitation of privatetraders, and whether they have ensured reasonable prices for the produce. $D$ ata from a representative sample of NTFP collectors and a sample of private traders and their prices indicated persistent indebtedness, illicit traffic with privatetraders and an inability 
of the GSCS to procure the total marketable surplus of NTFPs collected by tribal households (in fact they only collected $61 \%$ ). Prices offered were often below those of private traders. In the $\mathrm{C}$ entral $\mathrm{H}$ imalayan region of $\mathrm{U}$ ttar Pradesh, a marketing federation of government officials and politicians was set up in the 1960 s to protect villagers from exploitation. The federation did not prove to be a better option than the former relationship with intermediaries for a number of reasons ( $R$ ao and Saxena 1996). These include the fact that procurement is conducted at the motorable roadhead, but most of the collector costs are in transport between the forest and the road. Also, as in the case of the GSCS, prices offered were below those of private traders.

In these studies of various cooperative societies in India three types of factors explain most of the failures to either provide collectors with a greater share of NTFP profits or protect them from middlemen.

1. Excessive bureaucratisati on. In O rissa M ahapatra and M itchell (1997) identified a plethora of rules, laws, acts and agencies that operate differently for different products and in different places and levels of government. This has had the effect of creating numerous avenues for corruption and inhibiting the sale and trade of NTFPs. H eavy bureaucratisation can also slow payments to the point where it is impossiblefor impoverished forest dwellersto avoid either going into to debt to buy provisions or going to private traders who pay on the spot (e.g. Fernandes et al. n.d.).

2. Widespread inappropriate price-setting among various marketing institutions. In most cases, the problem is that cooperative prices are set below those offered by private traders. Thomas and Bai (1993) found in Kerala that private traders invariably offered a higher price than the G SC S, in one case the difference was 133\%. Also, the price paid to producers for honey by RTADCF was lower than private agents (C hakravarti and Verma 1991). The official price of tendu leaves has been set so low that production from private growers has declined since national isation (D awar 1994).

3. Increased opportunities for agents of government cooperatives to 'rentseek' by cheating or soliciting payments from collectors. In 0 rissa, government-set prices are not publicly announced, so unscrupulous collecting agents can cheat producers who lack access to official prices (M ahapatra and M itchell 1997). Burman (1990) identified the systematic misallocation of cooperative funds for the benefit of a few individuals, causing the cooperatives to operate at a loss and negating any benefits to producers.

India, of course, is not the only region that has attempted to eliminate middlemen through state marketing institutions and wefound a morepositive 
assessment of efforts elsewhere. In Papua N ew Guinea, insects are a valuable source of income for many villagers, due in large part to the success of the Insect Farming and Trading Agency (IFTA) (Slone et al. 1997). This agency operates with theaim to return as much income as possible to insect collectors. It has been relatively successful in that goal, although there appears to be an enormous mark-up from IFTA prices to retail prices, so it would seem that IFTA could judiciously increase prices without substantially reducing demand. The creation of the Botswanacraft $M$ arketing $C$ ompany appears to haveresulted in number of social and economic benefits for producers. It has helped $\mathrm{H}$ ambukushu people retain their handicrafts customs and avoid the problems of rural poverty and migration to urban centres (Terry 1984). It has brought significant amounts of cash into rural households and in many cases provides the solesource of incomefor rural women. Although definiteconclusions cannot bedrawn from this brief comparison, it is possibleto speculateon thedifferences between the situation existing in India and that in PN G and Botswana. Two main differences stand out. In PN G and Botswana, there was no preexisting and entrenched class of intermediaries dealing with the respective NTFPS. $M$ arketing of baskets in Botswana had been occurring for only a short time. In contrast, in India some of the N T FPs have been marketed for centuries. Second, the failures in India appear to be inseparable from structures of poverty and powerlessnessthat extend far beyond theissue of N TFP marketing. The extreme differences in class status that are evident in the Indian studies are not evident in the PN G and Botswana contexts.

Finally, there has been a highly publicised effort by non-state actors to reduce the roles of intermediaries in Amazonia. Commonly referred to as the 'rainforest harvest' initiative and led principally by two companies, Cultural Survival Enterprises and the Body Shop, thisintervention isintended to shorten the marketing chain (see Baker 1989; M ay 1991; C lay 1992; Richards 1993a). Implemented in 1989, the proposal was for these companies to buy directly from producers, thereby allowing them to pay higher prices. In addition, a portion of the revenue is 'reinvested' for development projects in the source communities. Brazil nuts have been the most important product, and the price to producers was initially increased. Thereis evidence that overall N TFP prices to producers have increased and that traditional middlemen have been eliminated or bypassed.

D espite the reports of success, rainforest harvest has come under harsh criticism (C orry 1993; IW GIA 1993). First, the market demand for rainforest harvest products is driven to a large degree by a faddish interest in 'saving the rainforest' in the consumer countries of the N orth. Corry (1993) argues that, by exposing N TFP collectors to volatileinternational markets for non-essential luxury goods, they will be subject to the same social and economic upheavals of previous boom-and-bust cycles. In fact Brazil nut prices crashed soon after 
theinitiation of rainforest harvest (IW GIA 1993). Second, the possibilities for widespread implementation of this approach are extremely limited to those communities with a saleable product and that are located near transport links. Finally, and perhapsmost critically, many of the development projects associated with the rainforest harvest arefunded through loans. In other words, collectors are tied to the product and its buyers in a way that appears similar to the traditional relations of debt bondage (C orry 1993). Even where loans are not involved, the new buyers take on roles that are in many ways indiscernible from the intermediaries they displace. As an IW GIA (1993) policy statement points out, when Cultural Survival pays a higher price, this is nothing other than under-cutting the local merchants' (p. 8). Thus research needs to address the question of the degree to which these types of interventions alter or fail to alter the fundamental economics of extraction.

The relationship between N TFP producers and the markets they supply may range from direct salesto a complex network. H ow these networksfunction and the roles of intermediaries can be seen in various contexts. Studies of the structureand function of marketing networks reveal are number of key points:

- The assumption that NTFP marketing 'middlemen' are procuring excessive profits ischallenged when indebtedness and the costsincurred by marketers are taken into account.

- NTFP markets are extremely dynamic socially, temporally and spatially, making it difficult to generalise about their functioning.

- State efforts to reduce exploitation by middlemen have often failed to benefit collectors due to high levels of bureaucratisation, inappropriate price setting and rent seeking by state officials.

\section{Summary}

O ne of the fundamental tools employed to assess the economic trade-offs of alternative forest uses is the value estimate, typically based on some measure of NTFP production per unit area of forest. W hile forest valuation studies are important for rough estimates of potential revenue from NTFP extraction, they have limitations. Estimates can be overly optimistic if they do not take into account ecological variability, accessibility and seasonal ity. There are also difficulties in translating forest production into income for a number of reasons. These include the fact that not all N T FPs produced are actually marketed and the likelihood that prices will fall if all production of an N TFP is marketed. Furthermore, the costs of extraction and marketing are often not fully accounted for in valuation studies, again causing overly optimistic projections. Costs such as transportation, equipment, labour, advertising and storage must be carefully calculated before the profitability of a particular N TFP or forest area can be 
estimated. Cost can be used in conjunction with the actual income derived from NTFP collection and marketing. Results from income studies suggest that the revenue from N T F Ps is often significant and relatively large, although unevenly distributed among community members.

Beyond the issue of the potential NTFP revenue from a given stand of forest is the question of the long-term sustainability of that revenue. Theanswer partly lies in the response of producers to changes in prices. Producers may overharvest as prices rise, leading to resource depletion in wild stands, and eventually to substitution with other natural or synthetic products, or to cultivation and domestication. H owever, the results of many studies indicate that the precise responses are difficult to predict for two reasons. First, the demand curves for many N TFPs are highly inelastic, meaning that prices will not continue to rise indefinitely; and second, the responses of producers is highly variable and dependent upon, among other things, the relationship between prices and production costs and the availability of and demand for substitutions.

$M$ any of theabove points are closely related to thestructureand functioning of marketing chains. Studies of marketing chains for globally traded NTFPS indicate that they involve, to varying degrees, elements of exploitation, risk, cooperation and collusion. Findings also suggest that marketing chains are highly dynamic in both time and space. Because of these complexities and the dynamism, the use of theterm 'middleman' to identify agentsoperating between the collector and the final consumer raises more questions than it answers. $\mathrm{N}$ evertheless, many studies suggest exploitative relations between producers and marketers result in the bulk of the profits from N TFPs accumulating far up the marketing chain from collectors. This general pattern has led to a variety of state interventions designed to reduce the level of exploitation of collectors by middlemen. The success of these interventions is mixed, but generally negative due to problems of corruption, excessive bureaucratisation and inappropriate pricesetting. Furthermore, such interventionscan rarely overcome historical and deeply entrenched structural inequalities that account for much of the exploitation in N TFP marketing. 


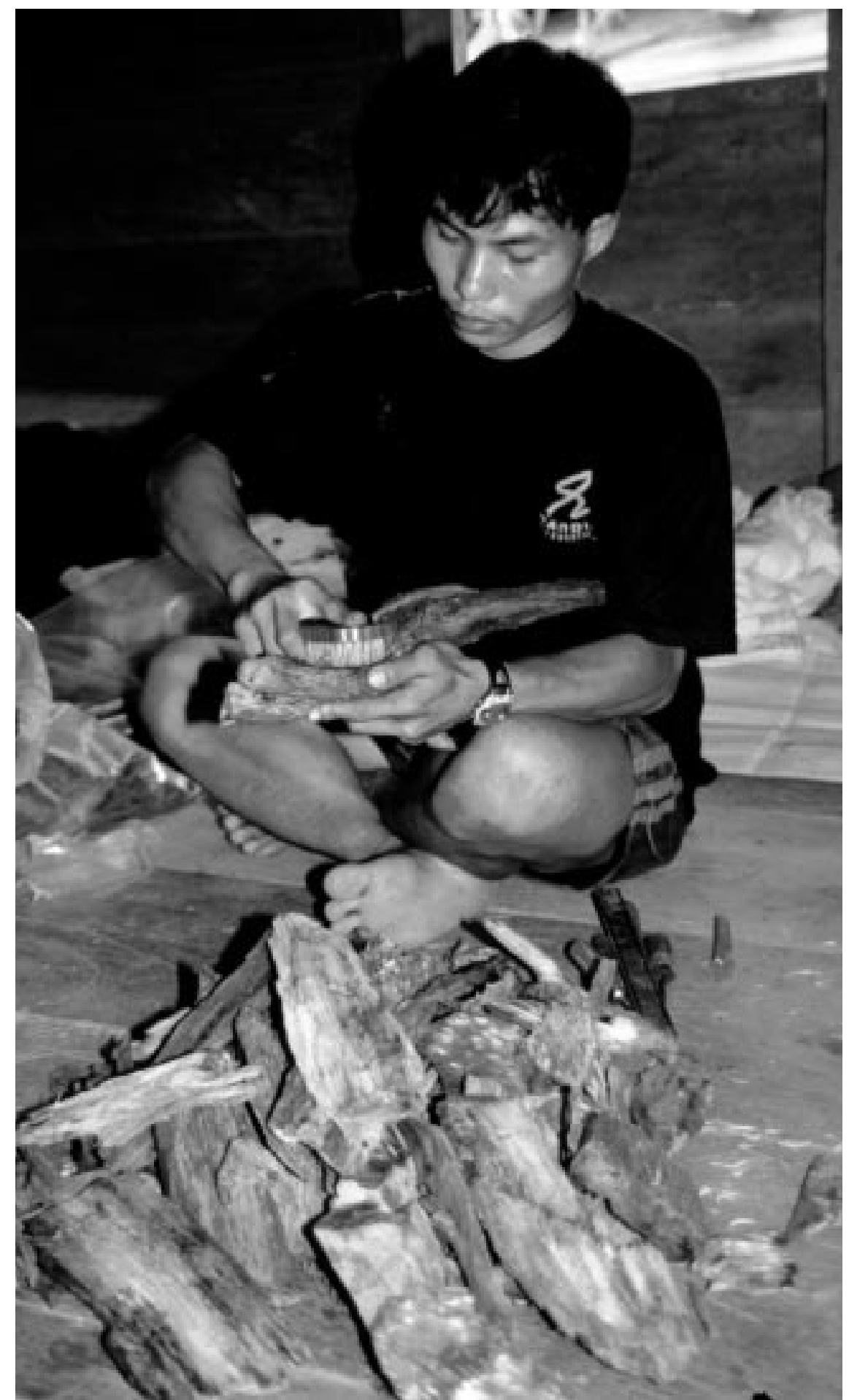

Gaharu (Aquilaria spp.) cleaned before it is sold at market, East Kalimantan (Photo: Christophe Kuhn) 


\section{Chapter Four}

\section{M anagement Issues for Commercial N T FPs}

The challenge of managing forests for commercial NTFPs is to promote economic development by maintaining and even increasing production while simultaneously maintaining or improving ecological conditions. The discussion of forest management, therefore, encompasses a wide range of social, economic, political and ecological questions. Setting the level of management intensity, for example, requires an economic assessment weighing the costs of additional inputs against the potential gains. $M$ anaging for 'development' implies a political decision about the distribution of benefits at various geographic scales, among geographic regions, and among various social groups: classes, ethnicities, men and women. Furthermore, forest management requires, at the very least, baseline ecological data and ongoing monitoring for assessment of the ecological impacts of N TFP harvesting. In short, forest management touches on some aspect of all the main issues of this entire review, and so in this chapter we have narrowed our focus.

We have opted to concentrate on the technical and formal institutional aspects of management. That is, we focus on the practices and techniques employed for the purpose of producing commercial N TFPs from forest lands and on the formal institutions established for their implementation. $M$ any of the political, social, ecological and economic elements of management we address in other chapters. Wealso concentrate on N TFP management in forests and in-depth questions associated with cultivation. There remains, however, a grey area in which the line between intensive management and cultivation, between natural forest and managed forest, or between extraction and agroforestry, is blurred. We explore that grey area through the management literature on a range of forest types including forest fallows in swidden systems, secondary forests and abandoned forest settlements. It is important to do so partly becauseintensively managed systemsareoften mistaken for natural forests and can be counted as such in national and regional tallies (Padoch and de Jong 1989; Fairhead and Leach 1998). It is al so necessary to include secondary forests and forest fallows because these are often the most important sources of commercial N TFPs (see C hapter Five) and because these sites are where most local, customary management takes place. 
We first make a rough distinction between stateled, 'scientific' forest management and 'customary' forest management. Scientific forest management refers to the practices devel oped in Western Europeand $\mathrm{N}$ orth America for the sustained yield harvesting of timber on state-owned reserves. The practices and objectives of scientific forest management were subsequently introduced into tropical regions through European colonialism (Peluso 1992a; N eumann 1997a). Customary management refers to the everyday practices of people living in countless tropical forest communities. These practices are founded on a geographically limited, but highly detailed body of knowledge of the local flora and fauna that has been acquired through generations of living in or near the forest. Using this framework, we begin the chapter with an exploration of the research on state-based, scientific management for commercial NTFPs. Weaddress the conflict and compatibility of traditional stateled management and N T FP collection, focusing particularly on research on the integration of timber and non-timber production. Wethen examinetheresearch on customary management practices for commercial N TFPs, drawing attention to the variety and flexibility of local land usestrategies. Thethird section looks at the research on ways to integrate community-based customary and state-led scientific management for N TFP production. This topic necessarily leads further into social and political questions, but in this chapter the more technical aspects of institutional arrangements are the focus and Chapter Two deals with the sociopolitical context.

\section{State-led M anagement of C ommercial N T FPs}

Until recently, most government forestry agencies in tropical regions were not actively managing for N TFP production and therefore research has been limited. ${ }^{8}$ In N epal, although local communities have had extensive responsibility for forest management, little consideration has been given to NTFPs in management plans. Virtually all farmers rely on N TFPs, but collection typically occurs in an uncoordinated and poorly managed fashion (Gautam 1995). Recently, however, the development of NTFPs was included as a goal of the government's Five Year Plan (1992-1997). Tewari (1994) points out that only after the International Timber O rganization (ITTO) called for the study of NTFPsin 1988 did research interest gain momentum and management studies begin to emerge. India's forest policies from the 19th century to the middle of the 20th century dealt exclusively with timber production on state-owned

\footnotetext{
${ }^{8} \mathrm{H}$ owever, as noted in the Introduction, earlier periods of interest in tropical resources did result in the accumulation of a large amount of information about commercial NTFP resources (e.g. Burkill 1935).
} 
'Reserve Forests' (M ahapatra and M itchell 1997). O ther categories of statecontrolled forest lands were left to meet the demand for forest products without the application of scientific management. It was not until the 1988 Forest Policy that the government madeguidelines for developing N TFPs (M ahapatra and $M$ itchell 1997). For many forest areas of India, N TFP data still have not been systematically collected and analysed (Appasamy 1993). A similar pattern emerges in other tropical regions. G akou et al. (1994) found that government forest management policies in $M$ ali ignored the vast majority of N T FPs essential to rural livelihoods. $\mathrm{O}^{\prime} \mathrm{H}$ ara (1998) concluded that critical monitoring and assessment practices for N TFP extraction has been absent in many of the recent community-based forest projects in Latin America and elsewhere.

\section{Studies of State-led N T FP M anagement}

Since the broadening in focus of tropical forest management to include commercial NTFPs is so recent, there is a limited amount of research that assesses alternative practices and techniques. Currently, there are very few areas that are managed by the state with an explicit N TFP emphasis. O ne such area is the Biligiri Rangan Temple W ildlife Sanctuary in southwest India that is actively managed for the production of amla fruit (Phyllanthus emblica), a commercially important N TFP. T he government foresters select the areas and times for harvesting based on field surveys in the Sanctuary. (Shankar et al. 1996) evaluated the extraction and productivity of alma fruit to determine if current management of the Sanctuary was sustainable. (We examine the methods and findings of this study in greater detail in Chapter Five and here concern ourselves with the implications for management practices.) The researchers suggest that generating greater profits locally (through value-adding processing) and reinvesting a portion of those profits in silvicultural work could improve management of the resource. Specifically, they propose broadcasting unused alma seed obtained during processing. These ideas have been implemented but their impact has yet to be evaluated (p. 278).

Another region designated specifically for N TFP management by the state is found in Belize. In 1993, the national government created the Terra N ova M edicinal Plant Reserveto protect and ensurethe future existence of medicinal plants and to providean area where traditional heal ers could sustainably extract their medicines. Sabin (1996) identified and studied two distinct periods of management: an early phase of relative success in which the Belize Association of Traditional H ealers (BATH) effectively carried out their management responsibilities over the Reserve, and a later period in which internal politics within BATH hindered the work of the Reserve. The measure of success includes the meeting of certain reservegoals such as plant conservation, theestablishment of nurseries, the development of educational opportunities for training in healing 
arts, development of incomegenerating activities for the surrounding community, and the establishment of ecotourism. After progress toward these goals in the first year of the Reserve, a quasicoup in which a new Board of Directors installed themselves at the helm of BATH has left the organisation ineffectual and slow to apply for grants to undertake Reserve work. Finally, the new directors have severed ties with a private research foundation that was important to the Reserve's early success.

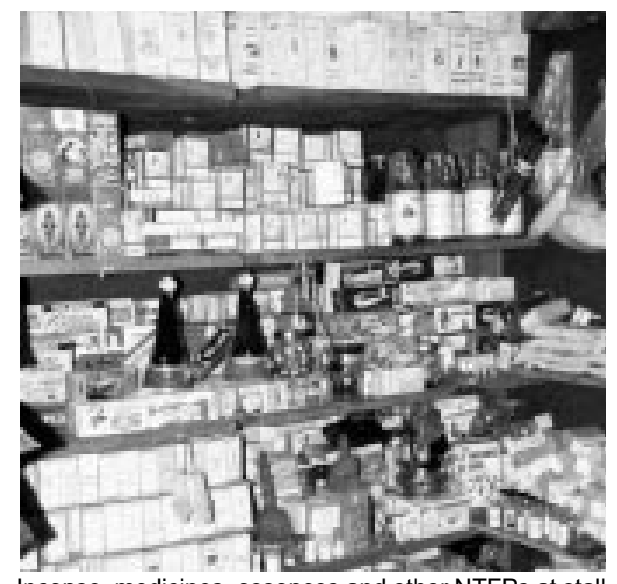

Incense, medicines, essences and other NTFPs at stall in Cruzeiro do Sul, Acré, Brazil

(Photo: Manuel Ruiz Pérez)

Particular commercially valuable N TFP species have been singled out as having potential for management on a large scale in state-owned or private forest reserves. Certain characteristics of the açai palm make intensive management cost effective (see M uñiz-M iret et al. 1996; Clay 1997b). Clay describes a natural forest enrichment practice of scattering açai seeds to encourage greater regeneration. Stands are then periodically thinned to reduce competition and individual palms are groomed to maintain stems in three size classes of three stems each. The three large stems would then be harvested on a three-year rotation. Similarly, M uñiz-M iret et al. (1996) studied the management of açai in the Amazon estuary and found that intensive management, including the thinning of competing plants, was cost effective for large areas of forest. Rattan is another example of a commercially valuable NTFP with the potential to be integrated into state-owned reserves. For two Indonesian national parks, Siebert (1995) argues that commercial rattan harvesting could becompatible with state management goals of forest protection because it is found abundantly in primary forests and can be collected with little disturbance to the forest. $\mathrm{H}$ is research findings (discussed in Chapter Five) suggest that extractive zones could be designated in the reserve and cane harvesting conducted at species-specific, growth-rate-dependent intervals.

D espite these initiatives, NTFP utilisation in state-owned forests across the tropics, whether reserved for protection or timber production, has by and large been ignored in forest management practices. $\mathrm{H}$ arvesting has often been allowed, sometimes through a permit system, but rarely have NTFPs been managed. This situation is partly a result of the general lack of forest management in tropical regions. In Latin America, Richards (1997) observes that the state has made claims of ownership over extensive areas of forest but 
has been unable to manage them. In addition, commonly in state forest reserves, NTFP harvesting is viewed as being in conflict with the goals of forest management, whether oriented toward protection or timber production. When the state does allow access through permit systems, it can be an opportunity for corruption and bribery and the source of conflict between the government forest officers and local communities (e.g. Agyemang 1994; Bhuiyan 1995; Falconer n.d.: 177). Permit systems, as Falconer (p. 194) notes for G hana, often work as a tax, not a management tool. Access to NTFPs has been prohibited in many forms of state reserves, yet it often continues illegally and unmanaged, such as in the national parks of Sulawesi, Indonesia (Siebert 1995). In mangrove forest reserves in Bangladesh, local communities who depend on extraction and marketing of NTFPs are viewed by government forest officers as threats to the forest and in need of strict control (Buiyan 1995).

Government-implemented community forest management projects are one popular strategy to divert N TFP harvesting away from state forest reserves. Appasamy's argument (1993: 260) that 'development of community lands for raising fuel, fodder, and medicinal species... would reduce pressure on the forest' is an example of this logic. Similarly, Gunatilake (1994: 25) suggests that a 'long term management plan of a protected forest should include programmes to reduce peripheral villager forest dependency'. Under this sort of approach, the strategy is to integrate local communities into the overall management of the forest by diverting demand. Instruments include the creation of buffer zones, community-based management projects and community plantations.

The research on management practices for commercial NTFPs is in its infancy, partly because research interests in NTFP commercialisation, as a conservation and development strategy, is relatively recent. It also results from the fact that the primary interest of scientific forest management historically has been timber. In this historical context, local extraction of NTFPs has often been outlawed or discouraged and rarely managed. In the past decade or so, however, new management studies have been conducted in an attempt to reduce the historic conflict between timber and N TFPs by integrating the two forest uses.

\section{Integrating Timber and NTFP Production}

Theprincipal concern of scientific forestry on state-owned forests has for decades been the production of timber products. $M$ any, if not most, national forest development plansand valuation studieshavethereforeneglected to incorporate N TFPs into management strategies (e.g. G unatillekeet al. 1993; Tewari 1994). Consequently, we know very little about the kinds of silvicultural treatments that could produce optimal combinations of timber and non-timber products 
from tropical forests. In fact, logging tends to be viewed as detrimental to N TFP harvesting (e.g. Peters 1996a). Tewari (1994) suggests, however, that although timber management has tended to destroy the NTFP potential of forests, the integration of timber and NTFPs could ensure the sustainable extraction of both. In this section we review studies that either directly examine the effects of different timber harvesting strategies on N TFPs or speculate on the potential for integrating particular N T FPsinto the management of timberproducing forests.

Research on managing simultaneously for NTFPs and timber has barely begun, in part because of a general attitude that tropical forest management is impossible. $\mathrm{H}$ artshorn's (1989) report of the timber harvesting experiments in Peru's Pichis-Palcazu Special Project has been widely cited as challenging this assumption. The results of timber harvesting experiments show potential for sustained yield management of natural forests and, by implication, for integrating NTFP harvesting. $\mathrm{H}$ artshorn points out that advances in the understanding of gap-phase dynamics - as the principal pattern of natural regeneration in most tropical forests- make natural forest management feasible. H e established demonstration clear-cut strips of $20 \times 75$ metres and $50 \times 100$ metres and allowed them to naturally regenerate. In the first plot, there were over 155 tree species regenerating after 27 months. By implication, these regenerated plots could contain numerousN T FP speciesthat could beharvested between timber rotations.

$H$ artshorn's research on sustained yield timber extraction in the tropics encouraged other studies on different harvesting and silvicultural treatments. O ne of the most carefully designed research experiments on the production and regeneration of N TFPs within timber management was conducted in the Atlantic lowland tropical rainforests of the Rio San Juan region of Nicaragua (Salick et al. 1995). The intent of the study was to quantify the abundance, density and diversity of NTFPs before and after logging and evaluate the potential for incorporating their management with silvicultural treatments. Two long-term sampling plots were evaluated by sampling all of the vegetation within random $10 \mathrm{sq} \mathrm{m}$ subplots. O ne long-term plot represented a primary tropical rainforest plot before and one year after selective logging, and the other plot represented a forest nineyears after selective logging with and without $\mathrm{H}$ utchinson Liberation Silviculture treatment (in which selected young trees are released from competition for light). Changes in ecological variables (e.g. species diversity, plant density) associated with logging, regeneration and silviculture were assessed, with particular attention on useful plant species.

0 ne year after logging there was in increase in species (from $19 \pm 5$ to 33 \pm 10 species $/ 10 \mathrm{~m}^{2}$ ) and density (from $42 \pm 19$ to $120 \pm 60$ plants $/ 10 \mathrm{~m}^{2}$ ) due to establishment or increase of secondary species (vines, grasses, balsa, cecropia) 
and seedling regeneration after logging. D ensities of vines and secondary species in particular increased dramatically with severe logging damage. $N$ ine years after harvest forest plots appeared to be returning to pre-harvest levels of species $\left(28 \pm 6\right.$ species $\left./ 10 \mathrm{~m}^{2}\right)$ and density $\left(76 \pm 21\right.$ plants/10 $\left.\mathrm{m}^{2}\right)$. H utchinson Liberation Silviculture, while promoting growth of desired timber, did not significantly affect either N TFPs or the basic physiognomy of the forest. Salick and her colleagues contrast these results with other silvicultural techniques, particularly the $\mathrm{H}$ artshorn Strip Clearcut, in which regeneration was dominated by resprouts and the proportion of vines was even higher. They conclude that Hutchinson Liberation Silviculture provides the potential for simultaneous management of NTFPs, and that their harvest can significantly reinforce silvicultural management. That is, it is possible that NTFP extraction can be combined with silvicultural treatments to reduce costs of management.

O ne possible approach for integrating N TFPs with timber management is suggested by research on the growth and propagation characteristics of particular N TFP species in South Asia. Gunatilleke et al. (1993) present results of interdisciplinary research at Sinharaja in the lowland rainforests of Sri Lanka. O ne of these findings is relevant to the

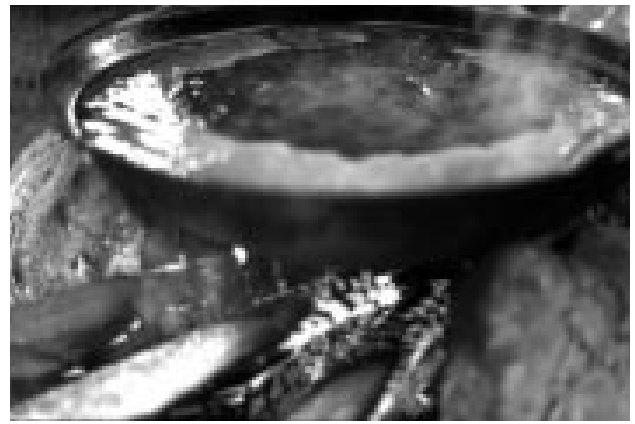

Processing palm sugar, Central Sulawesi, Indonesia (Photo: Brian Belcher) question of timber and N TFP integrated management: with increased human intervention in the primary forest, floristic richness declines but abundance of somenon-timber forest species increases. Specifically, sugar palm (Caryota urens), medicinal vine (Coscinium fenestratum), wild cardamon (Elettaria ensal) and rattans (Calamus spp.) greatly increased following selective logging. They continued to expand until the canopy closed. Wild cardamon was more common in logged sites than in undisturbed forests, and is especially common along logging trails and in locations where the canopy has been opened.

Another study in South Asia investigated the potential of tree stand improvement (TSI) practicesto raisetheproductivity of both timber and N TFPS from community forests in N epal. Karkee(1995) definesT SI as an intermediate tending operation past the sampling stage designed to regulate the growth of preselected crop trees by cleaning and liberation felling. TSI demonstration plots were laid out in a community forest in the Kaski District of $\mathrm{N}$ epal. Part of theinterest in this study comes from previous findings that some community forests are densely stocked with timber species and that silvicultural treatment would be beneficial for the production of the NTFPs required by the 
communities. The objective was to provide quantitative information on the availability of fuelwood, fodder, poles and timber that can be harvested over time under different silvicultural regimes. In the Kharchyng-Azingare community forest, six silvicultural regimes weretested: control, simple coppice system, phased coppice system, coppice with standards regular system, coppice with standards irregular system, and high forest system. The results of the study indicate that a simple coppice system will produce maximum fodder, a phased coppice system will produce high fuelwood and fodder, while a high forest system is best for poles and timber. Control had thelowest level of total biomass production.

Studies that involveexperiments specifically designed to test the integration of N TFP and timber management are rare. 0 ther research, however, has found potential for integration. Caldecott (1988 cited by W ickens 1991) speculated that management prescriptions can increase N TFP production while reducing harvesting intensity for timber in Sarawak. L ower timber yields could be offset by increased N TFP revenue and the reduction in logging would produce less ecological disruption. Richards (1993b) reports that, in forest areas of the Yucatan, logging in the dry season is combined with chicle extraction in the wet season. D eJong and M endelsohn (1992) suggest that rattan could be used for enrichment plantations in forests used primarily of timber extraction. Evaluating the potential for harvesting rattan and other less important N T FPS within permanent forest reserves in Indonesia, Van Valkenburg (1997) suggests using multipurpose tree species for enrichment planting in timber-producing forests in East Kalimantan. For example, Shorea species produce good quality timber that could be harvested on a 35-year rotation. In between rotations, illipe nut could be harvested as a commercial NTFP. He also describes the integration of planting and managing large diameter rattan with selective logging on a 35-year rotation. Large-diameter is preferable to small-diameter rattan that grows more densely and could inhibit silvicultural treatments. Timber and rattan harvesting, planting and maintenance could be combined to reduce management costs.

There are promising speculations about integrating timber and NTFP management, but few studies that experimentally test the possi bilities of different management techniques and silvicultural treatments. To a large degree, the status of research on timber-N TFP integrated management is reflective of the larger issue of a general lack of scientific knowledge for tropical forest management. Some of what is not known in the scientific literature, however, can be found in research on customary forest management. As de Jong and M endelsohn (1992) observe for Southeast Asia, many forest-dwelling societies have employed sophisticated management techniques to sustainably harvest NTFPs for generations. O ur review of this limited research, however, has highlighted the following points: 
- Although commercial harvesting of NTFPs has long taken place on state-owned forests, forest plans rarely (and only recently) explicitly address the management of NTFPs.

- Studies of logging and silvicultural practices suggest that there are opportunities for integrating timber extraction with NTFP collection for positive ecological and economic outcomes.

\section{Customary M anagement of C ommercial NT FPs}

Although stateled, scientific forest management may havehistorically ignored NTFPs, everyday forest users and customary owners have long manipulated forest plant communities to increasethe productivity of favoured N TFP species. In many cases, customary forest management practices are the result of generations of trial and error experimentation. There is no single body of literature encompassing local techniques for managing forests for commercial NTFP production. The results of research on customary forest management techniques are scattered in literatures representing a range of fields including geography, history and anthropology. W ithin these disciplines, there is a lack of data on the economic viability of managing for commercial NTFPs. As Padoch and de Jong (1989: 102) observe, it is difficult to find studies with 'production and income figures, as well as data on labor requirements that would demonstrate that local management for commercial NTFP extraction is a cost effectiveland use alternative. $M$ ore recently, however, the forest resource management literature has begun to incorporate the study of local knowledge and customary practices into research on tropical forest management for N TFP development. In this section, we will review studies of customary management of commercial NTFPsand examinethe ways in which it may bebuilt upon for further development.

A logical starting point for the investigation of customary management techniques is an exploration of the different levels of management intensity (i.e. the amount of investment of labour or capital in N TFP management). NTFPs can be managed in gardens, swidden plots, forest fallows, secondary forests and natural forests. 0 ften the level of management changes asintensively managed swidden plots becomeless intensively managed forest fallows (Padoch and de Jong 1989). M anagement practices include long-term weeding to encourage the growth or regeneration of commercially important species. For example, Padoch (1995) observed that D ayak weeding varies in timing and intensity depending on the species. Areas around durian trees are slash-weeded annually to clear the ground where fruit falls and other weeding is ad hoc to clear accessfor tapping rubber or palms. In the Amazon estuary, Anderson and Jardim (1989) documented a variety of management practices designed to increaseaçai palm production in swidden plots, forest fallows and natural forests. 
Selective pruning of açai stems and selective thinning of forest competitors are common management techniques in floodplain forests. Their research on the ecological effects of these management techniques is explored in detail in Chapter Five.

O ften, thelevel of intensity is recognised through localised nomenclatures for land. T he D ayaks of West K alimantan recognise threetypes of forest (Padoch 1995; Peluso and Padoch 1996):

1. Tembawang, or forest gardens. These are often former house sites. $M$ anagement includes occasional interplanting, weeding and clearing.

2. Tanah adat are forest reserves preserved by customary law. They have generally not been cleared, at least in village memory, but are heavily managed, including planting and selective clearing of underbrush.

3. Tanah usaha, or enterprise plots, are areas planted with highly marketable species. Rubber is by far the most important.

As in the case from Amazonia (Padoch and de Jong 1989) these plots are usually part of cyclic swidden-fallow agroforestry systems. The three managed forest types differ in their management schedules and priorities. Enterprise plots contain cash crops by definition, while forest gardens are rich in fruits and are specifically managed to produce quality construction materials and also contain marketed N TFPs.

Similarly, Anderson and Ioris (1992) observed that the level of NTFP management intensity on Combu Island in the Amazon estuary defined three major land use units.

1. H ouse gardens are the most intensively managed, typically involving the removal of at least part of the original forest. The site is planted with a variety of native and introduced plants that providefruit, latex and other products. Weeding is constant and organic material from the floodplain is frequently brought in as fertiliser.

2. Swidden plots arecultivated for oneto threeyears and then abandoned to forest fallow. Sometimes the site is managed through tree planting of useful species or by favouring their establishment. These plots are less common as the community's economy has shifted to the management of N T FPs from the third land type.

3. Flood plain forest. O $\mathrm{n}$ C ombu, this land is further divided into subcategories, açaizal, where açai palm dominates, and cacaual, where cacao groves dominate. The most common management practices in the former involve selective pruning of palm stems and the selective 
thinning of forest competitors. M anagement practices in the latter, which are the derived from abandoned plantations, is restricted to weeding at two-year intervals.

There are uncounted variations in customary management practices that have allowed the sustained harvesting of commercial NTFPs for decades. Customary management practices have been shown to increase income from commercial N TFPs, such as the in case of açai palm management in Amazonia. O ne effect of management for commercial exploitation, however, has been to reduce both thebiodiversity and biomass of açai forests relativeto less intensively managed stands (Anderson 1988). On the opposite side of Amazonia, in Ecuador, A phandra natalia, an economically valuablepalm, issubject to a variety of customary management practices to increase productivity (Pedersen and Balslev 1992). According to Quichua Indians in the region, clearing of competing vegetation promotes the improvement of fibre quantity and quality. De Beer and M CD ermott (1989) have documented a practice of rotational harvesting of sago groves that both avoids overharvesting and stimulates production by cutting only one or two trunks in each harvest cycle.

Variations in management intensity over time are often a response to the market. Padoch and de Jong (1989) note several species planted in an older forest fallow plot that are no longer in demand on the market. Anderson and Jardim (1989) document geographic variations in management intensity of açai palm in the Amazon estuary. Likewise, M uñiz-M iret et al. (1996) demonstrate that açai is managed at various levels of intensity, ranging from simple collection in natural forest stands to intensive management in home gardens. Profitability and management intensity is clearly tied to proximity to the main market. Even within a particular community, management intensity may vary considerably among forest sites of similar origin. Padoch and de Jong (1989) found that tree-planting and selective weeding (which allows for some natural regeneration) may be ongoing for years in one fallow plot, while in another, plot maintenance activities are halted after the second year of fallow.

O ne of the reasons that so little research has been conducted on the customary management of valuableN TFPsisthat outsideobservers, particularly government foresters, have only begun to notice local practices. Customary management often goes unrecognised by outsiders, partly because many of the practices are conducted in a casual manner and partly because the results of long-term management and manipulation can be mistaken for natural forests (Padoch and de Jong 1989). This is especially the case in areas whereforests are managed for diversity, such as in the Dayak-managed forests in West Kalimantan. Padoch (1995) found 224 individual trees representing 44 species 
in one $10 \times 200$ metre transect in a D ayak forest garden (tembawang). For West Africa, Fairhead and Leach (1996) convincingly argue that many of the forest patches in the savanna transition zone are not remnants of natural forests, as is commonly believed by most outside observers, but anthropogenic forests created as a result of human settlement. Both studies take pains to point out that although many naturally appearing forests arein fact derived from human manipulation, not all of the manipulation constitutes conscious management.

Based on the studies reviewed, we conclude that customary management for commercial NTFP production appears to occur least often in natural forests. There are a few exceptions in the literature. 0 ne example of commercial NTFPs that are managed in natural forests is honey and beeswax from bee keeping in M iombo woodlands in Africa (Fischer 1993). Also in Africa, G akou et al. (1994) found in M ali that the greatest number of N TFPS come from natural forests. H owever, many of these were not harvested for the market, but for household subsistence. Locally protected natural forests in the form of 'sacred' groves in Ghana are sometimes the sources of important NTFPs, especially medicinals (Falconer n.d.). The same study by Falconer, corroborated by Agyemang (1994), shows women in G hana harvest $M$ arantaceae

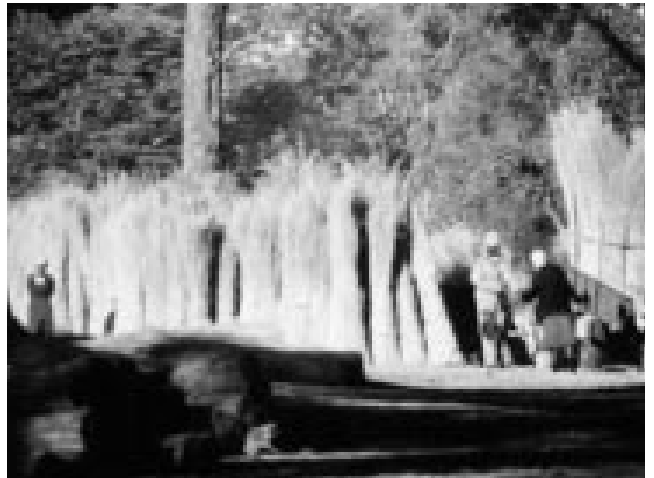

Africa's miombo woodlands provide tatching grass, wooden utensils and other products for the local market

(Photo: J. Clarke)

leaves in a locally managed rotation system in government forest reserves. In lowland Ecuador, some commercially valuable palm heart species, such as Euterpe chaunostachys, are harvested almost exclusively from natural forest stands (Pedersen and Balslev 1992).

The literature contains more examples of commercial NTFPs that are managed in secondary forests, forest fallows or swidden cultivation plots. In fact, M uñiz-M iret et al. (1996) use the term 'managed forests' as synonymous with 'secondary forests managed to produceN TFPs'. In a review of management practices in Southeast Asia, de Jong and M endelsohn (1992) document the widespread practice of intensive rattan management in secondary forests in $M$ alaysia and Indonesia. The main concentrations of commercial NTFPs are often found to be abandoned former settlements or forest garden sites (e.g. Fairhead and Leach 1996; Peluso and Padoch 1996; Peters 1996b). 
NTFP management is cost effective in customary systems partly because it is integrated with other land uses and labour activities (e.g. Padoch and de Jong 1989; Anderson and Ioris 1992; Padoch 1992b; Bishop and Scoones 1994). M ost often, incomefrom the gathering and processing N T F Psprovides a critical supplement for households, but it is not the sole means of support (e.g. Falconer n.d.). Thisstrategy of multipleand integrated production activities provides a great deal of flexibility in choosing where to direct labour for the greatest returns. Fischer's (1993) study of bee keeping in Africa's M iombo woodlands provides a good illustration of this adaptability. H oney hunting and traditional bee keeping using bark and log hives have long been part of the subsistence economy of the peoplein this region. Beekeeping is both integrated with and, in terms of time allocation, competes with other activities such as crop cultivation, hunting and fishing. Almost all bee keepers are al so farmers, but the degree of specialisation varies significantly as do the corresponding management strategies. D epending on the comparative profitability of honey at any given time or place, management intensity can beincreased or decreased. Part of the economic strategy of N TFP harvesting in the Amazon estuary is diversification, which allows for family subsistence during the rainy season when household income is low (Anderson and Ioris 1992). Fisheries, house gardening and N TFP harvesting are combined to produce viable livelihoods. Emphasis on one or another shifts seasonally.

Spatial and temporal flexibility in land and resource use iscrucial to many other customary management systems (e.g. transhumant pastoralism). This built-in flexibility could befundamentally incompatiblewith relatively inflexible scientific management systems. N evertheless, customary practices and local knowledge can be complemented by scientific, technical management techniques to increase productivity and promote forest conservation. Fischer (1993) observed that the traditional bee keepers of the M iombo woodlands had extensive and detailed environmental knowledge. Thisknowledgehas been successfully combined with new technologies, such as more efficient manufactured hives. In theSeringal Porongaba extractive reservearea, therubber tappers' association actively solicits outside technical assistance to enhance traditional market-oriented N TFP extraction (N epstad et al. 1992). We will return to theissues surrounding compatibility between customary and scientific management systems in the final section of this chapter.

Although the research literature on customary systems of commercial NTFP management is highly fragmented and incomplete, we can identify some salient points:

- The level of intensity of NTFP management is extremely variable in timeand space, even among households of the community. M any factors influencethis variability including market demand, geographic location and individual household livelihood strategies. 
- M ost customary N TFP management systems are part of larger integrated systems of land and resource use that typically involve various combinations of cultivation, fishing, hunting and gathering. This integrated land use strategy has a number of consequences for the economic viability of N TFP management, including minimising labour costs, reducing exposure to risk, and a high degree of flexibility in household production choices.

- Customary NTFP management rarely takes place in natural forests, but more commonly in swidden plots, forest fallows and secondary forests. Even when natural forests are managed for N TFP production, it often happens that the composition and structure of the 'natural' forest is actually the result of long-term human occupance.

- The long-term nature of human manipulation means that many customary management practices go unrecognised by outside observers.

\section{Participatory and C 0-M anagement}

In the past two decades there has been a worldwide movement to actively include the interests and needs of all forest users, not just timber extractors, in the management of forests. In the tropical regions, this has commonly meant that rural or forest-dwelling agricultural communities participate in someform in the management of resources from state-owned or communal forests. Participatory forest management was introduced in response to the social and political pressures applied by disenfranchised customary forest users to state forest agencies. These pressures combined with thegrowing ecological problems of deforestation and decreasing biodiversity to increase the urgency for action. Thus, in one sense, we can view the participatory approach as a responseto the perceived limits of 'scientific forestry' implemented by agents of the state (see Peluso 1992a). We need not go into the extensive literature on the meaning and practice of 'participation' in forest management here. It is sufficient to say that participation can range from the granting of limited usufruct rights to local communities to the creation of community managed forests to the comanagement of state-owned forest by special bodies comprised of government forest officers and local community residents. Participatory forestry, comanagement, joint forest management, social forestry and community-based forest management are just a few of the many terms that have been employed in labelling the general goal of local community involvement.

The goals of participatory forest management can overlap quite closely with the goals of commercial ising N TFPs for conservation and development. Participatory forest management projects often start by inventorying local nontimber uses of the forest as a way to incorporate community interests into 
planning. Almost by definition, participatory forest management incorporates some form of N TFP extraction by local residents. Yet we found a noticeable lack of research on the role of such an approach in commercial N TFP harvesting. $M$ any participatory management efforts are quite recent or arestill at the stage of gathering baseline data on N TFP uses (e.g. Appasamy 1993; W issink 1996). $M$ any reports describe projects for the participatory management of NTFPs, but few includefindings on its social and ecological effects. O ften these accounts are written by project participants who may have difficulty distancing themselves enough to critically evaluate the outcomes and consequences, both intended and unintended. N onetheless, thesecan beinsightful and useful asquasi research findings. In this section, we review these reports, along with the few studies located on participatory forest management of commercial N TFPs.

Within the tropical regions, the current interest in participatory forest management can be traced to South Asia in the 1970s. A brief review of this history, with a focus on N TFP harvesting, is a useful starting point. In India, one of the most successful initiatives in participatory management has been that of West Bengal (M alhotra 1993; M alhotra et al. 1993; G hatak 1995; Singh et al. 1997). Known as J oint Forest $M$ anagement (JFM ), participatory efforts began to emerge in the 1970s in sal-rich areas of the southwest of the state,

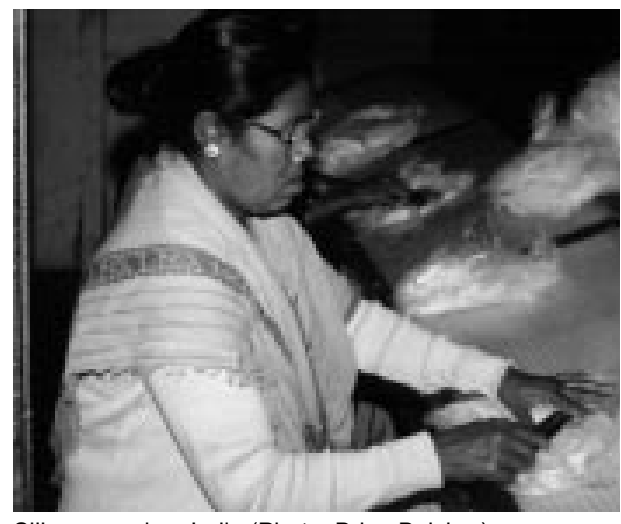

Silk processing, India (Photo: Brian Belcher) after decades of deforestation and loss of biodiversity ( $M$ alhotra 1993). In 1953, most of the natural sal forestshad been taken over by the state for scientific management (G hatak 1995). By the 1960s, the degradation of these forests and the growing conflicts between forestdependent communities and the forest staff led to the search for an alternative management strategy. Following a forest department conference in 1972,

participants urged the government to 'encourage setting up of local forest protection committees... [and] to identify the needs of forest produce of local population (sic)' (cited by M al hotra 1993: 748). T his was thefirst time 'perhaps in the whole country, that local people were involved as partners in the management of the forests' (p. 2).

Around the same period, $\mathrm{N}$ epal was also developing its version of participatory management. In 1976, national legislation was enacted to initiate community participation in the management of forest lands, and was quickly followed by further legislation 'decentralising' the management of community 
forests (G autam 1995; Fox 1995). The ensuing regulations recognised therights of villagers to manage community, or 'panchayat', forests with technical assistance from the $D$ epartment of Forests.

Variations on the theme of participatory forest management have now been established in virtually every region of the tropics. In West Kalimantan, Indonesia, a 'Social Forestry D evelopment Project' was initiated in 1990 to redress the loss of customary access with the implementation of state forest management (Graefen 1995; M aryani 1995). The project entails the creation of 'participatory forest management bodies' to manage community forests with the assistance of the forestry department. In Sub-Saharan Africa, al most every national park and many forest reserves now include local participation and community resource needs in their management efforts (N eumann 1997b). State forest agencies in Africa have established management units specifically to coordinate the involvement of communities settled adjacent to state-owned forests (e.g. Agyemang 1996).

After almost three decades, what do we know about the potential of participatory approaches to improve the management of commercial NTFP production and harvesting while simultaneously advancing socio-economic conditions in local communities? We can begin to address this question by referring to Fox's (1995) study of NTFP management that compared the forest-use practices of a village in the hills of central $\mathrm{N}$ epal at two

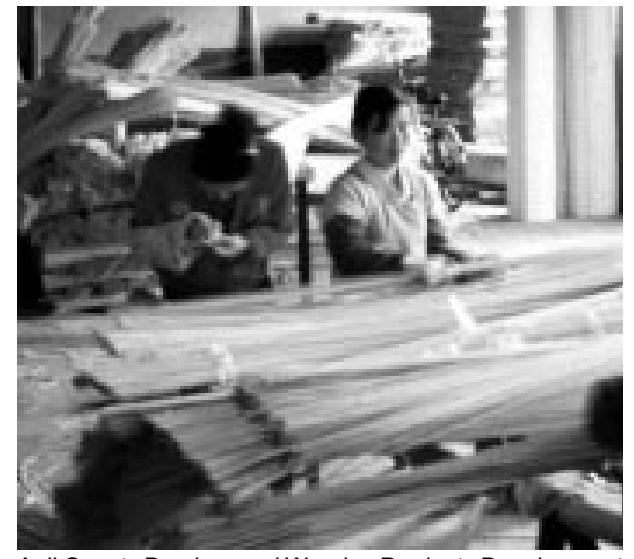

Anji County Bamboo and Wooden Products Development Co., Zhejiang, China (Photo: Manuel Ruiz Pérez) points in time: 1980 and 1990. This period coincides with theimplementation and modification of the government panchayat forest programme. In the early 1980 s, the national government transferred management of most state forests to the control of the panchayat (local government) administration. Panchayat boundaries included many villages and the forests that each traditionally had accessed and managed. But some villages found 'their' forests now legally belonged to an adjoining panchayat administration. D espitethe situation where official management of forest use lay outside villagers' control, they did create committees to manage and protect 'their' legally designated panchayat forests. Fox's study focuses on these community managed forests.

A number of events occurred between 1980 and 1990 that affected nontimber forest resources in the village. C ertain patches of forest land were turned 
over to the community through the panchayat forest regulations, a forest enrichment programme was initiated with state assistance and a road (which allowed the importation of chemical fertilisers) was completed. In 1990, a 'people's movement' overthrew the national government and as a result the decentralised but inadequate panchayat system was abolished. The forest committee no longer had to share the proceeds from management activities, such as thinning, with the panchayat leader. Forest management responsibilities were transferred from panchayat administrations to many much smaller, and much more directly involved, 'forest user groups'. As these developed, there were controversies over the rights to forest products that result from thinning, in part because the service castes were not fully represented in these groups. Gradually representation was broadened as it was realised that participation by all users was essential for effective management.

Fox found that while forest use did not appear very different, the condition of theforests themselves was much improved from 1980 to 1990 . H econcluded that this particular system of community-based management demonstrates improved both the productivity and the quality of the resource base. $\mathrm{He}$ attributes the success of community forest management to the democratisation of local government (culminating in the fall of the panchayat system), and the support of the state for community management, as well as outside interest and support.

Gautam's (1995) assessment of N epal's experiment is less optimistic than that of Fox. H esuggests that the management of N TFPs on community forests has been of limited success because it was oriented towards fodder, fuelwood and timber only. The different conclusions are partly because Fox countsfodder and fuelwood in the category of N TFPs. Gautam argues that many collectors and forest user groups in Nepal do not have the knowledge of NTFP management, processing and marketing that would allow them to take advantage of the potential benefits of commercial development. $\mathrm{H}$ e concludes that technical assistance in the form of extension services is required.

Several authors have reviewed the implementation of joint forest management (JFM) initiatives in West Bengal ( $M$ alhotra 1993; M alhotra et al. 1993; G hatak 1995; Singh et al. 1997). It is revealing to compare their findings. Success of JFM has been greatest where the for est-to-household ratio is high, the forest is dominated by rapidly regenerating sal that generates N TFP income at a relatively early stage under management, and the user populations possess local forestry knowledge and skills.

Themost recent study gives particular attention to thesocial and ecological aspects of NTFP use and marketing associated with JFM . Singh et al. (1997) stress the importance of a supportive, leftist state government in providing the political environment for implementing new institutions for community- 
oriented forest management in the 1980s. For example, in 1986 the forest department agreed to share $50 \%$ of the usufruct from some plantations with poor rural populations. M uch of the usufruct from these and other forests is in theform of N TFP harvesting for both subsistence and cash income. Ecologically theimplementation of JFM coincided with increased natural regeneration and a rise in the proportion of forest cover. The study showed, however, that the socio-economic impacts of JFM are mixed - women's involvement in management has not been significantly increased. The authors conclude that because of the heterogeneity of rural communities, many questions regarding social equity remain to be addressed by further institutional changes, especially in the area of property rights in forests.

Two studies separately corroborate these findings. M alhotra (1993) al so found positiveecological outcomes associated with theimplementation of JFM in West Bengal. He noted that through membership in forest protection committees (FPCs), local villagers participate in forest protection in return for free N TFP usufructs, first preference for employment, and a promise of a $25 \%$ share in the net cash benefits from sale of short rotation sal poles. The Forest D epartment provides financial assistance and technical expertise to FPCs. According to $\mathrm{M}$ alhotra, these material inducements and support have encouraged more careful management of sal forests, resulting in increased forest cover and biodiversity. In southwest Bengal G hatak (1995) found mixed results in thearea of women's involvement similar to those of Singh and Singh. G hatak's research emphasised women's current and potential rolesin N TFP management within thestate-sponsored programme of JFM . Villagersadjacent to JFM forests can become members of official forest user groups (i.e. FPC s), entitling them to earn income from forestry labour, help government in protection activities, and take part in management decisions.

Until recently, the role of women in NTFP collection, utilisation and management in rural India has been ignored, but it is now widely acknowledged that women are the primary users of forests. Since women spend much more time in the forest than men, they were granted the right to become official FPC membersin 1991 under a 'joint membership' rulefor husbands and wives. The main commercial NTFPs in the region are sal and tendu leaves, with plates made from sal being the most important income-generating activity for women. D espite the importance of women's roles, training programmes, marketing assistance, credit programs and other services often ignorethis group. Even though women are official FPC members by law, voting rightsarelimited to oneper family. Themen of thehouseholds usually takethe votes and women's opinions are rarely considered under this system. G hatak concludes that government foresters lack the skill and training needed to encourage women's participation in forest management. 
Rao and Saxena (1996) examined the management of NTFPs in three remote villages of the $\mathrm{C}$ entral $\mathrm{H}$ imalayas, $\mathrm{U}$ ttar Pradesh, India. They noted that scientific management of the state-owned forests structured a choice between either conservation (on ecologically sensitivelands) or timber extraction and did not incorporate customary NTFP extraction in a rational manner. That is, the state allowed the harvesting of NTFPs on a four-year rotation without any scientific data to justify the cycle. In contrast, panchayat forests scheduled NTFP harvesting of medicinal plant products on a 12-year cycle, suggesting that the government's 4-year cycle may be too short to sustain harvesting. $M$ anagement practices differ between government-owned forests and village community-owned forests and local communities were found to be more conscious of sustainable utilisation of the forests they own and manage.

In Sub-Saharan Africa, Agyemang (1996) was more positive about state efforts to encourage women's participation in management. He describes a pilot case study of participatory management of a state-owned forest reserve in Kwapanin, Ghana. For many of the women in Kwapanin, gathering foodwrapping leaves from the forest reserve provides a vital, sometimes the only, means of livelihood. D uring the 1980s, an atmosphere of mistrust characterised the relationship between leaf gatherers and the Forest D epartment. Villagers' complaintsincluded cumbersome collection permits (for collecting within the reserve), frequent bushfires coming from the forest, and little face-to-face relationship with Forestry D epartment officials.

To address these problems the Forestry D epartment, through its Participatory Forest $M$ anagement $U$ nit (PFMU), initiated an NTFP management experiment. Prior to the experiment, women leaf gatherers had organised themselves into an association with an appointed spokesperson. The PFM U worked through this association to implement a registration system that gave much responsibility for monitoring the activities of gatherers to village institutions, notably the chief and the government's representative in the Committee for the Defense of the

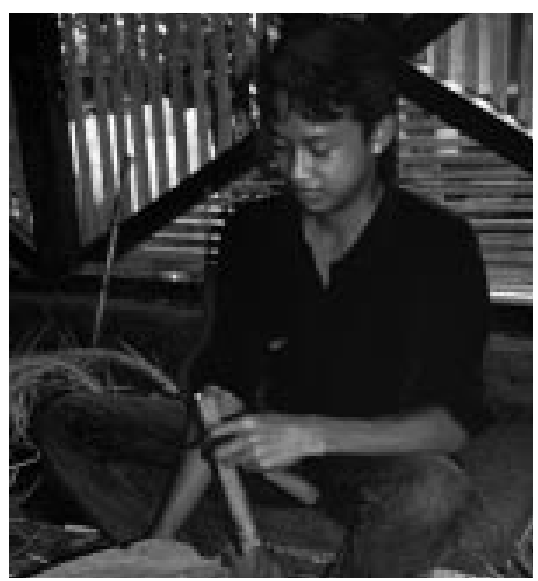

Making traditional bamboo music instruments, Tasikmalaya, West Java, Indonesia

(Photo: Manuel Ruiz Pérez)

Revolution. Agyemang believes the experiment established that NTFP users were capable of conducting themsel ves responsibly in the reserve and becoming effective partners in forest management. It also helped to improve solidarity among leaf gatherers and relations between gatherers and the Forestry 
D epartment, as well as raising the social standing of the women's leaf-gathering association within the community.

A Papua N ew Guinea effort to include women Galip nut (Canarium indicum) collectors in forest management has not yet had such positive results as the case from G hana (W issink's 1996). T he K andrian G loucester Integrated D evelopment Project, a five-year rural development project funded by AusAID, aimed to create a galip nut industry in W est $\mathrm{N}$ ew Britain Province. The project began in 1993 with the goal of providing increased wage-earning opportunities for women while conserving $C$. indicum, a traditionally significant and commercially valuable timber resource. The central plan was to offer the customary owners of communal forests an alternative to logging. Despite the programme's objectives, most of the galip nut sellers so far have been men, purportedly because women collectors in remote villages do not travel to the market sites. Wissink identifies a number of structural constraints inhibiting women's participation including disadvantages in education and political power relative to men, cultural restrictions on women's travel, and little experience working as paid labourers.

Also in Papua N ew Guinea, O Isson's (1996) report on a project to collect and market okari nuts offers insight on the difficulties of integrating fundamentally different decision-making processes into participatory forest management. C ritical to this project was a participatory model that addressed the perspectives of both outside advisers (who wish to move quickly based on decisions made by a group of representatives) and local stakeholders (who wish to consult and create consensus within the groups they represent). The solution was a two-tier process that entails both local village meetings (including everyone) and higher-level meetings (including only village representatives). O Isson suggests that an important lesson learned in this project is that traditional clan organisation should influence the management structure. The enterprise is moving from a strong central management to greater independence within its various zones. Also important to the enterprise's development was the printing, packaging and oral dissemination of community knowledge about current practices, appropriate technologies and various forms of baseline data.

Finally, two studies of Indonesia's Social Forestry D evelopment Project (SFDP) in Sanggau, West Kalimantan, suggest limits to the compatibility of partici patory management initiatives and efforts to promotecommercial N TFP extraction (Graefen 1995; M aryani 1995). The project is creating Participatory Forest $M$ anagement Areas (PFM A), with supervision from government, villages and agroforestry groups. Within the areas, communities will have long-term usufruct rights to forest lands under direction from the M inistry of Forestry (M aryani 1995). H owever, the development of marketable N TFPs from the highly diversified polyarchic forests of the region is difficult (Graefen 1995). The SF D P conducted a basic inventory of candidate N TFPs for commercial 
development. Three products not currently traded from this area (bamboo, rattan and damar) were considered worthy of further study. G raefen concludes that numerous obstacles must be overcome in the development of potential NTFPs in Sanggau's species-rich forests. He suggests that timber extraction combined with the intensive cultivation of NTFP species would be the most economically efficient objectives of participatory forest management.

Based on this set of studies and reports, we can identify several findings critical to the use of participatory management approaches to NTFP commercialisation.

- The results of participatory efforts can be quite uneven, both within and between particular management systems. Theecological conditions of the forest, for example, may be improved while socio-economic conditions for forest users may remain unchanged or even be worsened.

- The relative success of participatory forest management may, to a great extent, depend upon political and economic forces well beyond the control of a particular project. These forces might include a socially progressive central government or a grassroots democratisation movement.

- Communities are heterogeneous and NTFP-related interests may be fragmented within the community and may conflict along gender, class or ethnic lines. Participatory management efforts can bring these fissures to the fore of community social relations or even produce new fissures.

- There is a potential contradiction or even paradox in attempts to incorporateand be sensitive to local institutions and customary practices while at the same time targeting under-represented social groups for participation. For example, encouraging women'sinvolvement in forest management in communities that are strongly patriarchal implies a major transformation of existing cultural values, socio-economic structures and political institutions. In the cases from West Bengal and the Kandrian G loucester Project in PN G, women were targeted for involvement, but the programmes have as yet failed to truly integrate women's because of existing gender roles and gendered power relations within the communities.

- The incorporation of pre-existing institutions is important for the successful involvement of local communities (hence, the paradox mentioned above). In Ghana, the participatory forest management initiative operated through the existing leaf collectors association which in turn was linked to both customary and government political institutions. In the okari nut project in PNG, clan-based political institutionsutilising consensus were left intact but institutionally linked 
to a more westernised system of representative decision making. We will return to some of these questionsin the $M$ anagement I ssues section of Chapter Six.

All local communities do not necessarily possess the organisational skills and technical knowledge to conduct forest management for NTFPs. Some products historically may not have been economically important enough to have warranted the development of community based-management systems (Edwards 1996b: 37). Sometimes, as Lynch (1995) notes, community-based management projects owe their existence to third-party interventions (e.g. NGOs) which have helped with training and finance. Some aspects of community-based management, such as the effort to involve women forest users, may bealmost totally 'donor-driven' in many instances (Stephens 1995).

\section{Summary}

The focus of this chapter has been research that addresses the techniques, practices and formal institutional structures for the management of commercial NTFPs. We found that there have not been many studies on explicit state initiatives to manage commercial NTFPs, in part because there are in fact few stateled initiatives. Perhaps the most promising research results of state initiatives are found in analyses of management practices designed to integrate timber extraction with commercial NTFP harvesting. Conclusions indicate that silvicultural treatments can enhance the production of someN TFPs while simultaneously allowing for sustained timber harvesting.

The literature on customary management systems reveals a wide range of intensity both within and among forest communities. Intensity varies along multiple axes of social, economic, geographic and ecological factors. These include the distance of the NTFP source from dwellings, proximity to the market, the commercial value of the N TFP, thenature of ownership and access rights, the natural productivity of a particular forest area, and the temporal position of the land in the swidden cycle. In addition to the complexity of the possible combinations of thesefactors, the overall livelihood strategy of a forest community or household has a great influence on how much labour time is invested in N TFP management. That is, N T FP management practices can be integrated into other land use activities such as farming and hunting. What often makes customary management practices cost effective is the fact that they are carried out in conjunction with other activities.

Implementation of state co-management initiatives in South Asia has often been followed by improved ecological conditions of theforests. The research is inconclusive, however, with regard to the precise causal linkages between comanagement and ecological conditions. Most of the studies reviewed 
nonetheless suggest that participation and benefit sharing with local forest communities has resulted in more careful management with a subsequent increase in forest cover and increasing biodiversity. The socio-economic effects are less predictable, with many co-management initiatives neglecting the interests of large portions of forest communities. In terms of the distribution of social and economic benefits of commercial NTFP management, those initiatives that incorporate pre-existing institutions and organisations appear to have the most positive outcomes. 


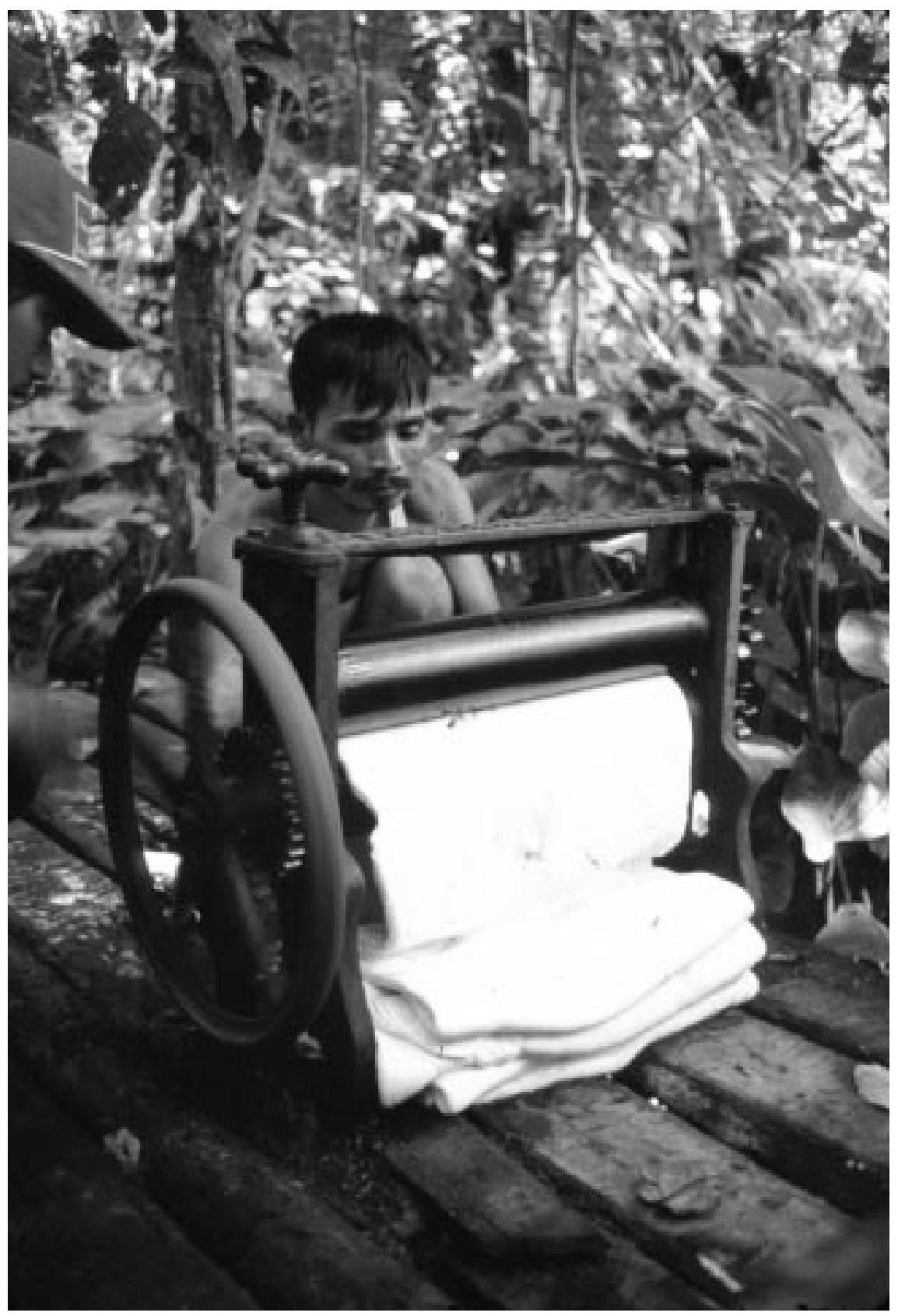

Latex processing in Central Kalimantan, Indonesia (Photo: Christian Cossalter) 


\section{Chapter Five}

\section{Ecological Aspects of N T FP Commercialisation}

The current wave of policy interest in marketable NTFPs is not the first of the modern era, although one may argue its character is historically unique. The initial search for useful N TFP species drove much of Europe's scientific explorations and economic enterprises in the tropical regions at least since the late 18th century (G rove 1995). D uring the era of European colonialism, colonial foresters, district administrators and agricultural officers were dutifully collecting information on local knowledge and uses of forest products and calculating their potential contributions to state revenue or private profit. Rubber, beeswax, quinine and gum arabic were just a few of the NTFPs from that early wave that helped fuel the expansion of the European empire and industrial growth. Today, however, the interest in NTFPs has shifted to emphasise - in some cases, to privilege - the potential ecological benefits of commercial harvesting. The startling rates of conversion of tropical forest lands and the associated negative effects on biodiversity over the past three decades have pushed scientists, government policy-makers and forest communities to search for new land use models. Extractive reserves exemplify the basic logic of these new models - that biodiversity can best bemaintained by linking it to people's economic self-interests. Commercialisation of N T FPs for forest conservation and biodiversity maintenance has thus been at the centre of the debates on the best policy directions.

In this chapter we examine the empirical evidence on the interactions of commercialisation and forest ecology, with special attention to biodiversity conservation issues. In assembling the literature, we concentrated on field studies that in someway addressed the ecological aspects of commercial N TFP exploitation. For most researchers, the central ecological question in any system of commercial exploitation is how much of the resource can be harvested without diminishing its capacity to regenerate or degrading the environment. In other words, the current interest in the link between forest ecology and NTFP commercialisation can beviewed as the most recent application of the principle of maximum sustained yield in forest management.

We begin the chapter in the area of ecological effects that result from commercial N TFP extraction. The studies were divided into those that found negative ecological effects and those that found neutral or positive outcomes, 
giving special attention to the roles of market, institutional and ecological conditions. We then look at the relationship between commercialisation and ecology in theother direction, focusing on findings that indicate how ecological conditions influence the potential for successful N TFP commercial isation. In the last section we focus on the methodological issues, examining how causal linkages between ecological conditions and commercialisation are demonstrated (or not) in this research.

\section{Ecological Effects of C ommercial H arvesting}

In this section we review the empirical evidence on the ecological impacts of commercialisation. of the cases (mostly field studies) reviewed, the majority (about 66\%) reported generally negativeimpacts from commercial harvesting. $\mathrm{H}$ owever, the negative findings of the majority of the studies should be interpreted with caution, not least because our sample of cases is not statistically representative of the population of all cases. Even if it were, there remains a problem of drawing conclusive generalisations since it is far easier to design research to demonstrate the presence of negative ecological impacts than their absence. With this cautionary note in mind, we have presented these studies by separating them into those with negative ecological findings and those with findings of minimal or no negative effects. N egative effects for our purposes generally means resource depletion, though somestudies attempt to document or predict environmental degradation more generally, particularly declines in biodiversity.

\section{Negative Ecological Effects of N T FP C ommercialisation}

$\mathrm{H}$ ere we summarise and categorise the types of negative effects of NTFP commercialisation. In addition, sincemany of thestudies cited (including field studies, historical studies and reviews) attempt to explain the social, economic or biological forces underlying resource depletion and habitat degradation, we make an effort to categorise explanations as well. For heuristic purposes, we use these categories of explanation for our review. While recognising the difficulties of singling out one causal factor, we have classified the literature based on each study's emphasis on one of three explanations: market, institutional or biological conditions.

O ne of the most common ecological concerns expressed by researchers is that the creation of new or the expansion of existing market demand for N TFPs will led to overharvesting and resource depletion. O ne interesting laboratory for examining the effects of the creation of new markets for NTFPs, where almost noneexisted previously, isfound in southern Africa. Several studies and overviews of a relatively new handicraft industry in basketry in the region 
document a rapid rise in demand for wild sources of fibre and dye over the past two decades (Terry 1984; Terry and Cunningham 1993; Bishop and Scoones 1994). The emergence of commercial handicraft basket production in southern Africa can be traced to $\mathrm{N}$ gamiland, Botswana, where it was established as an economic development project for a $\mathrm{H}$ ambukushu refugee population. $\mathrm{H}$ ambukushu manufacturing of baskets for export began in the early 1970s with the creation of the Botswana buying and marketing parastatal, Botswanacraft M arketing Company. Basket-makers responded by creating more complex and distinct designs that were more appealing to an export market (Terry 1984). In other parts of

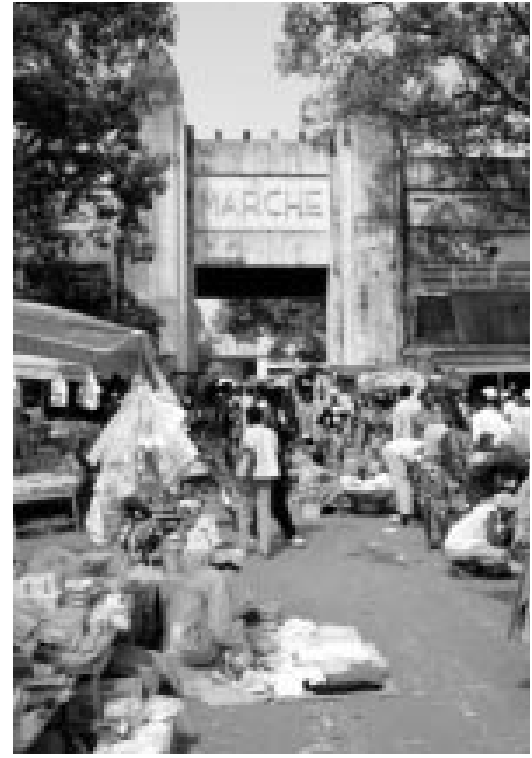

Old market, Burkina Faso, Africa

(Photo: Christian Cossalter) southern Africa, thebasket-making industry is even more recent. In theZambezi Valley in Zimbabwe, commercial production among the Tonga began in 1984 with about 20 weavers. Five yearslater there were 200 weavers producing baskets for sale (Terry and Cunningham 1993).

Ecological problems have accompanied the rapid growth of the industry in southern Africa, including resource depletion from destructive harvesting techniques and overharvesting. The resource base for basketry in the region includes at least 30 indigenous species for fibre and another 22 species for dyes (Terry and Cunningham 1993). These resources are coming under increasing pressure as the market expands and scarcities are being reported in several countries. In western Zimbabwe, a weaving club started in 1986 with 20 members and expanded to 500 by 1988, resulting in the diminished availability of a resource that had been previously viewed locally as unlimited (Terry and Cunningham 1993). In the case of N gamiland, mbare palms (H yphaene ventricosa), the source of fibre, became scarce within a few years of the start-up of basket-making. By the late 1970s, a group of specialised collectors had emerged to bring palm leaves from ever more distant areas (Terry 1984). Furthermore, an estimated $40 \%$ of these basket-makers engaged in harmful harvesting techniques that involve wholesale cutting of the trees rather than selective leaf harvesting that would allow continued growth. Likewise, the study by Bishop and Scoones (1994) of basket production in two N gamiland sites, 0 gxe and Wabe, demonstrates how the degree of resource depletion depends on theharvesting technique. In Wabeharvestersarenon-selectivein their cutting 
and use destructive tools (hoes and axes). As a result, harvesting pressure has threatened the supply of palms.

Two historical studies from quite different ecological settings provide further evidence of the dangers of resource depletion associated with a rapid rise in demand on the international market. The first analyses the case of the 19th-century gum arabic (Acacia senegal) trade in West Africa to demonstrate how increased commercialisation of an NTFP may lead to environmental degradation. $\mathrm{H}$ anson (1992) details the rise and decline in importance of gum arabic trade in the Senegal River area from the late 18th century to the 20th century resulting from the interrelated factors of unsustainable harvesting, repressive labour conditions and shifts in the world market. H e speculates that increasing market demand for gum arabic led to both an increase in labour demand - met by slavery - and destruction of the resource by overharvesting. In combination with the substitution of synthetics on the world market, this brought about the decline of production in West Africa and a shift in the centre of production towards the interior of the continent.

A second historical examplecomesfrom Clay's(1997b) detailed description and analysis of the ecological sustainability of açaí pal $\mathrm{m}$ (Euterpe oleracea $\mathrm{M}$ art.) heart harvesting in the Amazon estuary in Brazil. Palm hearts were first introduced on the international market in the 1950s. H arvesting to meet the increased demand for export 'led to the collapse of the palm heart industry in southern and eastern Brazil by the end of the 1960s' (p. 290). As in the case of gum arabic, the response to resource depletion was a geographical shift in production. In the 1970s, extraction moved to the Amazon R iver estuary where açaí grows in dense natural stands. A pattern of 'cut and run' continues in the new extraction zone whereby processing factories move from site to site as the surrounding resources are depleted. C lay cites the facts that shortages in supply are occurring and that the average size of marketed palm hearts has declined over the previous 20 years as evidence of continuing ecological degradation.

O ne of themost detailed studies of ecological impacts we reviewed attempts to document the effects of commercial N TFP extraction on the structure and composition of a dry deciduousforest in the Biligiri Rangan $\mathrm{H}$ ills, India (M urali et al. 1996). Specifically, the objectives were to ascertain the amounts of major NTFPs gathered per unit area, to determine the relative abundance of N TFP species, and to examine the impact of extraction on the population structure of extracted species. Thestudy was conducted around a hamlet of 92 households of members of the Soliga group, one of the indigenous tribes of south India. Two sites were chosen, one close to the settlement and one distant. Five onehectare plots were sampled in each of the sites. The frequency of different size classes indicates that overall regeneration is poor in the area. Proximal sites, where extraction is higher, showed higher tree mortality and fewer species. Furthermore, NTFP species showed a greater deficit of small size classes than 
the timber forest species, suggesting that regeneration is affected by collection of seeds and fruits from NTFP species.

The occurrence of negative ecological impacts resulting from expanding markets is closely associated with a second group of explanations: institutional conditions. This category includes property regimes and government regulatory mechanisms. The studies reviewed above appear to define a common pattern of property regime whereby an N TFP with a history of little or no commercial value is not subject to well-defined and enforceable claims of ownership and control. ${ }^{9}$ The problem of overharvesting quickly emerges because there are no existing controls on access and, therefore, a situation of open-access exists simultaneously with rapidly rising commercial value. A study assessing the economic and ecological effects of NTFP extraction in three districts of N epal found that residents are aware that there has been a gradual decrease in the amount of NTFPs available (Karki 1995). The development of market infrastructure over the last 30 years has encouraged overexploitation. The main problem for resource conservation is rising market demand, combined with ill-defined and misassigned property rights. This translates to a lack of incentives for individuals to conserve these resources for long-term use.

In the Peruvian Amazon, a local informant recalled how all the largest Croton lechleri (Euphorbiaceae) trees were felled by outsiders with no tenure claims for one-time commercial extraction of medicinal products (Phillips 1993). The immediate result of this situation is localised resource depletion and scarcities. Rising market demand may also undercut the resourceconservation role of existing property systems, as C unningham (1990a) suggests in his study of the ecological effects of sap tapping for two palm species, $\mathrm{H}$ yphaene coriacea and Phoeni $x$ redinata, in the $\mathrm{M}$ aputaland area of northeastern South Africa. Even though well-defined property rights have been long established there, the rapid shift from subsistence to a 'consumer approach to tapping' is leading to higher extraction rates and the possibility of resource depletion. Finally, Southgate (1998: 47) offers the 19th-century example of Cascarilla roja (Cinchona spp.), a natural source of quinine, as a case where rapidly rising demand led to resource depletion and the collapse of extractive activities.

The absence or weakness of institutions, customary or government, that can monitor and control the extraction process is another factor identified as underlying the adverse effects of commercial extraction. In this discussion, we include social institutions related to the possession and dissemination of knowledge of extraction techniques. Studying the sustainability of the extraction

\footnotetext{
${ }^{9}$ Systems of land and resource tenure and their relationships to commercial NTFP extraction are addressed at greater length in Chapter Two.
} 
of chicle latex (M anilkara zapota) in the M aya Forest Reserve, Guatemala, Dugelby (1998) detailed the organisation of labour for extraction, pointing out that $40 \%$ to $50 \%$ is migrant labour. She found important differences in the harvesting attitudes and techniques between local and migrant extractors; migrants tap a significantly greater proportion of available trees, leaving fewer for the next year. M igrant workers (whose proportion is increasing in thelabour force) are less affected by customary rules, less knowledgeable and less concerned with sustainability issues.

Another analysisthat providesimportant detail about the effect of labour organisation on the extraction process is by Cunningham and $\mathrm{M}$ benkum (1993) who focus on the harvesting of Prunus africana bark in Cameroon. Initially, a private company, Plantecam M edicam, had a monopoly on harvesting and employed its own harvesters, many recruited from theD shang region in western Cameroon. Workers were (and are) trained to harvest carefully and face dismissal if they are caught taking all of the bark from a tree. In 1985 the government licensed an additional 50 Cameroonian entrepreneurs to harvest the bark. Sincethen, the quantity of bark harvested has been increasing. Local harvesters interviewed express concern over both the killing of $P$. africana trees and the preferential employment of outsiders as harvesters. A partial ban was placed on harvesting in 1991 as a result of tree die-off from excessive bark removal and tree felling, a situation that the authors link to the influx of new extractors who have poorer knowledge, skill and attitudes towards sustainable extraction.

Clay's description of cut-and-run açaí palm heart (Euterpe oleracea $M$ art.) harvesting in Amazonia highlights the problems of monitoring and controlling the extraction process in order to minimise ecological impacts. In a word, there are powerful 'disincentives' (Clay 1997b: 300), some of them institutional, to using careful harvesting techniques. First, in the area where harvesting is concentrated, land tenure is commonly uncertain and ill-defined. Conditions of open-access often prevail. Second, small-sized palm hearts, though illegal, are readily saleable to processors due to weak enforcement of regulations. Third, the physical conditions of extraction are conducive to non-selective harvesting; once an extractor has made the arduous trip through undergrowth to reach the açaí, he will have little incentive to cut selectively (p. 300). Combining all of theseconditions, it is easy to see the rationality of overharvesting.

The biological characteristics of NTFP species, our third category of causal conditions, have an important influence on the potential for commercial extraction to result in negative ecological impacts. We refer to Clay (1997b) once again and his analysis of açaí palm heart extraction. 
Several species of Euterpe are harvested for hearts. Euterpe edulis is singlestemmed, so the individual plant does not survive harvesting, and natural stands can be quickly decimated. This species characteristic was a major factor in the relatively rapid collapse of theindustry in southern and eastern Brazil when harvesting for an international market began in the 1950s. Euterpeoleracea, on the other hand, is a multistemmed species and so hearts can be extracted without killing theindividual plant. Similarly, in thestudy of palm tapping in South Africa (Cunningham 1990a) both palm species, $H$ yphaene coriacea and Phoenix reclinata, occur in multistemmed clumps which survive tapping though individual stems may be killed.

Commercial bushmeat harvesting is an activity where biological characteristics influence individual species tolerances for higher levels of extraction. In Equatorial Guinea, West Africa, Fa et al. (1995) assessed the impact of commercial hunting on forest mammals. Their model included individual species biology, notably reproductive characteristics, to estimate potential productivity and harvestability. Rodents had high production figures and primates low figures. Species vulnerability to overharvest correlates strongly with their intrinsic reproductive potential. Similarly, FitzG ibbon et al. (1995) examined whether hunting and trapping off-take exceeds sustainable harvest rates of several small and large mammal species in Arabuko-Sokoke Forest, Kenya. Their findings suggest that harvesting has reduced the populations of primates and large ungulates while smaller species are harvested at sustainable rates. Again, differences in reproductive rates are among the main factors influencing the relativeimpacts of hunting.

An historical case study of commercial wildlife exploitation reinforces the importance of biological characteristics. Farrow (1995) employed an established economic model of extinction to examine the cases of the extinction of the passenger pigeon and the near-extinction of the American Bison. The historical evidence points to the importance of biological and ecological characteristics of individual species, such as habitat requirements, reproduction rates and minimum viable population size, in determining the possibilities for a non-extinction equilibrium.

M ost of the studies cited throughout this section focus on the impacts of commercial harvesting on populations of individual NTFP species. Other research, particularly on fruit or seed harvesting, has attempted to document or model the effects on community function and structure. N egative system effects include declines in nutrient supply, decreased system productivity and decreased biodiversity (H all and Bawa 1993; Shankar et al. 1996; O 'H ara 1998). In a continuing study to monitor the huano (Sabal mauritiiformis) harvest in the Río Bravo Conservation and M anagement Area of Petén in northwestern 
Belize, O 'H ara (1998) noted that this palm concentratessignificant amounts of potassium in its leaves. M onitoring the effects of long-term extraction on soil fertility is therefore critical to understanding system effects. Shankar et al. (1996) gathered data on the productivity of amla trees (Phyllanthus emblica), and the links between productivity and levels of extraction in India. Analysis indicates that approximately $13 \%$ of the fruits are commercially harvested (though this may be an underestimation). The authors speculate that fruit harvesting above some unknown threshold could have negative ecosystem

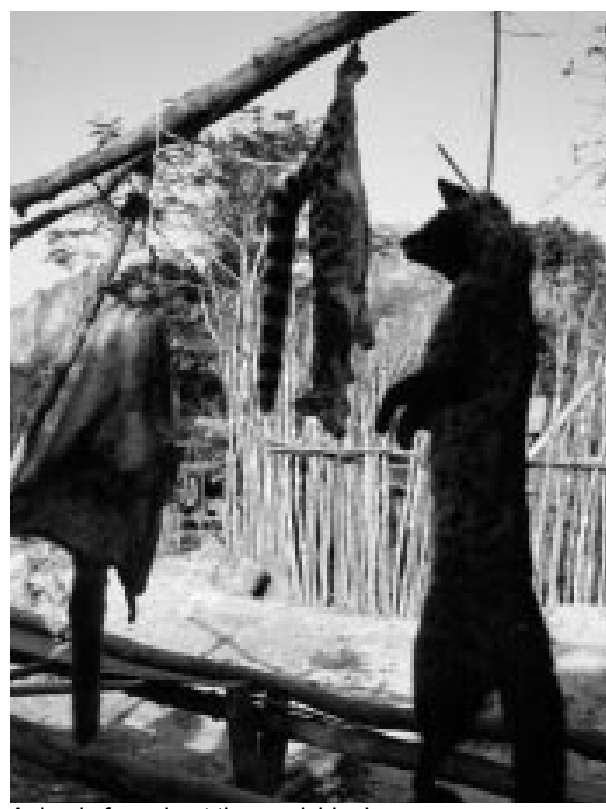

Animals for sale at the roadside, Laos (Photo: Brian Belcher) impacts by depriving wild animal species of an important food source. Bushmeat harvesting has the potential to al ter ecosystem structure and functioning where one or more important animal species are depleted (e.g. Fa et al. 1995; FitzG ibbon et al. 1995; Jorgenson 1998). H all and Bawa (1993: 246) point out that the harvesting of animals that 'act as pollinators, seed dispersal agents and herbivores... can influence... community level processes'. In the M aya Forest in Q uintana Roo, M exico, Jorgenson (1998) speculates that hunting may affect the forest biological community because of mammals roles in seed dispersal, herbivory and seed predation, and predation of other animals.

Even those studies that raise questions about system-wide effects of commercial extraction do so based on extrapolating from the empirical results of one to a few NTFP species. In fact very few of the research designs we evaluated directly measure ecosystem effects. While M urali et al. (1996) attempted such measurement in the Biligiri Rangan Hills of India, they could not definitively separate commercial extraction from other influences on the forest ecosystem. NTFP species showed a greater deficit of small size classes than the timber forest species, suggesting that regeneration is affected by collection of seeds and fruits from NTFP species. They note, however, that other factors beside NTFP extraction could be influencing diversity and regeneration including soils, microclimate, historical land use, fire, and grazing. Hence, even in well-designed field studies it is difficult to single out causal factors in environmental change and degradation. 
O $n$ an Amazonian site, Nepstad et al. (1992) compared biotic impoverishment for three different land uses: N TFP extraction, ranching and logging. Their findingsindicate that Brazil nut is the only tree species that may beundergoing population decline through extractor activities. H owever, a much larger percentage of the forest $(90 \%)$ remains intact through N TFP extraction than is the case through logging $(50 \%)$ or ranching $(50 \%)$. Forest conversion to pasture, practised by both ranchers and, to a lesser extent, N TFP extractors, clearly provokes the greatest biotic impoverishment of the activities examined; it can virtually eliminate the native biota, reduce carbon storage in biomass and alter hydrology. Differences in biotic impoverishment among the three land uses are related to the amount of forest canopy removed and the ability of the forest to recover from each usage. I mportant forest functions (e.g. energy exchange, carbon assimilation) 'are altered by logging and cattle ranching approximately five times more than they arealtered through N TFP extraction' (N epstad et al. 1992: 9).

\section{Neutral Ecological Effects of N T FP C ommercialisation}

In this section we review the studies that indicated minimal or no negative effects from N TFP commercialisation. For the sake of consistency in theanalysis, we havealso organised this section by type of explanation. T hus we present the literature grouped according to emphasis on one of three explanations: market, institutional or biological conditions.

$M$ arket conditions generally do not play a significant role in the research that identified neutral or minimal ecological impacts from commercial exploitation. If any generalisation can be made from such a small sample of cases, it is that the absence of a well-organised market for N TFPs results in the underutilisation of natural productivity and therefore little ecological impact. Boffa et al. (1996) examined the socio-economic and ecological aspects of commercial shea nut (Vitellaria paradoxa) harvesting in southern Burkina Faso. Thisstudy assessed shea tree production, the economic value of nut production at the farm level, and local collection practices. The research was carried out in the environs of a village. $N$ ut harvest over two years amounted to less than half of nut production, suggesting that farmers do not fully utilise this resource. The authors therefore concluded that a demand-driven approach is needed to revitalise the shea nut market, along with expansion of the export market.

From N epal, O Isen (1997a) concluded that even under market conditions of high demand, irreversible biotic impoverishment is unlikely to occur. $\mathrm{He}$ questions the accepted view in N epal that the harvest of commercial N TFPs is unsustainable and endangering a large number of species. Examining species within their specific NTFP-related management systems indicates that no species is threatened with extinction from commercial collection because 
economic extinction (i.e. when costs of collection outweigh benefits) precludes botanical extinction. Further, if returns from collection of a species remain competitive over a period of time and availability decreases significantly because of excessive harvesting, the species is subjected to domestication and/or cultivation. Finally, although there are examples of local resource depletion, only one species (Swertia chi rayita) is generally harvested unsustainably. Since commercial collection is highly unlikely to lead to species extinction, it may be acceptable, according to $\mathrm{O}$ Isen, for certain species to decline in particular areas at particular times.

Recent studies of new institutional forms (the second explanatory factor) that combine state and local community structures indicate positive effects of commercial extraction on forest ecology. In effect, these new forms attempt to balance local rights of access with state ownership and control over forest resources. This initiative can be traced to the development of 'social forestry' policies in thetropical countries, especially in South Asia in the 1970s (Freeze 1998). The emphasis on local forest management and the creation of comanagement institutions was in part a policy response to the ecological degradation that occurred under state institutions of forest control. The evidence presented in a review of participatory forest management (PFM) initiatives in West Bengal, India, suggests that degraded forests can be regenerated through fundamental institutional changes, including increased access to commercial NTFPs (Singh et al. 1997). The post-colonial state's attempt to control forests resulted in antagonistic relationships with forest villages and a de facto open-access situation. Vast areas of forest in the region were subsequently degraded.

Following the period of forest degradation, the state initiated a set of institutional reforms including revenue sharing and free access to N TFPs for forest villages (Singh et al. 1997: 64-68). NTFP access was an especially critical reform because of the importance of commercial harvesting to local incomes. Several positive ecological effects were seen as the result of the establishment of PFM and associated reforms related to N TFP access. For example, the area of forest cover has been increasing in West Bengal. Satellite imagery indicates that the land area in closed forest cover in one district has nearly doubled in a six-year period. $N$ atural regeneration is occurring from existing rootstock, including some of the most valuable N TFP species, and biodiversity is increasing for most life forms, including large mammals. Research by $M$ alhotra (1993) in the region of West Bengal largely substantiates the above findings, finding that N TFPs contribute $22 \%$ and $16 \%$ of total household income among tribes and castes, respectively. As a consequence of allowing free usufruct of these resources in exchange for village support in forest protection, $M$ alhotra suggests that biodiversity was improved even in the first year of programme implementation. 


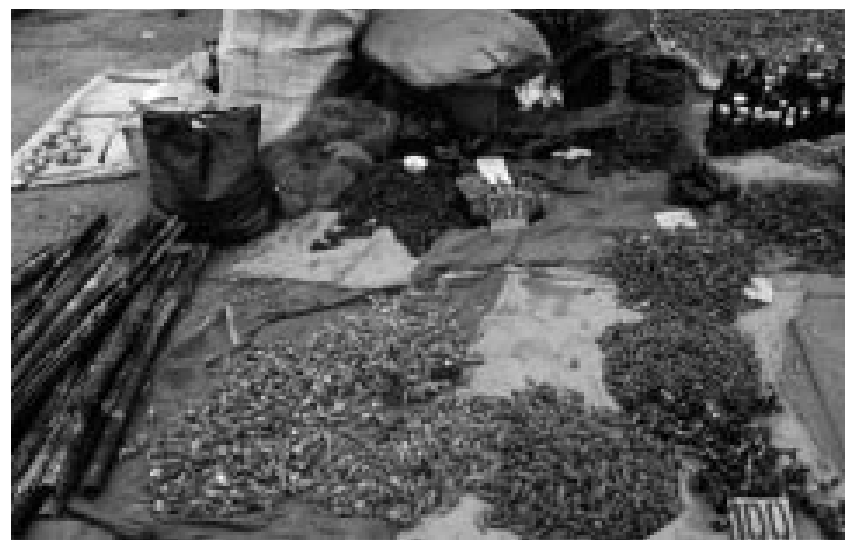

Barks for sale, Yaoundé, Cameroon (Photo: Manuel Ruiz Pérez)

Under certain biological and ecological conditions, our third category of explanation, there is evidence that the adverse impacts of commercial extraction are minimal or non-existent. Perhaps the most important biological characteristic that determines the impact of commercial harvesting is an organism's reproductive strategy. Ecologists typically divide species into two types, r-strategists and K-strategists, based on their reproductive strategies. Kstrategists are long lived, slow growing and slow reproducing whereas the $r$ strategists are short lived, fast growing and fast reproducing. The hunting studies by Fa et al. (1995) and FitzG ibbon et al. (1995), already discussed, illustrate the relevance of reproduction strategies for potential N TFP commercialisation. In both cases, K-strategist species (e.g. primates and large ungulates) were suffering declines in population numbers whiler-strategist species (e.g. rodents) were not. In general, there is a greater potential for ecologically sustainable commercial harvesting of both plant and animal r-strategists. The harvesting of $\mathrm{K}$-strategists will requirehigher costs in management, monitoring, regulation and enforcement in order to be sustainable.

Certain fast-reproducing tree species might also be easily exploited for commercial purposes with few adverse ecological effects. Peters (1990; see below for detail of method) measured the fecundity of wild tree species in Peruvian Amazonia to assess their potential for sustainable commercial harvesting of fruit. Productivity of two tree species, Grias peruviana and M yrciaria dubia, were quantified in detail. Using demographic data collected for $G$. peruviana Peters calculated the mortality rate versus seedling establishment to assess the species population dynamic. Species numbers appeared to be increasing slightly in the forest. He further determined that up to $80 \%$ of the fruit produced annually could beharvested without any negative effects on population numbers. Similarly, studies of tagua (Phytelephas aequatorialis) harvesting (Coles-Ritchie 1996; Southgate 1998) indicate that there are no negative effects on plant productivity 
or numbers resulting from seed extraction. Phytoecological studies in the middle Rio $\mathrm{N}$ egro area of Brazil show active regeneration in $\mathrm{H}$ avea cf. spruceana even after 30 years of latex extraction (Emperaire and Pinton 1993).

Pedersen's (1996) data on the production and harvest of the leaf fibres of the A phandra natalia palm providean example wherehigh levels of commercial exploitation have virtually no adverse effects. In Eastern Ecuador, where 48 individual trees were tagged and tracked over a two-year period, fibres from 21 of the tagged palms were harvested at the end of the study period. Analysis indicates that fibre production increases with increasing exposure to light, although even shaded palms still produce a fairly high amount of fibre. There were no signs that the palms suffered from harvest, as long as enough leaves were left intact on the palm. Even the continuous cutting of infructescences on many individuals did not have a discernible effect on regeneration. These findings are reinforced by the fact that fibres have been collected from the same individuals every year for almost 20 years in the plot under study.

It was also found that rattan (Calamus exilis and Calamus zollingeri) in Indonesia can beharvested indefinitely without damageto theindividual plants or the ecosystem. Siebert (1995) assessed demographic characteristics related to the potential for sustained yield harvesting of wild populations of rattan in the Kerinci-Seblat N ational Park, Sumatra, and in the D umoga-Bone N ational Park, Sulawesi. H e found that since both species produce multiple canes and propagatevegetatively, canedensities arehigh and therisk of population decline due to overharvesting is reduced. In addition, there appears to be no effect on theflora and fauna of the forest as a result of traditional harvesting techniques.

Finally, some research results suggest that commercial harvesting can actually enhance the ecosystem and improve the productivity of individual species. Peters (1992) suggests that commercial harvesting could even improve the genetic composition of a forest ecosystem over time when extractors manage the resource by selectively favouring the most vigorous and productive individuals. Anderson and Jardim (1989) report the findings of a field experiment (see below for methods) in IIha das O ncas, B razil, designed to compare the effects of different management practices used by river dwellers on fruit yields in natural stems of açaí palm. Alternative land-use practices (pruning and thinning) that permit both fruit harvest and palm heart extraction appear to be increasingly implemented by rural inhabitants. They report that pruning not only provides heart, but also increases the productivity of the remaining stems. Resultsfrom the experimental plots indicate that palm heart extraction can be carried out in populations of açaí without reducing the fruit harvest and possibly even increasing it.

Ecological effects of commercial harvesting of N TFPs have been found to be negative, positive and even neutral. Studies are available to show each of 
theseimpacts. From the research, theroles of markets, institutional arrangements and ecological conditions appear to be critical in determining impact in the following ways:

- N egative ecological consequencesfrom NTFP harvesting are most likely to result in situations where rapidly rising demand and poorly defined property rights are combined.

- NTFP species that reproduce rapidly and have more than one means of propagation are best able to withstand increased levels of harvesting without significant ecological consequences.

- Ecologically damaging extraction techniques are more likely to be employed when thelabour forceisnon-local, migratory and unregulated.

- Institutional reforms, such as a wider distribution of economic benefits and a decentralisation of control, have led to improved ecological conditions in forests subject to commercial NTFP harvesting.

\section{Ecological Influences on Commercialisation Potential}

W hile commercialisation of N TFPshas varying ecological impacts, the reverse relation ship exists whereby commercial potential is affected by ecological factors. In this section, we divided the studies into two groups: those that focused on the biological characteristics of individual species and those that focused on the ecological qualities of a particular forest community. The first group tends to address questions of resource productivity and the latter focuses more on questions of resource distribution and abundance. There were exceptions to thisgeneral pattern, such as a study by Phillips (1993) which addressed questions of the collective N TFP productivity of different forest types. For the purposes of analysing research results, forest types are divided into two broad categories, primary and secondary. Studies that compare these two forest types are considered in relation to questions of biodiversity, abundance and distribution.

\section{Natural Productivity and Commercial Exploitation}

LaFrankie (1994) asked the basic questions addressed in this section in the report of his study of two NTFP-producing trees in M alaysia. 'Are natural populations of [wild] species adequate to provide regular harvest? Do the biological properties of their populationsfacilitate or hinder their devel opment as an alternative forest product?' (p. 302). The literature suggests, at the very least, that broad generalisations about the ecological and economic benefits of harvesting wild NTFPsarebound to be misleading and ultimately indefensible. 
Wild populations pose important limits on commercial exploitation. Specifically, NTFP species tend to exhibit high degrees of variability and unpredictability in resource productivity, creating significant challenges for the design of extractive industries.

O neway in which productivity varies within wild populationsistemporally. In Amazonian Peru, Phillips (1993) found that production for most wild fruitbearing species was concentrated in the wet season months (between $\mathrm{N}$ ovember and April). This is one important impediment to the viable commercial extraction of edible fruits, even on the most productive forest sites. There is also a tendency for great variation from one year to the next. Production of shea nuts (Vitellaria paradoxa) in Burkina Faso is highly variable between years (B offa et al. 1996). Average nut production in the sample fluctuated almost fivefold from oneyear to thenext. This variability of annual production is seen as a disincentive to collection. Further, some N TFP-producing species in the tropics exhibit 'mast-fruiting' as a reproductive strategy, when an individual tree fruits at irregular intervals. Peters (1996b) reports that many illipe nut (Shorea spp.) trees fruit at irregular intervals from 2 to 10 years in West Kalimantan. 'W hat this means from a commercial standpoint ... is that the availability of seeds from year to year is al most impossible to predict' and 'may vary by more than three orders of magnitude' (p. 234).

Another important way in which productivity varies within wild populations is among individuals of a single species. In a study of chicle latex (M anilkara zapota) extraction in Guatemala, D ugelby (1998) measured the latex yield of individual trees. Productivity of individual trees varied a great deal and non-producing trees werefound in all size classes. Therefore, evaluating the potential of forest communities for commercial extraction is difficult since stand density does not directly measure potential productivity. Fifty per cent of the shea nut trees in theBurkina Faso sample of B offa et al. (1996) produced $85 \%$ of the nut production. 0 ver a period of three years, $30 \%$ of the trees were virtually worthless while $26.4 \%$ produced $59 \%$ of the nuts. From a study of gaharu (Aquilaria malaccensis, a resinous wood used for incense) in M alaysia, LaFrankie (1994) concludes that the particular qualities of the resource will frustrate commercial harvesting schemes. $G$ aharu is found in trunks and branches 'as fine striations or as spatulate or pencil-shaped deposits' (p. 302). The quantity and quality of gaharu per tree is unpredictable and most trees have none at all.

Finally, variation in production can be compared across different forest types. Phillips (1993) examined the variability of total wild fruit production in south-western Amazonia in four different forest types - terra firma forest (on both sandy and clay soils), alluvial forest and seasonal swamp forests. Productivity varied greatly among forest types, being highest in swamp forest and lowest in terra firma sandy-soil forest. Phillips stresses that the terra firma 
sites, which have the lowest productivity, are more typical of most of Amazonia than the other two more productive forest types. Peters (1992) also compares six different forest types, all variants of Amazonian oligarchic forests and all but one type located in seasonally flooded habitats. Even under these relatively homogeneous ecological conditions, there are significant production variations among forest types, with the highest producing forest type yiel ding roughly 10 times more weight than the lowest.

\section{Biodiversity, Primary Forests and Commercial Extraction}

O ne of the assumptions underlying the arguments for a mutually supportive relationship between biodiversity maintenance and sustained extraction could be summarised as the more species, the more opportunities for benefits to local populations'. This assumption is supported by the research on subsistence harvesting activities of four indigenous Amazonian groups - the Ka'apor and Tembé of Brazil, the Panare of Venezuela, and the C hacobo of Bolivia. For the terra firma dense forests, Prance et al. (1992) report that the percentage of tree species useful to each group was generally high, e.g. 78.7\% for the Ka'apor and $61.4 \%$ for theTembé. I ndividual species usage among the four groups is highly varied, both in terms of plants utilised and the way they were used. This variation is more a reflection of high levels of plant endemism than cultural differences per se. T hat is, theecological characteristics of theforest werethemost important factors determining patterns of use and extraction among the four groups. Furthermore, the data confirm that the terra firma rainforests of Amazonia contain an exceptionally large number of useful species. For Prance and his colleagues, this suggests that the conservation of many different forest sites is critical to maintaining both usage and biodiversity.

Positivelinksbetween high biodiversity and N TFP commercialisation, however, are not so evident in their findings. Whilemany different species are harvested for use, relatively few species are harvested for commercial purposes (Prance et al. 1992: 123). O ther studiesal so indicate a weak link between highly diverse natural forests and opportunities for commercial exploitation. In West Kalimantan, Indonesia, Lawrence et al. (1995) found that Dayak villagers harvest and market productsfrom trees they

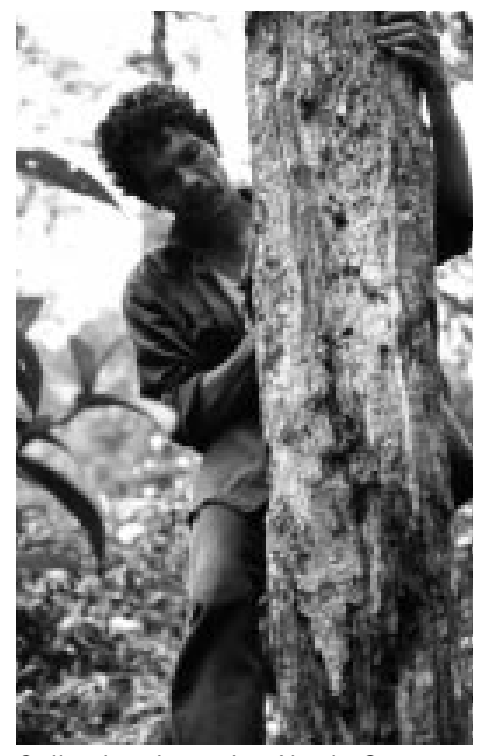

Collecting benzoin, North Sumatra, Indonesia (Photo: Brian Belcher) 
manage, rather than products extracted from primary forest. N either tengkawang (Shorea stenoptera) nor durian (D urio spp.) is currently extracted from primary forest because of their low density in natural stands. In other words, species abundance and community composition areimportant ecological measures of the potential for commercial extraction. $\mathrm{H}$ igh forest diversity generally means that individual plant species have low population densities. 'As a direct consequence of this high floristic diversity, trees of a particular species are usually scattered throughout the forest at relatively low densities' (Peters 1992: 15). From a policy perspective, theWest K alimantan data suggest that extractive reserves or extractive buffer zones around protected forests will not be effective in preventing further conversion of primary forest (Lawrence et al. 1995). Instead, villagers face strong financial incentives to create new gardens from primary forest.

In primary rainforest in the Pasoh Forest Reserve of Peninsular $M$ alaysia a similar relationship exists between biodiversity and the commercial viability of N TFP extraction. LaFrankie (1994) examined the population structure and dynamics of two economically valuable species: Aquilaria malaccensis, one source of gaharu, and Cinnamomum mollissimum, a source of wild cinnamon. The main purpose of the research was to determine whether natural populations could provide the basis for sustained commercial extraction. The population densities of A. malaccensis and C. mollissimum were found to be 2.5 and 2.24 trees per hectare, respectively, and both species were widely and evenly distributed. These low densities and wide spatial distributions severely constrain the possibilities for commercial ly exploiting natural populations of these species, since harvesters are unlikely to ever encounter individual trees without first making an exhaustive inventory. LaFrankie's preliminary consideration of production economics suggests that single-product harvesting schemes would therefore not be profitable. As Southgate (1998: 56) notes in his analysis of tagua in Ecuador, 'commercial non-timber-product extraction... usually does not take place in locations that are biologically diverse'.

If forest communities with high levels of biodiversity appear to offer limited opportunities for commercial N TFP exploitation, then a study by Peters (1992) supports the corollary that less diverse forests are more likely to be profitable for commercial extraction. In this Amazonian study, the author examined six native tree species known to form dense natural populations, or oligarchic forests - Euterpe oleracea, Grias peruviana, Jessenia bataua, M auritia flexuosa, $M$ yrciaria dubia and 0 rbignya phalerata. All produce fruit of commercial value. In terms of both density and yield, Peters suggests, oligarchic forests rival many of the commercial fruit orchards that have been established in the tropics. In particular, natural stands of Euterpe oleracea, M auritia flexuosa and O rbignya phalerata arecommercially exploited on a largescalein A mazonia. T husnaturally occurring oligarchic forests play a significant role in the market economies of the region. 
A positive relationship between low biodiversity and high NTFP profitability is further supported by research in disturbed secondary forests across the tropics. Some of the most commercially important NTFPs often originate from species-poor secondary forests rather than species-rich primary forests. H echt et al. (1988) convincingly demonstrate the importance of secondary successional babaçu (O rbignya phalerata) forests for the income of impoverished rural households in Amazonia. The densestands of babaçu found in Brazil are essentially artefacts of common slash and burn agricultural practices. W hile these secondary babaçu forests are low in biodiversity, they are the source of a number of commercially important NTFPs, including $89 \%$ of Brazil's oilseed production from non-domesticated sources. Likewise, almost all productive stands for commercial tagua (Phytelephas aequatorialis) extraction in Ecuador were established through secondary succession (Southgate 1998).

In West Kalimantan, Indonesia, the density of marketable NTFP species was found to be far higher in secondary forests than in primary forests(Lawrence et al. 1995). Shea butter (Viellaria paradoxa, formerly called Butyrospermum paradoxum) is one of the most economically important NTFPs of Africa's Sudan zone (running from Senegal to U ganda), providing cash income for peasant households. It is a particularly important enterprise for women. Viellaria paradoxa isfound in low diversity stands of parkland savanna, an anthropogenic forest

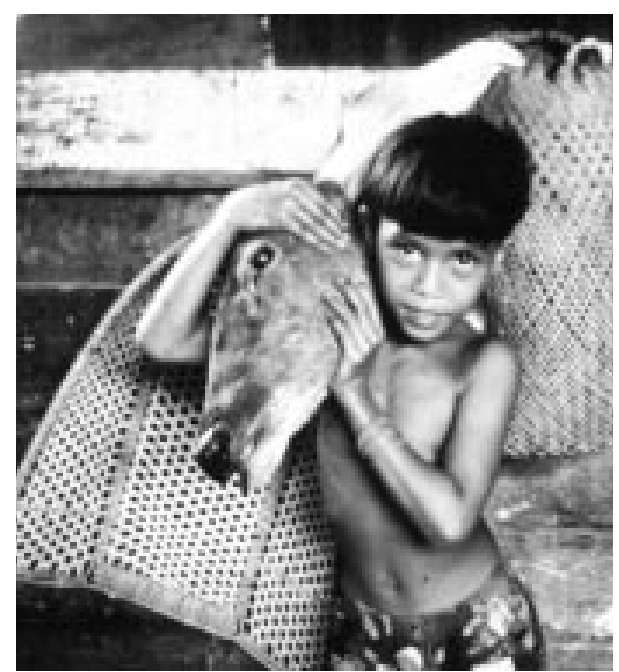

Punan boy carrying deer head, East Kalimantan, Indonesia (Photo: Esther Katz)

type (Boffa et al. 1996; M asters and Pugan.d.). In the continent's Afromontane forest zone, another economically important species, Prunus africana, is also found most abundantly in disturbed secondary forest sites (Cunningham and $M$ benkum 1993). $P$. africana is a source of both traditional medicines and a patented extract, 'Tadenan', used in treatments for prostate ailments. Trade in the extract is worth an estimated $\$ 150$ million a year.

Tie tie (D esmoncus schippii), a climbing palm used in basketry in C entral America, tends to have the highest densities in secondary forests (Belsky and Siebert 1998). Secondary broadleaf forest near $G$ ales Point, Belize had by far the greatest number of harvestable canes (532 per hectare compared with the next highest, 216 per hectare, found in montane forest). T he relatively high 
densities of tie tie in disturbed secondary forest indicate a high potential for commercial exploitation. In fact the authors suggest that the conversion of primary forests may be 'good' for commercial N TFP extraction activities. The plant's preference for disturbed sites 'may bode well for the future availability of cane supplies, as the area of disturbed forest is increasing in Belize' (Belsky and Siebert 1998: 145). In summary, this and the preceding studies indicate that low biodiversity secondary forests are more suitable for NTFP commercialisation than high biodiversity primary forests.

There appears to be an inverse relationship between species diversity and potential for NTFP commercialisation. Research has shown that:

- H igh variability and irregularity in production found in many naturally occurring N T FP species is a major constraint to commercialisation.

- H igh species population densities and low biodiversity, while relatively rare in natural situations, are the ecological conditions most conducive to commercial harvesting.

\section{Methods and Purpose of Ecological Studies}

We will now explore the various methodological approaches to ecological questions of NTFP commercialisation. We also evaluate the potential of the various methods and research designsto offer conclusive evidence on the causal linkages between commercialisation and ecological conditions and consequences. Themethods used are partly determined by the purpose or central research question of any research. For example, studies wishing to measure the impact of commercial N TFP extraction relative to other land uses engaged a comparative case study approach. Those whose purpose was to measure the ecological effects of existing extractive activities used a variety of standard ecological field methods (e.g. transect lines), often combined with social science methods (e.g. questionnaires). Where the aim is to predict the outcome of commercialisation, experiments to mimic harvesting, modelling or extrapolation from historical case studies may be used. We therefore organised this section according to the following typology of methodology:

- experiments intended to mimic commercial harvesting;

- ecological modelling;

- comparisons of alternative land uses;

- historical analysis; and

- direct measures of existing commercial harvesting systems. 


\section{Experiments to $\mathrm{M}$ imic $\mathrm{H}$ arvesting}

There are a variety of ways that researchers attempt to mimic the ecological effects of commercial harvesting. O nemethod isthrough projections of potential off-take based on measures of natural production rates. Peters (1990) established a series of $10 \times 10$ metre plots to measure densities and size-class structure of two fruit-producing species, M yrciaria dubia and Grias peruviana, in the Peruvian Amazon. After measuring fruit production on a sub-sample of adult trees, he estimated the potential effects of extraction on regeneration. A 'transition matrix' developed from the sample of $G$. peruviana was used to establish the ratio of mortality and seedling regeneration of the population and then fruit collections were simulated by reducing the fecundity coefficients in the matrix. The simulation results indicated that up to $80 \%$ of the fruit could beharvested without reducing theability of the population of $G$. peruviana to regenerate.

0 ther studies have used basic experimental design to estimate the potential impacts of commercial harvesting. By establishing sample plots and subjecting the plants to different treatments various harvesting techniques and intensities can be simulated. In the Amazon estuary, Anderson and Jardim (1989) established 16 permanent plots of açai palm (Euterpeoleracea $M$ art.) in mature floodplain forest. Four received no treatment, four underwent pruning of açai clumps, four had of forest competitorsthinned and four received pruning and thinning. The results indicated that the pruning of açai stems did not produce statistically significant effects on fruit productivity, although it did increase productivity slightly above that of the control plots. Thus, the extraction of palm hearts (equivalent to the pruning treatment utilised in the experiment) can be carried out in populations of açai without reducing the fruit harvest. Results also indicate that selected thinning of forest competitors produces a significant increase in fruit productivity per açai stem.

Using similar methods, Siebert (1995) evaluated the ecological effects of harvesting rattan in two Indonesian national parks (Kerinci-Seblat, Sumatra and D umoga-Bone, Sulawesi). The purpose was to assess the demographic characteristics of $C$. exilis and $C$. zollingeri and thus the potential for sustained yield harvesting. Between 1990 and 1992, plant and cane abundances were sampled in forty 0.05 ha plots selected at random intervals along transects in both sites. All canes greater than two metres were removed in January 1990, and cane resprout and growth rates were then measured in June 1992. T hirty months after experimental harvesting, $C$. exilisplants had produced an average of 3.2 new harvestable canes per plant, down from 6.8 harvestable canes per plant in 1990. 


\section{M odelling Ecological Effects}

Models are most common in studies that try to estimate the effects of commercial hunting on the population characteristics of wild animals. Fa et al. (1995) used a model developed by Robinson and Redford (1991) to estimate theimpact of commercial hunting on sustainableharvest in Equatorial Guinea. The model uses carrying capacity, maximum rate of population increase and the population density of a species that produces the maximum sustained yield. It provides an estimate of the optimum sustainable harvest. Results from the two research sites ranged from harvesting at rates 28 times greater than potential to $0.08 \%$ of the potential harvest. Farrow (1995) made creative use of two historical case studies to test an economic model of species extinction resulting from commercial hunting. The model relates changing prices to harvest rates and the population dynamics of the wild animal species - the passenger pigeon and the American bison. In the case of bison, extinction was avoided in a common property situation whileextinction of thepassenger pigeon took place after privatisation of stocks occurred.

D ufournaud et al. (1995) likewise developed a model that examined the role of property rights in determining whether a species would be driven to extinction, or at least to local exhaustion, as a result of overharvesting. Their mathematical model of N TFP extraction examines the sustainability of a forest stock subject to extraction under different exogenous factors (low economywide wage rate, reduced rainfall, population increase and a gain in the efficiency of household appliances used in the region). The partial equilibrium model of rational households gathering firewood indicates that the stock of N TFPs will decline in the face of an increasing population, reduced rainfall or the lowering of the overall wage rate. Increases in the efficiency of appliances causethe stock to increase (not as much fuel is needed for the same amount of energy), though not by the amount suggested by the increase in efficiency. Using data from the Sudan, it is demonstrated that a decline in rainfall will not completely exhaust resources, as the rate of harvest adjusts to the declining stock. For China, the model indicates that where there is population pressure, the modification of property rights is a solution

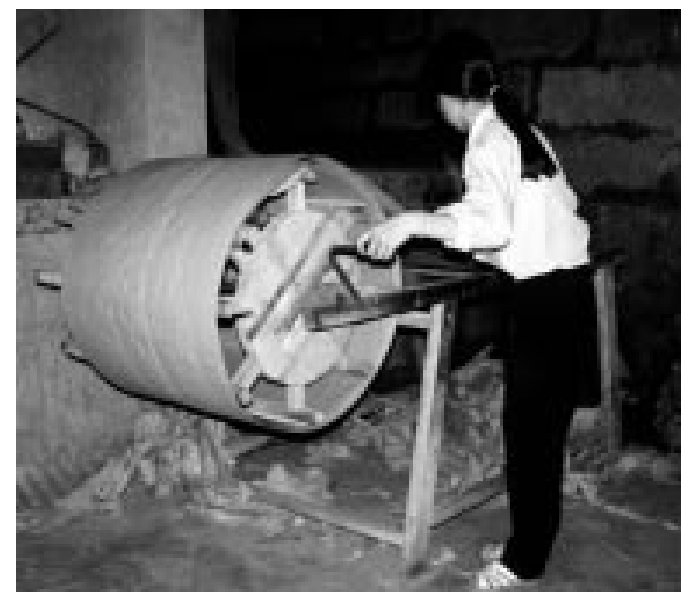

Traditional bamboo paper mill in Gao Guan Yin village, Muchuan, Sichuan, China (Photo: Manuel Ruiz Pérez) 
to sustain the harvested resource. The authors confinetheir study to subsistence harvesting, however, and their model may thereforenot be useful for questions of commercialisation.

\section{Comparisons of Alternative $L$ and $U$ ses}

Several studies were designed to eval uate the ecological impacts of commercial N TFP extraction in comparison with other land uses. Although this primarily addresses a policy question - that is, choices between alternatives - an assessment of ecological impacts is necessary. N epstad et al. (1992) three different land uses in Seringal Porongaba, part of the C hico M endes Extractive Reserve. The biotic impoverishment associated with commercial NTFP extraction was compared with that of ranching and logging in northeastern Pará. In a similar study, Anderson (1992) compares three different land uses: the Cachoeira extractive reserve in Acre, extensive agroforestry practised by river dwellers on Combu island near Belém, and intensiveagroforestry carried out near thetown of Tome-Acu. $\mathrm{H}$ is methods, however, are more relevant to answering questions of economic viability and social equity than comparing ecological impacts.

D issertation research by Etchart (1995) in the community of Tiningu, lower Amazon, Brazil, compared two land use alternatives: joint fishing/ forest gathering and cattle grazing. These land uses were selected from a range of possibilities based on ecological sustainability and other factors. Ecological, economic and social factors favour the traditional joint production alternative.

\section{H istorical Analysis}

$\mathrm{H}$ istorical analysis is sometimes employed to evaluate present-day potential for commercial NTFP extraction on a sustainable basis. H anson (1992) and Clay (1997b) used this approach to demonstrate the potential threat to the resource base during boom phases of N TFP marketing. $\mathrm{H}$ anson uses the history of the gum arabic trade in West Africa to highlight the ecological dangers of relying on extractivism. Clay's analysis reveals how an NTFP resource base (açaí pal $m$ in the Amazon) can be virtually eliminated in a very short time as a result of rapid commercial isation. $\mathrm{H}$ omma (1992) uses historical evidence to develop a model of the dynamics of forest product extraction in Amazonia. He identified four developmental stages that commercial NTFPs pass through. Of relevance here is the 'decline phase', in which the N TFP is overharvested and the resource base shrinks, thus leading to the eventual failure of extraction. According to his historical analysis, the economics of extraction led to harvest levels exceeding the regenerative capacity of the resource. 


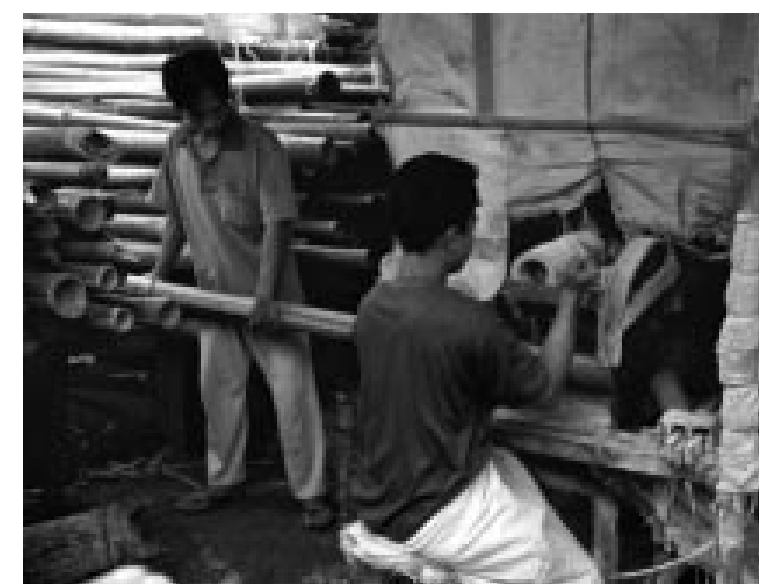

Jaya Abadi chopstick factory, cutting bamboo culms, Tasikmalaya, West Java, Indonesia (Photo: Manuel Ruiz Pérez)

\section{D irect M easures of Existing Commercial $\mathrm{H}$ arvesting Systems}

By far the largest number of ecological studies reviewed employed a variety of field methods to obtain primary data on the practices and effects of commercial NTFP extraction. $O$ ften these studies are multidisciplinary in their methods and driven by a combination of social, economic and ecological objectives (e.g. Belsky and Siebert 1998; D ugel by 1998; H echt et al. 1988; Cunningham 1990a; Ganesan 1995). Ganesan (1995) illustrates the multidisciplinary approach in his examination of anthropogenic disturbances of forest composition and their implications for biological sustainability in the dry deciduous forests of the N ilgirisBiosphere Reserve, M udumalai, Southern India. Addressing the impact of N TFP extraction, four of hissix objectives are broadly socio-economic and the remaining two ecological. M ultipleand diverse methods areused to meet theseobjectives, including questionnaires, interviews, secondary data collection from government documents, vegetation transects, observation and interviews.

Belsky and Siebert (1998) also used a multidisciplinary approach to examine tie tie (D esmoncus schippii) palm extraction in Central Belize. Their research combined measures of the reproductive and growth habits of tie tie with sociological data on extractors, obtained from participant observation, household surveys, oral histories and a questionnaire. The ecological data were obtained from twenty-five 10 x 10 metre sample plots where plants and canes were counted and measured.

0 ther field methods have been designed to monitor yields of individuals of a particular plant species, either for measuring the impact of extraction or projecting potential of future extraction (e.g. Cunningham 1990a; Peters 1990; 
Boffa et al. 1996). These are most useful in research concerning N TFPs from trees, such as sap, nuts or fruit, where a sample of individuals can be selected and monitored over time. Some studies rely on ecological field methods to obtain baseline data on resource abundance and then use models or other estimates to project the potential for commercial harvesting (Peters 1992; FitzGibbon et al. 1995; Murali et al. 1996; Pedersen 1996). Finally, a few studies with primarily ecological objectives rely solely on social science methods such asmarket surveys, questionnaires, and interviews (e.g. Anadu et al. 1988).

\section{D iscussion}

We wish to make a few brief points about methods before closing the chapter. We noted three factors that account for most of the variability in choice of methods: 1) thebiological and ecological characteristics of the N TFP resource; 2) the purpose of the research; and 3) the researchers' disciplinary background. $0 \mathrm{ften}$, two or more of these factors are relevant. The most general biological and ecological characteristic determining methods is whether the product is derived from animals or plants. Themobility of animals is themain characteristic that requires fundamentally different sampling methods. The purpose of the research is closely related to the methods chosen. 0 ften the purpose has a strong influence on results as well. Researchers who are sceptical of the conservation benefits of commercialisation, for example, have many historical cases to choose among for empirical support. Two general patternswere observed relating to researchers' disciplinary backgrounds and their influence on choice of methods. ${ }^{10}$ First, very few individual researchers are equally versed in both social and natural science methods. Following from this, in multidisciplinary studies it can happen that not all methodological procedures are conducted with equal rigour or produce results of equal validity.

0 ther trends that can beidentified from the review of methods used in research include:

- Experimental designs that attempt to mimic N TFP harvesting provide some of the most reliable findings on ecological impacts.

- M ost field studies have not been designed and conducted in such a way as to clearly isolatethe ecological effects of commercial N TFP harvesting from other causal factors.

\footnotetext{
${ }^{10}$ We make these observations, we should emphasise, based on a limited sample, as it is not al ways easy to identify a researcher's disciplinary training.
} 


\section{Summary}

This chapter has primarily focused on the results of field research on the ecological effects of commercial NTFP harvesting and the ecological possibilities for and constraints on sustainable extraction. The majority of the studies documented negative ecological impacts, especially when harvesting required killing the individual plant or animal that produces the NTFP. Examples of neutral or positive ecological effects were found in cases wherenew institutional forms were established to balance state authority with increased local management and control over the forest. In addition, certain biological characteristics of N TFP species, such as rapid rates of reproduction and multiple strategies for propagation, minimise negative ecological effects. In some cases, harvesting can actually improve the productivity of individual members of a species or of a forest ecosystem.

Research findings indicate that the biological properties of many useful tropical NTFP species pose critical limitations on commercial exploitation. $M$ any wild populations exhibit a great degree of variability and unpredictability in resource productivity. Productivity varies seasonally, annually, by forest type, and even among individuals of the same species. The variability is commonly of an order of magnitudeand often highly unpredictable. These properties can make the commercial exploitation of wild populations an unreliable source of income for local populations and a high-risk venture for private capital.

$M$ aintaining biological diversity in tropical forests is one of the main concerns of scientists, activists and managers. The findings discussed here, however, suggest that NTFP commercialisation is not a particularly useful strategy for biodiversity maintenance. Studies demonstrate a positive relationship between low biodiversity and high NTFP profitability. H ighly biodiverse forests inhibit commercial extraction because most plant species found there tend to havelow population densities and wide spatial distributions, making efficient, economically viable collection difficult. Thus forest with limited biodiversity, high plant population densities, and clustered distributions are most conducive to commercial NTFP extraction. This generalisation is supported by other findings that indicate that the majority of commercial NTFPs are extracted from secondary forests rather than highly diverse natural forests.

O ur review of field studies demonstrates the difficulties of designing research that can yield conclusive evidence about the relationship between commercial NTFP extraction and ecological conditions. Experimental designs that attempt to mimic harvesting practices and intensities and measure the resulting ecological effects have provided useful insights. Efforts to measure 
the direct ecological impacts in actual NTFP harvesting systems, however, are difficult because most 'real world' situations are so complex that other causal factors are hard to filter out. We also noted that few multidisciplinary studies are designed in such a way as to empirically demonstrate causal linkages between socio-economic forces related to NTFP commercialisation and ecological conditions. T hat is, while socio-economic and ecological data may be collected simultaneously in a single study, this does not necessarily reveal any conclusive relationship. For example, rising demand may result in higher prices that may result in greater extraction rates. All of these phenomena are readily measurable. The next step of causally relating these to ecological conditions proves to be quite difficult. There is a variety of reasons for this problem but, most importantly, it is not easy to single out commercial extraction from other causal factors. 


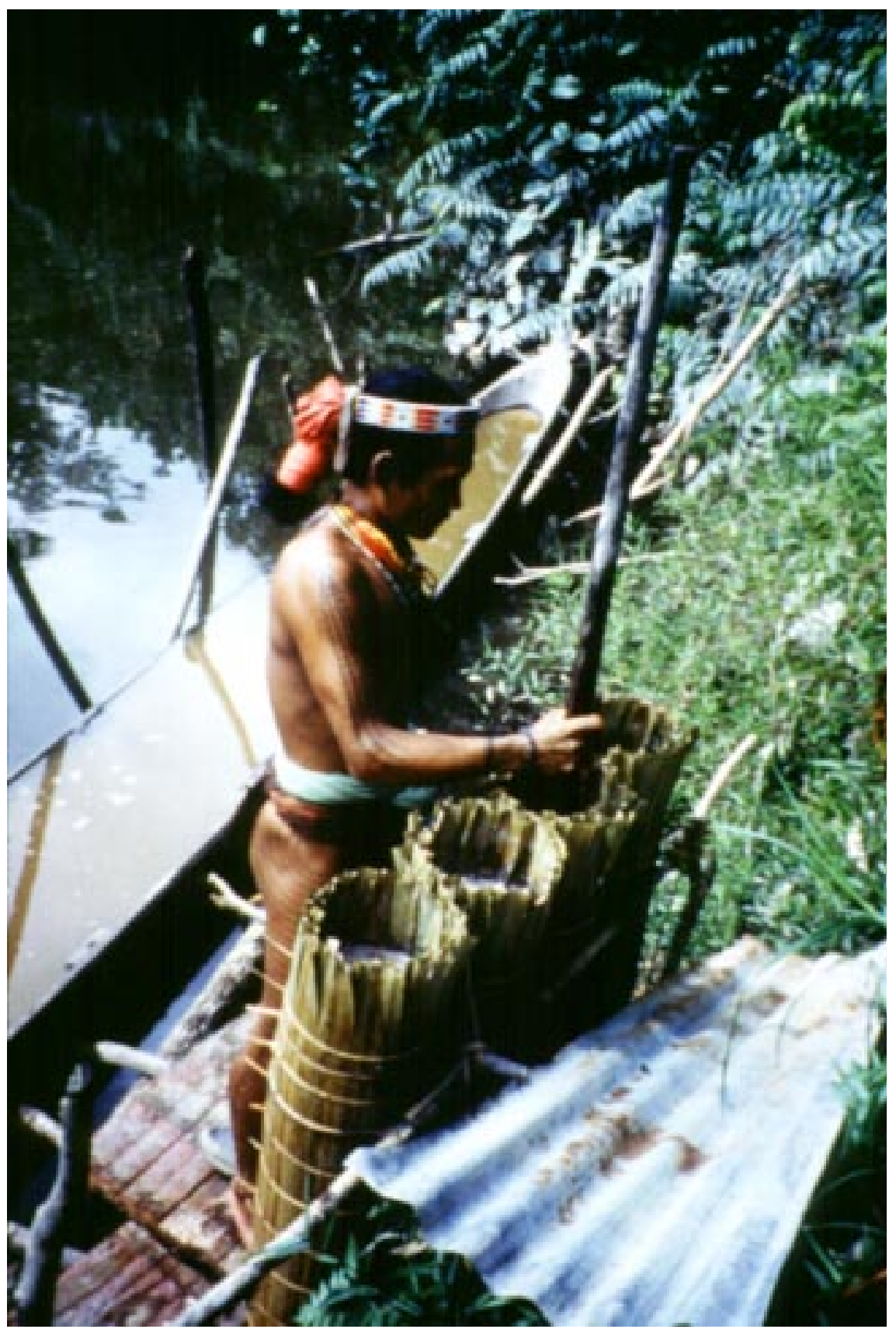

Sago making, West Sumatra, Indonesia (Photo: Susan Archibald) 


\section{Chapter Six}

\section{D irections for Research}

In this final chapter welay out some of the critical directions for future research. For each of the four issues addressed in the core chapters, we critically examine the theoretical, methodological and empirical implications of the N TFP studies reviewed. We present suggestions on the possibilities for cross-fertilisation from other areas of research, theneed for rigorous research design and the importance of clear and explicit theorisation and conceptualisation. These suggestions are derived both from the published insights of experts studying N TFP commercialisation as well as from our own critique of the research we reviewed here. We have organised the chapter by issue, beginning with socio-political issues, followed by economic, management and ecological questions.

\section{Socio-Political Issues}

The fundamental concern in this section is to analyse and theorise about the way in which socio-political processes and structures shape and are shaped by N TFP commercialisation. Importantly theseinteractions can havevery different consequences in different times and places, and results vary according to the scale at which the analysis is conducted, ranging from the extractor household to the global market. We first examine significant lacunae in our knowledge and understanding of the socio-political consequences of NTFP commercialisation. We then delve into theoretical issues fundamental for structuring research that can further develop this understanding.

\section{Knowledge G aps}

O ur consideration of socio-political aspects (C hapter Two) opened with the observation that political empowerment, improved social welfare and social justice for people living in and around tropical forests have been major foci of both NTFP commercialisation policy and research. At the same time, these terms are seldom rigorously defined in the literature reviewed. Rarely is the term 'social welfare' used as it is commonly understood and measured; for example, as nutrition, health care or education levels. M ore often than not, improving social welfare seems to be closely associated with, if not analogous 
to, raising rural incomes through NTFP commercialisation. $H$ igher levels of income are often correlated with such conditions as higher levels of nutrition, but it can not be assumed to be a unidirectional causal relationship. In fact, rising rural incomes can be associated with poorer nutrition when labour is diverted away from local staple crops to commercially valuable export products. The same problems are associated with use of the term 'social justice' in the NTFP literature. Social justice may often refer to land reform and wealth redistribution; sometimes it is supposed to be achieved by reducing state regulation of resource access and control of forests, sometimes by increasing state regulation. N TFP commercialisation is seen as the key component in a formula to accomplish what amounts to a fundamental social-structural transformation.

Whether or not the commercialisation of N TFPs will initiate or facilitate political empowerment and related changes is not the question that concerns us here. Rather, if the goal is to improve social welfare and social justice through NTFP commercialisation, there must be some common understanding of what is meant by these terms. Without this shared definition, it is extremely difficult to measure or assess outcomes and impossible to compare findings. This is not to say that research should attempt to quantify or operationalise, say, social justice as a dependent variable, but that we must be explicit about what social structures and processes are encompassed by the phrase. O nly then can we begin to theorise about

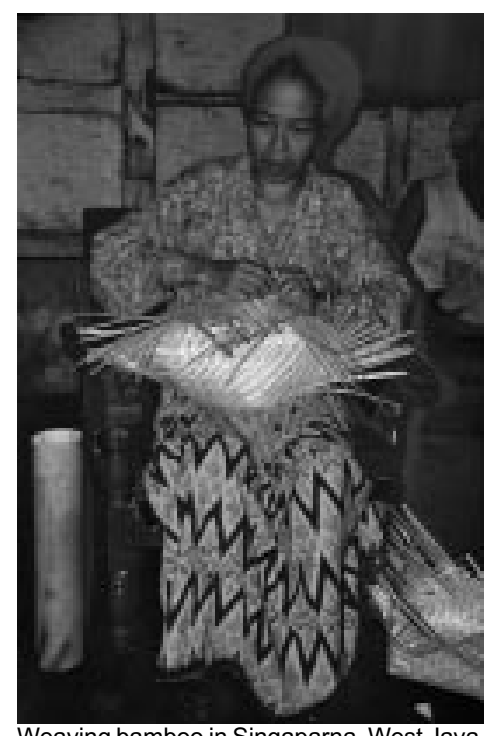

Weaving bamboo in Singaparna, West Java, Indonesia (Photo: Manuel Ruiz Pérez) the relationships between NTFP commercialisation and the social inequities

it is supposed to redress. O nly then can we ask more sophisticated questions concerning such as the differences in outcomes as we shift our level of analysis. W hose welfare is improved? The region's? The individual extractor's? M en's? Women's? D oes the political empowerment for onegroup mean reduced power for another? Under what conditions does commercialisation help to redress gender inequalities in basic welfare measures such as health, nutrition and education? Under what conditions does it create or increase gender inequalities? NTFP commercialisation research can not begin to answer these important questions without a more rigorous, conceptually sound, and theoretically based use of terminology. 
A second area where basic knowledge is lacking is in systems of land and resource tenure. Research shows that the structure of land and resource tenure is absolutely critical in shaping the potential social benefits of NTFP commercialisation. Yet thereissurprisingly little detailed analysis of the dynamics of customary tenure systems in the N TFP literature (see Peluso and Padoch 1996 for a significant exception). Even basic descriptive analyses of how customary tenure systems operate to control access to forest lands and N TFP resources are few. There is, of course, an enormous literature on common property systems in tribal and peasant communities in the tropics, but this has barely been integrated into the research on commercialisation. The literature reviewed that does address tenure in depth demonstrates the incredible complexity and variety of local rules and institutions governing forest access. $D$ etailed studies of local tenure systems can help formulate research questions and hypotheses, but with the current state of knowledge on commercial isation, general isations can be made only at great risk of being shown to be erroneous.

Research needs to focus on how N TFP commercialisation shapes and is shaped by dynamic tenure relations. That is, customary tenure systems are rarely static and fixed, but rather flexible and subject to ongoing negotiation and conflict. In property theory, increased commercialisation of agriculture is viewed as one of the principal forces behind the shift from communal property rights to individual private property rights. It is extremely important to investigate this in the case of N TFP commercialisation. We would suggest the kinds of detailed, ethnographically and historically based studies for N TFP as have been conducted for agriculture. For example, in the literature on African agrarian transformations, there is a significant amount of research on the relationships among systems of land tenure, commercialisation, resource conservation and increased production (e.g. Bassett and Crummey 1993).

\section{Issues of Social Theory}

There is a singular lack of engagement with explicit social theoretical perspectives in the literature, and much of the N TFP commercialisation research appears to be conducted in a theoretical vacuum. In the studies reviewed, seldom do authors address the voluminous devel opment literature on the various regions. Furthermore, there is very little analytical rigour applied in identifying social actors. For example, the word 'peasant' is not often used in the N TFP literature as a social category. Instead we find 'rural poor', 'forest dwellers', 'tribals', 'indigenous peoples' and so on; all terms that at best lack any clear theoretical meaning and at worst represent new permutations of the romantic ideal of the 'noble savage'. The extractors that are the focus of NT FP research rarely havea well-defined social identity in the literature. Interclass relations, peasant-state relations, structures of power and dominance, patterns of resistance - in a 
word politics - are seldom seen to be considered. This is not to say that these issues are non-existent; there are important, nuanced analyses of the political economy of commercial NTFP extraction (e.g. Peluso 1992b; Hecht et al. 1988; D ove 1995). But studies like these are rare and, relative to research on the political economy and sociology of agriculture and development, theN TFP commercialisation literature is theoretically bereft, although it is addressing many of the same fundamental issues.

A brief look at a key theoretical debatewill illustratethe problem in N TFP studies. Q uestions of N TFP commercialisation and social and political change amongst rural households touch upon theoretical issues that have been debated for almost a century in the literature on peasant societies. Specifically, the debate addresses the nature of social differentiation within the peasantry as commercialisation of agriculture and integration into a capitalist economy proceeds. The fundamental question surrounding peasants is whether they constitute a class within capitalism or represent a separate mode of production altogether. From the former perspective, peasants are class in transition under capitalism and are destined to differentiateinto either bourgeoisie or proletariat. In the latter, the peasant economy operates on a separate logic of production and reproduction and has a degree of long-term stability. Peasants have a place within the social division of labour of the global capitalist system and will persist side-by-side, and articulated with, capitalist forms of production. Chayanov's (1986) research on Russian peasant households is most closely associated with this view. Since the peasant household constitutes the basic unit of both consumption and production, its demographic characteristics will be the main determinant of its relative wealth within the community. Young households, those with high consumption demands relativeto available labour, will be relatively poor. M iddle-aged households with many hands to labour relative to the number of mouths to feed will be relatively wealthy. Differences in wealth in peasant communities are thus not a sign of the pending disappearance of the peasantry and the emergence of new classes, but are merely moments in the cycle of household demographics.

The implications of these two perspectives for N TFP commercialisation are enormous. For example, the household study by $\mathrm{H}$ egde et al. (1996) would seem to support the C hayanovian perspective. They found that larger, younger households in forest communities of the Biligiri Rangan $\mathrm{Hills}$ in India were the most dependent on NTFP collection for their livelihoods. From a Chayanovian perspective, one could predict the potential demand for N TFP access based on the household demographic profiles of adjacent communities. In contrast, the historical study by $\mathrm{H}$ anson (1992) tends to support the class differentiation thesis. A small group from a merchant class controlled the extraction of gum arabic to the detriment of both the resource base and the social welfare of the extractors. This position raises a different 
set of questions from those of C hayanov. IsN T FP commercialisation resulting in capital accumulation being concentrated in the hands of a few better-off households? If so, how fast is it happening and what are the implications for both the ecological conditions of the forest and the social welfare of the majority of households. Is the capital reinvested in maintaining the ecological sustainability of N TFP harvesting or is it invested in other enterprises, perhaps far distant from the forest? If NTFP commercialisation promotes class differentiation, is it likely to have adverse consequences for both the resource base and social welfare.

Related literature on contemporary agrarian transformation and uneven development could also provide an extremely powerful tool for guiding future research on NTFPs. Since many, if not most, extractors can be classified as either peasant farmers or rural wage labourers, there is no obvious reason why the rich, theoretically grounded literature on uneven development can not be adapted to research on N TFP commercialisation. The groundbreaking work on agrarian economies in Latin America by de Janvry (1981) is one example. D eJ anvry devel oped the concept of functional dualism in an attempt to explain how peasant relations of production could indefinitely persist geographically side by side with capitalist relations of production. Functional dualism refers to the condition in which a semiproletarianised peasant class (with access to

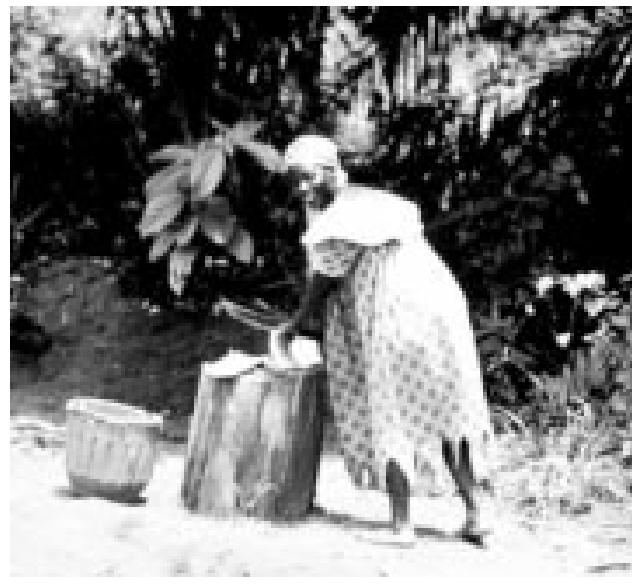

A woman splitting 'garlic bark' in Cameroon (Photo: Carol J.P. Colfer) small landholdings) exists within a fully developed capitalist system of production. These 'semiproletarians' provide a much cheaper source of labour for capitalist enterprises than the servile labour of the former feudal relations of production. In essence, structural conditions are such that a class of people is paid wages or receive prices for agricultural produce below the level needed to maintain themselves and their families. This concept would appear to have direct relevanceto research on NTFP commercialisation.

$M$ any of the studies reviewed indicate that it is frequently the rural poor who collect NTFPs, either for direct subsistence or for cash. O ften, they collect during times when alternative income is scarce because their labour is not needed either in capitalist enterprises or in their own landholdings. C avendish (1997) clearly demonstrates that N T FPs are critical for filling the income gap of poor rural households during slack employment periods, while at the same 
timethestructural causes of rural differentiation and poverty remain unchanged. From a functional dualism perspective, NTFP collection allows wages to be kept below the costs of peasant household reproduction and facilitates the maintenance of structural inequalities. Given these structural conditions, commercialisation is unlikely to be a path for economic development and improved social welfare, but a mechanism for the perpetuation of poverty.

A final body of knowledge that is particularly appropriate for NTFP commercialisation research is feminist social theory. Given the large, often dominant role of women in N TFP collection, processing and marketing and the persistent poverty of rural women in the tropics, sometheorisation about gender relations is necessary. Feminist theories of patriarchal power would add much to our understanding of women's roles in commercial N TFP use. Several of the studies noted that women were willing to process N TFPs for relatively poor returns on labour because they are able to integrate the work with other household tasks. This situation is hardly unique to NTFP processing and there is a large feminist literature on exploitative labour conditions of homework. Feminists point out that the economic result of the development of a domestic/female sphere and public/male sphere is to create the conditions for extremely low remuneration for labour conducted in or near the household. Under these conditions, returns to labour are well bel ow the market rate, thus providing an important source of accumulation for marketers of the product of women's labour.

Research on the socio-political consequences of N T FP commercialisation could greatly benefit from engagement with social theoretical literature. W ithout theory it is extremely difficult to formulate research questions to structure and guide investigations, let alone analyse and interpret findings. It can also have practical relevance for the devel opment of policy.

Important directions for future research on the socio-political aspects can be identified after reviewing the present body of literature:

- Studies should be more rigorous and consistently definekey terminology such as social justice, social welfare and empowerment in order to facilitate a greater understanding of the effects of commercialisation.

- A focus of research should be on the relationship among NTFP commercialisation, land tenure change, resource conservation and increased production, through detailed, ethnographic, historically based studies.

- NTFP commercialisation research would be enriched and advanced through more explicit reference to and application of relevant social theory, including theories of peasant economy, agrarian transformation and gender inequity. 


\section{Economic Issues}

H ow important, potentially and in reality, are NTFP resources to national economies and household economies? These are the economic issues that concern the NTFP literature most generally. Findings suggest that NTFP resources may have high potential for commercialisation in some forest areas, provided a full assessment of costs and market factors are undertaken. C learly, only a market study can effectively address these concerns for any particular NTFP enterprise, but academic research can address the basic framework in which enterprises operate.

Studies of either the general potential value of a forest region, or of all of the exploitable species within a plot, should be thought of as suggestive rather than descriptive. They may be important for furthering interest and research into N TFP resources, but dollar values estimated are not necessarily an indication of potential profitability. Thus, researchers should avoid making val ue estimations, particularly using simple price data, without being aware of the issues that make estimation problematic. On the other hand, studies of potential value can be very useful when identifying which particular forest types or NTFP species could become candidates for exploitation. Thus more consistent methodology for valueestimation is needed in order to make sensible comparisons among forest regions or particular N TFP species. M ethodology goes hand in hand with purpose; participatory rural appraisal and other such approaches may be more appropriate than neoclassical quantitative estimation for addressing local knowledge and empowerment.

Where N TFP production already provides significant household incomes, the distribution of that income may be highly uneven and complex. M ore research can elucidatethese patterns, and in particular suggest how, why, under what circumstances, and with what consequences marginalised groups and individuals engage in N TFP production. $\mathrm{H}$ ow does N TFP income serve as a buffer, as a means of livelihood, as a supplement or as a source of social mobility? W hat is the relationship between control over NTFP collection, NTFP marketing and the distribution of income derived from marketing? M ost importantly, researchers should investigate newly commercialised enterprises to assess their impact on and relationship to established systems of income distribution and control. Such enterprises are not created in a vacuum and central questions of power cannot be answered without understanding the structure that is already in place. They may be expected to interact with, and perhaps disturb, patterns of control within households, across regions and through trade networks.

Researchers have identified the costs most commonly associated with ongoing NTFP enterprises, particularly collection and transportation costs. Further, studies indicate that costs may range from negligible to prohibitive 
depending on the resourceand situation. A better understanding of cost patterns is necessary: their quantitative significance across different resources and forest situations, how they emerge, how and to whom they accrue, and how marginal costs rise with diminishing supply. In addition, considerations of supply and demand should not begin and end with forest inventories and lists of uses. The relationship between supply and demand curves and prices, and especially market imperfections, which affect pricing such as taxes and monopoly purchasers, should be given more than casual attention.

Identifying patterns in the slope and movement of supply and demand curves over time can help researchers to establish typical depletion paths and identify phases in the lifetime of a resource. This may improve our ability to predict and even intervene in patterns of resource use, resource substitution and domestication. H omma's model (1992) suggests one typical path; research should identify others, both theoretically (by using supply/demand analysis to predict paths under differing initial conditions) and empirically (by explaining the variation in actual resource use). Again, the complexities of supply and demand curves should be central to the analysis. Demand curves have been particularly neglected in many analyses.

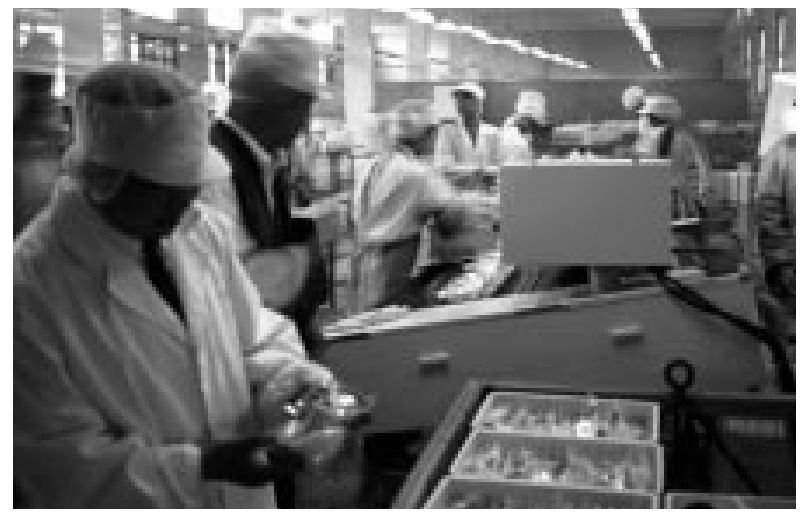

Packing bamboo shoots at Anji Food Products Company, a China-Japan co-venture (Photo: Manuel Ruiz Pérez)

Investigations of the market often leave gaps in the complex marketing chains that usually characterise NTFP trade. As Warner (1995) points out, case studies often end at the community or with the initial middleman. Little is known about products between the time they leave the community and before they arrive at the final consumer. M ore studies on the economics of marketing chains, such as that by Edwards (1996b), are needed that take the whole chain into account, that quantify the levels of exploitation, and that identify the kinds of value added which accrue as products move through the chain. It is not enough to identify that middlemen take on activities which add and involve cost and risk; pricing, costs and profits need to be quantified in 
order to evaluate competitiveness and, if desirable, to plan economically intelligent interventions. $M$ arketing cooperatives, the most dramatic of interventions into marketing chains, have not proven entirely successful. The differences in conditions or strategies between successful and unsuccesfful marketing cooperatives should be identified.

Much of the data concerning the economic significance of NTFPs is qualitative, suggestive, and stands outside any explicit theoretical economic framework. This implies that more careful use of economic data is required, but also that it is not necessary to be trained in economics to report highly useful data on income and cost patterns. As for more detailed analysis, economists have made some attempts to create an agenda to address key issues in NTFP economics (Godoy and Bawa 1993; Vosti and Witcover 1996). Because this agenda has implications for the study of control, power and inequality, it should attract the interest of the wider academic community.

Godoy and Lubowski (1992) provide detailed guidelines for future researchers regarding forest context, the evaluation of quantity, the determination of price and marginal costs and the assessment of sustainability. They suggest that researchers distinguish between inventory (the quantity in the forest) and flow (the quantity used by people), use shadow pricing when eval uating value to the country as a whole, and account for the cost of materials used in extraction. They conclude, and we concur, that researchers must pay more attention to problems of methods if future valuation studiesare to produce general iseable results.

Looking beyond what can be deduced from the literature reviewed in this study, there is a need to draw more on broader bodies of theories and research that have a bearing on the way N TFP use evolves. O ne of these would be work on the functioning of the non-farm economy (e.g. $\mathrm{H}$ aggblade and Liedholm 1991), and how this might provide insights into the factors that need to be taken into account in researching the conditions in which people engage in different types of N TFP activity in order to generateincome, and the conditions favouring or discouraging particular activities. Related to this could be a need for more research into factors that influence the evolution of market demand for different types of N TFP.

The potential and existing importance of N TFP resources to both national and household economiesare the issuesmost common in the literature reviewed. In order to effectively evaluate these questions, the following key points need to be considered:

- More consistent methodologies for value estimation are necessary to facilitate comparisons of findings and more appropriate methodologies are needed where researchers are interested in local knowledge and empowerment. 
- Research is required to identify different patterns in the slope and movement of supply and demand curves for NTFPs over time. This can help to improve our ability to predict and even intervene in patterns of resource use, resource substitution and domestication.

- More studies are needed that take the whole marketing chain into account, that quantify the levels of exploitation, and that identify the kinds of value added which accrue as products movethrough thechain.

\section{$M$ anagement Issues}

O ur analysis of management concerns is divided into two sections. The first reviews some of the fundamental gaps in knowledge that currently exist regarding themanagement of tropical forests for N TFPs. T he second part relates to broader research questions and explorations of research design and methods.

\section{Knowledge $\mathbf{G}$ aps}

Because of the historical neglect of NTFPs in conventional scientific forest management, the information gaps arenumerous. Theamenability and response of wild N TFP species to management has rarely been examined. Siebert (1995) noted that no research had been conducted on the feasibility of enrichment planting for wild rattan, a highly marketableand internationally traded N TFP. In a report on NTFPs in Southeast Asia, de Jong and M endelsohn (1992) present a long list of knowledge gaps for the region that could safely be generalised for most tropical forest areas. For example, there is a need to study quantitative measures of natural production rates for most N TFPs. Testing of different management techniques to improve natural production rates is necessary. If wild N TFPsareto bemanaged, information on production, growth rates and harvesting regimes must becompiled. Baseline data on forest ecosystem and biological characteristics of individual NTFPs is currently scarce (see Chapter Five). Systems of monitoring NTFP harvesting and its ecological impact need to be identified and tested.

\section{Research Q uestions for C ommercial N T FP M anagement}

$M$ anagement compatibility of timber and NTFPs is a critical issue. Beyond what we have reviewed here, studies that test the integration of timber and N TFPsin management regimesarerare (Panayotou and Ashton 1993). Research is needed to clarify the response of N TFP species to different timber harvesting techniques, such as strip clear cuts versus selective logging. This information is required for NTFPs in general as well as for specific, high-value species, and also in different tropical forest communities. The same sorts of questions must 
be answered for various silvicultural practices as well. H ow do N TFPs respond to different silvicultural practices? $\mathrm{H}$ ow can silvicultural treatments becombined with N TFP harvesting to reduce management costs? W hat is the best timing to apply treatmentsfor optimal results for both timber and NT FP production? Field experiments, such as that conducted by Salick et al. (1995) in N icaragua, are essential for to address these types of issues. H owever, promising management strategies can al so beacquired from studies by ecologists on tropical forest dynamics (e.g. gap dynamics) and on the biological characteristics of particular NTFP species. Since timber and NTFP collection were more integrated in forest management before the middle of this century (W hitmore 1990), forest and environmental historians may provide answers or clues to some of these questions. Practical insights can be gained by searching historical documents on previous management practices.

Although the ethnobotanical research on forest management practices in peasant and tribal societies is quite rich, it is fragmented and scattered. Furthermore, the knowledge produced by this research has only recently begun to be recognised in the scientific forest management literature. As a result, important local management practices are often overlooked. In the extreme case, forests that are the result of intensive customary management are taken to be natural by outsider observers. Padoch (1995) also makes the point that the lack of recognition of management practices can serve to reinforce state claims of forest ownership. Even when the relevance of customary management systems is recognised, they are often viewed as

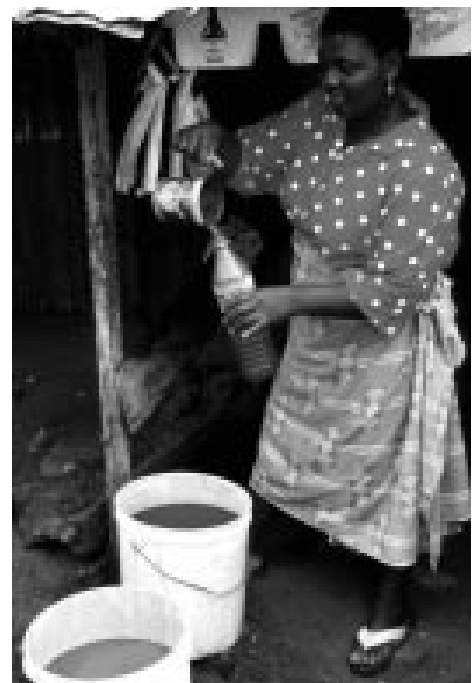

Oil palm trader in Limbe, Cameroon (Photo: Manuel Ruiz Pérez) fundamentally incompatiblewith scientific systems. This is because the collection and organisation of local knowledge are not viewed as 'systematic' or 'objective' - in a word, it is 'unscientific'. In addition, there is a prevalent and persistent assumption among practitioners of scientific forest management that the land uses of local communities arethreats to forests. Taken together, these problems create barriers to the incorporation of customary management techniques with state-directed forestry.

Research that can assist to translate local practices for adaptation into scientific management systems is needed. Compiling and synthesising theresults of the rich ethnobotanical research on forest communities is probably only of limited help. M ost of these types of studies were not specifically conducted to inform forest management. M ore studies likethat conducted by Fal coner (n.d.), 
which are specifically oriented towards collecting data on local N TFP use and harvesting practices for the purpose of inclusion in forest management are necessary. The costs of customary management intensity have not received attention either. M easuring returns to labour is difficult in many customary systems because practices may be carried out over very short time periods and in an incidental manner (Padoch and de Jong 1989: 109). Research methods need to be adapted to measure labour requirementsunder such systems. Survey questions about the amount of management work conducted daily in the forest may missfruit picking or weeding done casually in the course of other activities, because these may not be considered 'work'. Close participant observation is most likely the only method that can accurately assess labour costs in such cases. A concentrated research effort is needed to investigate the patterns of historical forest occupation and abandonment and their influences on NTFP production and abundance. G eographers and environmental historians can also contribute to this work in their studies of landscape changes resulting from human-forest interactions.

There remain serious questions regarding the long-term sustainability of incorporating customary practices into forest management. It cannot be assumed that because an N TFP is marketable and frequently collected that it is subject to local customary management. In the literature reviewed, we found that local communities do not manage many commercially val uable N TFPsin any way. Sometimes when local practices have positive forest conservation outcomes or encourage the growth and spread of NTFP species they are unintentional and not theresult of conscious management. W hat social, political and economic conditions are conducive to the development of management practices? Under what conditions do customary practices and local knowledge disappear? Richards (1997) observed that thetraditional exchange economy of tribal cultures in Latin America is often destroyed or highly monetised as indigenous populations are integrated into the market economy. As cultural values fade, so too may the knowledge of and motivation for forest management practices that facilitated sustainable harvesting of N TFPs. Similarly, Falconer (n.d.), considering increasing monetisation and rapid change in cultural values, raised doubts about the long-term viability of sacred groves as a customary management strategy in Ghana.

When customary management practicesarein place, what are the potential points of conflict and compatibility with scientific forest management? The latter remains geared toward the objective of maximum sustained yield (M SY; see $C$ hapter Five) which can conflict with local management objectives and interests. Flexibility, livelihood security and risk avoidance are likely to be far more important than M SY for the poor rural communities in and near tropical forests. In short, we need to systematically identify the existence of local forest management, understand the objectives of customary practices, and determine their fit with scientific forest management objectives. 
Given the mixed results reported from South Asia and elsewhere, there is a great need for studies to identify existing institutions and suggest new ones for co-management initiatives. H ow can joint management institutions be structured in such a way as to simultaneously satisfy the objectives of both the state and the community members most dependent upon NTFPs for their livelihoods? Because of our interest in identifying specific areas for future research, this question is purposely quite technical, but it is one that implies the potential for fundamental political and social transformation. Even in small rural villages, interests in the forest are quite heterogeneous. Karkee (1995) found the economic and political elites of forest communities generally are not dependent on the forest for their livelihoods. Yet these are often the people selected for community forest or joint management committees. Therefore the bulk of local residents who are dependent on NTFPs may find that their interests are not adequately represented in joint forest management initiatives. Similarly, Fox (1995) raises questions about participatory management in $\mathrm{N}$ epal. Whose views do forest committees represent - outsiders and elites, or the most frequent and dependent forest users? H ow capable are these committees at management? In short, the process and structure of JFM often appear to favour the participation of elite community members who may have little direct knowledge of NTFP management. A second issue that the question of institutional structure raises is how to mesh what are often very different decision-making processes. In PN G, O Isson (1996) describes both the incompatibilities of the decisionmaking processes and structures and a creative solution to overcome it. In that case, and in Agyemang's (1996) study of joint management of leaf collection in G hana, there was an intermediary institution that was able to mediate between the two systems. In PN G, it had to be created as part of the JFM project. In G hana, it was already in existence. Far more research is needed to investigate these sorts of institutional structures and arrangements.

Thefield of management of N T FPscoversa widerange of social, economic, political and social issues. The literature reviewed revealed a number of important areas where future investigations are called for.

- Research is needed to fill critical knowledge gaps regarding questions of the amenability and response of wild N TFP species to management, techniques to improve natural production rates, and the effects of different harvesting regimes.

- More studies that test the integration of timber and NTFPs in management regimes are essential.

- Studies of customary management systems are needed that specifically address returns to labour and patterns of historic forest occupation and abandonment. 
- Research should address the serious question of the long-term sustainability of incorporating customary practices into forest management for commercial extraction, especially the effects resulting from increased monetisation of local economies.

- There is a great need for studies to identify existing customary institutions and suggest new ones for the purposes of co-management.

\section{Ecological Issues}

This section examining the literature on ecological questionsfirst reviews some of the fundamental gaps in knowledge that now exist regarding NTFPs and tropical forest ecosystems. We then discuss research designs that can identify causal linkages between forest ecology and commercial extraction. Finally basic theoretical issues are identified that need to be addressed in future research.

\section{G aps in Ecological Knowledge}

From the literature, the single most frequently recurring problem in NTFP research appears to bea lack of basic ecological knowledge, at the levels of both individual species and forest ecosystems. Research on commercial NTFP extraction in the tropics has simply not attracted the scientific attention and financial resources on a scale that logging or agriculture, the two main landuse alternatives, have done. M ost N TFP studies are designed to collect data on only one species. For example, Phillips (1993) noted that at that time there had been no directly measurement of forest fruit productivity on an area basis in Amazonia. M ost assessments look at only one species, and even those studies are few. As Freese (1998: 105) noted, 'detailed information on production patterns of most non-timber forest products is lacking'. O 'H ara (1998) also concluded that there is very little baseline biological data for most NTFPs. Even for the more valuable species, the ecological knowledge available is inadequatefor drawing reliableconclusionsabout N TFP commercial extraction. Clay (1997a), for instance, found that Brazil nuts are one of the most studied species with great economic value, yet little is known about the species' overall distribution, reproduction and productivity. The effects of harvesting on individual species are not well understood, with the exception of a very few cases (H all and Bawa 1993). For N TFPs from reproductive propagules, determining the impact of harvesting is difficult because of the lack of basic ecological knowledge. Peters (1996a: 45) stated that 'density-dependent seedling mortality has never been studied in tropical forests under exploitation and therefore the direction and magnitude of the shifts in mortality that will occur as a result of fruit collection are difficult to estimate'. In summary, without baseline biological data on NTFP species, the ecological effects of commercialisation cannot be fully evaluated. 
There is a many times greater gap in scientific understanding of the structure and functioning of tropical forest ecosystems for individual NTFPproducing species. Few baseline ecological data are available and there is little knowledge about structure, composition and dynamics for most tropical forest types and geographic regions. Forest types that cover immense stretches of geography have been inadequately studied. M urali et al. (1996: 266) found only one 'published report on the structure of tropical deciduous forests in south India'. Furthermore, as H all and Bawa (1993) point out, there is a basic theoretical gap since ecologists' understanding of tropical forest ecosystem dynamics is not very advanced in comparison to temperate forest systems . This makes it difficult to even formulate appropriate research questions and test hypotheses.

In addition to these lacunae, we identified one important and very fundamental limitation to increasing ecological knowledge - the use of a consistent and identifiable nomenclature for forest types is lacking in the literature. Fifty-eight different forest names were used in the studies included in our database, with citations of standard ecological references a rarity. $\mathrm{N}$ ot infrequently authors used vagueand indeterminatetermssuch as 'tropical forest' or 'secondary forest'. Sometimes the forest type was not named at all. Even when nomenclature is consistent, definitions and geographical boundaries can vary significantly among studies. As Fairhead and Leach (1998) cogently demonstrate for West Africa, confusion over the very definition of 'forest', combined with questionable assumptions about the natural extent of forest types, leads to uncertainty about the extent of deforestation. The lack of a consistent nomenclatureand definition makesit extremely difficult to compare studies, draw generaliseable conclusions from the literature, build a corpus of ecological knowledge, or gauge the level of ecological impact of NTFP commercialisation.

\section{Research D esign}

The most striking finding from our analysis of the literature is that research on the relationship between commercial N TFP extraction and ecological conditions is rarely designed in such a way as to convincingly demonstrate causeand effect. This istrue for immediate, long-term or secondary ecological effects, with the level of uncertainty surrounding cause and effect increasing from the former to the latter. I mmediate effects are the short-term measurable impacts of harvesting on the mortality of individuals of particular plant or animal species and the aggregate population numbers and density. Longterm effects encompass the cumulative consequences of extraction on population survival and reproduction of a particular plant or animal species. Secondary effects are changes to a forest ecosystem's overall structure and functioning caused by extraction. 
The clearest immediate effect is harvest-related mortality when the individual must be killed in order to collect the resource, as for hunting or when a tree is cut down to make fruit more accessible to harvest. In these examples, cause and effect is readily demonstrated, but it becomes less clear when individuals do not have to be killed directly for extraction. If we consider the case of NTFPs that are plant exudates, such aslatex, attributing the cause of individual mortality to extraction can bemore difficult. 0 ther possible causes, such as drought and insect and disease outbreaks, must be factored in synergistically. Individual mortality and survival must be linked to questions of variablethreshold levels of extraction among individuals of the species and individual plant genetics related to disease resistance.

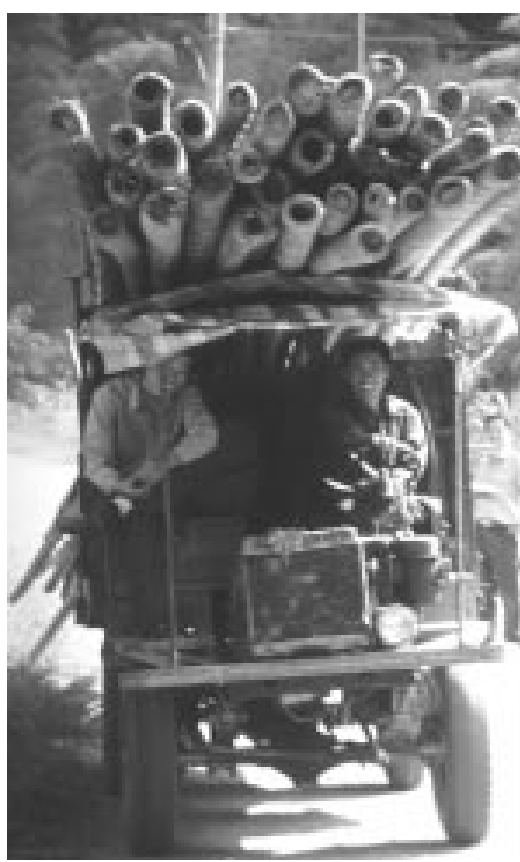

Transporting bamboo culms in Hunan, China (Photo: Manuel Ruiz Pérez)

Long-term effects on survival and reproduction become increasingly speculative in the absence of good baseline knowledge of the biological characteristics of individual species and consistent monitoring over time. The 'most intractable element of population dynamics is to measure the temporal variability in mortality or recruitment, from either natural causes or human harvesting' (H all and Bawa 1993: 239). It is in this area where research design becomes critical. There is nearly a complete absence of studies on the effects of commercial NTFP extraction designed to include both the collection of longitudinal data and the establishment of unharvested control plots. Collection of longitudinal data is needed in order to measure the effects of extraction on replacement rates and the ability of individualsto survive over time. U nharvested control plots are necessary to isolatethe effects caused by harvesting from other possiblecauses. Without this sort of rigorous design it is impossible to positively attribute to N TFP extraction any changes in a population's survival and reproduction patterns.

Secondary ecosystem effects from commercial extraction are the most complex to measure and the most difficult to link to specific causal factors. In the literature reviewed, many of the conclusions about the secondary ecological impacts of commercial extraction are extrapolations at best, and often merely speculations based on the results of different studies of different species in different ecological settings. As G odoy and Bawa (1993: 216) observe, '[t]he 
assumption of sustainability [or, we would add, degradation] often rests on indirect, anecdotal evidence'. M easuring and tracking causal linkages is difficult largely because of the complexity of ecological interactions in many tropical ecosystems. $O$ ne area of potential secondary effects relates to plant and animal interactions in tropical forest ecosystems. Peters (1994) noted that the vast majority of tropical trees rely on animal seither for pollination or seed dispersal. We could therefore hypothesise that the commercial hunting of animal species responsible for pollination or dispersal will affect the distribution and regeneration rates of some plant species. Conversely, animal species rely on NTFP plant species as food sources. Thus wecould predict that the commercial harvesting of NTFPs will reduce the food supply of some animal species and therefore affect reproduction and survival of those species.

Problems in research design arise, however, in trying to gather evidence to support these hypotheses. First, there must be empirical evidence or a reliable model to determine the threshold rate of extraction at which other species will be adversely affected. Secondly, the research must be designed in order to isolate the effects of harvesting on ecosystem structure and functioning from myriad other causal factors. It is possible, for example, that some bird populations may be reduced as a result of increased commercial harvesting of their food source, but we found little empirical evidence in the literature demonstrating causal links. The design of the study by M urali et al. (1996) in Biligiri Rangan $\mathrm{H}$ ills, India, comes closest to enabling solid conclusions about the effects of extraction on ecosystem structure and composition. Even that study, however, could not rule out other causal factors such as fire and grazing. Furthermore, the focus was limited to sampling the population structure of selected timber and N TFP species and forest plant species composition. M ore complex causal interactions among plants and animals or secondary effects on ecosystem functioning were not traced.

Partly due to the difficulties of designing research that directly measures the ecological aspects of commercial NTFP extraction, some of the studies used proximal measures of ecological change. These methods are usually based on questionnaires and interviews with local NTFP extractors, processors and marketers. They can be useful for gathering local perceptions of environmental change and resource scarcity. W hile these can be valuable sources of evidence, perceptions must be calibrated with and corroborated by other techniques, which must also be carefully and rigorously applied or the results will be unreliable. O ften in the literature on theecological aspects of commercial N TFP extraction, neither of these conditions was met when questionnaires and surveys were used. Q uestions about extraction activities, particularly when local knowledge equates to trade secrets or when extraction is illegal, are highly sensitive and not always answered honestly. In one study, the authors observed that respondents were often openly hostile to questioners, yet the results were used as evidence of the ecological effects of commercial N TFP extraction. Thus, 
when designing multidisciplinary research, the standards of social and natural science methods must be adhered to equally.

\section{Theoretical Issues}

As we suggested in opening this chapter and, as $\mathrm{O}$ ' $\mathrm{H}$ ara (1998) detailed in her research, studies and policies of ecologically sustainable N TFP extraction are founded on the principle of maximum sustained yield (M SY) - a management strategy designed for the harvesting of a single species at levels that do not exceed replacement rates. O ften M SY is closely associated with the concept of carrying capacity, in both theory and practice. Underlying M SY is a theoretical construct of ecosystem functioning which assumes that natural systems attain a state of stable equilibrium and remain at that point unless otherwisedisturbed. $\mathrm{N}$ ature, in a word, is constant and will return to a its original status after disturbance. The use of M SY asa principle for ecologically sustainable extraction has been seriously questioned since the late 1970s (Freese 1998). Since that time, the approach has become increasingly untenableas advances in ecological theory undermine its conceptual foundations. Specifically, the assumption of a stable equilibrium, or natural steady state, is not supported by the reality of ecosystem functioning and a 'new ecology' has arisen to address this disjunction.

The term 'new ecology' has been used since the 1980s to label a theoretical shift in biological ecology (Zimmerer 1994; seealso Botkin 1990; Worster 1990). The new ecology challenges the basic assumption of homeostasis that is the foundation of systems ecology and replaces it with a focus on instability, chaotic fluctuations and non-cyclical change. Under thisconceptualisation of ecology, carrying capacity, so critical to management for M SY, becomes an extremely elusive benchmark. As Zimmerer (1994) carefully argues, the assumption of a stable equilibrium is embedded in the carrying capacity concept. Furthermore, estimates of carrying capacity assume the spatial and temporal homogeneity of environments, yet studies of ecosystem functioning show that these assumptions do not often hold. Botkin (1990) proposes that the conditions to allow M SY to operate are rarely met in reality.

In the N TFP literature, these theoretical shifts in biological ecology have yet to beintegrated into research designs. An assumption of stable equilibrium isusually implicit, and sometimes explicit, in questions of sustai nable extraction. Peters (1996a), presenting a slightly morepoetic version of the notion of natural homeostasis, warns that the 'delicateecological balancemaintained in atropical forest is easily disrupted by human intervention' (p. 37). Similarly, M SY continues to guide the research on extraction exemplified by the model of Robinson and Redford (1991) for harvesting wild life. The authors assume 'the maximum production from the population for human use' as the basis for 
sustainable harvesting (p. 415). The model is based on carrying capacity and a (hypothetical) maximum rate of population increase. 0 ther researchers have adopted this model to guide their studies of commercial N TFP extraction (Fa et al. 1995; FitzG ibbon et al. 1995). Furthermore, almost all field studies that try to estimate the sustainability of N TFP harvest rates implicitly assume that the population of the species under examination is uniformly distributed in spaceand time. Thus, most of the sustainability literature is based on matching extraction rates to an assumed natural stable equilibrium that has been increasingly called into question by recent advances in theory.

Closely related to these theoretical issues is a common practice in NTFP research of measuring the ecological impacts of extraction against the standard of a natural, undisturbed forest ecosystem. This 'virgin' forest ideal is often accompanied by the assumption that the arrival of humans necessarily results in ecological degradation. It is implicitly (sometimes explicitly) assumed that '[a]ll land-uses result in biotic impoverishment at some level' ( $N$ epstad et al. 1992: 2). The presumption of a natural, pre-human forest ecosystem as well as the automatic assumption of denigration from human use is also being increasingly undermined by recent empirical findings (e.g. H echt and Cockburn 1992; Fairhead and Leach 1996; K andeh and Richards 1996).

A clear distinction between managed or secondary forest and pristine, primary forest is increasingly difficult to maintain. In his study of the ecology of illipe nuts (Shorea spp.) in West Kalimantan, Peters (1996b) found that most nuts are collected from gardens or managed forests. H owever, nuts are al so collected from what is presumed to be pristine forests. In fact, Shorea trees in seemingly undisturbed forests are actual ly planted remains of old longhouse sites long abandoned, making it difficult to distinguish between wild and planted individuals. Peluso and Padoch (1996) make a similar point for the case of durian trees in West Kalimantan, noting that the presence of durian in a forest suggests the location of a prior residence. These are but two brief examples of recent studies that show the ecology of presumed pristine forests to be shaped by many years of human habitation and management. $M$ ore specifically, the distribution and abundance of highly valued NTFPs are more and more being demonstrated to be the result of deliberate management. This suggests that more of the ecological research related to NTFPs should be focused on the ecology of fallow and other managed secondary forests.

An even morefundamental challengeto the common scenario of an original climax forest ecosystem threatened by disturbance and degradation from human use comes from recent research in West Africa. Fairhead and Leach (1996) produced a provocative analysis of the forest-savanna mosaic in $\mathrm{G}$ uinea. In the zone where tropical forests of the south give way to savanna of the north, forest ecologists and other outside observers have long viewed the forest patches surrounded by savanna as relics of a once-intact forest zone. From this 
perspective, population pressure and mismanagement by local farmers have led to deforestation, and the forest patches are all that remain and these will soon vanish without outside intervention. U sing a variety of methods from ethnography to remote sensing, Fairhead and Leach draw conclusions that challenge this neo-M althusian view of human-environment interactions. They arguethat their evidence shows that human occupance has actually created the forest patches, in essence extending the forest zone into the savanna. In other words, forest patches presumed to be pristine relics are in fact anthropogenic.

In other research in West Africa there are indications that biodiversity for certain taxa is higher in managed forests than in undisturbed reserves. $\mathrm{O} n$ the basis of their research in an area of southern Sierra Leone, Kandeh and Richards (1996) suggest that a high level of bird species diversity in the region 'may be a direct result of the complex human history of the forest and the resulting patchwork of mature secondary forest and undisturbed high forest islands' (p. 92).

The critical theoretical point derived from these and other studies is that a much more complex and indeterminate model of biological ecology and human-environment relations is called for in future NTFP research. If new research is questioning the very idea of pristine undisturbed forests - or, at the very least, greatly minimising its geographic extent - then it becomes increasingly difficult to locate a standard against which to measure change. The challenge for NTFP research is to incorporate much more detailed analyses of environmental history and account for the role of human occupance in shaping forest ecosystems and possibly even enhancing biodiversity.

In the area of research on the ecological issues related to commercialisation of N TFPs, the literature reviewed highlighted a number of directions for future research.

- Thereisa critical need for baselineecological studies of NTFPs, at both the level of individual species and forest ecosystems that sustain them.

- In order to understand the relationship between NTFP extraction and ecological change, more studies are required with rigorous research designs that include both collection of Iongitudinal data and the establishment of unharvested control plots.

- Theoretical shifts in biological ecology, particularly with regard to the concept of carrying capacity, must be integrated into research designs.

- The ideal of a pristine forest that needs to be protected from all human interference should be substituted with a more complex and indeterminate model of human-environment relations in future ecological research 


\section{Summary}

There are several patterns and generalisations across all of the four issue areas addressed in the core chapters that are important both to the results of current studies and to the direction of future studies. First, it is clear that the questions and relationships under study do not fit neatly within the jurisdiction of a single discipline. Interdisciplinarity is thereforealmost demanded in research on NTFP, whether conducted by an individual or a team. H owever, the demand for interdisciplinarity creates problems of rigour, reliability and comparability. Researchers trained in the natural sciences conduct social investigations, noneconomists conduct studies on NTFP economics, and social scientists study ecological impacts. Problems arise when individual researchers are not familiar with the body of literature in disciplines other than their own or are untrained in research methods outside their field of specialisation. As a result, findings may not be reliable, data may be incompatible and conclusions may be misleading.

Secondly, a problem exists of a lack of clear definition and consistent use of nomenclature in all of the areas of research. Thereneeds to begreater emphasis placed on defining terms, using recognised references for definitions, and employing greater rigour in the use of terms. In the absence of consistency, it is extremely difficult to compare results from one study to the next.

Thirdly, there is a general scarcity of knowledge and systematically collected baseline data about N T FPs and commercial harvesting and marketing systems. This is more or less equally true in the social, economic and biological realms. If commercial N TFP harvesting and marketing are to play important roles in tropical forest conservation and economic development, more resources are needed to acquire baseline data.

Finally, there is inadequate attention paid to theoretical debates in either the natural or social sciences. Several problems arise from this, including a failure to benefit from related research, the employment of flawed assumptions in research design and an inability to predict or explain outcomes. Similar to the issue of nomenclature, already identified, there needs to be an explicit and clear enunciation of theory in order to facilitate the formulation of sound research design and the comparison of findings. An engagement with research in areas outside the narrow field of tropical forest management that addresses similar ecological, social and ecological questions will help to hasten the advance of knowledge about the consequences of and potential for NTFP commercialisation. 


\section{Bibliography}

Abeygunawardena, P. and Ekanayake, E.R.M . 1994 Valuation of conservation commodity of the Sinharaja Forest: towards total economic value. Sri Lankan Journal of Agricultural Economics 2(1): 7-21.

Adams, W.M. 1990 Green development: Environment and sustainability in theThird World. Routledge, London.

Agarwal, V.S. and Kailash Kumari Amroha. 1995 A case study of Ibrahimpur Region. Bishen Singh M ahendra Pal Singh, D ehra D un, India.

Agyemang, M.M.O . 1994 The leaf gatherers of Kwapanin, Ghana. Forest Participation Series 1. International Institute for Environmental D evelopment, London.

Akella, A.S. and Ankarfjard, R. $1997 \mathrm{H}$ arvesting palm fruits in the JaciParana Extractive Reserve, Brazil. TRI N ews 16.

Alcorn, J.B. 1995 Economic botany, conservation, and development: what's the connection? Annals of the M issouri Botanical Garden 82: 34-46.

Amadi, R. M alleson. $1993 \mathrm{H}$ armony and conflict between N TFP use and conservation in Korup National Park. In: NTFPs - Three views from Africa, 21-8. N etwork Paper 15c (Summer). Rural D evelopment Forestry Network, London.

Anadu, P.A., Elamah, P.O and O ates, J.F. 1988 The bushmeat trade in southwestern N igeria: a case study. H uman Ecology 16: 199-208.

Anderson, A.B. 1988 U se and management of native forests dominated by açai palm (Euterp oleraceae) in the Amazon estuary. Advancesin Economic Botany 6: 144-54.

Anderson, A.B. 1992 Land-use strategies for successful extractive economies. In: Cousell, S. and Rice, T. (eds.) The rainforest harvest: Sustainable strategies for saving the tropical forests?, 213-22. Friends of the Earth, London.

Anderson, A.B. and Ioris, E.M. 1992 Valuing the rain forest: economic strategies by small-scal eforest extractivistsin the Amazon Estuary. H uman Ecology 20: 337-69. 
Anderson, A.B. and Jardim, M .A.G. 1989 Costs and benefits of floodplain forest management by rural inhabitants in the Amazon estuary: a case study of Acai palm production. In: Browder, J.O. (ed.) Fragile lands of Latin America: Strategies for sustainable development, 114-29. Westview Press, Inc., Boulder, Colorado.

Anderson, D.M.W. 1993 Some factors influencing the demand for gum arabic (Acacia senegal (L.) W illd.) and other water-soluble tree exudates. Forest Ecology and $M$ anagement 58: 1-18.

Anon. 1995 Report of the CIFOR workshop on 'Research on N on-timber Forest Products', H ot Springs, Zimbabwe, 28 August-2 September 1995. Typescript.

Appasamy, P.P. 1993 Role of non-timber forest products in a subsistence economy: the case of a joint forestry project in India. Economic Botany 47: 258-67.

Arnold, J.E.M ., Liedholm, C., M ead, D . and Townson, I.M . 1994 Structure and growth of small enterprises using forest products in southern and eastern Africa. O FI O ccasional Paper N 0. 47. 0 xford Forestry Institute, 0 xford. Also GEM IN I Working Paper N 0. 48. Growth and Equity through M icroenterprise Investments and Institutions (GEM IN I) Project, Bethesda, M aryland.

Arvidsson, M. $1996 \mathrm{~N}$ on-timber forest products: A resource in conservation of the Samoan rainforests. Working Paper 312. Swedish University of Agricultural Science, International Rural D evelopment C entre, U ppsala.

Baker, L. 1989 M arketing non-timber tropical forest products: Prospects and promise- a workshop report. Unpublished report prepared in conjunction with a workshop of the Consultative Group on Biological Diversity in cooperation with Cultural Survival, Inc. held on N ov. 7, 1989.

Balick, M .J., Ferro Frazao, J.M ., Anderson, A.B. and. M ay, P.. 1985 Babassu pal $m$ in the agroforestry systems in Brazil's mid-north region. Agroforestry Systems 3: 275-95.

Barborak, J.R. 1998 Buffer zone management: lessons for the M aya Forest. In: Primack, R.B., Bray, D .B., G alletti, H .A. and Ponciano, I. (eds.) Timber, tourists, and temples: Conservation and development in the $M$ aya forest of Belize, Guatemala and M exico, 207-221. Island Press, Washington, DC.

Bassett, T. and C rummey, D. (eds.) 1996 Land in African agrarian systems. University of W isconsin Press, M adison, W isconsin. 
Belsky, J.M . and Siebert, S.F. 1998 N ontimber forest products in community development and conservation: the palm 'D esmoncus schippii' in Gales Point, Belize. In: Primack, R.B., Bray, D.B., G alletti, H .A. and Ponciano, I. (eds.) T imber, tourists, and temples: Conservation and development in the M aya forest of Belize, G uatemala and M exico, 141-153. I sland Press, Washington, DC.

Bhuiyan, A.A. 1995 Who benefits and who loses: theBawalisand non-timber forest products of the Sundarbans, Bangladesh. In: Fox, J., D onovan, D. and DeC oursey, M. (eds.) Voices from the field: Sixth workshop on 'Community $M$ anagement of Forest Lands', 31-52. East-West Center, $\mathrm{H}$ onolulu, $\mathrm{H}$ awaii.

Bishop, J. and Scoones, I. 1994 Beer and baskets: The economics of women's livelihoods in $\mathrm{N}$ gamiland, Botswana. $\mathrm{H}$ idden $\mathrm{H}$ arvest Project 3. Sustainable Agriculture Programme, IIED, London.

Blaikie, P. and Brookfield, H. 1987 Land degradation and society. M ethuen, London.

Boffa, J-M ., Yameogo, G., N ikiema, P. and Knudson, D .M. 1996. Shea nut (Vitellaria paradoxa) production and collection in agroforestry parklands in Burkina Faso. In: Leakey, R.R.B., Temu, A.B., M elnyk M., and VantommeP. (Eds.) D omestication and commercialization of N on-Timber Forest Products in agroforestry systems. N on-Wood Forest Products 9, 110-121. FAO, Rome.

Botkin, D.B. 1990 D iscordant harmonies: A new ecology for the twenty-first century. O xford University Press, N ew York.

Brosius, J.P. 1995 Bornean forest trade in historical and regional perspective: the case of Penan hunter-gatherers of Sarawak. In: Fox, J. (ed.) Society and non-timber forest products in tropical Asia,13-26. East-West Center $O$ ccasional Papers, Environment Series 19. East-West C enter. H onolulu, H awaii.

Browder, J.0 . 1992a Thelimits of extractivism: tropical forest strategies beyond extractive reserves. BioScience 42: 174-82.

Browder, J.0 . 1992b Social and economic constraints on the development of market-oriented extractive reserves in Amazon rain forests. In: N epstad, D.C. and Schwartzman, S. (eds.) N on-timber productsfrom tropical forest: evaluation of a conservation and development strategy, 33-41. The $\mathrm{N}$ ew York Botanical G arden, Bronx, N ew York.

Browder, J.0. 1992c Extractive reserves and the future of the Amazon's rainforests: somecautionary observations. In: Cousell, S. and Rice, T. (eds.) 
The rainforest harvest: Sustainablestrategies for saving the tropical forests?, 224-35. Friends of the Earth, London.

Burkill, I.H . 1935 A dictionary of the economic products of the Malay Peninsula (Second Edition 1966). M inistry of Agriculture and Cooperatives, Kuala Lumpur.

Burman, J.J. Roy. 1990 A need for reappraisal of minor forest produce policies. Indian Journal of Social Work LI: 649-58.

C aldecott, J. 1988 Proposal for an independent review of forestry policy in Sarawak. Land Associates, London (unpublished).

Campbell, J.Y. (Ed.) 1991 Women's role In dynamic forest-based small scale enterprises in Asia: Pattan- $\mathrm{M}$ atchmaking- $\mathrm{H}$ andicrafts. Community Forestry Case Study 4. Bangkok: FAO.

Caron, C.M. 1995 The role of nontimber tree products in household food procurement strategies: profile of a Sri Lankan village. Agroforestry Systems 32(2): 99-117.

Castro, A. de. 1993 Extractive exploitation of the Açai (Euterpe precatoria) near $M$ anaus, Amazonia. In: H ladik, C.M., H ladik, A., Linares, O .F., Pagezy, H ., Semple, A. and H adley, M . (eds.) Tropical forests, peopleand food: Biocultural interactions and applications to development, 779-82. $\mathrm{M}$ an and the Biosphere 13. U NESCO , Paris.

Caufield, C. 1984 In the rainforest: Report from astrange, beautiful, imperiled world. University of Chicago Press, Chicago.

Cavendish, M.W.P. 1997 The economics of natural resource utilization by communal area farmers of Zimbabwe. PhD dissertation. Oxford University, UK.

Chakravarti, I. and Verma, R. 1991 M arketing of a minor forest produce (M FP) in Tribal Sub Plan (TSP) areas through cooperatives in R ajasthan. Indian Journal of Economics 71: 311-21.

Chayanov, A.V. 1986 On the theory of peasant economy. University of $W$ isconsin Press, M adison, W isconsin.

Chen, Xie, Zhong M aogong, Belcher, B., Xie Jinzhong, Fu M aoyi and Ruiz Pérez, M 1996 Policy change in china: the effects on the bamboo sector of Anji County. Journal of Forest Economics 2: 149-76.

Chopra, K. 1993 The value of non-timber forest products: an estimation for tropical deciduous forests in India. Economic Botany 47: 251-57. 
Clay, J. 1992 Building and supplying markets for non-wood tropical forest products. In: Cousell, S. and Rice, T. (eds.) The rainforest harvest: Sustainable strategies for saving the tropical forests?, 250-5. Friends of the Earth, London.

Clay, J. 1997a Brazil nuts: the use of a keystone species for conservation and development. In: Freese, C.H . (ed.) H arvesting wild species: Implications for biodiversity conservation, 246-282. Johns H opkins U niversity Press, Baltimore.

Clay, J. 1997b The impact of palm heart harvesting in the Amazon estuary. In: C.H . Freese (ed.) H arvesting wild species: Implications for biodiversity conservation, 283-314. Johns H opkins U niversity Press, Baltimore.

Coles-Ritchie, M.C. 1996 Analysis of non-timber extractive products from tropical forests: The tagua example in Ecuador. M asters thesis. Bard College.

Corry, S. 1993 'H arvest moonshine' taking you for a ride. Survival international, London.

Cousell, S. and Rice, T. (eds) 1992 Therainforest harvest: Sustainablestrategies for saving the tropical forests? Friends of the Earth, London.

Cunningham, A.B. 1990a Income, sap yield and effects of sap tapping on palms in south-eastern Africa. South African Journal of Botany 56: 13744.

Cunningham, A.B. 1990b Theregional distribution, marketing and economic value of the palm wine trade in the Ingwavuma district, $N$ atal, South Africa. South African Journal of Botany 56: 191-8.

Cunningham, A.B. and M benkum, F.T. 1993 Sustainability of harvesting Prunus africana bark in Cameroon: A medicinal plant in international trade. People and Plants Working Paper 2. U N ESC O, Paris.

D aniels, R.J .R., Gadgil, M . and Joshi, N .V. 1995 Impact of human extraction on tropical humid forests in theW estern G hats in U ttara Kannada, South India. Journal of Applied Ecology 32: 866-74.

Dawar, R. 1994 M arketing and politics of tendu leaves in India. Uppal Publishing $\mathrm{H}$ ouse, $\mathrm{N}$ ew D elhi, India.

de Beer, J.H . and M cD ermott, M . 1989 The economic value of non-timber forest products in Southeast Asian with emphasis on Indonesia, M alaysia and Thailand. M anuscript by $\mathrm{N}$ etherlands $\mathrm{Committee}$ for IUCN, Amsterdam. 
de Fretes, Y. 1992 Community versus company-based rattan industry in Indonesia. In: Cousell, S. and Rice, T. (eds.) The rainforest harvest: Sustainablestrategies for saving the tropical forests?, 142-9. Friends of the Earth, London.

de Janvry, A. 1981 The agrarian question and reformism in Latin America. Johns H opkins U niversity Press, Baltimore.

de Jong, W. and M endelsohn, R.O . 1992 M anaging the non-timber forest products of Southeast Asia. Unpublished manuscript prepared for the World Bank, Southeast Asia Division, M ay 30, 1992.

D ewees, P.A. and Scherr, S.J. 1996 Policies and markets for non-timber tree products. EPTD D iscussion Paper 16. International Food Policy Research Institute, Washington, DC.

Dove, M .R. 1993 A revisionist view of tropical deforestation and development. Environmental Conservation 20: 17-24.

D ove, M .R. 1994 M arketing the rainforest: 'green' panacea or red herring? Analysis from the East-West Center 13: 1-7.

Dove, M .R. 1995 Political versustechno-economic factorsin the development of non-timber forest products: lessons from a comparison of natural and cultivated rubbers in Southeast Asia (and South America). Society and N atural Resources 8: 193-208.

D ufournaud, C.M ., Q uinn, J.T., H arrington, J.J., Yu, C.C., Abeygunawardena, P. and Franzosa, R. 1995 A model of sustainable extraction of nontimber forest products in subsistence societies. Environment and Planning A 27: 1667-76.

D ugelby, B.L. 1998 Governmental and customary arrangements guiding chicle latex extraction in Petén, Guatemala. In: Primack, R.B., Bray, D.B., Galletti, H .A. and Ponciano, I. (eds.) Timber, tourists, and temples: Conservation and development in the $M$ aya forest of Belize, Guatemala and M exico, 155-177. Island Press, Washington, DC.

Economic D evelopment Associates. 1993 The scope of sustainable commercialization of N TFPsin the G arhwal H imalaya. Unpublished draft by Economic Development Associates for Appropriate Technology International, Washington DC.

ED A. (1993) The scope for sustainable commercialisation of NTFPs in the Garhwal Himalaya. D raft Report for Appropriate Technology International. Gurgaon, India: Economic D evelopment Associates. 
Edwards, D .M . 1996a. The trade in non-timber forest products from N epal. M ountain Research and D evelopment 16(4): 1-20.

Edwards, D.M. 1996b N on-timber forest products from N epal: Aspects of the trade in medicinal and aromatic plants. FO RESC M onograph 1/96. M inistry of Forests and Survey Center, Babar M ahal, Kathmandu, N epal.

Emperaire, L. and Pinton, F. 1993 Ecological and socio-economic aspects of extractivism on the M iddle Rio N egro. In: H ladik, C.M., H ladik, A., Linares, O .F., Pagezy, H ., Semple, A. and H adley, M . (eds.) Tropical forests, peopleand food: Biocultural interactions and applications to development, 783-8. M an and the Biosphere 13. U N ESC O, Paris.

Escobar, A. 1995 Encountering development: Themaking and theunmaking of the T hird World. Princeton U niversity Press, Princeton.

Etchart, G. 1995 Sustainable development in one Amazonian varzea. PhD dissertation. University of Washington.

Evans, B. 1996a What we don't know about indigenous nuts in M elanesia. In: Stevens, M.L., Bourke, R.M . and Evans, B.R. (eds.) South Pacific indigenous nuts, 67-74. Australian Centre for International Agricultural Research, C anberra, Australia.

Evans, B. 1996b O verview of resource potential for indigenous nut production in the South Pacific. In: Stevens, M.L., Bourke, R.M. and Evans, B.R. (eds.) South Pacific indigenous nuts, 10-35. Australian Centre for International Agricultural Research, C anberra, Australia.

Fa, J.E., Juste, J., Perez del Val, J. and Castroviejo, J. 1995 The impact of market hunting on mammal species in equatorial Guinea. Conservation Biology 9: 1107-15.

Fairhead, J. and Leach, M. 1996 M isreading the African landscape: Society and ecology in a forest-savanna mosaic. University of Cambridge Press, Cambridge.

Fairhead, J. and Leach, M. 1998 Reframing deforestation: Global analysis and local realities. Studies in West Africa. Routledge Press, London.

Falconer, J. 1990 The major significance of minor forest products - examples from West Africa. Appropriate Technology 17(3): 13-16.

Falconer, J. 1992 A study of the non-timber forest products of $G$ hana's forest zone. In: C ousell, S. and Rice, T. (eds.) T he rainforest harvest: Sustainable strategies for saving the tropical forests?, 135-41. Friends of the Earth, London. 
Falconer, J. n.d. N on-timber forest productsin southern Ghana: main report. Chatham, UK: N atural Resources Institute.

FAO . 1987 Small-scale forest based processing enterprises. Forestry Paper 79. FAO, Rome.

Farrow, S. 1995 Extinction and market forces: two case studies. Ecological Economics 13: 115-23.

Fearnside, P.M . 1989 Extractive reserves in Brazilian Amazonia. BioScience 39: 387-93.

Fernandes, W., M enon, G. and Viegas, P. n.d. Forests, environment and tribal economy. In: Forests, environment and tribal economy. Tribes of India Series. Indian Social Institute.

Fischer, F.U. 1993 Beekeeping in the subsistence economy of the M iombo savanna woodlands of South-C entral Africa. In: NTFPs - Three views from Africa, 1-12. N etwork Paper 15c (Summer). ODI, Rural D evelopment Forestry N etwork, London.

Fitzgibbon, C.D ., M ogaka, H . and Fanshawe, J.H . 1995 Subsistencehunting in Arabuko-SokokeForest, Kenya, and its effects on mammal populations. Conservation Biology 9: 1116-26.

Fox, J. 1995 Non-timber forest products in a N epali village in 1980 and 1990. In: Fox, J. (ed.) Society and non-timber forest products in tropical Asia, 37-54. East-W est Center O ccasional Papers, Environment Series 19. East-West $\mathrm{C}$ enter, $\mathrm{H}$ onolulu, $\mathrm{H}$ awaii.

Franklin, D.J. 1993 The productive potential for ancient oak-coppice woodland in Britain. In: From the field, 19-24. Network Paper 15d (Summer). OD I, Rural D evelopment Forestry N etwork, London.

Freese, C.H . 1997 The 'use it or lose it' debate: issues of a conservation paradox. In: Freese, C.H. (ed.) H arvesting wild species: Implications for biodiversity conservation, 1-47. Johns H opkins University Press, Baltimore.

Fui, Lim H in. 1992 Aboriginal communities and the international trade in non-timber forest products: the case of Peninsular $M$ alaysia. In: $D$ argavel, J. and Tucker, R. (eds.) Changing Pacific forests, 77-88. Forest H istory Society, D urham, N orth Carolina.

Fui, Lim H in and Jamaludin Ismail. 1994 The uses of non-timber forest products in Pasoh Forest Reserve, M alaysia. Research Pamphlet N 0.113. Forest Research Institute M alaysia, Kuala Lumpur, M alaysia. 
Gakou, M ., Force, J.E. and M cLaughlin, W.J. 1994 N on-timber forest products in rural M ali: a study of villager use. Agroforestry Systems 28: 213-26.

Ganesan, B. 1993 Extraction of non-timber forest products, including fodder and fuelwood, in M udumalai, India. Economic Botany 47: 268-74.

Ganesan, B. 1995 Fire, grazing, and extraction of non-timber forest products in the N ilgiris Biosphere Reserve, Southern India: Implications for forest policy, sustainable use and local economies. PhD dissertation. Rutgers University.

Gautam, M. 1995 N on-timber forest product development: new directions for N epal's community forestry program. In: Fox, J., D onovan, D. and DeC oursey, M. (eds.) Voices from the field: Sixth workshop on 'Community Management of Forest Lands', 53-63. East-West Center, $\mathrm{H}$ onolulu, $\mathrm{H}$ awaii.

G hatak, S. 1995 A recipe for success: women and non-timber forest products in Southwest Bengal, India. In: Fox, J., D onovan, D . and D eC oursey, M. (eds.) Voices from thefield: Sixth workshop on 'Community M anagement of Forest Lands', 164-79. East-West Center, $\mathrm{H}$ onolulu, $\mathrm{H}$ awaii.

Godoy, R.A. 1990 Theeconomics of traditional rattan cultivation. Agroforestry Systems 12: 163-72.

Godoy, R.A. and Bawa, K.S. 1993 Theeconomic valueand sustainableharvest of plants and animals from the tropical forest: assumptions, hypotheses and methods. Economic Botany 47: 215-19.

Godoy, R.A. and Lubowski, R. 1992 Guidelines for the economic valuation of nontimber tropical-forest products. Current Anthropology 33: 42332.

Godoy, R.A. and Tan Ching Feaw. 1989 The profitability of smallholder rattan cultivation in Southern Borneo, Indonesia. H uman Ecology 17: 347-63.

Godoy, R.A., Brokaw, N . and W ilkie, D. 1995 The effect of income on the extraction of non-timber tropical forest products: model, hypotheses and preliminary findings from the Sumu Indians of $\mathrm{N}$ icaragua. H uman Ecology 23: 29-52.

Graefen, A. 19950 pportunities and limitations of non-timber forest product development: a case study from polyarchic forest in West Kalimantan, Indonesia. In: Fox, J., D onovan, D. and D eC oursey, M. (eds.) Voices from the field: Sixth workshop on 'C ommunity $M$ anagement of Forest Lands', 103-16. East-West Center, H onolulu, H awaii. 
Gray, A. 1992 Indigenous peoples and the marketing of the rainforest. In: Cousell, S. and Rice, T. (eds.) Therainforest harvest: Sustainablestrategies for saving the tropical forests?, 236-45, Friends of the Earth, London.

Grove, R. 1995 Green imperialism: Colonial expansion, tropical island Edens and the origins of environmentalism, 1600-1860. C ambridge U niversity Press, Cambridge.

Gunatilake, H.M. 1994 Factors influencing peripheral villager dependency on forest resources use in the K nuckles Forest Range. Sri Lankan Journal of Agricultural Economics 2(1): 23-33.

Gunatilake, H .M ., Senaratne, D .M .A.H . and Abeygunawardena, P. 1993 Role of non-timber forest products in the economy of peripheral communities of Knuckles $\mathrm{N}$ ational W ilderness Area of Sri Lanka: a farming systems approach. Economic Botany 47: 275-81.

Gunatilleke, I.A.U.N ., Gunatilleke, C.V.S. and Abeygunawardena, P. 1993 Interdisciplinary research towards management of non-timber forest resources in lowland rain forests of Sri Lanka. Economic Botany 47: 282-90.

$\mathrm{H}$ aggblade, S. and Liedholm, C. 1991 Agriculture, rural labor markets, and evolution of the rural nonfarm economy. GEM IN I Working Paper N 0. 19. Growth and Equity through M icroenterprise Investments and Institutions (GEM IN I) Project, Bethesda, M aryland.

$\mathrm{H}$ all, P. and Bawa, K.S. 1993 M ethods to assess the impact of extraction of non-timber tropical forest products on plant populations. Economic Botany 47: 234-47.

$\mathrm{H}$ anson, J.H. 1992 Extractive economies in a historical perspective: gum Arabic in West Africa. Advances in Economic Botany 9: 107-14.

H artshorn, G.S. 1989 Sustained yield management of natural forests: the Palcazu production forest. In: Browder, J.O. (ed.) Fragile lands of Latin America: Strategies for sustainable development, 130-7. Westview Press, Inc., Boulder, Colorado.

Hecht, S.B. and Cockburn, A. 1990 The fate of the forest: D evelopers, destroyers and defenders of the Amazon. $\mathrm{H}$ arper Perennial, N ew York.

Hecht, S.B., Anderson, A.B. and M ay, P. 1988 The subsidy from nature: shifting cultivation, successional palm forests, and rural development. H uman O rganization 47: 25-35.

H egde, R., Suryaprakash, S., Achoth, L. and Bawa, K.S. 1996 Extraction of non-timber forest products in the forests of Biligiri Rangan Hills, India: 1. Contribution to rural income. Economic Botany 50: 243-51. 
H idalgo, R.C. 1992 The tagua initiative in Ecuador: a community approach to tropical rain forest conservation and development. In: Plotkin, $M$. and Famolare, L. (eds.) Sustainable harvest and marketing of rain forest products, 263-273. Island Press, Washington, DC.

H omma, A.K.O 1992 The dynamics of extraction in Amazonia: a historical perspective. In: N epstad, D.C. and Schwartzman, S. (eds.) N on-timber products from tropical forests: Evaluation of a conservation and development strategy, 23-31. Advances in Economic Botany 9. The N ew York Botanical G arden, Bronx, N ew York.

H opkins, J.C., Scherr, S.J . and Gruhn, P. 1994 Food security and the commons: Evidence from N iger. Report to U SAID by the International Food Policy Research Institute, Washington, DC.

$\mathrm{H}$ ot Springs W orking Group 1995 Local-level economic valuation of savanna woodland resources: $\mathrm{V}$ illage cases from Z $\mathrm{Zimbabwe}$. The $\mathrm{H}$ idden $\mathrm{H}$ arvest: The Role of Wild Foods in Agricultural Systems Research Series 3(2). International Institute for Environment and D evelopment, London.

Hulse, J. 1996 Flavours, spices and edible gums: opportunities for integrated agroforestry systems. In: Leakey, R.R.B., Temu, A.B. , M elnyk, M. and Vantomme, P. (Eds.) Domestication and commercialization of nontimber forest products in agroforestry systems, 86-96. N on-W ood Forest Products 9. FAO, Rome.

H yde, W.F. and Amacher, G.S. 1996 Applications of environmental accounting and the new household economics: new technical economic issues with a common themein forestry. Forest Ecology and $M$ anagement 83: 137-48.

IWGIA. 1993 Indigenous peoples and the commercialization of forest products. IW G IA N ewsletter 3(July-September): 7-9.

Jiwu, Xie. 1992 Tropical forest products and extractive resources in Xishuangbanna, C hina. In: Cousell, S. and Rice, T. (eds.) The rainforest harvest: Sustainablestrategies for saving the tropical forests?, 130-4. Friends of the Earth, London.

Jodha, N .S. 1986 Common property resources and rural poor in dry regions of India. Economic and Political Weekly 21(27): 1169-81.

Jodha, N.S. n.d. Rural common property resources: A growing crisis. Gatekeeper Series N 0. 24. International Institute for Environment and Development, London.

Jorgenson, J.P. 1998 The impact of hunting on wildlife in the M aya Forest of M exico. In: Primack, R.B., Bray, D.B., Galletti, H.A. and Ponciano, I. 
(eds.) Timber, tourists, and temples: Conservation and development in the $M$ aya forest of Belize, Guatemala and M exico, 179-193. Island Press, Washington, DC.

Kainer, K.A. and D uryea, M.L. 1992 Tapping women's knowledge: plant resource use in extractive reserves, Acre, Brazil. Economic Botany 46: 408-25.

Kandeh, H.B.S. and Richards, P. (1996) "Rural people as conservationists: Q uerying neo-malthusian assumptions about biodiversity in sierra leone. Africa 66(1): 90-103.

Karkee, T.B. 1995 U sing TSI (tree stand improvement) to enhance nontimber production in N epal's community forests. In: Fox, J., D onovan, $D$. and D eC oursey, M. (eds.) Voices from the field: Sixth workshop on 'Community $M$ anagement of Forest Lands', 145-63. East-West Center, $\mathrm{H}$ onolulu, $\mathrm{H}$ awaii.

Karki, J.B.S. 1995 U se, availability, and marketing of non-timber forest products in eastern N epal. In: Fox, J., D onovan, D . and D eC oursey, M . (eds.) Voices from the field: Sixth workshop on 'Community $M$ anagement of Forest Lands', 64-82. East-West Center, $\mathrm{H}$ onolulu, $\mathrm{H}$ awaii.

Kisdwiutomo, Wahyu 1995 Damar trading in South Sumatra, Indonesia: who benefits?. In: Fox, J., D onovan, D . and D eC oursey, M. (eds.) Voices from the field: Sixth workshop on 'C ommunity $M$ anagement of Forest Lands', 193-202. East-West Center, H onolulu, $\mathrm{H}$ awaii.

LaFrankie, J.V. 1994 Population dynamics of some tropical trees that yield non-timber forest products. Economic Botany 48: 301-9.

Lawrence, D .C., Leighton, M . and Peart, D .R. 1995 Availability and extraction of forest products in managed and primary forest around a $D$ ayak village in West Kalimantan, Indonesia. Conservation Biology 9: 76-88.

Leocadio, F. 1995 Beyond marketing: developing the products of the Philippines uplands. In: Fox, J., D onovan, D . and D eC oursey, M . (eds.) Voices from the field: Sixth workshop on 'C ommunity M anagement of Forest Lands', 117-30. East-West C enter, H onolulu, $\mathrm{H}$ awaii.

Lescure, J.-P., Emperaire, L., Pinton, F. and Renault-Lescure, O . 1992 $N$ ontimber forest products and extractive activities in the M iddle Rio N egro Region, Brazil. In: Plotkin, M .and Famolare, L. (eds.) Sustainable harvest and marketing of rain forest products, 151-7. Island Press, Washington, DC. 
Lescure, J.-P, Emperaire, L. and Pinton, F. $1994 \mathrm{M}$ an and forest products in Central Amazonia: A multidisciplinary approach of extractivism. Typescript.

Lim, H .F., Vincent, J. and Woon, W.C. 1994 M arkets for non-timber forest products in the vicinity of Pasoh forest reserve, $M$ alaysia: preliminary survey results. Journal of Topical Forest Science 6: 502-7.

Ling, L. 1995 N on-timber forest products in southwest Sichuan. In: Fox, J., Donovan, D. and D eCoursey, M. (eds.) Voices from the field: Sixth workshop on 'C ommunity $M$ anagement of Forest Lands', 133-44. EastWest $\mathrm{C}$ enter, $\mathrm{H}$ onolulu, $\mathrm{H}$ awaii.

Lynch, 0. 1995 Involving local people in the management and harvesting of non-wood forest products. In: D urst, P. and Bishop, A. (Eds.) Beyond timber: Social, economic and cultural dimensions of non-wood forest products in Asia and the pacific, 37-46. FAO, Bangkok.

M ahapatra, A. and M itchell, C.P. 1997 Sustainable development of nontimber forest products: implication for forest management in India. Forest Ecology and $M$ anagement 94: 15-29.

M alhotra, K.C. 1993 People, biodiversity and regenerating topical sal (Shorea robusta) forests in West Bengal, India. In: H ladik, C.M., H ladik, A., Linares, O .F., Pagezy, H., Semple, A. and H adley, M . (eds.) Tropical forests, peopleand food: biocultural interactions and applicationsto development, 745-52. $\mathrm{M}$ an and the Biosphere 13. U NESCO, Paris.

M al hotra, K.C., D ebal D eb, D utta, M ., Vasulu, T.S., Yadav, G . and Adhikari, M. 1993 The role of non-timber forest products in village economies of south-west Bengal. In: From the field, 1-8. N etwork Paper 15d (Summer). OD I, Rural D evelopment Forestry N etwork, London.

M ander, M ., M ander, J. and Breen, C. 1996. Promoting the cultivation of indigenous plants for markets: experiences from KwaZulu-N atal, South Africa. In: Leakey, R.R.B., Temu, A.B. , M elnyk, M . and Vantomme, P. (Eds.) D omestication and commercialization of non-timber forest products in agroforestry systems, 104-109. N on-Wood Forest Products 9. FAO, Rome.

M argoluis, R.A. 1994 Conservation for health: exploring the association between the small-scale commercial utilization of non-timber forest resources and human health in a tropical forest biosphere reserve. PhD dissertation. 
M aryani, R. 1995 A forest concession for local people in Sanggau, West Kalimantan, Indonesia. In: Fox, J., D onovan, D . and D eC oursey, M . (eds.) Voices from the field: Sixth workshop on 'Community $M$ anagement of Forest Lands', 20-30. East-West Center, $\mathrm{H}$ onolulu, $\mathrm{H}$ awaii.

M asters, E. and Puga, A. n.d. The Shea Project for local conservation and development. Draft Report Cooperative Office for Voluntary Organizations (COVOL), Uganda.

M attson, L. and C huan-Zhong Li. $1994 \mathrm{H}$ ow do different forest management practices effect the non-timber value of forests? An economic analysis. Journal of Environmental M anagement 41: 79-88.

M ay, P.H . 1990 Local product markets for babaçu and agro-industrial change in M aranhão, Brazil. Advances in Economic Botany 8: 92-102.

M ay, P.H . 1991 Building institutions and marketsfor non-wood forest products from the Brazilian Amazon. Unasylva 42(165): 9-16.

M cC all, M .K . and M .M. Skutsch. 1993 Taungya farmers of H ambantota. In: From the fiel, 9-18. Network Paper 15d (Summer). ODI, Rural D evelopment Forestry N etwork, London.

M CElwee, P.D . 1994 Common property and commercialisation: D eveloping appropriate tools for analysis. M asters Thesis, 0 xford U niversity.

M elnyk, M . 1996 Indigenous enterprise for the domestication of trees and the commercialization of their fruits. In: Leakey, R.R.B., Temu, A.B., Melnyk, M. and Vantomme, P. (Eds.) Domestication and commercialization of non-timber forest products in agroforestry systems, 97-109. N on-Wood Forest Products 9. FAO, Rome.

M endelsohn, R.O. and M.J. Balick. 1992 Assessing the economic value of traditional medicines from tropical rain forests. Conservation Biology 6 : 128-30.

M uniz-M iret, N ., Vamos, R., H iraoka, M ., M ontagnini, F. and M endelsohn, R.O. 1996 The economic value of managing the açai palm (Euterpe oleracea $M$ art.) in the floodplains of the Amazon estuary, Para, Brazil. Forest Ecology and $M$ anagement 87: 163-73.

M urali, K.S., Shankar, U ., Shaanker, R.U ., G aneshaiah, K .N . and Bawa, K.S. 1996 Extraction of non-timber forest products in the forests of Biligiri Rangan Hills, India: 2. Impact of NTFP extraction on regeneration, population structure, and species composition. Economic Botany 50(3): 252-69. 
M urrieta, J. Ruiz and Levistre Ruiz, J. 1993 Aguajales: forest fruit extraction in the Peruvian Amazon. In: H ladik, C.M., H ladik, A., Linares, O F., Pagezy, H. . Semple, A. and H adley, M . (eds.) Tropical forests, people and food: Biocultural interactions and applications to development, 797-804. $M$ an and the Biosphere 13. U N ESCO, Paris.

M yers, N . 1979 The sinking ark: A new look at the problem of disappearing species. Pergamon Press, N ew York.

N ations, J.D . 1992 Xateros, C hicleros, and Pimenteros: harvesting renewable tropical forest resources in the Guatemala Petén. In: Redford, K.H . and Padoch, C. (eds.) Conservation of neotropical forests: Working from traditional resource use, 208-19. Columbia U niversity Press, N ew York.

$\mathrm{N}$ ational G eographic Society. 1992. The C oexistance of indigenous peoples and the natural environment. Special map supplement to Research and Exploration, Spring. The Society, Washington, D.C.

N epstad, D.C. and Schwartzman, S. (eds.) $1992 \mathrm{~N}$ on-timber products from tropical forest: Evaluation of a conservation and development strategy. Advances in Economic Botany 9. TheN ew York Botanical Garden, Bronx, N ew York.

N epstad, D.C., Brown, I.F., Luz, L.,. Alechandre, A and Viana, V. 1992 Biotic impoverishment of Amazonian forests by rubber tappers, loggers and cattle ranchers. In: N epstad, D .C. and Schwartzman, S. (eds.) N ontimber products from tropical forest: Evaluation of a conservation and development strategy, 1-14. The N ew York Botanical Garden, Bronx, N ew York.

N eumann, R.P. 1997a Forest rights, privileges, and prohibitions: contextualizing state forestry policy in Tanganyika. Environment and H istory 3(1): 45-68.

N eumann, R.P. 1997b Primitive ideas: protected area buffer zones and the politics of land in Africa. D evelopment and Change 28: 559-82.

N eumann, R.P. 1998 Imposing wilderness: Struggles over livelihood and nature preservation in Africa. Berkel ey: U niversity of C alifornia Press.

Nilkamhaeng, N 1995 Lac: promising forest and agro-forestry product in Thailand. In: Fox, J., D onovan, D . and D eC oursey, M . (eds.) Voices from the field: Sixth workshop on 'C ommunity $M$ anagement of Forest Lands', 180-92. East-West Center, H onolulu, H awaii.

O 'C onnor, M. (ed.) 1994 Is capitalism sustainable? Political economy and the politics of ecology. Guilford Press, N ew York. 
O 'D onnel Sills, E. 1990 Extractive reserves in the Brazilian Amazon. BA Thesis, Wodrow Wilson School of Public and International Affairs, Princeton University.

$\mathrm{O}$ 'H ara, J. 1998 M onitoring nontimber forest product harvest for ecological sustainability: a case study of $\mathrm{H}$ uano (Sabal mauritiiformis) in the Rio Bravo Conservation and $M$ anagement Area, Belize. In: Primack, R.B., Bray, D.B., Galletti, H.A. and Ponciano, I. (eds.) Timber, tourists, and temples: Conservation and development in the Maya forest of Belize, Guatemala and M exico, 195-207. Island Press, Washington, D C

Olsen, C. Smith. 1997a A qualitative assessment of the sustainability of commercial non-timber forest product collection in N epal. In: O Isen, C. Smith, Commercial non-timber forestry in Central Nepal: Emerging themes and priorities, Chapter 6 (submitted to M ountain Research and D evelopment).

Olsen, C. Smith. 1997b The trade in medicinal and aromatic plans from central $\mathrm{N}$ epal to northern India. In: OIsen, C. Smith, Commercial nontimber forestry in C entral $\mathrm{N}$ epal: Emerging themes and priorities, $\mathrm{C}$ hapter 3 (submitted to Economic Botany).

Olsson, G. 1991 The socio-economic importance of non-timber forest products in the South Pacific: focus on Vanuatu. Unasylva 42(165): 24-30.

Olsson, M. 1996 O kari Ecoenterprises: a snapshot of participatory rural development. In: Stevens, M.L., Bourke, R.M. and Evans, B.R. (eds.) South Pacific indigenous nuts, 94-9. Australian Centre for International Agricultural Research, Canberra, Australia.

Pachauri, R. 1990 Sal plate processing and marketing in West Bengal. Sustainable Forest M anagement Working Paper \#12. Ford Foundation, N ew D elhi, India.

Packham, J. 1993 The value of indigenous fruit-bearing trees in M iombo woodland areas of South-C entral Africa. In: NTFPs - Three views from Africa, 13-20. N etwork Paper 15c (Summer). O D I, Rural D evelopment Forestry N etwork, London.

Padoch, C. 1992b M arketing of non-timber forest products in Western Amazonia: general observations and research priorities. In: N epstad, D.C. and Schwartzman, S. (eds.) N on-timber products from tropical forests: Evaluation of a conservation and development strategy, 43-50. Advances in Economic Botany 9. The New York Botanical Garden, Bronx, N ew York. 
Padoch, C. 1992a The economic importance and marketing of forest and fallow products in the Iquitos region. In: Cousell, S. and Rice, T. (eds.) The rainforest harvest: Sustainablestrategies for saving the tropical forests?, 177-97. Friends of the Earth, London.

Padoch, C. 1995 Creating the forest: Dayak resource management in Kalimantan. In: Fox, J. (ed.) Society and non-timber forest products in tropical Asia, 3-12. East-West Center O ccasional Papers, Environment Series 19. East-West Center, $\mathrm{H}$ onolulu, $\mathrm{H}$ awaii.

Padoch, C. and de Jong, W. 1989 Production and profit in agroforestry: an example from the Peruvian Amazon. In: Browder, J.0 (ed.) Fragile lands of Latin America: Strategies for sustainable development, 102-13. Westview Press, Inc., Boulder, Colorado.

Panayotou, T. and Ashton, P. $1992 \mathrm{~N}$ ot by timber alone. Economics and ecology for sustaining tropical forests. Island Press, Washington, DC.

Panya, O ., Lovelace, G.W., Prasat Saenchi and Panomsak Promburom. 1988 C harcoal making in rural northeast Thailand. Research report of the KKU FO RD Rural Systems Research Project, Khon Kaen University.

Pedersen, H .B. 1996 Production and harvest of fibers from Aphandra natalia in Ecuador. Forest Ecology and $M$ anagement 80: 155-61.

Pedersen, H. Borgtoft and Balslev, H. 1992 The economic botany of Ecuadorian palms. In: Plotkin, M. and Famolare, L. (eds.) Sustainable harvest and marketing of rain forest products, 173-91. Island Press, Washington, DC.

Peet, R. and Watts, M . 1993 D evelopment theory and environment in an age of market triumphalism. Economic G eography 69: 227-53.

Pelomo, P.M ., Barasi, R.N ., Liliqula, R. and Roposi, N . 1996 Canarium nut and oil marketing in the Solomon Islands. In: Stevens, M.L., Bourke, R.M . and Evans, B.R. (eds.) South Pacific indigenous nuts, 76-8. Australian Centre for International Agricultural Research, Canberra, Australia.

Peluso, N.L. 1992a Rich forests, poor people: Resource control and resistance in Java. University of C alifornia Press, Berkeley.

Peluso, N.L. 1992b The rattan trade in East Kalimantan, Indonesia. In: Nepstad, D.C. and Schwartzman, S. (eds.) N on-timber products from tropical forests: Evaluation of a conservation and development strategy, 115-27. Advancesin Economic Botany 9. T heN ew York Botanical G arden, Bronx, N ew York. 
Peluso, N.L. and Padoch, C. 1996 Changing resource rights in managed forests in West Kalimantan. In: Padoch, C. and Peluso, N .L. (eds.) Borneo in transition: People, conservation, and development, 121-36. Oxford University Press, 0 xford.

Pendelton, L.H . 1992 Trouble in paradise: practical obstacles to nontimber forestry in Latin America. In: Plotkin, M. and Famolare, L. (eds.) Sustainable harvest and marketing of rain forest products, 252-62. Island Press, Washington, DC.

Peters, C.M. 1990 Population ecology and management of forest fruit trees in Peruvian Amazonia, 86-90. In: Anderson, A.B. (ed.) Alternatives to deforestation: Steps toward sustainable use of the amazon rain forest. Columbia University Press, N ew York.

Peters, C.M. 1992 The ecology and economics of oligarchic forests. In: N epstad, D.C. and Schwartzman, S. (eds.) N on-timber products from tropical forests: Evaluation of a conservation and development strategy, 15-22. Advances in Economic Botany 9. TheN ew York Botanical G arden, Bronx, N ew York.

Peters, C.M . 1994 Sustainableharvest of non-timber plant resources in tropical moist forest: An ecological primer. Biodiversity Support Program, Washington, DC.

Peters, C.M. 1996a The ecology and management of non-timber forests resources. World Bank Technical Paper N umber 322. The World Bank, Washington, DC.

Peters, C.M . 1996b Illipenuts (Shorea spp.) in West Kalimantan: use, ecology, and management potential of an important forest resource. In: Padoch, C. and Peluso, N.L. (eds.) Borneo in transition: People, conservation, and development, 230-44. 0 xford University Press, 0 xford.

Peters, C.M., Gentry, A.H . and Mendelsohn, R.O. 1989 Valuation of an Amazonian rainforest. N ature 339(29): 655-6.

Peters, C.M., Rosenthal, J. and U rbina, T. 1987 O tomi bark in Mexico: commercialization of a pre $\mathrm{H}$ ispanic technology. Economic Botany 41 : 423-32.

Phillips, O .L.B. 1992 Thepotential for harvesting fruits in tropical rainforests: new data from Amazonian Peru. Biodiversity and Conservation 2: 18-38.

Phillips, O L.B. 1993 Comparativevaluation of tropical forestsin Amazonian Peru. PhD dissertation. Washington University. 
Pimentel, D ., M cN air, M ., Buck, L., Pimentel, M . and Kamil, J. 1997 The value of forests to world food security. H uman Ecology 25: 91-120.

Pinheiro, C. Urbano B. and Ferro Frazao, J.M. 1995 Integral processing of babassu palm (O rbignya phalerata, arecaceae) fruits: villagelevel production in M aranhão, Brazil. Economic Botany 49: 31-9.

Place, S. 1993 Tropical forests: Latin American natureand society in transition. Scholarly Resources Inc, W ilmington.

Plotkin, M. and Famolare, L. (eds.) 1992 Sustainable harvest and marketing of rain forest products. Island Press, Washington, DC.

Prance, G. 1989 Economic prospects from tropical rainforest ethnobotany. In: J.0. Browder (ed.) Fragile lands of Latin America: Strategies for sustainable development, 61-73. Westview Press, Inc., Boulder, Colorado.

Prance, G., Balee, W. and Boom, B. 1992 Q uantitative ethnobotany and the case for conservation in Amazonia. In: Cousell, S. and Rice, T. (eds.) The Rainforest H arvest: SustainableStrategies for Saving theTropical Forests?, 117-29, Friends of the Earth, London.

Prasad, R. and Bhatnagar, P. 1993 N on-wood forest products and the indigenousfringedwellers in M adhya Pradesh. Journal of Tropical Forestry 9: 188-95.

Prempeh, Y. Afua Breh 1993 N on-timber forest products, trade policies and the conservation of forest resources in South Sulawesi: T he case of rattan. $M$ asters thesis. $D$ al housie University.

Rao, A. Ratna and Singh, B.P. 1996 N on-wood forest products contribution in tribal economy (A case study in South Bihar and South West Bengal). Indian Forester 122: 337-41.

Rao, K.S. and Saxena, K.G. 1996 M inor forest products' management: problems and prospects in remote high altitude villages of Central $H$ imalaya. International Journal of Sustainable D evelopment and World Ecology 3: 60-70.

Rawal, R.B. 1995 Constraints to the development of non-timber forest products in N epal. In: Fox, J., D onovan, D. and D eC oursey, M. (eds.) Voices from the field: Sixth workshop on 'C ommunity $M$ anagement of Forest Lands', 203-20. East-West Center, H onolulu, H awaii.

Redford, K.H. and Padoch, C. (eds.) 1992 Conservation of neotropical forests: Working from traditional resource use. Columbia University Press, $N$ ew York. 
Redford, K. 1992. Game harvesting in tropical forests. In: Cousell, S. and Rice, T. (eds.) The Rainforest H arvest: Sustainable Strategies for Saving the Tropical Forests?, 150-4, Friends of the Earth, London.

Redford, K. and Robinson, J.G. 1987. The game of choice: patterns of Indian and colonist hunting in the neotropics. American Anthropologist 89: 650-67.

Richards, E.M . 1993a Commercialization of non-timber forest products in Amazonia. N RI Socioeconomics Series 2. Natural Resources Institute, Chatham, UK.

Richards, M. 1993b The potential of non-timber forest products in sustainable natural forest management in Amazonia. C ommonwealth Forestry Review 72: 21-7.

Richards, M. 1997 Common property resource institutions and forest management in Latin America. D evelopment and Change 28: 95-117.

Robinson, J.G. and Redford, K.H. 1991 Sustainable harvest of neotropical forest animals. In: Robinson, J.G. and Redford, K.H . (eds.) neotropical wildlife useand conservation, 415-429. Chicago U niversity Press, Chicago.

Romanoff, S. 1992 Food and debt among rubber tappers in the Bolivian Amazon. H uman O rganization 51: 122-35.

Ruiz Pérez, M . and Arnold, M. (eds.) 1997 Current Issues in N on-Timber Forest Products. Center for International Forestry Research, Bogor, Indonesia.

Sabin, J.R. (1996) Theterra nova medicinal plant reserve: Bridging conservation with development. $\mathrm{M}$ asters thesis. U niversity of $\mathrm{N}$ ew M exico.

Salick, J., M ejia, A. and Anderson, T. 1995 Non-timber forest products integrated with natural forest management, Rio San Juan, N icaragua. Ecological Applications 5: 878-95.

Saulei, S.M . and Aruga, J.A. 1994 The status and prospects of non-timber forest products development in Papua N ew Guinea. Commonwealth Forestry Review 73: 97-105.

Schreckenberg, K. 1996 Forests, fields and markets: a study of indigenous tree products in the woody savannas of the Bassila region, Benin. PhD dissertation. University of London.

Schroeder, R. 1995 Contradictions along the commodity road to environmental stabilization: foresting $\mathrm{G}$ ambian gardens. Antipode 27: 325-42.

Schwartzman, S. 1989 Extractive reserves: the rubber tappers' strategy for sustainable use of the Amazon rainforest. In: Browder, J.0 . (ed.) Fragile 
lands of Latin America: Strategies for sustainable development, 150-63. Westview Press, Inc., Boulder, Colorado.

Schwartzman, S. 1992 Social movements and natural resource conservation in the Brazilian Amazon. In: C ousell, S. and Rice, T. (eds.) The Rainforest H arvest: Sustainable Strategies for Saving the Tropical Forests?, 207-12, Friends of the Earth, London.

Schwartzman, S. and Allegretti, M.H. 1987 Extractive production in the Amazon and the rubber tappersmovement. Environmental $D$ efenseFund, Washington, DC.

Sekar, C., V inaya Rai, R.S. and Surendran, C. 1993 Price regime analysis, marketing and trade of minor forest products. Center for $\mathrm{M}$ inor Forest Products, D ehra D un, India.

Shakeb, A. 1992 Extractive reserves: economic-environment issues and marketing strategies for non-timber forest products. Unpublished draft for EN VAP, The World Bank, Washington, D C.

Shankar, U., M urali, K.S., Shaanker, R.U ., G aneshaiah, K.N . and Bawa, K.S. 1996 Extraction of non-timber forest products in the forests of Biligiri Rangan H ills, India: 3. Productivity, extraction and prospects of sustainable harvest of amla Phyllanthus emblica (Euphorbiaceae). Economic Botany 50: $270-9$.

Siebert, S.F. 1995 Prospects for sustained-yield harvesting of rattan (Calamus spp.) in two Indonesian national parks. Society and N atural Resources 8 : 209-18.

Siebert, S.F. and Belsky, J.M . 1985 Forest-product trade in a lowland Filipino village. Economic Botany 39: 522-33.

Singh, S, A. D atta, A. Bakshi, A Khare, S. Saigal, and Kapoor, N. 1997 Participatory forest management in West Bengal, India. In: Freese, C.H. (ed.) $\mathrm{H}$ arvesting wild species: Implications for biodiversity conservation, 44-92. Johns H opkins U niversity Press, Baltimore.

Siscawati, M . 1995 Potential impacts of non-timber forest product certification in Indonesia. In: Fox, J., D onovan, D. and D eC oursey, M. (eds.) Voices from thefield: Sixth workshop on 'C ommunity M anagement of Forest $L$ ands', 1-19. East-West Center, $\mathrm{H}$ onolulu, $\mathrm{H}$ awaii.

Sizer, N .C. 1993 Socio-economic aspects of extractivism in the Jau N ational Park, Amazonia. In: H ladik, C.M ., H ladik, A., Linares, O .F., Pagezy, H ., Semple, A. and Hadley, M. (eds.) Tropical forests, people and food: Biocultural interactions and applications to development. $M$ an and the Biosphere 13, 789-96. U N ESC 0, Paris. 
Slone, T.H ., O rsak, L.J. and M alver, O. 1997 A comparison of price, rarity and cost of butterfly specimens: I mplications for the insect trade and for habitat conservation. Ecological Economics 21: 77-85.

Southgate, D. 1998 Tropical forest conservation. O xford U niversity Press, Oxford.

Stephens, A. (1995) "Participatory management and gender issues in nonwood forest product development". In: D urst, P. and Bishop, A. (Eds.) Beyond timber: social, economic and cultural dimensions of non-wood forest products in Asia and the Pacific, 47-53. FAO, Bangkok.

Stiles, D . 1994 Tribals and trade: astrategy for cultural and ecological survival. Ambio 23(2): 106-11.

Taylor, D.A. 1997 Saving the forest for the trees. Environment 39(1): 6-11, 33-6.

Taylor, F., M ateke, S.M . and Butterworth, K.J . 1996 A holistic approach to the domestication and commercialization of non-timber forest products. In: Leakey, R.R.B., Temu, A.B. , M elnyk, M . and Vantomme, P. (Eds.) Domestication and commercialization of non-timber forest products in agroforestry systems, 75-85. N on-Wood Forest Products 9. FAO, Rome.

Terry, M .E. 1984 Botswanacraft and $\mathrm{H}$ ambukushu basketry: The effects of a major marketing operation on a group of African people, their traditional craft, and the natural resources. Botswanacraft M arketing Company. Unpublished typescript.

Terry, M.E. and Cunningham, A.B. 1993 Impact of commercial marketing on the basketry of southern Africa. Journal of M useum Ethnography 4: 25-48.

Tewari, D.D. 1994 D eveloping and sustaining nontimber forest products: policy issues and concerns with special reference to India. Journal of World Forest Resource M anagement 7: 151-78.

Tewari, D.D. and Campbell, J.Y. 1996 Increased development of nontimber forest products in India: some issues and concerns. Unasylva 47(187): 26-31.

Tewari, D .N . 1993 N on-timber forest produce in poverty alleviation. Indian Forester 119: 959-69.

Thomas, P. 1996 Collection and marketing of non-timber forest products by the K irala G irijans. C entre for M inor Forest Products, D ehra D un, India.

Thomas, P. and M eera Bai, M. 1993 M arketing of non-timber forest produce (N TFP) and the tribal economy of Kerala- an economic analysis. Journal of Tropical Forestry 9: 196-203. 
Tilling, A.J. 1994 Realising the potential of non-timber forest products: the predicament of West Coast indigenous forest-based users in the South Island, N ew Zealand. Journal of World Forest R esource M anagement 7(2): 129-50.

Ting, Zuo. 1995 From resource to market: non-timber forest product development in Yunnan, C hina. In: Fox, J., D onovan, D . and D eC oursey, $M$. (eds.) Voices from the field: Sixth workshop on 'Community $M$ anagement of Forest Lands', 83-102. East-West Center, $H$ onolulu, H awaii.

Townson, I.M . 1995 Incomes from non-timber forest products: Patterns of enterprise activity in the forest zone of southern G hana. OD A, London.

van Valkenburg, J.L.C.H. 1997 Non-timber forest products of East Kalimantan: Potentials for sustainable forest use. TheTropenbos Foundation, Wageningen, The $\mathrm{N}$ etherlands.

Verheij, B. and Reinders, M . 1997 Thestatus of the extraction and marketing of timber and non-timber forest products by Amerlndians in the G uyanese context. BOS N iEuW SLET TER. 16(1/35): 15-21.

Vosti, S.A. and W itcover, J. 1996 N on-timber tree product (N T TP) market research workshop - an overview. M P-8 Working Paper (M ay). EPTD, International Food Policy Research Institute, Washington, DC.

Warner, K. 1995 M arketing, valuation and pricing of N WFPs. In: D urst, P. and Bishop, A. (eds.) Beyond timber: Social, economic and cultural dimensions of non-wood forest products in Asia and the Pacific, 97-108. FAO, Bangkok, Thailand.

Watts, M. 1991 Visions of excess: African development in an age of market idolatry. Transition 51: 125-41.

Whitmore, T.C. 1990 An Introduction to tropical rainforests. Clarendon Press, 0 xford.

Wickens, G.E. 1991 M anagement issues for development of non-timber forest products. Unasylva 42(165): 3-8.

Wissink, D. 1996 Galip (Canarium indicum) as a cash crop in West N ew Britain, Papua N ew Guinea: experiences of the Kandrian Gloucester integrated development project. In: Stevens, M.L., Bourke, R.M. and Evans, B.R. (eds.) South Pacific indigenousnuts, 84-91. Australian Centre for International Agricultural Research, Canberra, Australia. 
Worboys, M . 1990 The Imperial Institute: the state and the development of the natural resources of the colonial empire, 1887-1923. In: M ack enzie, J.M. (ed.) Imperialism and the natural world, 164-85. University of $M$ anchester Press, $M$ anchester.

World Commission on Environment and D evelopment. 1987. O ur common future. 0 xford University Press, 0 xford.

Worster, D. (1990) "Transformations of The Earth". Journal of American H istory 76(4): 1087-106.

Zimmerer, K. 1994 H uman geography and the 'new ecology': the prospect and promise of integration. Annals of the Association of American Geographers 84: 108-25. 


\section{Appendix A}

\section{Fields for NT FP D atabase}

\begin{tabular}{|c|c|c|}
\hline Field Name & D escription & Valid Entries \\
\hline $\begin{array}{l}\text { Article. } \\
\text { IDNUMBER }\end{array}$ & assigned identification number & 4-digit number \\
\hline $\begin{array}{l}\text { Article. } \\
\text { TITLE }\end{array}$ & title & text \\
\hline $\begin{array}{l}\text { Article. } \\
\text { UN PUBL }\end{array}$ & $\begin{array}{l}\text { information on unpublished } \\
\text { material }\end{array}$ & text \\
\hline $\begin{array}{l}\text { Article. } \\
\text { EDITOR }\end{array}$ & editor & full name \\
\hline $\begin{array}{l}\text { Article. } \\
\text { PUBLACE }\end{array}$ & place of publication & text \\
\hline $\begin{array}{l}\text { Article. } \\
\text { BOOKNAME }\end{array}$ & title of book & text \\
\hline $\begin{array}{l}\text { Article. } \\
\text { SERIES }\end{array}$ & title of series & text \\
\hline $\begin{array}{l}\text { Article. } \\
\text { PUBLISHER }\end{array}$ & name of publisher & text \\
\hline $\begin{array}{l}\text { Article. } \\
\text { JOURN AL }\end{array}$ & name of journal & text \\
\hline $\begin{array}{l}\text { Article. } \\
\text { VOLUME }\end{array}$ & volume & number or text \\
\hline $\begin{array}{l}\text { Article. } \\
\text { ISSUE }\end{array}$ & issue & number or text \\
\hline $\begin{array}{l}\text { Article. } \\
\text { YEAR }\end{array}$ & date & number \\
\hline Article. & page numbers & number \\
\hline $\begin{array}{l}\text { Article. } \\
\text { STUDYTYPE }\end{array}$ & type of research & $\begin{array}{l}\text { literature review, } \\
\text { historical }\end{array}$ \\
\hline $\begin{array}{l}\text { Article. } \\
\text { METHODS }\end{array}$ & methods used & various \\
\hline $\begin{array}{l}\text { Article. } \\
\text { CONTENU }\end{array}$ & is ownership of resource made clear? & yes or no \\
\hline
\end{tabular}




Field Name Description Valid Entries

Article.

CONVAL

Article.

CONGOV

Article.

CON M ARK

Article.

CONRELIST

Article.

SUPPORT

Article.

PFOCUS

Article.

SFOCUS

Article.

SWTYPE

Article.

ABST RACT

Article.

NOTES

Article.

FINISHED

Case.

IDNUMBER

Case.

CASENUM

Case.

LOCAL

Case.

COUNTRY

Case.

REGION

Case.

SPECIES is economic value of resource

calculated?

are government policies described? yes or no

are marketing patterns

described?

is a list of commercial NTFPs

provided?

article support or discourage

extraction?

primary focus

secondary focus

finer distinction within "social

welfare"

summary of content and

findings

notes

is all information for this record entered?

assigned identification number

case number

location information below

country level

country

region

species name for resource number

text

text

support or

discourage

social welfare,

management,

tenure, ecology

social welfare, management, tenure, ecology

social justice, income, resource use, other

text

text

yes or no

number

text

text 
Field N ame

D escription

common name for resource

resource type

Case.

RESTYPE

Case.

PRODTYPE

Case.

USES

Case.

FOREST

Case.

H ARVEST

Case.

PRO CESSING

Case.

COMMERCIAL

Case.

SUBSIST EN CE

Case.

LABORGH

Case.

LABGEN H

Case.

LABAGEH

Case.

LABO RG P

Case.

LABGEN P

Case.

LABAGE

Case.

M ARREL

Case.

M ARSTR

Author.

FIRSTNAME product type

uses for the product

forest type

temporal harvesting characteristics text

is there significant local processing? yes or no

commercial history

subsistence history

labor organization in harvesting

gender character of harvesting

age character of harvesting

labor organization in processing

gender character of processing

age character of processing

local relations of resource

marketing

market for product's final

destination

author's first name
Valid Entries

Text

"tree"

for example

"bark"

for example

text

text

text

text

text

text

text

text

text

text

text

text

text 
Field Name

Author.

M I

Author.

LAST N AM E

Author.

SPECIALTY

Author.

AUTHSEQN UM
D escription

author's middle initial

author's last name

author's specialty or department

order of author in multipleauthored docs
Valid Entries

text

text

text

1, 2, 3, etc. 


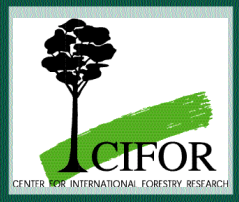

Center for International Forestry Research P.O. Box 6596 JKPWB, Jakarta 10065, Indonesia Tel.: +62 (251) 622622; Fax: +62 (251) 622100 Web site: http://www.cifor.cgiar.org

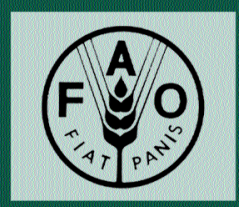

Food and Agriculture Organization of the United Nations Viale delle Terme di Caracalla, 00100 Rome, Italy Tel: : +39.0657051; Fax: +39.0657053152

Web site: http://www.fao.org 